
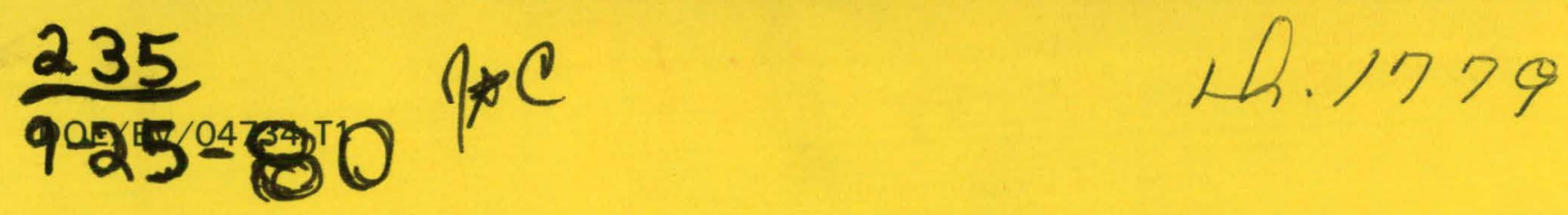

\title{
The Feasibility of Methods and Systems for Reducing LNG Tanker Fire Hazards
}

Published August 1980

Prepared for

U.S. Department of Energy

Assistant Secretary for Environment

Division of Environmental Safety and Engineering

Under Contract No. EP-78-C-02-4734.A000 


\section{DISCLAIMER}

This report was prepared as an account of work sponsored by an agency of the United States Government. Neither the United States Government nor any agency Thereof, nor any of their employees, makes any warranty, express or implied, or assumes any legal liability or responsibility for the accuracy, completeness, or usefulness of any information, apparatus, product, or process disclosed, or represents that its use would not infringe privately owned rights. Reference herein to any specific commercial product, process, or service by trade name, trademark, manufacturer, or otherwise does not necessarily constitute or imply its endorsement, recommendation, or favoring by the United States Government or any agency thereof. The views and opinions of authors expressed herein do not necessarily state or reflect those of the United States Government or any agency thereof. 


\section{DISCLAIMER}

Portions of this document may be illegible in electronic image products. Images are produced from the best available original document. 
Printed in the United States of America

$$
\text { Available from }
$$

National Technical Information Service U.S. Department of Commerce

5285 Port Royal Road

Springfield, VA 22161

NTIS price codes

Printed Copy: $\$ 12.50$

Microfiche Copy: $\$ 3.50$ 
DOE/EV/04734-T1

UC-11

The Feasibility of Methods and Systems for Reducing LNG Tanker Fire Hazards

Published August 1980

Prepared by

Author D. Little, Inc.

Acorn Park

Cambridge, MA 02140

Under Contract No. EP-78-C-02-4734.A000

Prepared for

U.S. Department of Energy

Assistant Secretary for Environment

Division of Environmental Safety and Engineering

Washington, D.C. 20545

Under Contract No. EP-78-C-02-4734.A000

COVER POO. 1065 (548) 
ABSTRACT

In this program concepts for reducing fire hazards that may result from LNG tanker culllstons are identified and their technical feasibility evaluated. Concepts considered include modifications to the shipborne LNG containers so that in the event of a container rupture less of the contents would spill and/or the contents would spill at a reduced rate. Changes in the cargo itself, including making the LNG into a gel, solidifying it, converting it to methanol, and adding flame suppressants are aiso evaluated. The relative effectiveness and the costs of implementing these methods in terms of increased cost of gas at the receiving terminal, are explained.

The vulnerability of an LNG tanker and its crew to the thermal effects of a large pool fire caused by a collision spill is estimated. and methods of protecting the crew are considered. It is shown that the protection of ship and crew so that further deterioration of $a$ : damaged ship might be ameliorated, would require the design and installation of extraordinary insulation systems and life support assistance for the crew.

Methods of salvaging or disposing of cargo from a damaged and disabled ship are evaluated and it is concluded that if the cargo cannot be transferred to another (empty) LNG tanker because of lack of avallability than the burning of the cargo at a location somewhat distant from the disabled tanker appears to be a promising approach.

Finally, we examined the likelihood of the vapors from a spill being ignited due to the frictional impact of the colliding ships. It is found that the heating of metal sufficient to ignite flammable vapors would occur during a collision but it is questionable whether flammable vapor and air will, in fact, come in contact with the hot metal surfaces. 


\section{ACKNOWLEDGEMENTS}

The work presented in this report was jointly sponsored by the Division of Environmental Control Technology, Department of Energy and the Office of Commercial Development, Maritime Administration.

The principal Arthur D. Little, Inc. contributors to this study were as follows:

D. S. Allan - Project Director;

P. K. Phani Raj - Hazard analysis and vulnerability of LNG tankers and crews to fire;

P. Athens - Methods of reducing the outflow of LNG.

E. G. Pollack - Cargo disposal;

N. M. Laurendeau and R. N. Caron - Ignition and mechanisms and experiments.

A. A. Fowle - Solid natural gas and availability of flammable mixtures to ignition sources.

Others included R. P. Wilson, Jr. who contributed to the ignition studies, M. H. Long wh' surveyed the occurrence of tanker accidents, and S. E. Dale who developed cost estimates for a representative LNG import project.

We are particularly grateful to Dr. John Cece of the Division of Environmental Control Technology for his overall guidance and his technical contributions to the program. 
ABSTRACT

ACKNOWLEDGEMENTS

ACKNOWLEDGEMENTS

iif

LIST OF TABLES

LIST OF FIGURES

viii

$\mathbf{x}$

1.0 INTRODUCTION $\quad$ 1-1

2.0 EXECUTIVE SUMMARY $2-1$

2.1 PROGRAM OBJECTIVE, GUIDELINES, AND APPROAC̣

2.2 HAZARD-REDUCTIION METHODS 2-2

2.2.1 Methods of Reducing Spill Rate and Quantity 2-2

2.2.2 Other Methods of Reducing Tanker Fire Hazards 2-6

2.2.3 System Costs 2-8

2.3 VULNERABILITY OF LNG TANKERS AND CREWS TO FIRES 2-11

2.3.1 Vulnerability of Ship and Crew 2-11

$2: 3.2$ Protection of Ship and Crew $2-11$

2.4. CARGO DISPOSAL AND PLANNING 2-12

2.4.1 Salvage and Disposal 2-12

2.4.2 Contingency Planning 2-13

2.5 IGNITION DURING AN IMPACT COLLISION 2-13

3.0 CONCLUSIONS AND RECOMMENDATIONS 3-1

3.1 CONCLUSIONS 3-1

3.2 RECOMMENDATIONS 3-2

4.0 HAZARD REDUCTION METHODS 4-1

4.1 REDUCTION IN LNG FIRE HAZARDS 4-1

4.1.1 Introduction 4-1

4.1.2 LNG Pool Fires 4-1

4.1.3 Disperston of LNG Vapor Clouds 4-5

NOMENCLATURE (Section 4.1) 4-17 
TABLE OF CONTENTS (continued)

4.2 REDUCING THE OUTFLOW OF LNG 4-18

4.2.1 Introduction 4-18

4.2.2 Characteristics of LNG Tanker Collisions 4-20

4.2.3 Compartmentalization of Existing LNG Tankers 4-26

4.2.4 Mult1-tank LNG Tanker Designs . 4-37

4.2.5 Reduction in Spill Rate from LNG Cargo Tanks 4-52

4.2.6 Summary 4-60

4.3 OTHER METHODS OF REDUCING LNG TANKER FIRE HAZARDS 4-65
4.3.1 General
4.3.2 Gelled LNG
4.3.3 Methyl Fuel
4.3.4 Addition of Flame Suppressant 4-84
4.3.5 Solid Natural Gas $\quad 4-89$

5.0 VULNERABILITY OF LNG TANKERS AND CREWS TO FIRE 5-1

5.1 INTRODUCTION $\because$. 5-1

5.2 CRITICAL SHIP COMPONENTS AND THEIR LOCATION 5-2

5.2.1 LNG Tankers in General 5-2

5.2.2 Pertinent Features of Two Types. of LNG 5-4

5.2.3 Fire Protection System in an LNG Ship 5-11

5.2.4 Characteristics and Susceptibility of $5-12$ Mateirials to Fire

5.3 HEAT TRANSFER FROM FIRE TO STRUCTURES 5-16

5.3.1 Scenarios of Fires, Their Sizes, and Locations .5-16

5.3.2 Heat Transfer to Various Components and 5-19 Their Temperature History

5.4 CREW POSITIONS AND SURVIVABILITY $5-25$

5.4.1 Crew Functions $\quad$ 5-25

5.4.2 Typical Manning Positions when Underway 5-26

5.4.3 Typical Manning Positions during Cargo 5-27

Transfer

5.4.4 Fire Threat 5-29

5.4.5 Exposures and Access to Protective Enclosures 5-29

5.4.6 Summary . . 5-32 
TABLE OF CONTENTS (continued)

PAGE

5.5 CREW PROTECTION FROM FIRE $\quad 5-34$

5.5.1 Air Systems $\quad 5-34$

5.5.2 Thermal Protection Shelters 5-34

5.5.3 Crew Motivation and Training 5-39

5.5.4 Other Crew Protection/Escape Systems 5-40

5.6 THERMAL PROTECTION OF THE SHIP 5-41

5.7 CONCLUSIONS 5-42

6.0 CARGO DISPOSAL 6-1

6.1 BACKGROUND $6-1$

6.2 CONDITIONS REQUIRING SALVAGE/DISPOSAL OF CARGO 6-3

6.2.1 General Considerations : 6-3

6.2.2 Primary Failure Modes and Causes 6-3

6.2.3 The Need for Emergency off-Loading 6-6

6.3 URGENCY OF OFF-LOADING 6-8

6.4 SUMMARY OF OFF-LOADING REQUIREMENTS 6-9

6.5 SALVAGE AND DISPOSAL 6-11

6.5.1 General 6-11

6.5.2 Rate of Disposal 6-11

6.5.3 Removal of Cargo from Shipborne Containers 6-12

6.5.4 Transfer from Damaged and Disabled Ships 6-16

6.5.5 Salvage and Disposal Methods 6-17

6.6 CONCLUSIONS AND RECOMMENDATIONS RELATING 6-25

TO CARGO DISPOSAL

6.6.1 Conclusions 6-25

6.6.2 Recommendations 6-26

6.7 CONTINGENCY PLANS $\quad 6-27$

6.7.1 General 6-27

6.7.2 Components of a Contingency. Plan: 6-27 
TABLE OF CONTENTS (continued)

$\underline{\text { PAGE }}$

7.0 IGNITION OF SPILLED CARGO 7-1

7.1 INTRODUCTION 7-1

7.2 IGNITION OCCURRENCES IN TANKER ACCIDENTS 7-3

7.2.1 Background ․ 7-3

7.2 .2 U.S. Coast Guard Data $\quad+7-3$

7.2.3 Lloyd's Data 7-4

7.2.4 Liverpool Casualty Returns 7-5

7.2.5 Summary of Tanker Accident Data 7-5

7.3 A REVIEW OF FUNDAMENTAL MECHANISMS PERTAINING 7-8

TO IMMEDIATE IGNITION OF ACCIDENTAL LNG SPILLS

7.3.1 Collision Scenario 7-8

$\begin{array}{ll}\text { 7.3.2 Characteristics of Anticipated 7-10 } & \text { 7-8 }\end{array}$

Fue1-Air Mixtures

7.3.3 Summary of Ignition Sources 7-13

7.3.4 Ignition by Frictional and Electrical Sparks 7-15

7.3.5 Frictional Heating and Ignition 7-24

7.4 EXPERIMENTAL INVESTIGATION OF IGNITION BY HOT 7-57 SURFACES

7.4.1 Experimental Facility 7-57

$\begin{array}{lr}7.4 .2 & \text { Experimental Procedure } \\ 7.67\end{array}$

$\begin{array}{lll}7.4 .3 & \text { Results } & 7-69\end{array}$

7.5 THE OCCURRENCE OF FLAMMABLE MIXTURES AT POTENTIAL $7-80$

IGNITION SITES

7.5.1 Background $\quad 7-80$

$\begin{array}{ll}7.5 .2 & \text { System Mode1 } \\ 7-81\end{array}$

7.5.3 Fluid Spill at Region 1 7-83

7.5.4 Mixing in Region 2 7-84

7.5 .5 Potential for Ignition in Region 3 7-86

$\begin{array}{ll}7.5 .6 & \text { Summary } \\ 7-87\end{array}$

7.6 CONCLUSIONS AND RECOMMENDATIONS 7-89 
TABLE OF CONTENTS (continued)

APPENDIX A--CRITERTON FOR CLASSIFYING SPILLS INTO INSTANTANEOUS AND CONTINUOUS TYPES

APPENDIX B--A MODEL FOR THE GRAVITY SPREAD OF Á HEAVY VAPOR RELEASED CONTINUOUSLY FROM A SOURCE

APPENDIX C--CALCULATION OF HEAT TRANSFER TO THE HULL PLATE

APPENDIX D--EFFECT OF AN EXTERNAL FLAME ON LNG TANK COVERS AND INSULATION

APPENDIX E--FIRE PROTECTION COATINGS

APPENDIX F--TEMPERATURE, SIZE AND DURATION OF HOT SPOT CREATED BY FRICTIONAL IMPACT OF LNG TANKER

NOMENCLATURE (Section 7.0 and Appendix F)

REFERENCES $\underline{\text { PAGE }}$

$\Lambda-1$

B-1

C-1

D-1

E-1

F-1

$\mathrm{N}-1$

$\mathrm{R}-1$

vii 


\section{LIST OF TABLES}

PAGE

TABLE 2.1: THERMAL RADIATION AND VAPOR CLOUD HAZARDS

$2-3$

FOR DIFFERENT SPILL SIZES AND, SPILL DURATIONS

TABLE 2.2 : ESTTMATE OF COSTS FOR LIQUEFYING, TRANSPORTING, AND REGASIFYING LNG (ARZEW, ALGERIA TO TEXAS)

TABLE 4.1 : CROSS-OVER TIMES FOR VARIOUS SPILL SIZES 4-4

TABLE $4.2:$ CHANGES IN CHARACTERISTICS AND COSTS FOR 4-28 INTEGRATED TANK LNG VESSELS

TABLE $4.3:$ COMPARTMENTALIZATION OF EXISTING LNG CARGO 4-62 CONTAINMENT DESIGNS

TABLE 4.4 : SPILL-RATE CONTROL IN EXISTING. LNG CARGO- 4-63 CONTAINMENT DESIGNS

TABLE 4.5: PROPOSED LNG CARGO-CONTAINMENT DESIGNS . 4-64

TABLE 4.6 : YIELD SHEAR STRESS AND VISCOSITY OF LNG GELS 4-68

TABLE 4.7 : COMPARATIVE PROPERTIES OF LIQUEFIED NATURAL 4-74 GAS AND METHANOL

TABLE 4.8 : CHARACTERISTICS OF SOME EXTINGUISHANTS

4-85

TABLE 5.1 : LOCATION OF MACHINERY ON LNG SHIPS--GENERAL

TABLE 5.2 : THERMAL CHARACTERISTICS OF STRUCTURAL MATERIALS 5-14 AND' INSULATION

TABLE $5.3:$ FIRE SIZE AND DURATION 5-17

TABLE 5.4: TYPICAL MANNING OF AN LNG SHIP DURING PORT 5-28 ENTRY AND CARGO TRANSFER

TABLE 6.1 : PRTMARY FAILURE MODES 6-4

TABLE $6.2:$ PRIMARY CAUSES $\quad$ 6-5

TABLE 6.3 : ACCIDENTS REQUIRING EMERGENCY LNG OFF-LOADING , 6-10 
LIST OF TABLES (continued)

PAGE

TABLE 7.1 : TANKER COLLI3ION3, WORLDWIDE (1964-PREEENT) : 7-6,

TABLE $7.2:$ COMPOSITION AND PROPERTIES OF LNGS FROM 7-11 DIFFERENT SOURCES

TABLE 7.3 : HYDROCARBON PROPERTIES RELEVANT TO IGNITION 7-12

TABLE 7.4 : MINIMUM IGNITION ENERGY AND QUENCHING DISTANCE 7-22 FOR STAGNANT FUEL-AIR MIXTURES AT STP. CONDITIONS

TABLE $7.5:$ LIST OF VENDORS 7-60

TABLE 7.6 : GAS CHROMATOGRAPHIC ANALYSIS OF METHANE-AIR 7-67 MIXTURE

TABLE $7.7:$ EXPERIMENTAL CONDITIONS 7-70

TABLE 7.8 : PULSE IGNITION TESTS IN SEVEN PERCENT METHANE- 7-74 AIR - MIXTURES

TABLE 7:9: IGNITION TEMPERATURES FOR METAL ST⿱RIPS IN SEVEN 7-75 PERCENT METHANE-AIR MIXTURES

TABLE 7.10: PULSE IGNITION TESTS FOR PAINTED METAL STRIPS 7-79 


\section{LIST OF FIGURES}

PAGE

FIGURE 4.1 : TYPES AND MAGNITUDES OF HAZARDS CONSIDERED '" 4-2 IN THE ANALYSES

FIGURE 4.2 : HAZARD DISTANCE FOR BURN INJURY AS A FUNCTION 4-6 OF LNG RELEASE

FIGURE 4.3 : HAZARD DISTANCE FOR BURN INJURY AS A FUNCTION 4-7 OF DURATION OF LNG RELEASE

FIGURE 4.4 : HAZARD DISTANCE FOR BURN INJURY AS A FUNCTION 4-8. OF DURATION OF LNG RELEASE

FIGURE 4.5 : HAZARD DISTANCE FOR BURN INJURY AS A FUNCTION 4-9 OF DURATION OF LNG RELEASE

FIGURE 4.6 : WIDETH OF FLAMMABLE REGION AS A FUNCTION OF DISTANCE FROM SPILL POINT FOR $1,000 \mathrm{~m}^{3}$ LNG SPILL ON WATER

FIGURE 4.7 : WIDTH OF FLAMMABLE REGION AS A FUNCTION OF DISTANCE FROM SPILL POINT FOR $25,000 \mathrm{~m}^{3}$ LNG SPILLS. ON WATER

FIGURE 4.8 : WIDTH OF FLAMMABLE REGIONS AS A FUNCTION OF DISTANCE FROM SPILL POINT FOR $50,000 \mathrm{~m}^{3}$ LNG SPILL ON WATER

FIGURE 4.9 : MAXIMUM DOWNWIND DISTANCE TO 5\% CONCENTRATION 4-14 VS. SPILL VOLUME.

FIGURE 4.10: MAXIMUM SEMI WIDTH OF CLOUD TO 5\% CONCENTRATION 4-15 VS. SPILL VOLUME

FIGURE 4.11: COLLISION RESISTANCE OF BEN FRANKLIN 4-22

FIGURE 4.12: MOSS SPHERICAL TANK SYSTEM PARTITIONING 4-30 ARRANGEMENTS

FIGURE 4.13: CONCH II PRISMATIC TANK SYSTEM PARTITIONING 4-35 ARRANGEMENTS

FIGURE 4.14: OCEAN PHOENIX TANK

FIGURE 4.15: ARRANGEMENT OF THE OCEAN PHOENIX TANKS 4-41 
LIST OF FIGURES (continued)

\section{$\underline{\text { PAGE }}$}

FIGURE 4.16: VEROLME LIQUEFIED NATURAL GAS CARRIER $4-43$ (GENERAL ARRANGEMENT OF CARGO TANKS)

FIGURE 4.17: VEROLME LIQUEFIED NATURAL GAS CARRIER - 4-44

FIGURE 4.18: MULTI VESSEL T'ANK SYSTEM (MVT) . . $4-49$ (ARRANGEMENT OF CARGO TANKS)

FIGURE 4.19: MULTI VESSEL TANK SYSTEM (MVT) $\quad$ 4-50

FIGURE 4.20: SINGLE CURTAIN BARRIER ARRANGEMENTS WITHIN 4-56 LNG TANKS

FIGURE 4.21: COST OF ENERGY DELIVERED FOR DIFFERENT 4-82 SHIPPING DISTANCES

FIGURE 5.1 : SCHEMATIC OF SHIP AREAS 5-3

FIGURE 5.2 : LONGITUDINAL SECTION OF MEMBRANE SHIP SHOWING 5-7 THE LOCATIONS OF TANKS

FIGURE 5.3 : SECTION THROUGH MIDSHIP OF THE DESCARTES 5-8 SHOWING DETAILS OF THE CARGO TANK

FIGURE 5.4 : DETAILS OF INSULATION FOR A MEMBRANE TANK DESIGN 5-8

FIGÜRE 5.5 : LONGITUDINAL SECTION OF FREE-STANDING SPHERICAL 5-9 TANK LNG SHIP

FIGURE 5.6 : CROSS_SECTION THROUGH A SPHERICAL TANK 5-10

FIGURE 5.7 : SCHEMATIC REPRESENTATION OF TWO POSSIBLE 5-18 SPILL-FIRE SITUATIONS CAUSED BY SHIP COLLISIONS

FIGURE 5.8: POSSIBLE ARRANGEMENT OF INSULATION ON THE WALLS 5-38 OF THE THERMAL ISOLATION ROOM

FIGURE 5.9 : ADDITIONAL PROTECTION WITHIN WATER JACKETS ON 5-38 COLD SIDE

FIGURE 6.1 : SCHEMATIC OF ARTICULATED TRANSFER LINK 6-15

FIGURE 6.2 : FLARE SYSTEM CONCEPT $\quad 6-24$ 
LIST OF FIGURES (continued)

PAGE

FIGURE 7.1 : DEVELOPMENT OF FRICTIONALLY INDUCED HOT SURFACE 7-9 UPON LNG TANK PENETRATION

FIGURE 7.2 : INITIAL TEMPERATURE--EQUIVALENCE RATIO REGION

$7-14$ FOR FLAMMABLE. ALGERLAN LNG MIXTURES. TNI'TIAL LNG VAPOR TEMPERATURE ASSUMED TO BE - $160^{\circ} \mathrm{C}$. AMBIENT AIR TEMPERATURES ASSUMED TO BE $0-25^{\circ} \mathrm{C}$. STOICHIOMETRIC CONDITIONS FOR LNG VAPOR GIVEN BY $8.6 \% \mathrm{~V} / \mathrm{V}$. THE EQUIVALENCE RATIO $\phi$ IS GIVEN BY [FUEL/AIR] ${ }_{\text {ACTUAL }} /\left[\right.$ FUEL/AIR] ${ }_{\text {STOICH. }}$

FIGURE 7.3 : THE MINIMUM WEIGHTS OF STATIONARY PARTICLES $7-19$ NECESSARY TO IGNITE METHANE--AIR MIXTURES. THE PARTICLES ARE INITIALLY AT $1100^{\circ} \mathrm{C}$ (BOWDEN AND LEWIS, 1958)

FIGURE 7.4 : CHARACTERISTICS OF SPARK IGNITION FOR FLANGED $7-21$ ELECTRODES

FIGURE 7.5: IGNITION OF NATURAL GAS--AIR MIXTURES BY HEATED 7-31 STRIPS OF NICKEL AND PLATINUM (COWARD AND GUEST, 1927)

FIGURE 7.6 : VARIATION OF IGNITION TEMPERATURE WITH METHANE 7-33 COMPOSITION AND AREA OF TUNGSTEN STRIP (CUTLER; 1974)

FIGURE 7.7 : IGNITION TEMPERATURES FOR SPHERES OF VARYING DIAMETER PASSING THROUGH FUEL-AIR MIXTURES.

FIGURE 7.8 : IGNITION TEMPERATURES FOR PLATES OF VARYING SIZE AND POSITION IN AN EXPLOSION BOX CONTAINING $6 \%$ METHANE (RAE et al., 1964)

FIGURE 7.9 : IGNITION TEMPERATURE VS. STREAM VELOCITY FOR $7-38$ 6mm DIAMETER HEATED ROD. STOICHIOMETRIC PENTANEAIR AT $70^{\circ} \mathrm{C}$ AMBIENT TEMPERATURE (MULLEN et a1., 1949)

FIGURE 7.10: TEMPERATURE PROFILES NEAR HEATED SURFACE 7-41 SURROUNDED BY FLAMMABLE MIXTURE.

FIGURE 7.11: INFLUENCE OF STRIP SIZE ON IGNITION TEMPERATURE 7-48 FOR RAPID HEATING IN 7\% METHANE-AIR 
LIST OF FIGURES (continued)

PAGE

FIGURE 7.12: INFLUENCE OF PLATE AREA ON IGNITION TEMPERATURE 7-50

FOR 6\% METHANE-AIR (RAE et a1., 1964)

FIGURE 7.13: IGNITIUN TEMPERATURES FOR SPHERES OF VARYING $\quad 7-51$

DIAMETER AND VELOCITY IN 10\% COAL GAS-AIR

(SILVER, 1937; PATERSON, 1940)

FIGURE 7.14: IGNITION TEMPERATURE $\Lambda$ S A FUNCTION OF STREAM

$7-52$

VELOCITY FOR 6mm HEATED ROD IN STOICHIOMETRIC

PENTALE-AIR (MULLEN et al., 1949)

FIGURE 7.15: CORRELATION OF METHANE IGNITION DATA FOR VERTICAL 7-53 FLAT PLATES UNDER FREE CONVECTION (ONO et al., 1976)

FIGURE 7.16: DEPENDENCE OF IGNITION DELAY ON ROD TEMPERATURE

$7-56$ FOR STOICHIOMETRIC PENTANE-AIR MIXTURES AT ROOM TEMPERATURE AND PRESSURE (ADOMEIT, 1965)

FIGURE 7.17: OVERVIEW OF METHANE-AIR IGNITION FACILITY

$7-58$

FIGURE 7.18: REACTOR SCHEMATIC

$7-61$

FIGURE 7.19: ELECTRICAL HEATING SYSTEM

$7-62$

FIGURE 7.20: METHANE-AIR MIXING AND PURGE SYSTEM

$7-64$

FIGURE 7.21A: FRONT VIEW OF THERMOCOUPLE ASSEMBLY

$7-66$

FIGURE 7.21B: THERMOCOUPLE INSERTED IN FOIL

$7-66$

FIGURE 7.22: TEMPERATURE RISE PROFILES FOR 2mm (2T-7) AND. 7-71 10mm (10S-3) METAL STRIPS

FIGURE 7.23: TEMPERATURE DECAY PROFILES FOR 2mm (2T-7) AND 10mm (10S-3) METAL STRIPS

FIGURE 7.24: INITIAL TEMPERATURE--TIME PROFILE. FOR 3mm

$7-73$ TUNGSTEN STRIP IN NITROGEN AND METHANE-AIR AT SAME VARIAC SETTING (3T-5)

FIGURE 7.25: IGNITION TEMPERATURE VS STRIP WIDTH IN 7\% $7-76$ METHANE-AIR MIXTURES

FIGURE 7.26: DEPENDENCE OF STRIP SIZE ON SURFACE IGNITION 7-78 TEMPERATURE

FIGURE 7.27: MODEL SYSTEM FOR EVALUATION PURPOSES 


\subsection{INTRODUCTION}

Liquefied natural gas (LNG) tankers are presently servicing U.S. import and export terminals on a regular basis, and the implementation of plans for additional import facilities will, significantly increase tanker traffic in the future. It has been estimated (Johnson, 1978), for example, that, "in a few years.. . each day, on the average, about 200,000 cubic meters of LNG could be in transit, in U.S. waters, in places like Boston, Chesapeake Bay, Savannah River, Lake Charles, La., Matagorda Eay, Tex., somewhere in California, and Alaska." This is roughly equivalent to about one fully. loaded tanker transiting U.S. waters every day of the year, plus another tanker every other day.

The current and projected tanker operations present risks to property and life along various U.S. shipping channels. In fact, a major cargo spill might cause an exceptionally large fire which could effect thermal damage and injury over considerable distances beyond the area of the spill itself. However, the harmful risks have been examined in great detail for most LNG import programs, and it is generally concluded that the likelihood of a major accident occurring is remote--so remote, in fact, that a large spill would not be expected to occur during the projected lifetimes of these projects. In addition, the extraordinary measures that are currently being enforced by the U.S. Coast Guard, along with continuing attention to improvements in shipping operations, are expected to reduce these risks even further.

In spite of the very small chance that a large accident could occur, the consequences of such an accident remain quite large. The additional lowering of such risks, then, are potentially achievable by the implementation of methods and systems that not only reduce the probability of accidents occurring, but, very importantly, diminish the consequences of the accidents. The evaluation of the feasibility of employing such methods and systems to reduce the consequences of tanker accidents by the amelioration of LNG tanker fire hazards is the subject of this report. 
In this study, we considered methods of reducing the rate and/or quantity of LNG that might be released in a major accident, techniques for altering the physical and chemical state of the natural gas, and the use of fire suppressants as a means of diminishing tanker fire hazards.

In addition, we considered systems for protecting the LNG tanker and Its crew from the thermal effects of a large fire and methods for disposing of the cargo from a damaged and/or disabled tanker as approaches to preventing the escalation of an accident involving the spill from one or, at the most, two cargo containers.

Finally, because the hazards that are to be reduced depend upon the time of occurrence of ignition of spilled cargo, we have examined in some detail, the propensity for ignition taking place at the time of a collision impact.

The work reported here is the result of one of several projects being sponsored within the Liquefied Gas Fuels Safety and Environmental Control Assessment Program of DOE. Additional information related to the feasibility of methods of reducing LNG tanker fire hazards will, in the future, derive from other studies being performed within the DOE program, such as fires and explosion studies, vapor generation and dispersion studies, and other release prevention and control projects. 


\subsection{EXECUTIVE SUMMARY}

\subsection{PROGRAM OBJECTIVE, GUIDELINES, AND APPROACH}

The objective of this program was to identify and evaluate new and novel concepts for reducing the hazards presented by LNG tanker transits of navigable waters in the United States. The study also included a preliminary assessment of the technical feasibility and the costs associated with the concepts that were identified.

In this study, we focused our interest on tankers that transport about 125,000 cubic meters $\left(\mathrm{m}^{3}\right)$ of $\mathrm{LNG}$, since we expect them to be predominant in the LNG shipping trade and, in fact, are currently the largest ships in service. Ships of both the membrane and free-standing tank design were considered.

A rapid spill of the entire contents of one LNG cargo tank ( 225,000 $\mathrm{m}^{3}$ ) was generally used as the basic accidental event, in this report, since this volume is characteristic of a potential spill expected by the collision of a large ship with an LNG tanker. In risk studies performed for various projects, the collision accident has been considered as representative of the most hazardous occurrence deemed crèdible.

The principal approaches to reducing LNG tanker hazards that were considered in this study consisted of modifications to the ship and/or its cargo so that the magnitude of the fire would be decreased should a spill occur. Generally, there is little that can be accomplished in the way of fire fighting or inerting the flammable vapor once a large spill has occurred. Methods that might be applied to ships already built (as for example, by retrofit) are regarded to be of particular importance since many of the ships that will be used in the U.S. LNG trade over the next 10 to 20 years may be either under construction or already in service. 


\subsection{HAZARD-REDUCTION METHODS}

\subsubsection{Methods of Reducing Spill Rate and Quantity}

\subsubsection{Hazard Reduction}

The penetration of an LNG cargo tank of an existing tanker; such as could happen in a major collision, is apt to result in the release of the entire contents of the tank within a few minutes. In fact, the spill time has been estimated to be so short that the modeling of spill hazards in most prior risk estimates assumes, for reasons of simplicity (and conservatism), that the LNG spills instantaneously.

To establish the gains to be made by slowing down the rate of release and/or limiting the total amount that is released in a single spill, estimates have been made of the resultant decrease in pool fire and vapor cloud hazards. An example of the results of these estimates is presented in Table 2.1. The table shows that by reducing the spill size to only $1,000 \mathrm{~m}^{3}$ rather than $25,000 \mathrm{~m}^{3}$, and by causing the spill to occur at a constant rate over a period of some 30 minutes or more rather than near instantaneous, the thermal radiation hazard from a pool fire would be so curtailed that significant thermal effects' would remain essentially within the vicinity of the spill; 1.e., within about 400 feet of the center of the spill. The size of the potential vapor cloud (under adverse meteorological conditions) would also be diminished; however, it would still present a hazard some 4500 feet from the center of the spill. Greater reductions are theoretically possible, but become more difficult and expensive to achieve.

\subsubsection{Methods}

We have considered four different ways in which the accidental spill quantity or rate of release of LNG may be reduced. Each is described below:

(1) Partitioning of Lxlsting liank Jesigns - Cargo tanks may be divided Into separate compartments so that when a collision occurs only the LNG in the compartment that is accidentally penetrated would be released. To partition tanks in this manner, however, requires that 
TABLE 2.1

THERMAL RADIATION AND VAPOR CLOUD HAZARDS

FOR

DIFFEREN'I SPILL SIZES AND SPILL DURATIONS

\begin{tabular}{ccc} 
Distance of & 1 \\
Harmful. & Maximum & Maximum \\
Thermal & Travel & Half Width \\
Rdiation from & of Vapor & of Vapor \\
Pool Fire, m* & Cloud, $\mathrm{Km}^{\text {** }}$ Cloud, $\mathrm{m}$ \\
\hline
\end{tabular}

Spill ${ }^{3}$
Dize, $\mathrm{m}^{2}$ Duratioil, min. Pool Fire, $\mathrm{m}^{*}$ Cloud, $\mathrm{Km}^{\text {** }}$ Cloud, $\mathrm{m}$

$\begin{array}{ccccc}25,000 \quad \text { "instantaneous" } & 2100 & 20 & 1 & 700 \\ 10 & 900 & 10 & \cdots & 300 \\ 30 & 550 & 3.2 & & 150\end{array}$

$10,000 \quad$ "Instantaneous" . $1500 \quad 14 \quad 500$

$\begin{array}{ccllr}10 & 600 & 7.5 & : & 200 \\ 30 & 350 & 2.7 & 100 \\ 1,000 \quad \text { "Instantaneous" } & 660 & 5 & 200 \\ 10 & 190 & 2.8 & 70 \\ 30 & 120 & 1.4 & : 35\end{array}$

* distance from center of spill where radiation $=5 \mathrm{~kW} / \mathrm{m}^{2}$.

** Maximum travel distance of unignited flammable vapor cloud assuming flammable limit is $5 \%$ methane in air, atmosphere condition $\mathrm{F}$ 
the bulkheads be structurally capable of withstanding the liquid forces when one compartment is emptled, and the increased heat input to the liquid in the remaining compartments would also have to be accomodated.

A review of the designs of LNG tankers already built or under construction indicates that there are several difficulties associated with this approach. It does not appear feasible to insert bulkheads or partitions in existing membrane systems within a reasonable cost since the membrane linings will not in themselves provide adequate support. The free standing spherical containers will support partitions but because of the increased difficulties in analyzing stresses In such a system there is some possibility that the classification of the tanks would be changed; thus introducing the requirement that a full secondary cryogenic barrier be introduced. This would not appear to be practical.

Only the self supporting rectangular tanks of the Conch design may be receptive to the installation of partitions without introducing other severe problems, but there is a limited number of ships of this configuration. In any event, either a large number of partitions or a complex and expensive design would be required in order to achieve large reductions in spill quantity. Partitioning of tanks may be most cost effective, however, when combined with other approaches such as the addition of filler.material that would restrict the outflow of LNG.

(2) Mult1-tank Sh1p Designs - There are two ship designs that utilize a large number of smaller cargo tanks being proposed for LNG trade. One of these being offered by Verolme uses 3,400-m uninsulated vertical cylinders located in groups within insulated holds in the ship. The major effort by Verolme at present is concentrated on a large vessel design, with a payload of $330,000 \mathrm{~m}^{3}$. Spillage of LNG by penetrating the ship in a collision would be greatly reduced, but the flooding of the hold in such a case may create venting problems for the undamaged containers. 
The other ship design referred to as the OCEAN PHOENIX uses a complex system of partially compartmented multi-lobed vessels for LNG containment at pressures in the 40 to 70 psi range. This design provides the advantage of reduced spill rates in an accident, but bursing of pressurized vessels due to thermal exposure could result in explosions and possible propagation of the failure to other tanks.

Since both of these ship designs are being proposed as competitive alternatives to existing ship configurations, their cost may be near that of ships now being built of similar capacity.

(3) Insertion of Open Cell Filler Material - The object of this approach would be to restrict the flow of LNG from the container by requiring it to pass through small restrictions within an open celled filler material that has been placed in the tank. This principle has been applied to small flammable liquid containers using open-cell foams or rolled-up sections of expanded aluminum to form a cell-11ke structure within the tank. Only a few percent of the container volume is occupled by the filler material. Additional analysis is required, however, before the loss of cargo space and the restriction of outflow from an LNG tank may be established.

A variation of this approach utilizing much less filler would be the Installation of partitions of material suspended as curtains which would tend to block tank openings created by ship collision penetrations. The rate of outflow would be reduced by the impedence offered by the small passages through which the LNG would have to travel.

This approach appears to warrant further investigation, at least as a potential hazard reduction technique that might act as a retrofit for the free standing tank designs.

(4) Combine Cellular Filler Material with Compartmentalization This approach offers the opportinuty of reducing both the rate and quantity of spill. It also might allow the cellular material to be applied only to those compartments that are most vulnerable to 
penetration during an accident, thus reducing the loss in cargo space and cost.

\subsubsection{Other Methods of Reducing Tanker Fire Hazards}

Other techniques that are considered for achieving reduced-levels of fire hazards from LNG tanker spllls are described in the sub-sections that follow.

\subsubsection{Gelled LNG}

a:

Experiments have demonstrated that LNG can be transformed to a gel using small percentages of either water or methanol. The gels have been shown to evaporate at a slower rate (on a unit area of heat transfer surface basis) than the liquid, and it is predicted that the spreading rate of the gel on water (on spilling from a cargo tank) would be less than that of LNG as well. The maximum size of the evaporating pool may also be reduced. It has been estimated, using the results of sma11-scale experiments that the maximum distance that a vapor cloud might travel when gel is spilled in water would be about one-fourth that if the same amount of LNG were spilled. The effect of gelling of LNG on hazards from pool fires has not been estimated, but significant decreases might be expected.

The extent of actual benefits to be derived, however, requires an evaluation of the effect of scale on pool size and evaporation rates. It would also appear that additional development work on the manufacturing process is also required so as to better establish feasibility and cost. 


\subsubsection{Methanol}

The conversion of methane, the primary component of natural gas, to methanol has been considered in the past as a means of reducing the cost of transportation. Methanol could be shipped in slightly modified, conventional (crude oil) tankers, which are much less costly than LNG ships. The savings in transportation, however is not large enough to compensate for the increased costs associated with energy losses incurred in the conversion of natural gas to methanol and the later transformation of methanol back to a synthesis gas. This trade of $f$ also has become less attractive as the result of the increases in gas prices that have been experienced in recent years.

Methanol would be safer to transport. It is miscible with water and when spilled, would disperse in water quite rapidly to the point where the resultant mixture would no longer be flammable. Methanol also has a relatively low vapor pressure so that vapor cloud hazards would be greatly diminished. Large quantities spilled and mixed with water would adversely affect the aquatic environment, and could be toxic to humans who obtain water from sources along shipping routes.

The methanol approach, then, offers the opportunity of achieving safer transport, but at an increased cost. This would probably be true even if markets were developed for the direct use of methanol or as a gasoline extender and the costly reconversion to synthesis gas were to be eliminated. However, if the cost of LNG tankers were to be increased for safety reasons, the methanol route might become more attractive, particularly for projects requiring long shipping distances. The implementation of a methanol import project would require a large capital investment, some risk, and an extended period of time before it could be put in operation.

\subsubsection{Flame Suppressants}

In concept, extinguishants, such as halons, could be mixed with LNG and render it non-flammable. In practice, however, excessive amounts would be required. Uniform mixtures of the suppressant and vapor 
could not be achieved, and the separation and difficulties associated with the complete removal of the extinguishant at the receiving terminal might result in trace (but hazardous) quantities being. present in the gas send-out. This concept is considered impractical.

\subsubsection{Solid Natural Gas}

If natural gas were to be shipped as a solid instead of a liquid, the spillage of cargo during the most severe of collisions would be expected to be minimal and the hazards to the surroundings greatly reduced, if not completely eliminated. The basic technology for converting the liquid to solid exists so that the prime consideration for shipping natural gas as a solid reduces to the increase in costs related to facilities and energy for converting liquid to solid (and back to liquid again at the receiving terminal) relative to the benefits to be derived from the hazard reduction that is achieved. Some of the increased costs associated with conversion might be alleviated, however, by the potential use of lower cost single hulled (but insulated) tankers for transporting the solid.

\subsubsection{System Costs.}

Generally speaking, improvements in safety are accompanied by increased costs, and this appears to be true for all of the LNG tanker fire reduction concepts that have been reviewed in this study. In this preIIminary evaluation we consider very approximate indicators of costs and benefits so as to identify areas of potential interest and to eliminate totally infeasible, concepts.

As an indicator of hazard reduction (benefits) that may be achievable with one or more approaches, we assume that the best that might be attained is that equivalent to the effect of the previously mentioned $1,000-\mathrm{m}^{3}$ spill over a period of 30 minutes.

For a cost baseline, we have used the costs associated with a somewhat typical LNG project consisting of a billion standard cubic feet per day project, with the LNG shipped from Algeria to Texas. The baseline costs are shown in Table 2.2 . 
TABLE 2.2

$\frac{\text { ESTIMATE OF COSTS FOR }}{\text { LIQUEFYING, TRANSPORTING, AND REGASIFYING LNG }}$

$1 \mathrm{BSCF} /$ Day

'Cost in Dollars

Cost of Gas

$\$ 0.50 / \mathrm{M} \mathrm{SCF}$
Fraction of Total Cost

.181

Liquefaction

Fuel

.075

.027

.037

$.240 \quad .304$

Shippịng

Fuel

.030

.092

.84

.011

.033

.286

(vessel)

.790

Fixed Costs $\quad .225 \quad 1.137$

.285

.081

.412

.103

$2.762 / \mathrm{M} \mathrm{SCF}$

TOTAL

$2.762 / M$ SCF 
Using this baseline, we estimate that the cost of gas at send-out might be increased by as much as 1 percent of the total (some 3c/MSCF) for tank partitioning and for multi-tank vessel. concepts. A value of less than 0.5 of 1 percent increase might be reasonable for the concept involving the hanging wall of expanded metal used to impede the outflow of LNG.

Since industrial processes for making gelled or solid LNG in quantity have not been developed, the costs assoclated with these concepts are more uncertain than the above methods. For reducing the rate and quantity of spill. However, assuming that new and unique plants would have to be built for both concepts, and new ship designs and terminal facilities developed for solid LNG, the incremental increases in cost of gas might be as much as 15 percent for the two concepts.

It is also estimated that the achievement of the improved safety attainable by transporting methanol instead of LNG might require as much as a 10 percent, or more, increase in cost per unit of energy delivered.

The economic impact of cost increases of the magnitude presented here will also require considerable analysis. One perspective, however, is to compare the potential reduction in monetary loss attainable by significant improvements in safety with the cost of employing these improvements. If, for example, one were to assume that a hazardreduction concept could achieve a decrease in the total losses that might occur in a single major accident of $\$ 100$ million (including property loss plus losses assoclated with the ship itself), and.if it is further assumed that the yearly probability of such an accident occurring is unusually large, say of the order of 1 chance in a 1000 per year, then the prorated yearly savings would be about $\$ 100,000$. Clearly, the hazard reduction concepts considered here would greatly exceed this value and, on this basis alone, might not be considered to be cost-effective. 
This, however, does not consider the indeterminate value of losses associated with injuries and fatalities that might result from a major accident nor does it take into account the possibility that the overall impact of the incremental increase in cost of gas might be considered to he. 1 nw relative to the potential benefito.

\subsection{VULNERABILITY OF LNG TANKERS AND CREWS TO FIRES.}

\subsubsection{Vulnerability of Ship and Crew}

Most of the published work on the safety of LNG tankers has centered on hazards presented to personnel and property external to the tanker itself. However, a large pool fire from a $25,000-\mathrm{m}^{3}$ spill of LNG might cause extensive damage to the ship and either severely or fataliy injure the crew as well. The fire exposure might elther directly or indirectly cause failures of cargo tanks that are not damaged in the initial phases of the accident and, at the very least, may result in a severely damaged and immobile vessel with no trained crew to assist in its salvage.

A prelimiary review of the vulnerability of ship components to fire from a large LNG spill indicates that: fire exposure may cause the hull plates to buckle or warp, or perhaps rupture the external protection of the cargo containers and compromise their insulation. Piping, deck machinery, life boats, and communication and navigation equipment may be severely damaged and glass windows may be destroyed during the early phases of such an exposure. If the latter occurs, hot gases may enter certain areas and adversely affect the ship's controls.

On existing tankers, most, if not all, of the critical locations for the ship's operations may be exposed to the thermal effects of fire. This includes positions within enclosures, but which become vulnerable due to hot gases entering through window: openings, as well as exposed locations on deck.

\subsubsection{Protection of Ship and Crew}

Thermal insulation offers an opportunity to reduce greatly the critical damage caused by fire. Water deluge systems would also provide protection, but the reliability of pumps and water distribution systems 
is questionable, particularly if the ship were severely damaged in a collision. Protecting the hull would be extremely difficult, but thermal damage to an unprotected hull would not be expected to be great enough to cause the ship to sink. The cargo tank covers, piping, critical enclosures (including windows), and other equipment could, at least in theory, be protected by thermal insulation. Conventional insulating materials may not be adequate for some components, however. In the case of protective enclosures for crew members, special insulation would be required. On the basis of a conservative criterion that living space must be maintained at $100^{\circ} \mathrm{F}$ or lower for exposure to a fire of one hour, special insulative coatings of the intumescent and/or transpirational cooling type would be required. Laboratory-tested coatings that appear adequate for these purposes are available.

\subsection{CARGO DISPOSAL AND PLANNING}

\subsubsection{Salvage and Dispossal}

Past shipping accidents with other cargos indicate that possibly the remaining cargo would have to be off-loaded from a severely damaged LNG tanker at some location other than a loading or unloading terminal. Either the tanker would be incapable of being moved to a terminal or being moved may be deemed to be too hazardous.

Currently; no satisfactory method exists for the emergency offloading of cargo from LNG tankers other than at terminals, unless an empty tanker that could receive the cargo happens to be nearby. Equipment and procedures need to be developed for off-loading or disposal of a damaged LNG tanker. In this study, we have considered the transfer of cargo to other ships, the disposal of cargo by ship flares or combustors aboard ship, and eventual disposal after the cargo has been transferred by pipeline to some location external to the vessel.

The transfer of cargo from a disabled LNG tanker in or near a U.S. port to another carrier during an emergency does not represent a very likely solution, since it, would be rare for another vessel to be available and close enough to effect the transfer within the short interval of time (several days) as demanded by the urgency of the 
situation. Burning the LNG on board the tanker at the high rates needed to empty the ship in a short time would be difficult, if not impossible, to accomplish with flares, because of the potential thermal damage that could be effected by the large flames. Combustion equipment that would provide for burning aboard ship with little or no thermal hazard cannot be accommodated aboard existing ships, and would occupy excessive space on new tankers.

The țransfer of cargo to platforms located at an approprlate distance from the damaged tanker, however, offers an opportunity of burning LNG at high rates without endangering the LNG carrier. A matrix of small flares, or a series of waste heat bollers, mounted on a barge might be used for disposal. The development of flexible metal hoses for transferring the LNG from the ship to the barges at a distance represents a formidable undertaking, but appears to be feasible.

Another simpler but, perhaps, limited method -- also requiring flexible transfer lines -- would be the discharge and ignition of LNG on the water at an adequate distance from the tanker. This would eliminate the need for barges and associated burner equipment to be continuously on standby at each port. Controlled pool burning of the LNG could be accomplished satisfactorily if a location could be found in which thermal hazards would not endanger nearby property.

\subsubsection{Contingency Planning}

Appropriate and timely responses to LNG tanker accidents may prevent the escalation of the consequences of an accident. Contingency planning is necessary to achleve proper response and to conserve labor and funds in carrying out any plan. In this report, requirements for contingency planning for major LNG tanker accidents are considered, and primary inputs to these plans are discussed.

\subsection{IGNITION DURING AN IMPACT COLLISION}

The effectiveness of spill control methods depends upon whether ignition of the spilled cargo occurs at the time of impact and a pool fire takes place or ignition occurs only after an unignited vapor cloud travels 
some distance and enters a populated area (see Table 2.1). Because the evidence that ignition will occur at the time of impact (although generally considered to be true) is limited, the mechanisms by which ignition could occur were examined in this study.

The statistics of past accidents involving collisions with tankers carrying flammable liquids were examined. It was found that a significant fraction (about 0.3 ) of the collisions where cargo was spilled resulted in immediate ignition. Where it could be determined that there was a significant penetration of the flammable liquid carrier by an impacting ship, immediate ignition occurred in almost 100 percent of the accidents. Hence, ignition sources appear to be present when there is a substantial impact of one ship with another.

The potential causes of ignition were then analyzed using empirical and analytical data on the ignition of flammable gases. It was found that hot surfaces created by frictional impact of two colliding ships are the most likely sources of ignition for LNG spill accidents. The sliding of one steel surface against another under the forces that would occur in a substantial impact collision would cause the surfaces to be heated, momentarily, to the melting point of the steel $\left(\approx 1500^{\circ} \mathrm{C}\right)$. These surfaces when exposed will be large enough and remain sufficiently hot over a long enough period of time to cause ignition of flammable methane-air mixtures.

This determination was confirmed by a series of experiments in which thin strips of inert metal were rapidly heated to elevated temperatures, appraoching the melting point of steel. The surface areas, temperatures, and times to ignition were consistent with the analysis and supported theoretical correlations developed in this study.

Although this work demonstrated that ignition sources may be present in an impact collision, consideration must also be given as to whether these sources will, in fact, be exposed to flammable mixtures of methane and air during an accident. For example, ignition may have 
been more likely in collisions of tankers carrying flammable liquids since the vapor space in the cargo tanks may have contained flammable mixtures of vapor and air at the time of the collision. This would not be true for LNG carriers, and flammable mixtures would have to form after the cargo is released and the vapors external to the tank mix with air.

The results of a first order analysis are unclear as to whether, in fact, flammable mixtures of methane and air will come in contact with hot surfaces, long enough for ignition to take place. By the nature of the collision impact, the exposed hot surfaces will tend to form in the region between the two hulls of the LNG vessel being impacted; an area where mixing of the spilled cargo vapors with air may be insufficient for significant volumes of flammable mixtures to occur.

A more detailed analysis of the structural deformation of the impacting ships and of the fluid mechanics associated with the discharges of cargo and its mixing with air is needed before the likelihood of ignition at the time of impact for an LNG tanker accident can be predicted with reasonable certainty. 


\subsection{CONCLUS IONS AND RECOMMENDATIONS}

\subsection{CONCLUSIONS}

of the spill control methods that were examined, the use of curtains suspended within the LNG cargo tanks to inhibit or restrict the outflow of LNG through a breach in a tank offers the most promise. The curtain system would be relatively low in cost and may be adaptable to existing LNG tankers.

The filling of LNG cargo tanks with a porous inert structure as a means of impeding the outflow through a breach in a cargo tank offers some promise, but the potential effectiveness of the method needs further evaluation. The tank filler may make periodic inspections of the tank walls difficult, if not impossible.

New tanker designs with many small cargo tanks Instead of the five or six large containers on conventional LNG tankers would result in smaller spills (and hence reduced fire hazards) in collision accidents. There is a problem, however, in protecting undamaged, uninsulated cargo tanks from being overpressurized upon exposure to inflowing warm sea water that might enter a breach in the ship's hulls.

With respect to other methods of reducing LNG tanker fire hazards:

- Gelling of the LNG may be the least costly, but its potential for reducing the hazards from pool fires and unignited vapor clouds has not been well-established.

- Shipping natural gas either as methanol or as a solid cloud very significantly reduce the consequences of fire from a major collision of an LNG tanker with another ship. Given a spill, methanol could be an aquatic hazard. Both forms would probably be transportable in modified, less costly conventional oil tankers rather than existing LNG ships. 
A11 methods of reducing fire hazards result in an increase in cost of gas at send-out from the importing terminal. Preliminary analysis indicates that the increase in costs might range from one percent for spill control curtains to ten percent or more for shipping natural gas as methanol or as a solid.

Provisions for protecting the LNG tanker and crew in the event. of a large pool fire caused by a collision are feasible but will require extraordinary measure for life support and thermal insulation systems.

At present, there is no feasible method for the removal of LNG from a disabled tanker in or near a U.S. port in an emergency, unless there is an empty LNG tanker nearby. Methods of flaring the LNG at. a site remote from the ship appear to offer the most promise.

The hazardous distance from an LNG spill is much less if the spilled material is ignited during a collision and a pool fire results than if an unignited vapor cloud is produced. Frictional impact when two ships collide is the most likely source of ignition at the site of a collision.

Hot spots on the hulls and other ship components that occur due to frictional impact will ignite flammable mixtures of natural gas and air. The likelihood that these ignition sources will actually be exposed to flammable mixtures during a collision needs further evaluation.

\subsection{RECOMMENDATIONS}

We recommend that the following additional effort be considered, as a means of improving the safety of LNG tankers:

- Design and test prototype spill control curtains to establish their feasibility and cost.

- Carry out further analysis of the effectiveness and practicality of porous tank fillers for retarding the outflow of ING from breached tanks. 
- Conduct additional research to develop concepts for converting and shipping natural gas as a gel or as a solid and to evaluate the effectiveness of gelled LNG in reducing fire hazards.

- Develop life support and insulation concepts for protecting the ship and crew from large fires.

- Investigate methods of disposing of LNG from disabled tankers by burning the cargo at a site external to the ship.

We also recommend that consideration be given to:

- The applicability and effectiveness of spill control and other methods of reducing fire hazards that were examined in this study as potential hazard mitigation methods for land storage.

- Continuing research on the ignition of LNG by frictional impact to better establish the likelihood that ignition will take place during a major collision of an LNG tanker with another ship. 


\subsection{HAZARD REDUCTION METHODS}

\subsection{REDUCTION IN LNG FIRE HAZARDS}

\subsubsection{Introduction}

Potential methods of reducing the hazards (or consequences) of LNG tanker accidents depend upon:

- reducing the rate and/or quantity of the LNG that is discharged;

- modifying the cargo so that the emission rate of flammable vapor from the spilled liquid is lowered, or even perhaps

- rendering the liquid non-combustible during transit.

To. provide a basis for establishing how much different methods might ameliorate fire hazards, we have to estimate the reduction in (a) the thermal radiation from LNG pool fires and (b) the size and maximum travel of unignited vapor clouds. Although these estimates apply to hazard reduction methods that serve to decrease the rate and quantity of LNG discharged in an accident, tiey may, by inference, aid in evaluating other methods as well.

In this analysis, spill sizes of from 1,000 to $50,000 \mathrm{~m}^{3}$ and spill durations of from "Instantaneous" (very rapid spilis) to ,30 minutes are considered. The range of conditions for which the estimates are made are presented in Figure 4.1.

Also, as is noted in the following discussions specific relationships are developed in this work for both pool fires and vapor dispersion so as to accommodate extended spill times and to differentiate between the effects of rapid spills and longer-term "continuous" releases.

\subsubsection{LNG Poo1 Fires}

\subsubsection{Classification of Spills into Instantaneous and Continuous Categories}

One of the principal difficulties in estimating the distances over which thermal radiation hazards from burning pools of LNG exist lies in estimating the dimensions, or size, of the spreading pool of spilled 1iquid. Spread models exist for the idealized "Instantaneous" (very 


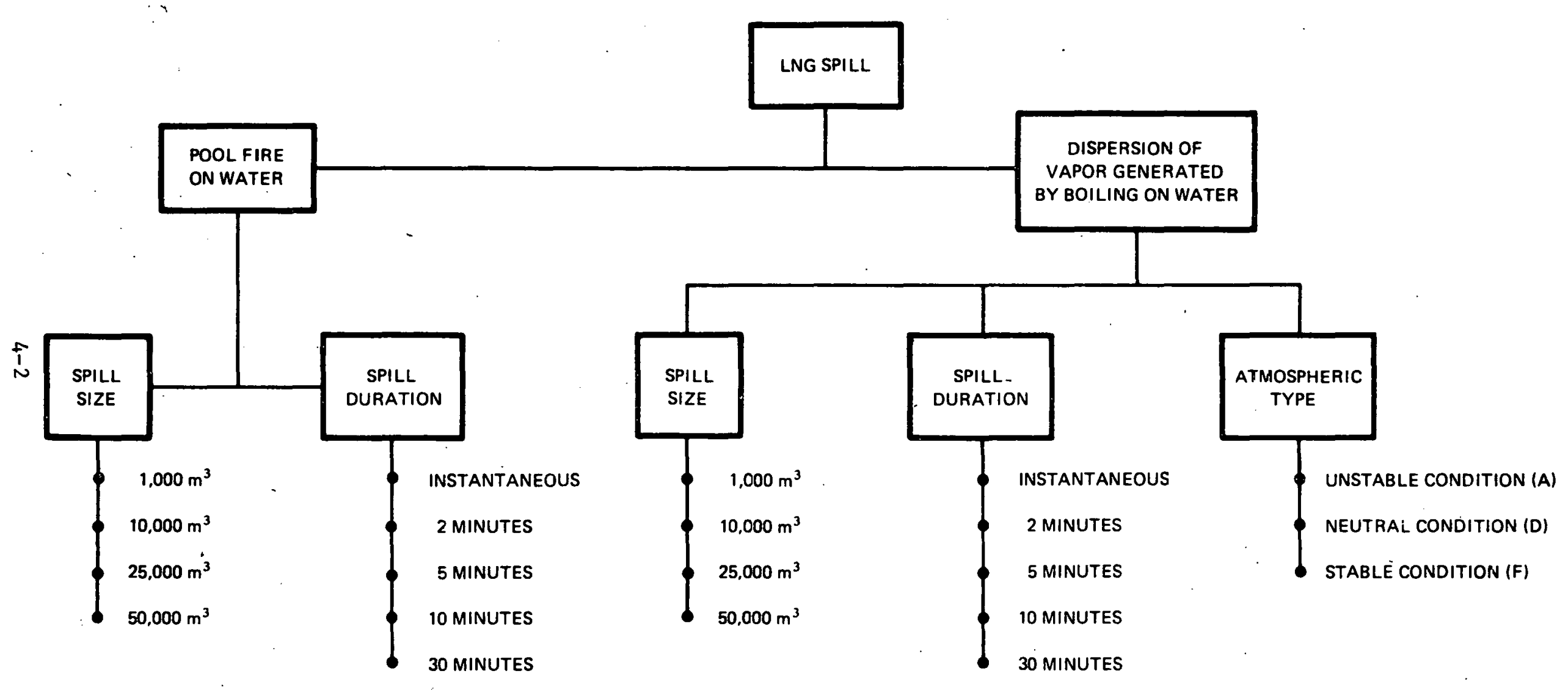

FIGURE 4.1 TYPES AND MAGNITUDES OF HAZARDS

CONSIDERED IN THE ANALYSES 
rapid) release case and for the "continuous" (long-term) releases. Since no spill is truly instantaneous, it is important to establish when the spill duration might be short enough for the spill to be considered as occurring instantaneously.

This question has been addressed in Appendix A, and a time criterion (cross-over spill times) has been obtained for spill durations that may be considered as being short enough for the spill to be represented as occurring instantaneously. For spill durations longer than the crossover time, continuous spill models are used. Table 4.1 shows the value of the cross-over times for various spill sizes. The table shows, for example, that a two-minute spill of $50,000 \mathrm{~m}^{3}$ may be considered as an instantaneous spill, whereas two-minute spills of smaller quantities are more representative of continuous discharges.

\subsubsection{Analytical Models for Thermal Radiation Hazards}

The basic relationships used in estimating thermal radiation hazards (Raj, 1977) consist of the following:

The maximum spread radius is represented by

$$
\begin{aligned}
& R=\left[\frac{v^{3} g \Delta}{\dot{y}^{2}}\right]^{1 / 8} \text { for INSTANTANEOUS spill } \\
& R=\left[\frac{v}{\pi t \dot{y}}\right]^{1 / 2} \text { for CoNTINUOUS spill }
\end{aligned}
$$

The height of fire is assumed to be three times the diameter of the burning pool, and the emissive power of the LNG fire is estimated to be $100 \mathrm{~kW} / \mathrm{m}^{2}$.

The hazard distance to skin burn infury is estimated on the basis of a skin burn criterion of $5 \mathrm{~kW} / \mathrm{m}^{2}$. While other criteria exist, 
TABLE 4.1

CROSS-OVER TIMES FOR VARIOUS SPILL SIZES

Volume of LNG

$\operatorname{Spil1}\left(\mathrm{m}^{3}\right)$

$$
1,000
$$

10,000

25,000

50,000
Cross-over

time* $(\mathrm{sec})$

31

68

92

116

* If the duration of spill is longer than the cross-over time, the spill is to be modeled as a continuous spill. 
It is seen that, even for the case of an expanding fire the Iifetime of which is greater than about 40 seconds, the above burn criterion is appropriate.

The hazard distance from the vertical cylindrical fire then is estimated by obtaining the distance at which the view factor at ground level is equal to 0.05 (i.e., $5 \mathrm{kw} / \mathrm{m}^{2} \div 100 \mathrm{kw} / \mathrm{m}^{2}$ ). In the case of dry atmosphere, it is seen $(\operatorname{Raj} 1977)$ that this distance is about 8 radii from the center of the fire. In the case of thermal absorption by water in the atmosphere, the hazard distance would be less than that depicted above. It has to be evaluated using the transmissivity v's. distance curves presented in Raj, 1977.

\subsubsection{Results}

The results obtained by utilizing. the models set forth above are shown in Figures 4.2 through 4.5. The figures indicate tie distance (from fire center) to the skin burn hazard for different release times for each of the spill volumes considered. A $0 \% \mathrm{RH}$ atmosphere and a $50 \% \mathrm{RH}$ atmosphere have been considered.

\subsubsection{Dispersion of LNG Vapor Clouds}

\subsubsection{Method of Analysis}

If the vapors from an accidental spill of LNG onto water, are not ignited, then a vapor cloud will develop which will travel with and be dispersed by the prevalling wind. Depending on the rate of release of LNG and the total quantity released, flammable concentrations may persist in the cloud for considerable distances. In this analysis, estimates are made. of the downwind distances over which the vapor cloud will remain flammable and of the maximum width of the cloud as a function of spill volumes, spill rates, and atmosphertc conditions.

The spread of LNG on water was estimated in a similar fashion to that done for pool fires. The estimation of the spreading of vapor produced due to $1 t$ being more dense than the surrounding air followed that of Germeles and Drake (1975) for rapid or "instantaneous" spills. 


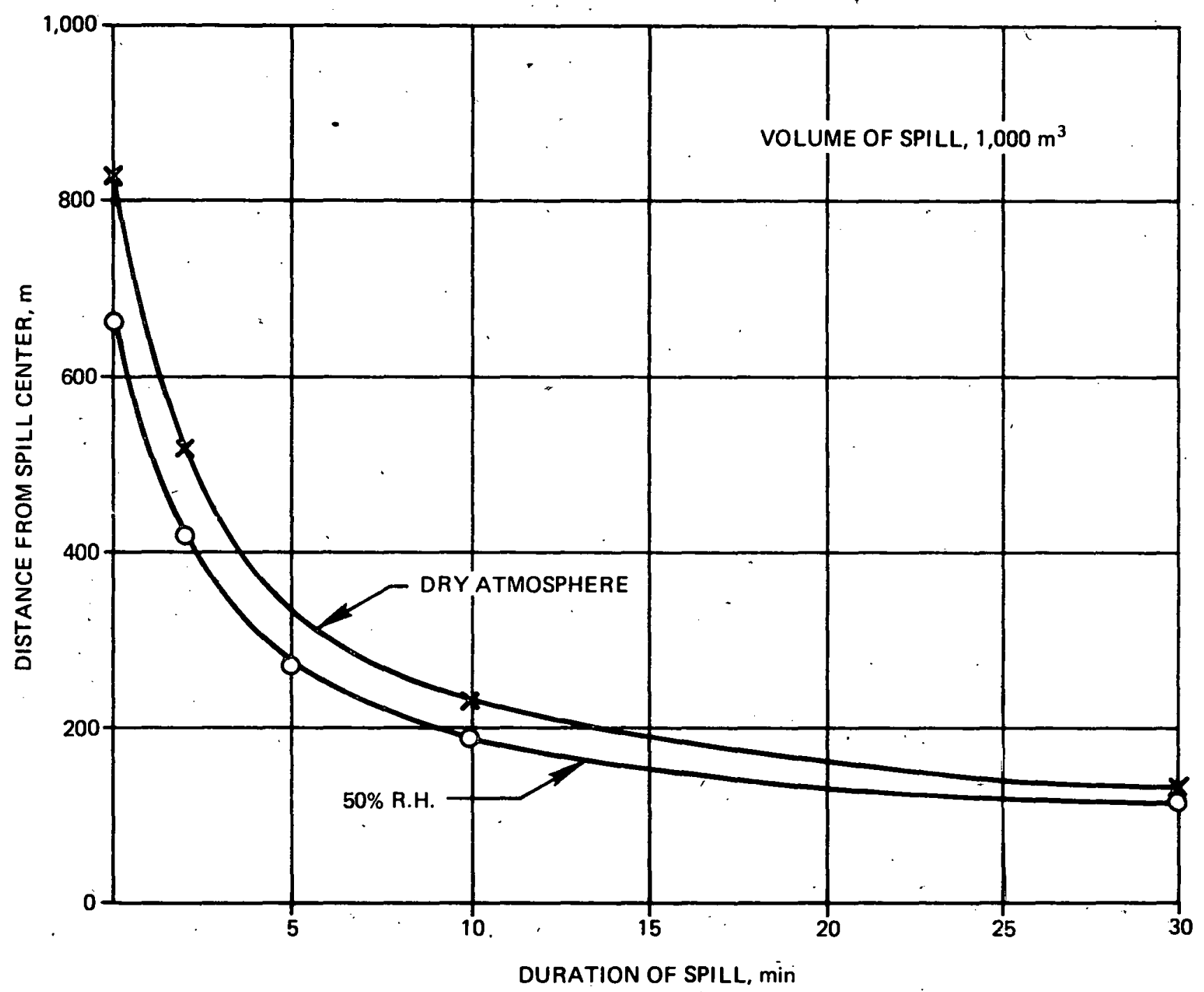

FIGURE 4.2 HAZARD DISTANCE FOR BURN INJURY AS A FUNCTION OF DURATION OF LNG RELEASE 


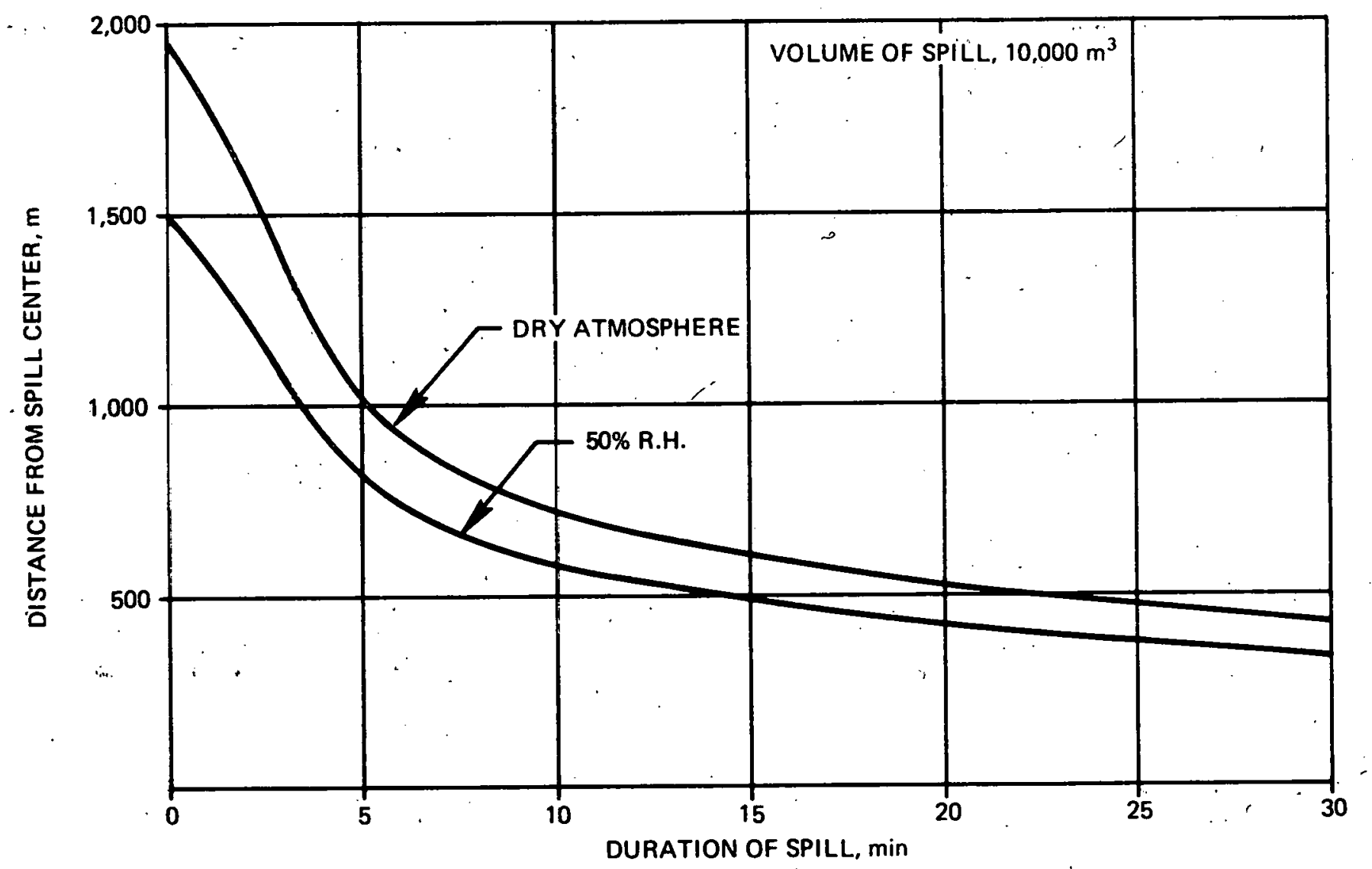

FIGURE 4.3 HAZARD DISTANCE FOR BURN INJURY AS A FUNCTION OF DURATION OF LNG RELEASE 


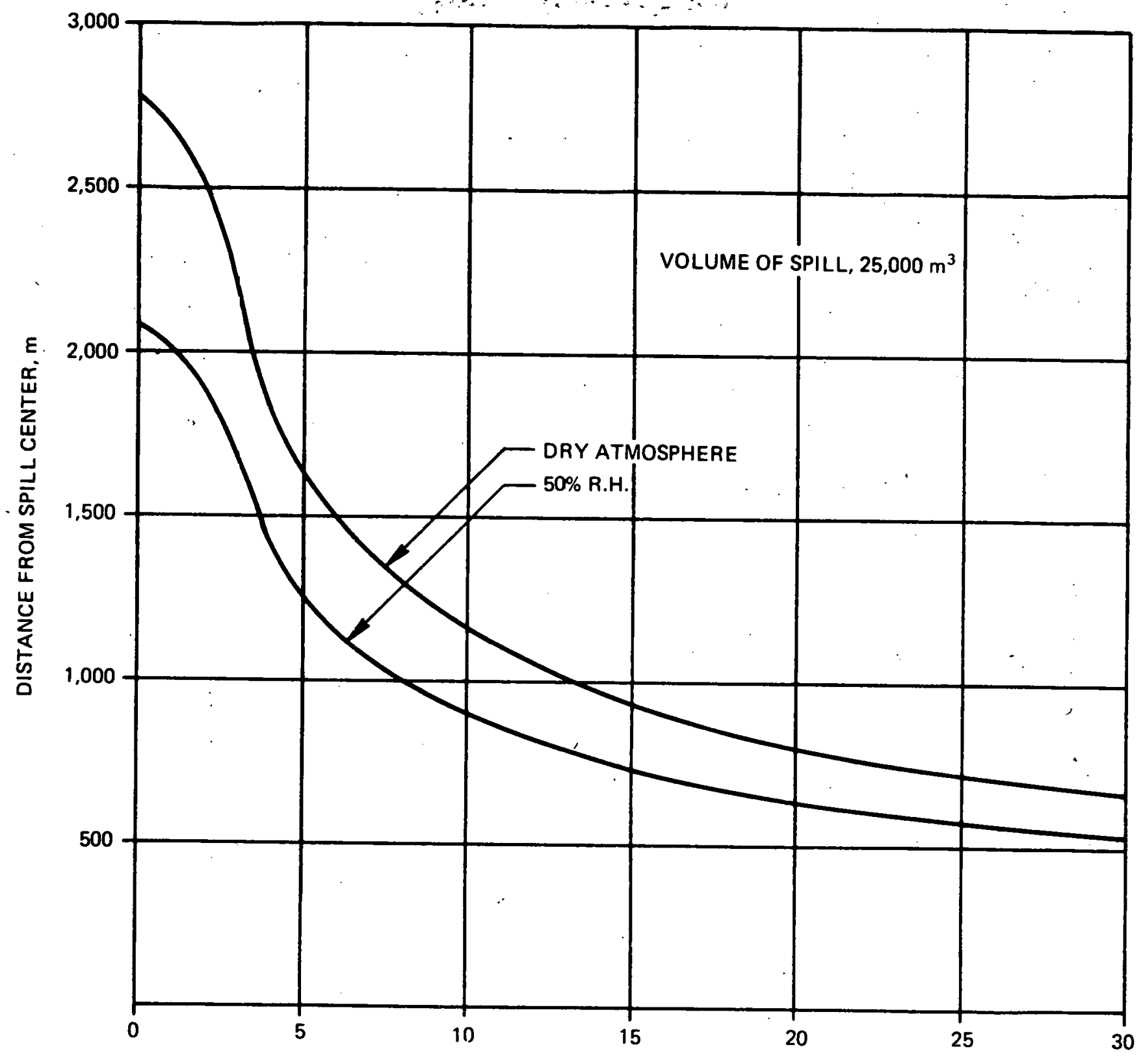

DURATION OF SPILL, min

HAZARD DISTANCE FOR BURN INJURY AS A FUNCTION OF DURATION OF LNG RELEASE 


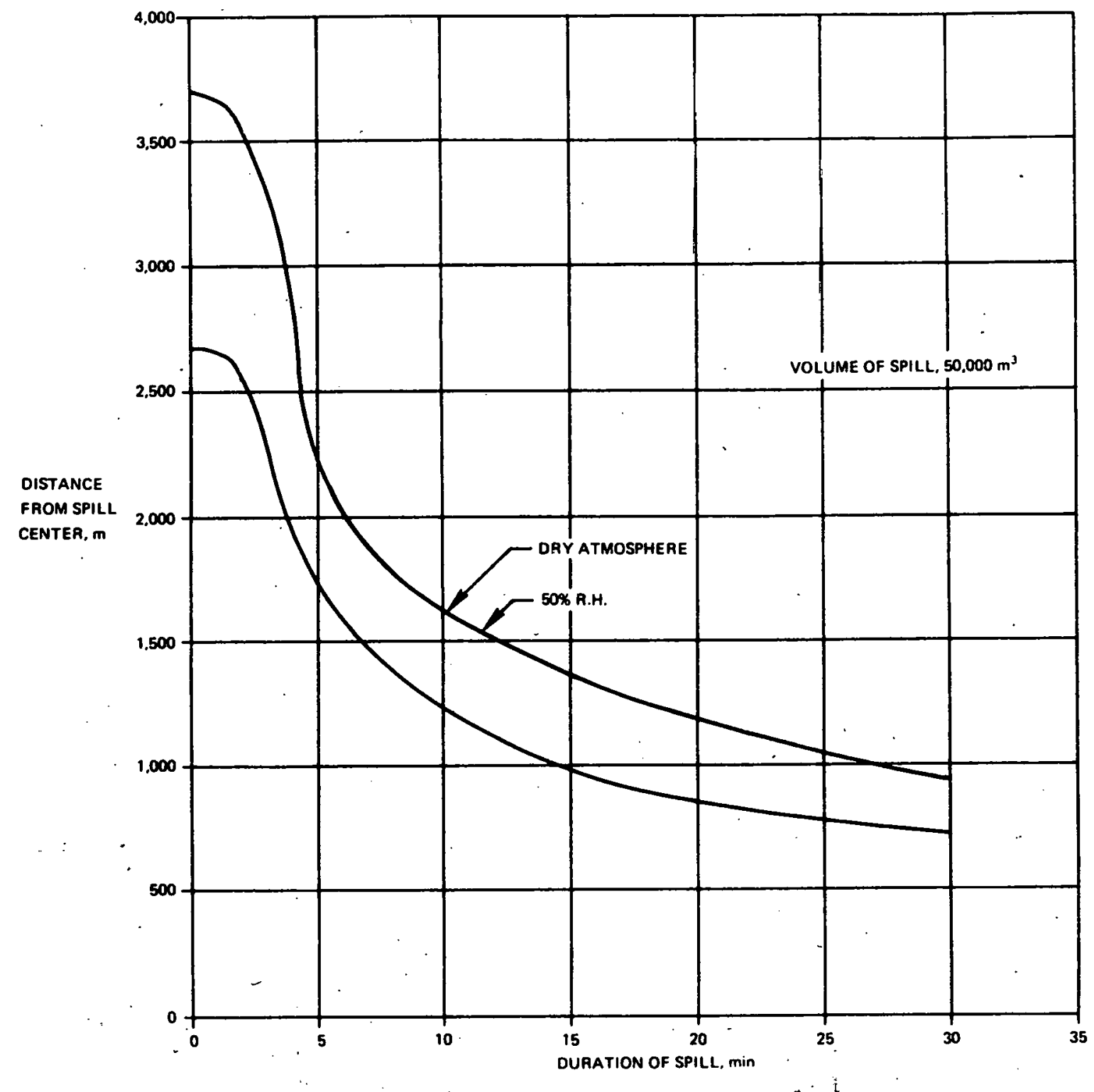

FIGURE 4 . 5 HAZARD DISTANCE FOR BURN INUURY AS A FUNCTION OF DURATION OF LNG RELEASE 
A vapor gravity spread model had to be developed, however, for slower (continuous) releases, as described in Appendix B. In this model it is assumed that the vapor spreads in the lateral direction only and is diluted by air entrainment. The gravitational spread is terminated (somewhat arbitrarily because of lack of any other relevant criterion) when the spread velocity is equal to or less than the prevailing wind speed.

The subsequent vapor dispersion is analyzed using the conventional Pasquili Gifford dispersion models. However, the vapor dispersion is modeled as if the vapors were lssuing from a virtual source. The location of the virtual source is determined by matching the vapor concentration at the end of the gravity spread with the concentration of vapor at the samelocation obtalned from a conventional dispersion model (with the source being the virtual source).

\subsubsection{Results}

The dispersion results are presented in the form of semi-widths of flammable region as functions of downwind distance. The atmospheric condition is used as a parameter. The results for each spill volume and type of spill (Instantaneous, continuous) are shown in separate flgures.

Figures 4.6 through 4.8 show the semi-width of flammable regions for the Instantaneous spills of $1,000 \mathrm{~m}^{3}, 25,000 \mathrm{~m}^{3}$, and $50,000 \mathrm{~m}^{3}$. In each figure, the gravity spread regime and turbulent dispersion regimes are clearly shown.

In Figure 4.9, the maximum downwind distance to $5 \%$ concentration (LFL) Is shown for different spill volumes, with the duration of spill as a parameter. The figure refers to dispersion in very stable weather conditions, 1.e., In $\mathrm{F}$ weather with $3-\mathrm{m} / \mathrm{sec}$ wind. Figure 4.10 shows the semi-widths to $5 \%$ concentration. In both figures, the results of instantaneous spill results are also indicated. 


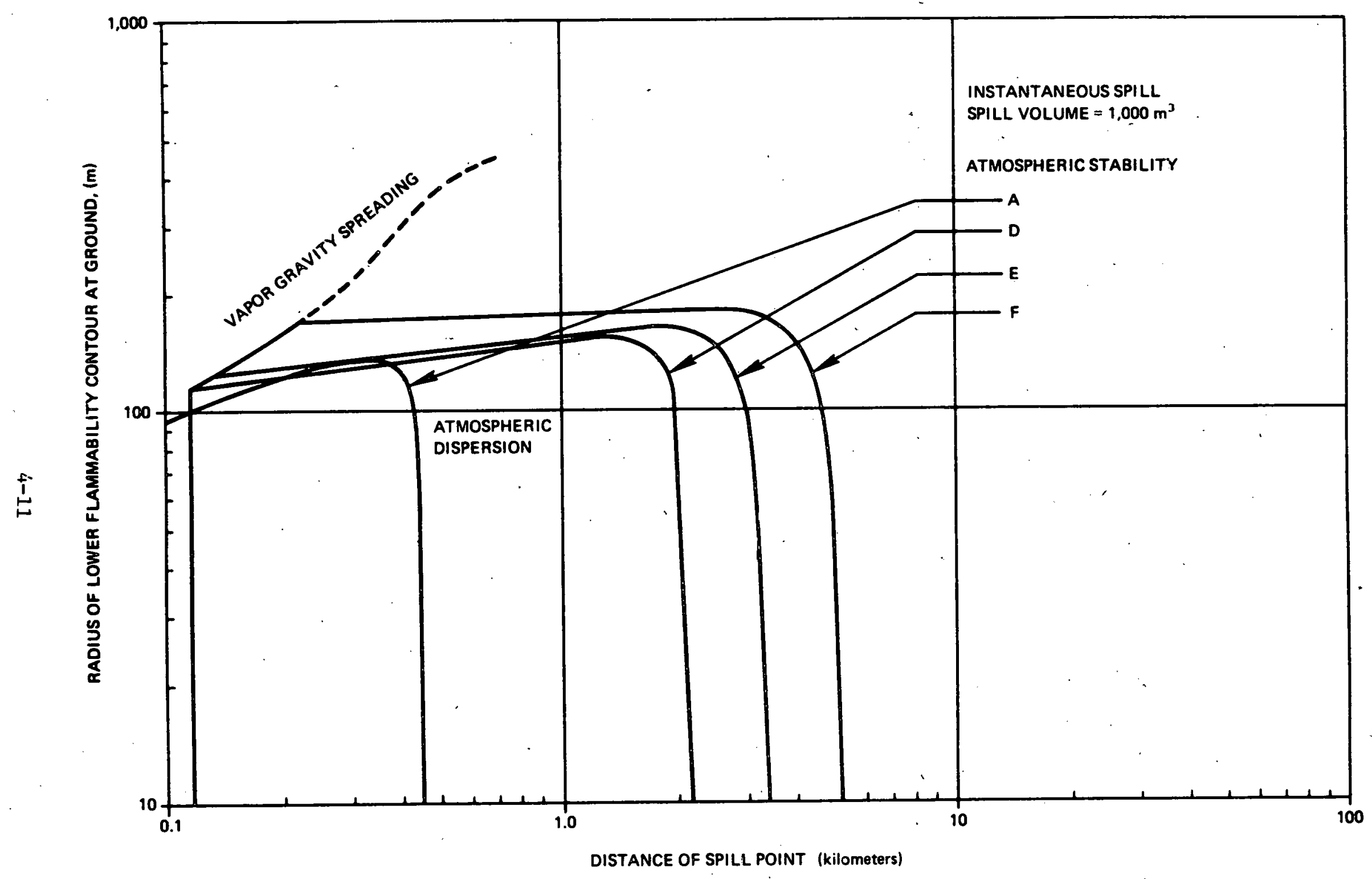

FIGURE 4.6 WIDTH OF FLAMMABLE REGION AS A FUNCTION OF DISTANCE FROM SPILL POINT FOR $1,000 \mathrm{~m}^{3}$ LNG SPILL ON WATER 


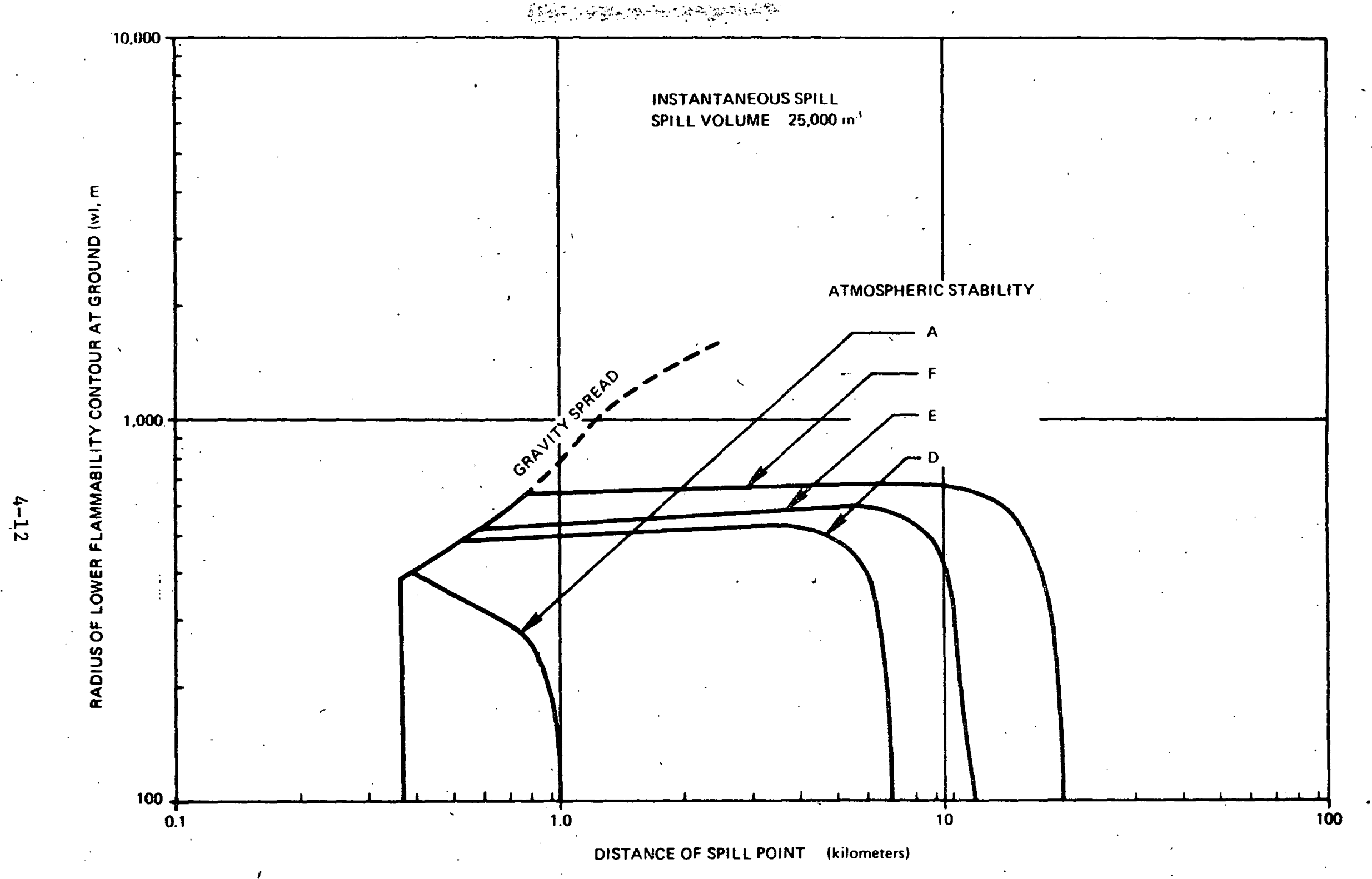

FIGURE 4.7 WIDTH OF FLAMMABLE REGION AS A FUNCTION OF DISTANCE FROM SPILL POINT FOR $25,000 \mathrm{~m}^{3}$ LNG SPILLS ON WATER 


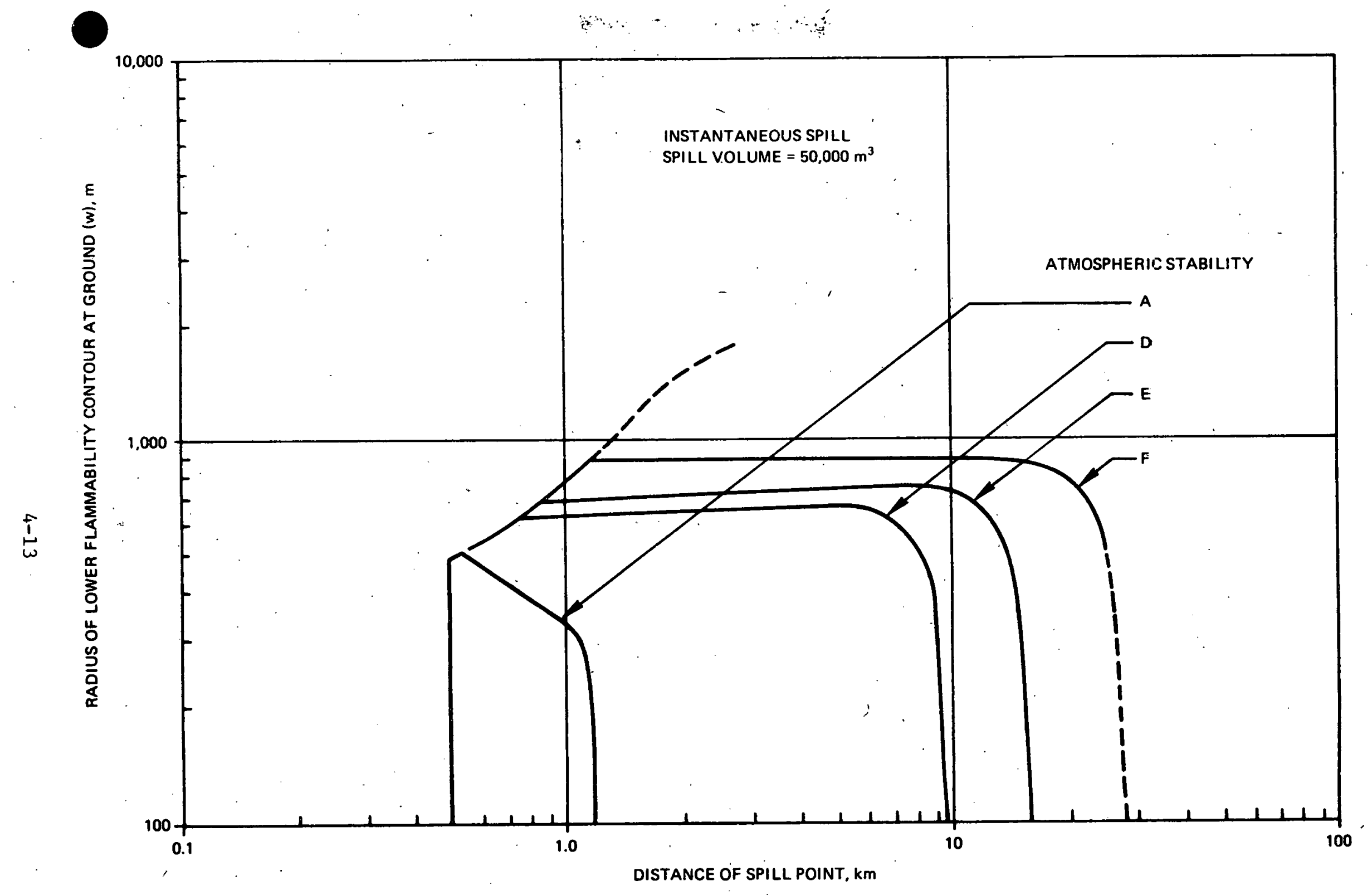

FIGURE 4.8 WIDTH OF FLAMMABLE REGIONS AS A FUNCTION OF DISTANCE FROM SPILL POINT FOR $50,000 \mathrm{~m}^{3}$ LNG SPILL ON WATER 


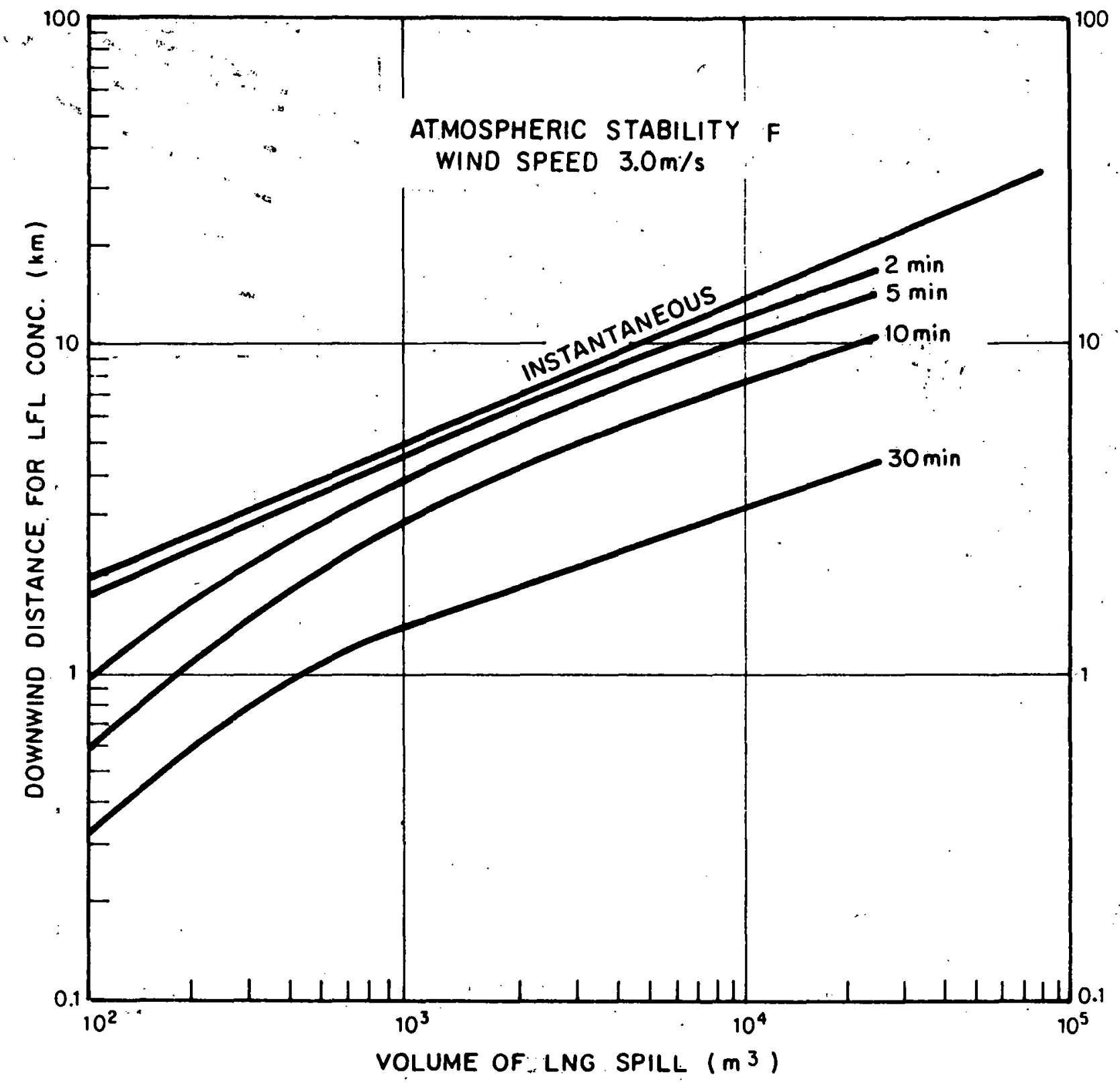

FIGURE 4.9: MAXIMUM DOWNWIND DISTANCE TO $5 \%$ CONCENTRATION VS.: SPILL VOLUME. 


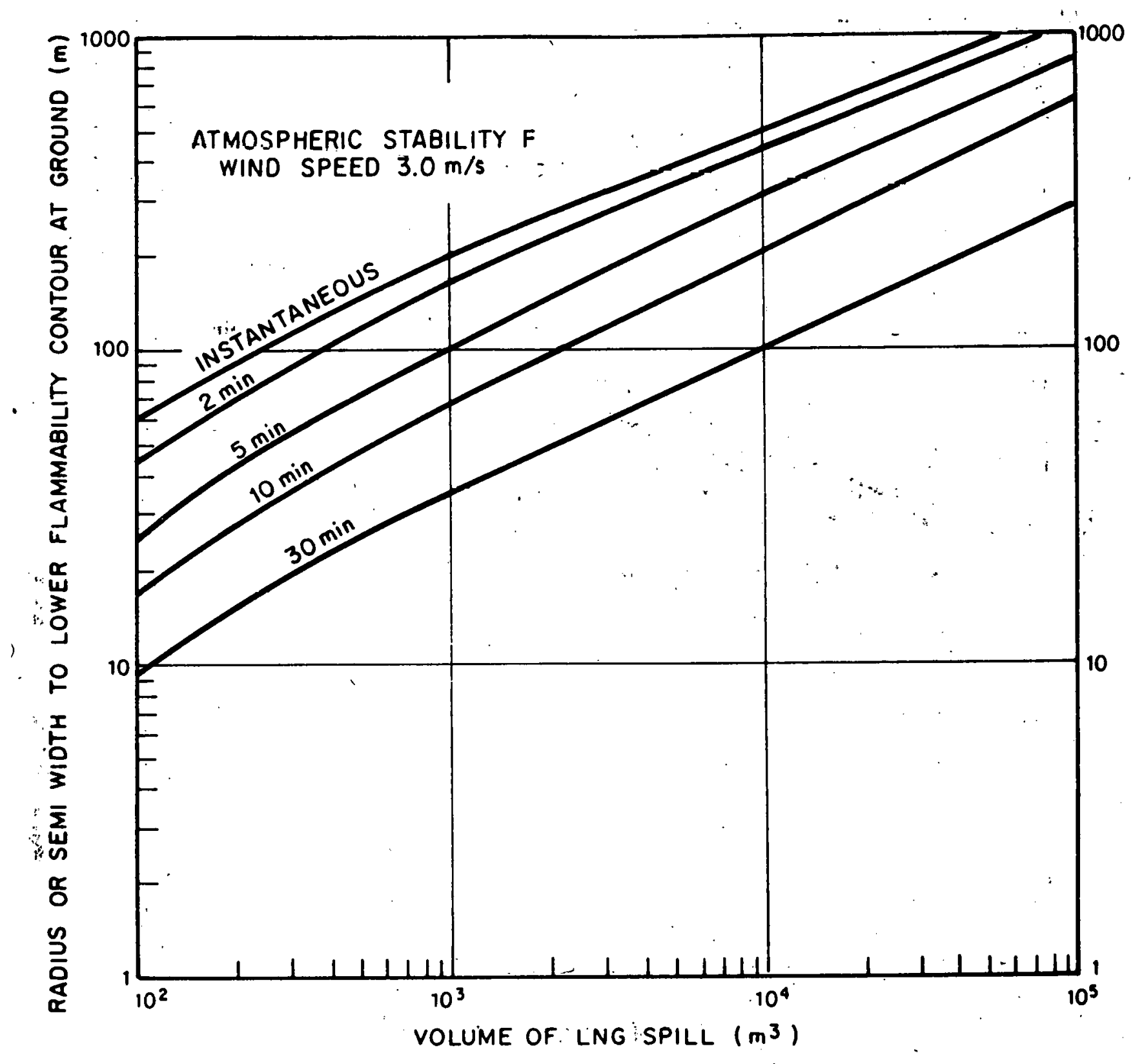

FIGURE 4.10 MAXIMUM SEMI WIDTH OF CLOUD TO $5 \%$ CONCENTRATION VS SPILL VOLUME 


\subsubsection{Discussion}

Figures 4.9 and 4.10 indicate that the extent of the hazard (measured in total ground area of concentration above 5\% LFL) diminishes with increase in the duration of the spill. This is what one would expect inituitively in developing the curves shown in Figures 4.9 and 4.10; the gravity spreading of vapor and its subsequent atmospheric dispersion were considered in toto in the case of instantaneous spill. The effects of heat transfer to the cloud from the water surface and the effect of atmospheric humidity were taken into consideration. However, in the case of continuous release spills, the computation of maximum downwind distance to LFL and the width of the maximum lateral hazard extent were made initially using the gravity spread model developed in Appendix $B .^{*}$ Unfortunately, the results were not only against the inituitive estimates, but also indicated some peculiarities, such as a 30 -iminute release hazard width being the same as that from an instantaneous spill of the same volume of liquid. The curves indicated for continuous spills in Figures 4.9 and 4.10 have, therefore, been obtained by first considering releases of very low volumes and analysing the dispersion of these vapors from such small spills, with conventional dispersion models. Vapors from small volume spills $\left(100 \mathrm{~m}^{3}, 1000 \mathrm{~m}^{3}\right)$, especially those that are spilled over significant durations (more than five minutes) have very little tendency to gravity spread. The behavior of vapors from larger spill volumes were extrapolated from the results of $100 \mathrm{~m}^{3}$ and $1000 \mathrm{~m}^{3}$, but with guidance from the gravity spread model (Appendix B) as to the variation with size. Therefore, it is cautioned that by merely exercising the model given in Appendix B, the results indicated in Figures 4.9 and 4.10 cannot be obtained. They are based partly on the gravity spread model, partly on conventional dispersion model and engineering judgment.

The results indleated for the downwind himard extent for the case of continuous spills are only approximate. Improved results can be obtained by modifying the vapor gravity spread model to include the ground heat transfer and the heat of water vapor condensation. The instantaneous spili results, however, would not be expected to vary with these changes.

* This model is approximate and does not include the effects of heat transfer and of the atmospheric humidity. 


\begin{tabular}{|c|c|c|c|}
\hline g & $=$ & acceleration due to gravity & $\left(\mathrm{m} / \sec ^{2}\right)$ \\
\hline L & $=$ & characteristic length scale $\left(\mathrm{V}^{1 / 3}\right)$ & (m) \\
\hline $\mathbf{R}$ & $=$ & maximum spread radius & (m) \\
\hline$t_{c}$ & $=$ & characteristic time $-\mathrm{L} / \mathrm{y}$ & $(s) \cdot$ \\
\hline \multicolumn{2}{|c|}{$t_{\text {cross-over }}$} & $\begin{array}{l}=\text { cross-over time for change in type } \\
\text { of spill }\end{array}$ & (s) \\
\hline ts & $=$ & duration of spill & (8) \\
\hline V & $=$ & volume of liquid spilled & $\left(\mathrm{m}^{3}\right)$ \\
\hline y & $=$ & $\begin{array}{l}\text { liquid regression rate (volume boiling } \\
\text { per unit area per unit time) }\end{array}$ & $(\mathrm{m} / \mathrm{s})$ \\
\hline
\end{tabular}

\section{GREEK}

$\Delta .=$ density defect $\left(1-\frac{\rho_{11 g}}{\rho_{\text {water }}}\right)$

$p_{11 q}=\quad$ 11quid density

$\mathrm{kg} / \mathrm{m}^{3}$

$\rho_{\text {water }}=$ water density

$\mathrm{kg} / \mathrm{m}^{3}$

$\xi \quad=$ dimensionless radius of spread

$\tau=$ dimensionless time 


\subsection{REDUCING THE OUTFLOW OF LNG}

\subsubsection{Introduction}

In their analyses, Federal agencies, marine societies, and various transportation and risk consultant firms have concluded that the major risk to public safety associated with the marine transportation of LNG is the potent1al release of LNG cargo in the event of a collision. In general, these analyses have Indicated that the consequences of such LNG spills to public safety and property are quite formidable, although their probability within harbors or close to populated shorelines is very sma11.

The magnitude of hazards due to LNG spills--resulting in either a pool fire at the site of the spill, or an Ignited vapor cloud downwind from the spill site--is a function of the quantity spilled and 1 ts rate of discharge from the breached cargo container. The concepts for reducing the magnitude of the hazards presented by LNG tanker transits, therefore, are related to methods of reducing the size of the individual LNG cargo tanks, or providing means of controlling the rate of outflow following a casualty.

Tank size reduction might be accomplished by containment design; e.g., the relatively large tanks, such as those generally found in the LNG tanker fleet, could be compartmentalized by internal bulkheads or other type structures. Such compartmentalization might be accomplished as a retrofit modification in existing LNG vessels, or as a design modification in new ships or, in some cases, in those presently under construction.

Another approach would be to construct new LNG tankers with cargocontainment systems comprised of a relatively large number of small tanks. The several multi-tank configurations proposed in recent years by various firms would be included in this category. The rate of LNG outflow following a marine casualty might be controlled by porous filler materials, curtains, or internal baffle structures within the cargo tanks. 
The technical and economic feasibility of several such concepts have been discussed in meetings and in correspondence with firms which have developed--and are st111 developing--LNG martrie containment systems, as well as with major marine elasslfication societies and the U.S. Coast Guard. These organizations and Individuals who provided us with their views and technical information include the following:

- General Dynamics, Quincy Shipbuilding. Division (Dr. R. Glasfeld),

- American Technigaz, Inc. (Dr. G. Nassopoulos and D. Blackley),

- Kvaerner-Moss, Inc. (J.. Howard),

- Ocean Transport Group, Inc. (R. Ffooks),

- Naval Projects Construction Company (C. Verolme and Dr. A. K. Winkler),

- Linde A. G. (W. Foerg),

- American Burèa of Shipping (A. Gillies and J. Feskos),

- Lloyd's Register of.Sh1pping (J. Mattewson; J. Fraser and B. Rapo),

.. Dot Norske Veritas (Dr. H. Hansen, E. Skramstad, and T. Jennsen),

- Bureau Veritas (J. Benoit, H. Arnoux, M. Engerrand), and

- U.S. Coast Guard (Dr. A. Schnelder, Lt. Com. P. Pluta, and Lt. J. Sedlek).

The information gathered in our contacts with these organizations was augmented by a 1iterature search, concentrating on cargo-containment methods and techniques, and by the results of our own prior studies and others which dealt with the characteristics of ship casualites and the structural resistance of ship structures to such casualties. 
The results of these investigations, including discussions of the technical aspects and, where possible, estimates of the potential costs Involved in modifications or in new design concepts, are presented in the following subsections. To provide a frame of reference, a general discussion of LNG ship structural resistance to collisions, the impact velocities required for penetration of the cargo-containment systems, and some of the characteristics of the structural damage are presented before the results of the investigations.

Although much of the data and information presented was obtained from the stated sources, the statements concerning technical feasibility, advantages and disadvantages, and estimates of cost of the varlous modifications or designs given, unless explicitly stated to the contrary, were derived during the conduct of this study.

\subsubsection{Characteristics of LNG Tanker Collisions}

\subsubsection{Methods of analysis}

Up to the present time, the structural effects of ship collisions have been analyzed in three ways:

1. Empirical methods, using data from actual collisions to define relationships between the energy of the collision and some measure of the degree of structural damage;

2. Model studies, in which scaled structural models simulating vesse 1 bows and sidewalls have been fabricated and tested in the laboratory; and

3. Analytical studies in which the elastic and plastic energles absorbed in collisions by specific portions of a ship's structure are evaluated using simplifying assumptions regarding the deformation modes and the structural behavior of specific scantilngs. 
The effects of ship collisions using an empirical approach was first performed in 1959 by V.U. Minorsky (1959) whose major concern at that time wac the vuluerab1lity of ship structures with reference to the impact protection of marine nuclear power plants. His study was based on data from actual ship collisions, mostly tankers, over a period of 12 years, and concluded that a correlation could be established between the total kinetic energy lost during the collision and certain structural characteristics of the vessels involved. The relationship developed by Minorsky has been used to define critical impact velocities (corresponding to penetration of the sidewall up to the cargo-containment system) for various sized vessels in collision with the sidewall tankage area of several different types of LNG vessels. Some typical results of such analyses are shown in Figure 4.11 for the Ben Franklin, a $125,000 \mathrm{~m}^{3}$ tanker of the Technigaz membrane system design (Athens, 1974). Such studies, which have been used in risk analyses of LNG transportation projects, are generally believed to be conservative, although the applicability of Minorsky's results, which were derived from collision data involving single-hull ships, to the more complex structural configurations of double-hull ships is somewhat uncertain.

Analyses of the collision problem through experiments with scaled models have been performed by investigators in several countries. For the most part, these experiments have shown that Minorsky's results are reasonable, albeit somewhat conservative (in the sense that structural damage is less than that predicted by Minorsky's relationship) in those instances in which the ship's sidewall structure is more complex than that representative of oil tanker designs. In particular, an extensive series of experiments carried out by Woisin (1971) in Germany, with a rela- 


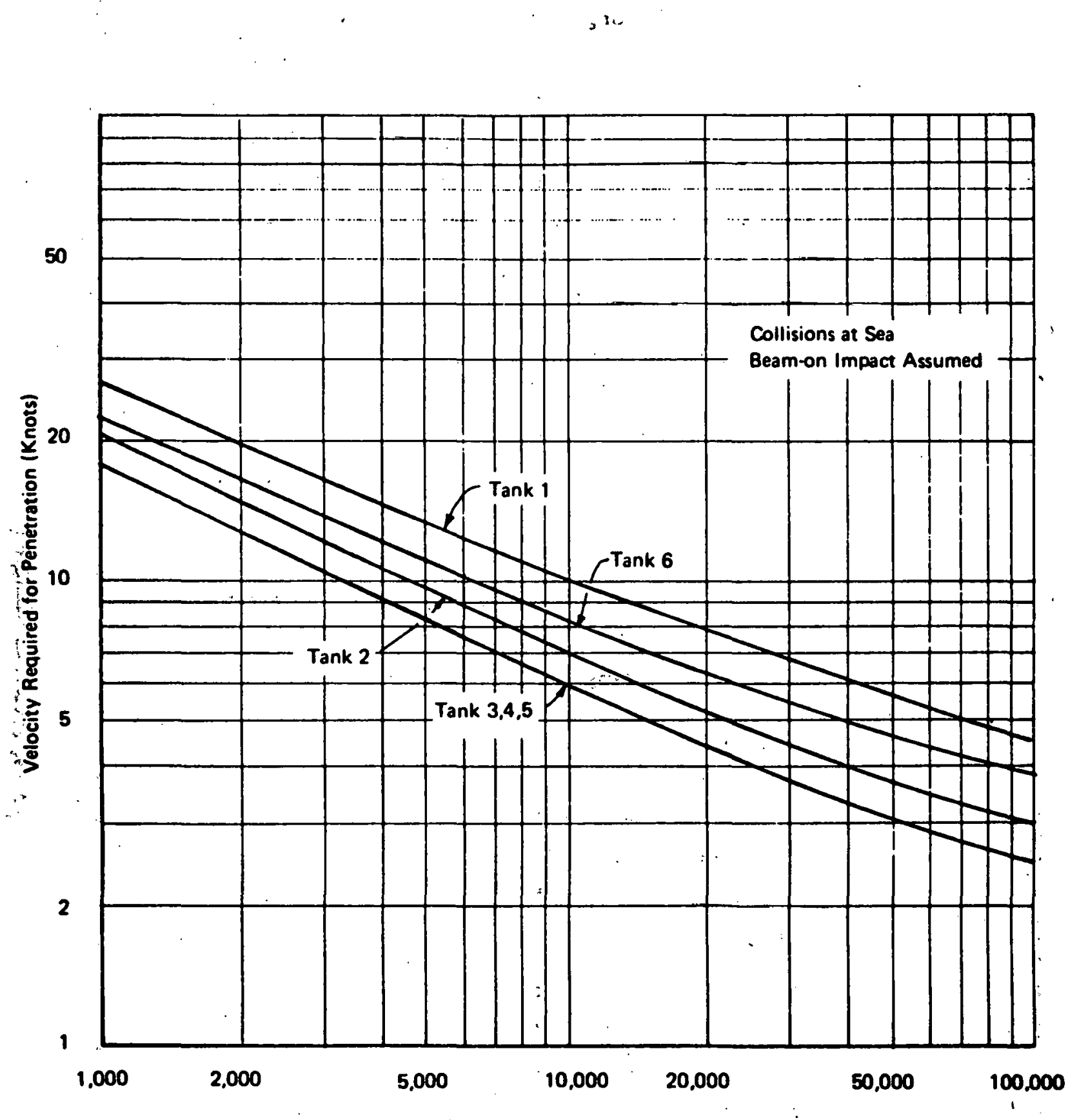

Displacement of Striking Ship (Tons)

COLLISION RESISTANCE OF BEN FRANKLIN

FIGURE 4.11 
tively closely-spaced gridwork of longltudinal and transverse bulkhead members, showed that the resistance to penetrations from a collision with a ship of such a configuration is greater than that of fered by a ship with more conventional sidewall construction. The indications that a grid-type construction is highly resistant to impact is not, of course, surprising--honeycomb or corrugated types of assembly have been used extensively in ship and other construction for shock and impact absorption.

Some caution must be exercised in accepting the validity of structural failure studies carried out with scale models, however. One of the problems associated with model studies is concerned with the method used for scaling the s actural elements, since the type of fallure assumed will, to some degree, dictate the scaling method; and the type of failure of a given structural consideration is not always known $\underline{\text { a }}$ priori. Another problem. inherent in many of these model tests is related to the way the models are held or șupported in the test fixture. Certain postures may result in behavior during impact quite different from that of two moving bodies, both of which are free to move in the water.

Nevertheless, the results obtained from such model studies appear to be credible, and consequently, the fact that such studies have shown generally that the Minorsky empirical relationship is reasonable adds to the level of confidence and validity of the application of Minorsky's method of collision-risk studies.

Finally, evaluation of the elastic and plastic energies absorbed in collisions by specific portions of the ship structure has been made using analytical methods, together with simplifying assumptions regarding the deformation modes of the structure. The principal purpose of a study of this type, carried out by the M. Rosenblatt firm, was to develop an analytical method of ranking the relative effectiveness of various sidewall structural configurations adapted to oil tankers for collision 
protection. The method developed by the Rosenblatt firm is quite complex, and although it has proven useful in relative evaluations of structural resistance, it has not been applied to date in studies of the absolute collision resistance of ship sidewalls.

\subsubsection{Effects of Collisions}

Minorsky's study of actual collision data suggested that:

1. Most of the structural damage (on the order of 90\%) would generally be incurred by the struck ship; and

2. The configuration of the structural damage in the struck ship would approximate the bow-shape of the striking ship.

The results shown on Figure 4.11 were developed using these assumptions. For each class ọ̣ size of potential striking ship, furthermore, estimates can be made of the location of the impact and penetration of the sidewall structure relative to the LNG cargo tank height and distance to the waterline. As an example, consider the main center tanks of the Ben Franklin. In a collision scenario, striking ships of 20,000 and 50,000 tons displacement, with typical raked bows, would impact the sidewall of the Ben Franklin at vertical locations of approximately 20 and 30 feet above the waterline. Since the cargo tank itself extends 63 feet above the waterline ( 87 feet high from top to bottom of tank), breaching the cargo tank by ships of these sizes would result in a rapid release of up to one-half of the tank's contents.

Striking ships. that have bulbous bows would present a somewhat different damage configuration. The bulb structure of a striking ship would contact the sidewall of the LNG ship below the waterline and, depending upon the displacement or size of the vessel, the contact point could be in the region of the tankage, or at the depth of the double bottom or turn of the bilge. Resistance to penetration in these areas is generally very high, and the structural configuration of typical bulbous bows is such that they are susceptible to crushing under impact conditions. Breaching of the cargo tanks due to impact of the bulbous bow is, therefore, considered much less likely than penetration from 
the bow stem which would impact above the waterline. The consequences of breaching the tanks below the waterline, however, would be more severe, with the attendant uncertainties of the mixing of the sea water and LNG, and the subsequent flooding of the insulated holds with sea water.

Another characteristic of importance to this study is the size of the opening in the cargo tank following a collision severe enough to cause breaching. The size, along with the location of the opening, will determine the inftial quantity of LNG spilled and its rate of outflow. Based on Minorsky's relationship, the increase in the impact velocity of a ship striking normal to the LNG ship's sidewall needed to produce a relatively large opening, say, 100 square feet, is about $40 \%$ higher than the impact velecity which would cause damage up to the tankage. This suggests that the probability that a collision would result in an opening small enough to limit the outflow to small rates is not high. The most likely occurrence, given a collision severe enough to produce breaching of the cargo tanks, is that the flow rate and quantity spilled would be high enough that some means of control, such as those considered in the following section, would be required to greatly reduce the resulting fire hazards. 


\subsubsection{Compartmentalization of Existing LNG Tankers}

\subsubsection{Container Designs*}

Three basic LNG container designs presently account for more than 90\% of the total LNG vessel capacity:

1. The integrated systems, including both the Technigaz corrugated stainless-steel containment system and the Gaz transport Invar sheet containment system;

2. Kvaerner-Moss free-standing spherical tank system; and

3. The Conch II free-standing prismatic tank system.

Although the compartmentalizing or subdividing of each of these containment systems involves problems unique to the basic type of containment, certain considerations would be common to all. The most fundamental of these is that any such subdivision or reduction in the size of LNG cargo tanks would take place in the presence of other and conflicting criteria. Principal of these criteria are those dealing with the capital and operating costs of the vessels involved. Another is that subdivision in a horizontal plane is immediately excluded, because of structural support problems and operational logistic problems involved in such configurations.

For those cargo-containment systems in which internal dividing bulkheads are feasible, two considerations must be addressed:

1. The strength of such bulkheads, and

2. Their heat-transfer characteristics.

In an undamaged condition, assuming that sluice gates or some such type of mechanism is used tolallow cross flooding paths during normal operations, no problems would be anticipated. In a damaged condition, however, with one of the cargo volumes open to the sea, the bulkheads between the damaged element and the other tank elements would be required to sustain a hydrostatic head differential (and probably a dynamic loading

* For a more detailed description of container designs, see Section 5.2-Critical Ship Components and Their Location. 
from one side), and the thermal loads associated with cryogenic temperatures on one side and ambient or sea water temperatures on the other. If the interior bulkhead were not insulated, the second condition would result in a rapid vaporization and pressure rise in the adjacent intact tank elcments, but fallure resulting from overpressurization would occur at a later time and might not add to the hazards of the initial spill. If, on the other hand, the bulkheads were designed as insulating and load-bearing barriers, the cargo system would essentially evolve into a design with a larger number of smaller tank units.

The following sections describe such subdivision or compartmentalization for each of the basic containment designs.

\subsection{Integrated Tank Systems}

Integrated tank system designs are characterized by a flexible metallic "membrane" liner as a primary barrier. This is supported by load-bearing insulation which in turn, transmits the cargo loading to the ship's inner hull and inner bottom structures. A secondary barrier is required for integrated systems; this barrier is imbedded within the insulation system. As a result of the structural character of this barrier, there are no strength or swash bulkheads within the tank systems.

Partitioning of integrated tanks with some type of internal bulkhead or barrier structure is not a feasible approach since attachments to the membrane of the type required would introduce serious constraints in the mechanical and structural behavior of the membrane in response to cargo loads and the corresponding thermal loads. For these tank systems, the only method of compartmentalizing which would appear feasible from an engineering viewpoint would be a design involving a larger number of smaller tanks, with each tank designed as a separate, insulated, integrated system.

Some basic vessel characteristics and corresponding capital and operating cost estimates have been developed by American Technigaz, Inc. (ATI) for such subdivisions of a proposed LNG vessel design and furnished to us for use in the present study. 
The basic vessel design is that of a five-tank, $130,000 \mathrm{~m}^{3}$ capacity vessel incorporating the Technigaz stainless-steel waffle membrane containment system. Taking the total, vessel capacity, draft, speed, and the design bolloff rate as constant, ATI developed the principal vessel characteristics and estimated cost increments for similar yessels with 8- and 16-insulated tank configurations. A summary of some of their results in comparative form is presented in Table 4.2.

TABLE 4.2

CHANGES IN CHARACTERISTICS AND COSTS FOR INTEGRATED TANK LNG VESSELS (PERCENT)

Tank Profile

\section{CHARACTERISTIC}

Volume of Largest Tank

Length between Perpendiculars

Beam

Depth

Light Ship Weight

Full Load Displacement

Ship Horsepower

Capital Costs

Operating Costs

\begin{tabular}{cc}
\multicolumn{2}{c}{ Tank Profile } \\
\cline { 1 - 2 } 5 to 8 Tanks & 5 to 16 Tanks \\
\hline 50 & 25 \\
+4.0 & +9.5 \\
0 & +1.0 \\
+1.0 & +2.7 \\
+12 & +26 \\
+3.6 & +8.0 \\
+3.6 & +7.3 \\
$+10-15$ & $+20-25$ \\
+5 & +10
\end{tabular}

The capital cost figures include the increase in the cost of the fabrication and materials for the containment system, Increases due to the increased size of the structure other than the containment system, increases in the cost due to larger prime movers, and increases due to the larger number of pumps and a more complex piping system. The tabulated increases in operating costs are probably upper 1imits, and represent primarily more fuel and more costly maintenance due to more mechanical equipment. 


\subsection{Spherical Tank Systems--Independent Type B}

The Independent tank (Type B) systems in current use are of the Kvaerner-Moss design, consisting of spherical tanks of either $9 \%$ nicke1steel or aluminum alloy, supported at their equator by a cylindrical skirt, which, in turn, is attached to a shell structure forming part of the double bottom. The partial secondary barrier in this design consists of a drip tray below the sphere with a capacity limited to liquid volumes from potential small leaks. These Type B systems are based upon a "leak before fallure" approach, with the reduced secondary barrier allowed by the regulatory authorities on the basis that the tank is designed using well-established analysis methods and model tests to determine fatigue life; stress levels, and crack propagation characteristics; and that the relatively simple unstiffened-shell structure serving as the primary containment can be analyzed in this manner with a high degree of confidence.

LNG vessel designs of this type have also been developed by Technigaz, Sener, and Hitachi in collaboration with Chicago Bridge and Iron. Up to the present time, however, only vessels based on the Kvaerner-Moss system have been put in LNG vessels.

Concepts for internal partitioning of spherical containers include an approach using one or more vertjcal bulkhead structures, or, following a more unique approach, using one or more vertical cylinders placed concentrically within the sphere. Such concepts are sketched in Figure 4.12. Internal partitioning using vertical bulkheads would Include three possible options:

1. One or more non-liquid-tight bulkheads, which would be effective primarily in controlling the rate of outflow in the event of a major casualty;

2. One or more liquid-tight bulkheads, which would subdivide the cargo volume, but which would, under some accident conditions, be susceptible to vaporization and pressure rise conditions, so that their effectiveness 


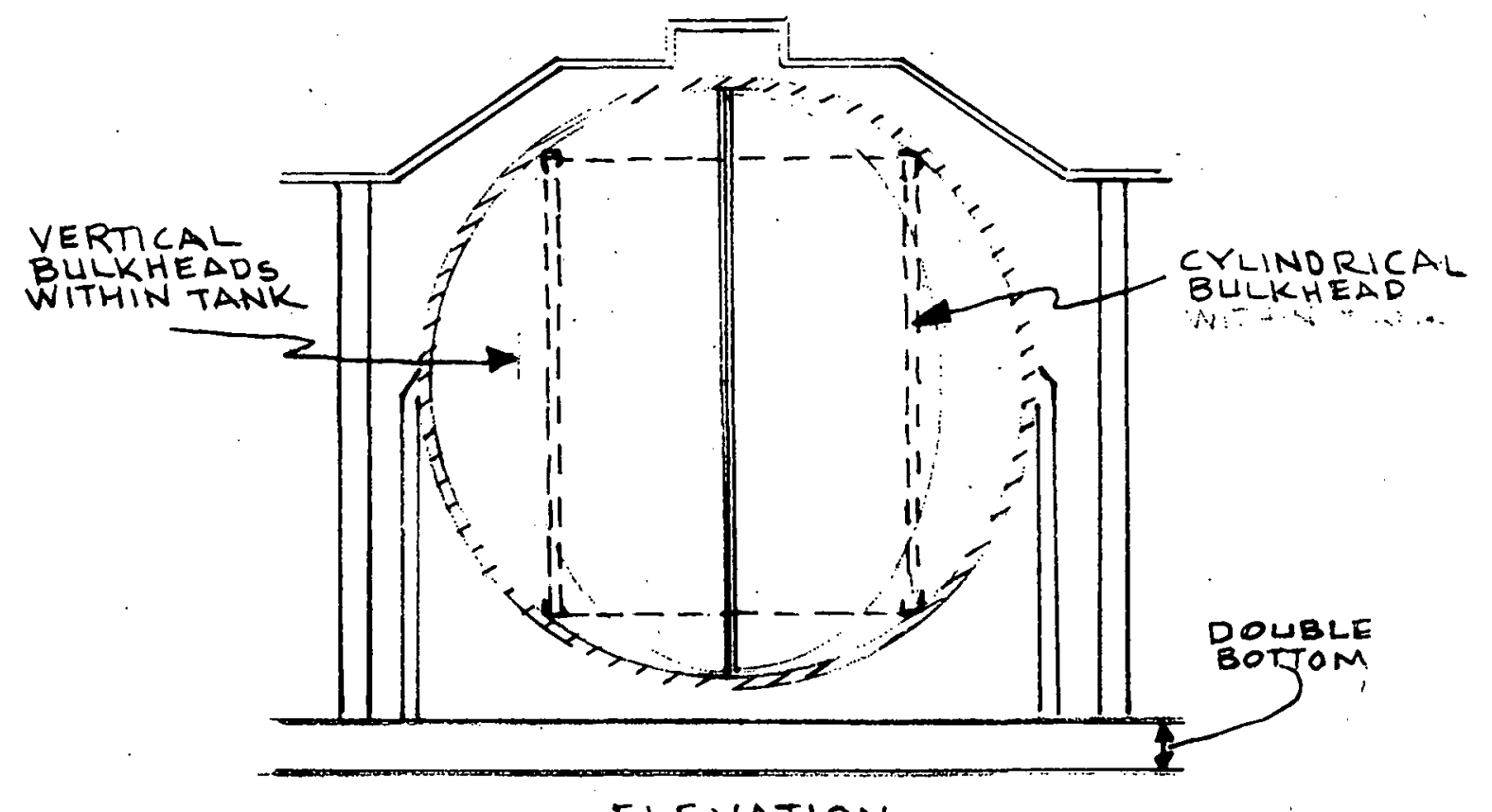

ELEVATION

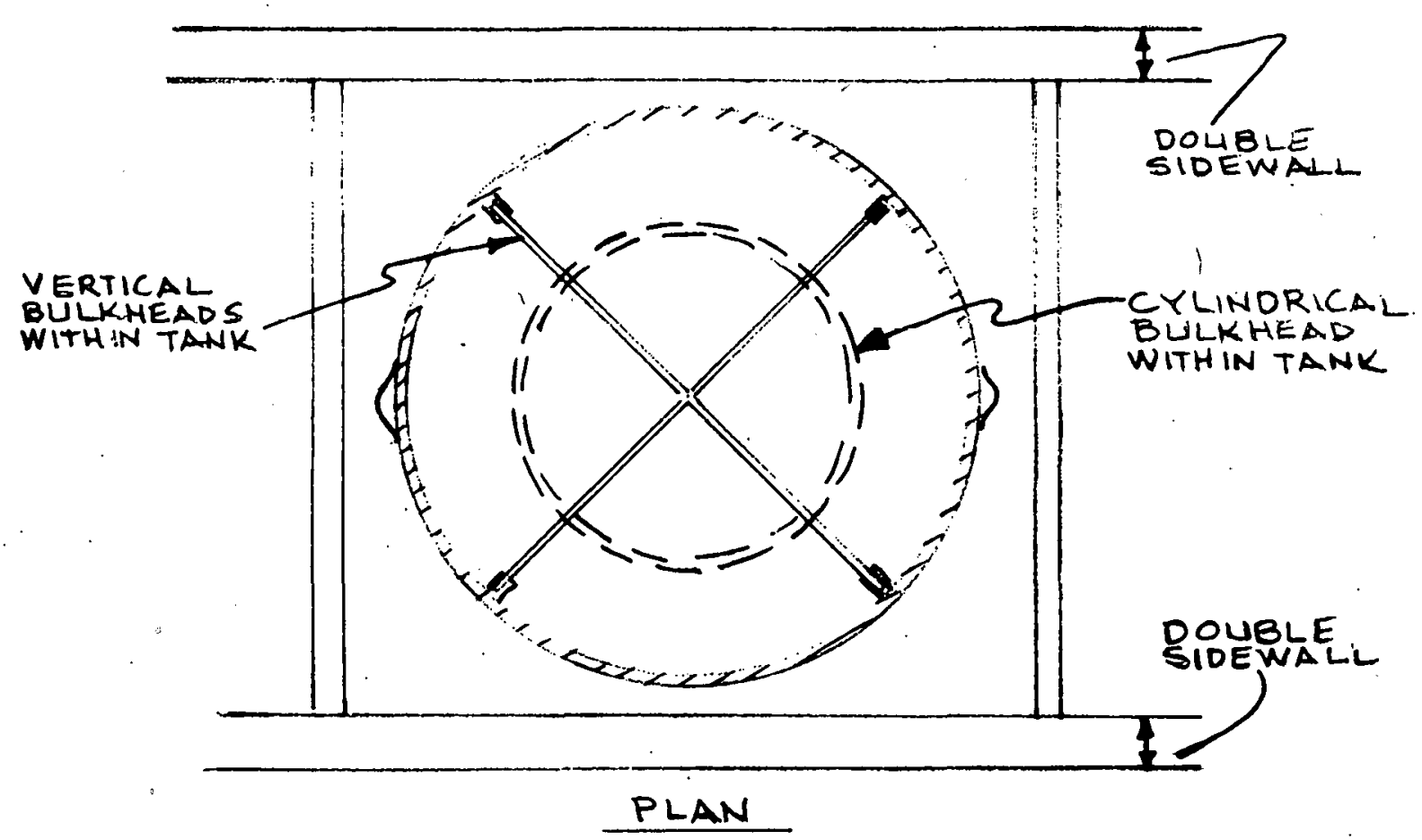

MOSS SPHERICAL TANK SYSTEM

PARTITIONING ARRANGEMENTS

FIGURE 4.12 
would also be primarily in reducing the rate or timesequencing of the outflow; and

3. Liquid-tight and insulated cofferdam partitions, which would effectively subdivide the spherical volume into smaller cargo spaces, thereby reducing the total volume spilled under most casualty situations.

Subdivision or partltioning of spherical Type B tank systems by any of the concepts or combination of concepts described presents two fundamental considerations:

1. Although it is technically feasible to conceive of such modifications on a retrofit basis, on economic and logistic grounds they may be quite costly. Partitioning approaches as described, therefore, would be applicable only during the fabrication phase of the containment system when internal members could be installed as part of the construction process.

2. Any of the modifications discussed would present serlous problems in terms of the basic classification of the containment system as an independent Type B system. The opinions of the technical staff surveyors from several of the major ship classification societies in regard to this consideration varied somewhat. It is clear that the introduction of any structural members to the internal spaces of the spherical container would, at the very least, require a significant amount of additional analysis and test work for the Type $B$ classification to be maintained.

An area of special concern when internal members are considered is the equator zone where the sphere is attached to the supporting cylinder. If internal structures introduce constraint to radial movement in this area, it is uncertain at this time whether the system could be satisfactorlly analyzed with current fracture mechanics methodology 
as approved for Type $B$ systems. If such analysis procedures are not applicable, the classification requirement would be based on Type $A$ analyṣis methods which would place spherical container systems at a distinct disadvantage to prismatic tank systems.

What, then, are the possible internal structural arrangements which would meet the compartmentalization objectives and which would not violate the Type B containment requirements? Liquid-tight partitions (i.e., those that are fixed to the tank over a sizable portion of their periphery), insulated or not, would appear to be unsatisfactory. The possible exception might be an arrangement of one or more cylindrical shells within the sphere, rigidly attached to the sphere at their bases and free at the top, perhaps in some type of collar or, more simply, free at the top at some distance below the spherical surface arrangement. Although such a tank configuration would present formidable fabrication problems, it would seem to partition the cargo volume into a relatively small peripheral sector at the region of maximum vulnerability to collision impact, thereby confining the immediate spill to a small portion of the total tank volume.

Other possibilities using non-liquid-tight partitions would include one or more vertical bulkheads designed with both the sides and the bottom edges sleeved into channel structures to allow vertical and radial movement without constraint on the sphere. Another arrangement might be side-channeled buikheads, free at the top, with a sluicegate system of some type at the base to prevent full hydrostatic loadings on the bulkhead. Such designs, of course, would not reduce the total quantity spilled in the case where the tank sidewall was breached, but rather would be effective in controlling the rate of outflow.

For a pair of vertical partitions of this type, dividing the volume of the sphere into four sections, it is estimated that the costs would be in the range of $\$ 1$ to $\$ 2$ million per tank, representing about a 4 to $8 \%$ increment on the ship's total cost. For the more novel concept of a cylinder within the sphere, costs could be more difficult to estimate; however, the increase would likely not be less than $50 \%$ of 
the present containment system costs, corresponding to approximately 10 to $15 \%$ increment on the ship's total cost. For either arrangement, the increase in light ship weight would probably be in the 1000- to 1500-ton range, so that the effect of the partitions on the operating costs would not be significant.

\subsection{Free-Standing Tank Systems, Independent Type A}

Independent Type A tank systems, like the other Independent type systems, are self-supporting, do not constitute part of the ship's hull, and are not essential for hull strength. The Type A configurations are generally of prismatic shape and are designed using classical structural analysis procedures conforming to ship classification society rules. According to IMCO regulations and classification soclety requirements, a complete secondary barrier is required for Type A systems.

LNG containment systems in this classification include those developed and constructed using the Conch I and Conch II prismatic designs, the Esso prismatic design, and the Gas de France cylindrical/ conical design. Other Type A systems which have been proposed include a Hitachi prismatic design, similar to the Conch system; a PDM/Gaz Transport cylindrical/conical design; and earlier designs by McMullen Associates and A. G. Weser. At present, of the 125,000 cubic meter ship size, only the Conch II design appears amenable to the addition of bulkload or partitioning. Three such vessels are presently under construction at the Avondale Shipyards for E1 Paso.

These Avondale ships incorporate large prismatic cargo tanks, holding 25,000 cubic meters each, which are fabricated outside of the hull and then fitted into each of the holds of the LNG ships. The flat sides of these tanks are strengthened with vertical stiffeners and by horizontal girders. Each tank is subdivided by one liquid-tight longitudinal bulkhead and by one swash traverse bulkhead to enhance ship stability and reduce liquid sloshing effects. As a result of these bulkhead structures, both the quantity and the rate of outflow would be restricted in the event of a major collision involving breaching of the cargo tanks. 
Structural modifications involving these tank systems, such as Increasing the number of the internal bulkheads, or their geometry, or changing the swash bulkheads into liquid-tight barriers, or even modifying the longitudinal bulkhead, for example, into an insulated cofferdam structure, would be relatively simple in terms of design and fabrication. In addition, these modifications would not be likely to involve significant increases in overall costs, at least in comparison to comparable changes in other types of containment systems. Thus, several partitioning options and variations are possible with the Conch II system, as shown in Figure 4.13:

- A larger number of smaller tanks, such as that configuration discussed for the membrane systems. For example, providing an insulated cofferdam arrangement along the longitudinal centerline of the ship would double the number of tanks. In the event of a major collision, this modification would limit the total LNG spilled to 12,500 cubic meters. The rate of the outflow would also be controlled by the swash bulkheads in each lateral tank. For the Conch II system, we estimate that such a modification would increase the ship's total costs about 5 to $8 \%$, and the ship's total welght by perhaps 600 to 800 tons.

- Increase in the number of transverse swash bulkheads. This modification would serve to control the rate of outflow in the event of a major casualty to the tank system. Adding two additional transverse bulkheads to each half of each tank, for example, would subdivide the total tank volume Into quantities of about 3000 cubic meters each. Since bulkheads need not be designed to resist the full hydrostatic head, their construction is relatively light--on the order of 50 tons for each ( 500 tons per ship set). The increase in a ship's total cost for this type of modification should not exceed 1 to $2 \%$. 

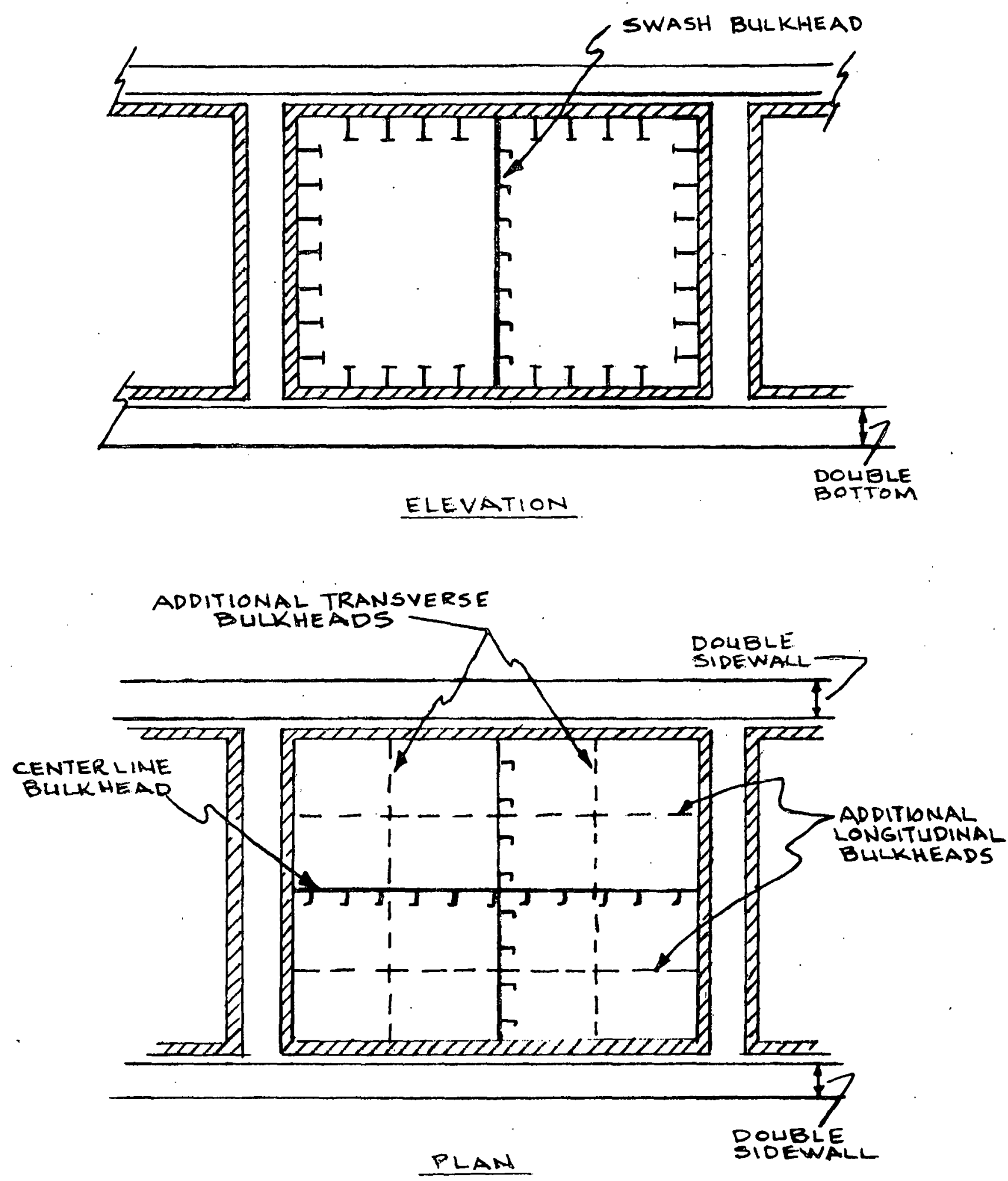

CONCH II PRISMATIC TANK SYSTEM
PARTITIONING ARRANGEMENTS

FIGURE $\quad 4.13$ 
- Change swash bulkheads to 1iquid-tight bulkheads. This modification would serve to control the spillage of LNG in the event of a major casualty over a much larger period of time than would the swash bulkheads. In some casualty events, e.g., those in, which the penetration of the cargo containment is above the waterline, such watertight bulkheads could contain the LNG cargo for a very long time, depending upon the heat-transfer charcteristics and venting capabilities of the tank system. Our estimate is that a modification of the swash bulkheads, as presently designed; to a liquid-tight configuration would increase the ship's total cost by 1 to 2 percent, and increase the ship's total weight by no more than 200 to 300 tons.

- A combination of all of the modifications above would be quite effective in terms of limiting the volume and rate of outflow of LNG following a major marine casualty. With such a configuration, the maximum spill quantity would be 12,500 cubic meters for below waterline collision damage, as low as 3,000 cubic meters for above waterline damage, an "immediate spill" quantity of 3000 cubic meters under most collisions situations, and an outflow of the remainIng LNG cargo exposed over a relatively long period of time. The incremental capital cost would be of the order of $10 \%$ of the ship's total cost, and the additional weight and equipment would likely involve an increase in the operating costs of the vessel of about 5 percent. 


\subsubsection{Multi-tank LNG Tanker Designs}

The idea of marine transportation of liquefied gas products in a large number of small tanks is not a new one. Most of the earlier vesse1s used for LPG and anhydrous ammonia were designed with a number of uninsulated cylindrical pressure vessels, usually vertical, arranged below or partly below deck lines and mounted in cradles or mat-type foundations. For total ship capacities up to a few thousand cubic meters, use of such pressure vessels, with the contents pressurized at ambient temperature conditions, was simple and economical. As the demand for such products increased, larger ships were needed, with better hull space utilization and more efficient tank weight-to-cargo weight factiors. This led, first, to semi-pressurized tank design, allowing use of tankage materials down to the $0^{\circ} \mathrm{C}$ range, and, later, fully refrigerated insulated tanks operating at service temperatures corresponding to ambient pressure conditions.

For LNG transportation, most of the cargo-containment designs conceived up to now, and all of the vessels which have been in LNG service, have utilized a small number of relatively large insulated tank systems--in the range of four to nine tanks per vessel--operating at cryogenic temperatures and at essentially ambient pressures.

Such tank configurations are generally considered to be most economical, minimizing the light ship weight and the operating and maintenance costs, at least in terms of the more common ship sizes in service, or on order ranging up to 125,000 cubic meter capacity. Alternate designs, each having special features aimed at specific trade utilization, or particular fabrication or safety characteristics, or which are based on presumed economies of scale beyond the current fleet sizes, have been investigated over the years. Two of these designs, the Ocean Phoenix system and the Verolme system, are in intensive development stages at present.

The features of these two systems and a summary of some other proposed multi-tank systems which have been proposed in the past, but which are now inactive, are described in the following subsections. 


\subsubsection{Ocean Phoenix Pressure-LNG System}

More than 10 years ago, marine transportation and land storage of LNG under pressure was investigated by the Ocean Transport Group (OTG), made up of the Columbia Gas Company and several other firms. This group was considering processes for both MLG (medium-condition liquefied gas) operating at approximately $-180^{\circ} \mathrm{F}$ and $200 \mathrm{psig}$, and CNG (compound natural gas) operating at $-80^{\circ} \mathrm{F}$ and $1150 \mathrm{psig}$. The marine shipment of these products was to be carried out in a vessel using a large number of vertical cylindrical pressure vessels; the process and methods were, in fact, demonstrated on three ocean voyages using the "SigAlpha", a converted Liberty ship. For several reasons, the further development of this process was terminated shortly thereafter.

In 1974, Ocean Phoenix Transport, Inc., (OP), re-activated the pressure LNG process in a modified form, based on the avallability of rich gas which could be economically processed, shipped, and stored at vapor pressures in the range of 40 to 70 psig. Design and engineering for the LNG vessel and the cargo-containment system are proceeding along two paths:

1. A representative ship of $173,000 \mathrm{~m}^{3}$ capacity is being studied in detail by J.J. Henry, Co., Inc.; and

2. A VLCC conversion; with an OP pressurized cargo storage system, plus a liquefaction plant instailed on board, is under study for potential use in collecting and liquifying rich gas from several small gas fields in the North Sea.

In both of these desjgns, the basic OP cargo-containment system would be used. This system, the concept of which has been approved by the U.S. Coast Guard, is a multilobe trapezoidal tank, fabricated of $9 \%$ nickel steel or aluminum alloy, and which qualifies as an Independent Type C pressure vessel system.

As presently designed, the system could also be used for containment of LNG at atmospheric pressure. Nine such multilobe tanks would be fitted into the five insulated hulls of the proposed $173,000 \mathrm{~m}^{3}$ LNG 
vessel, so that each would have a total capacity of about 20,000 cublc meters. Although this capacity per tank is not significantly different from the LNG tank system in current use, the unique feature of the $O P$ tank is its internal grillage structure, comprised of both horizontal and vertical plate sections, arranged such that the LNG is contained in a labyrinth of tunnels within the tank. We belleve this internal design would be extremely effective in limiting the rate of outflow of LNG in the case of breaching of the tank system due to a marine casualty. Sketches of the tank configuration and the proposed layout in an LNG ship are shown in Figures 4.14 and 4.15.

A major uncertainty concerning this containment design in the event of major marine casualties is the behavior of pressurized LNG when suddenly exposed to atmospheric conditions. The advantages claimed by $O P$ in this regard are that a substantial part of the pressurized LNG--on the order of $70 \%$-- would flash to gas after exposure to atmospheric pressure, and that the density of the flashed gas, being at higher temperatures, would be less than that of natural gas at $-260^{\circ} \mathrm{F}$. It might thus become buoyant and not present a downwind hazard at ground leve1. However, a potential problem associated with this rapid generation of gas, which has not to our knowledge been examined, is the possibility of a BLEVE-type event, or other explosions which may develop under situations involving the rapid generation of gas vapor and expansion upon exposure of the pressurized LNG to ambient conditions. Such events are not uncommon in accidents involving other pressurized liquefied gases.

Another problem common to all types of ship configurations which group more than one cargo tank within a common insulated hold is the Inflow of sea water into the hold in the case of penetration of the ship hull below the waterline. The rapid heat transfer as the sea water surrounds the cargo tanks would act to generate high internal tank pressures which may be in excess of the capacity of the safety vent systems. 


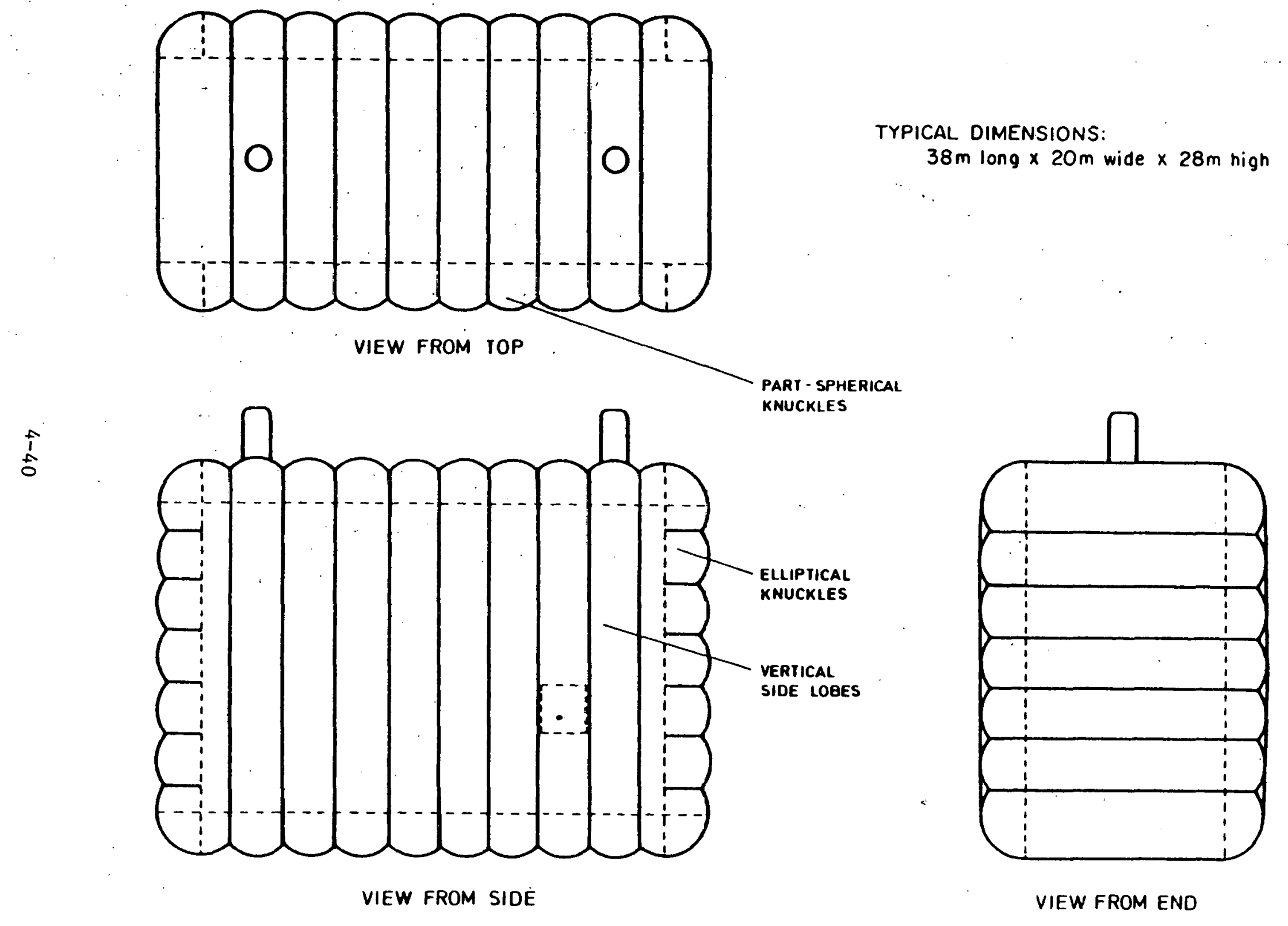


FIGURE 4.14: OCEAN PHOENIX TANKS

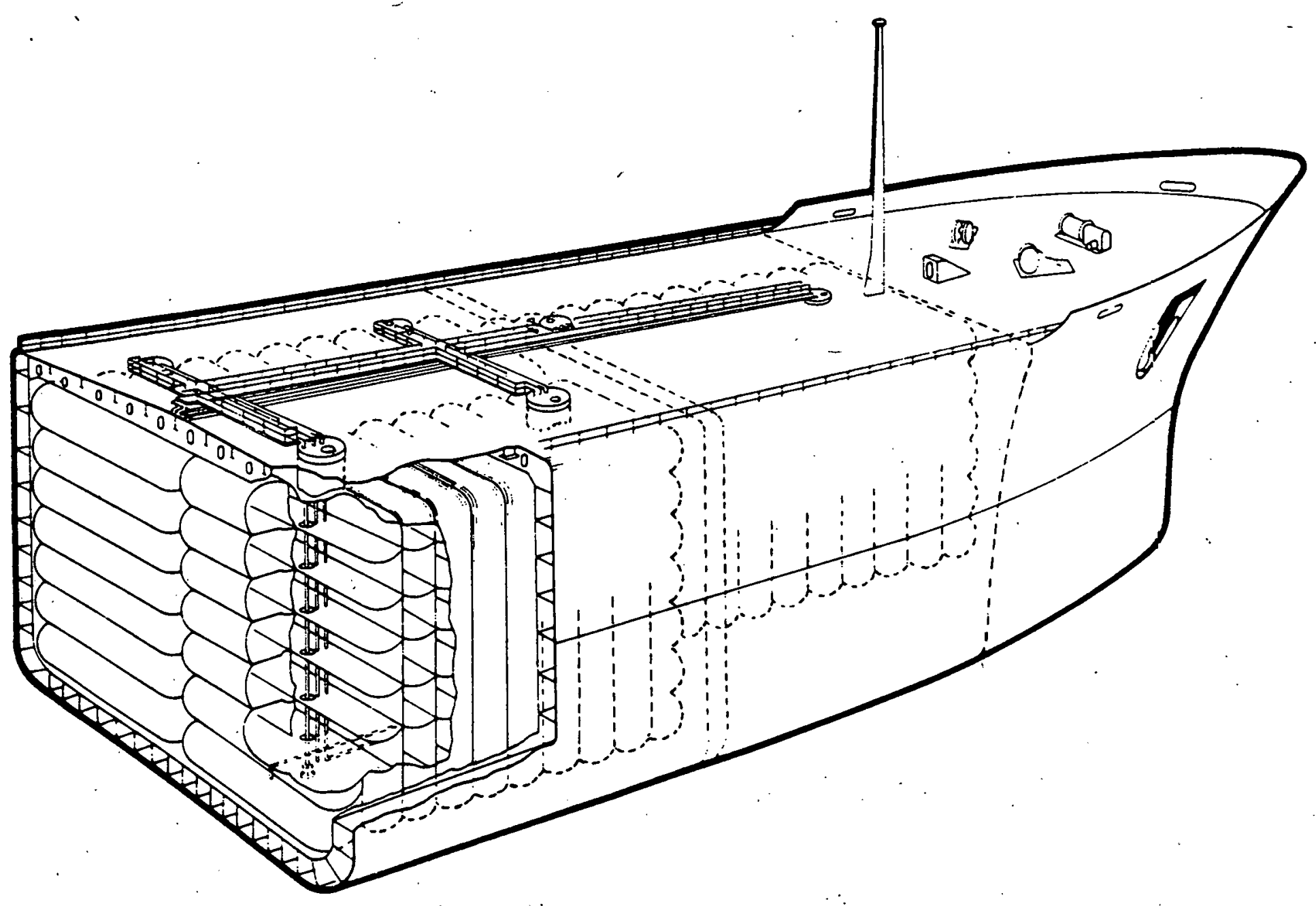

FIGURE 4.15: ARRANGEMENT OF THE OCEAN PHOENIX TANKS 


\subsubsection{Verolme Multi-tank System}

The Verolme LNG carrier system, under development by the Naval Profect Development Company of Rotterdam, utilizes a number of vertical cylindrical contalners, each having a capacity of about 3400 cubic meters, arranged in groups in insulated holds of the LNG vesse1. This system, which has also received concept approval from the U.S. Coast Guard, is presently under intensive study by Lloyd's Register of Shipping, with major concentration on the structural and stability aspects, particularly the tank support framework/drip-tray structure onto which the individual tanks within each hold are positioned and attached. In addition, both Lloyd's and Det Norske Veritas are carrying out a variety of model tests of the Verolme system.

The basic idea of the Verolme system is that LNG vessels of various capacities can be constructed using the $3400^{-m^{3}}$ cylindrical containers in different arrangements or groupings, but with an essentially similar tank support arrangement, insulated hold design, and piping and mechanical systems. Currently, studies are being concentrated on a $330,000-m^{3}$ vessel, using 97 tanks in five insulated holds; other vessel sizes proposed include one of 125,000 cubic meters, of capacity similar to most large vessels in current use, and others of 220,000 and 440,000 cublc meters. Sketches of the tank arrangements are shown in Figures 4.16 and 4.17. Similar groupings of the basic tank within a large circular insulated structure under a simple roof system are under consideration for land-based LNG storage.

A novel feature of this multi-tank arrangement is that the loading and unloading piping networks connecting each of the individual tanks within an insulated hold are also located within this hold, with only a main piping system penetrating the hold. Since the IMCO regulations in relation to containment system classificaiton define the boundaries of the containment system as the insulated hold, these interfor piping networks must also conform to Independent Tank Type B requirements. It is our understanding that some of the design and analysis efforts on the parts of Lloyd's and DNV are orfented toward satisfying this requirement. 


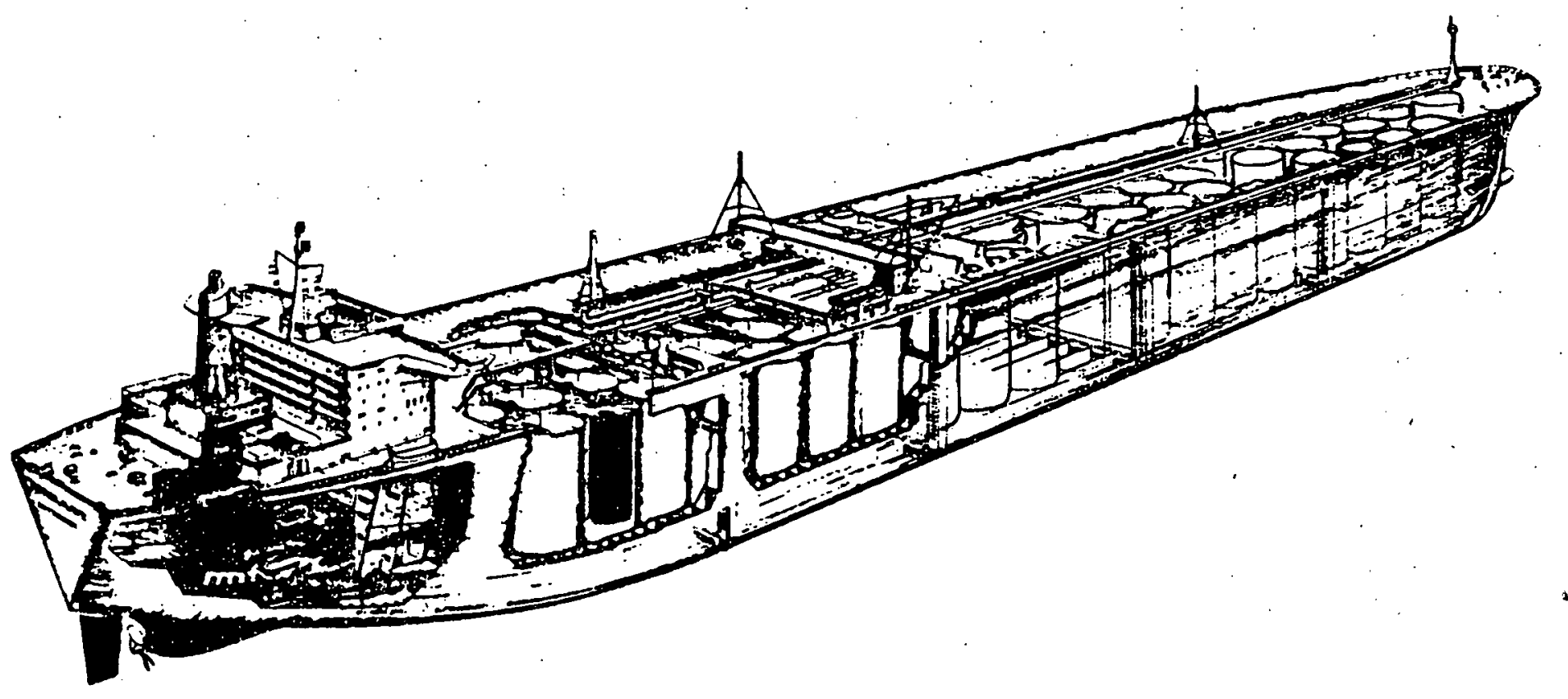

FIGURE 4-16

VEROLME LIQUEFIED NATURAL GAS CARRIER

(General Arrangement of Cargo Tanks) 

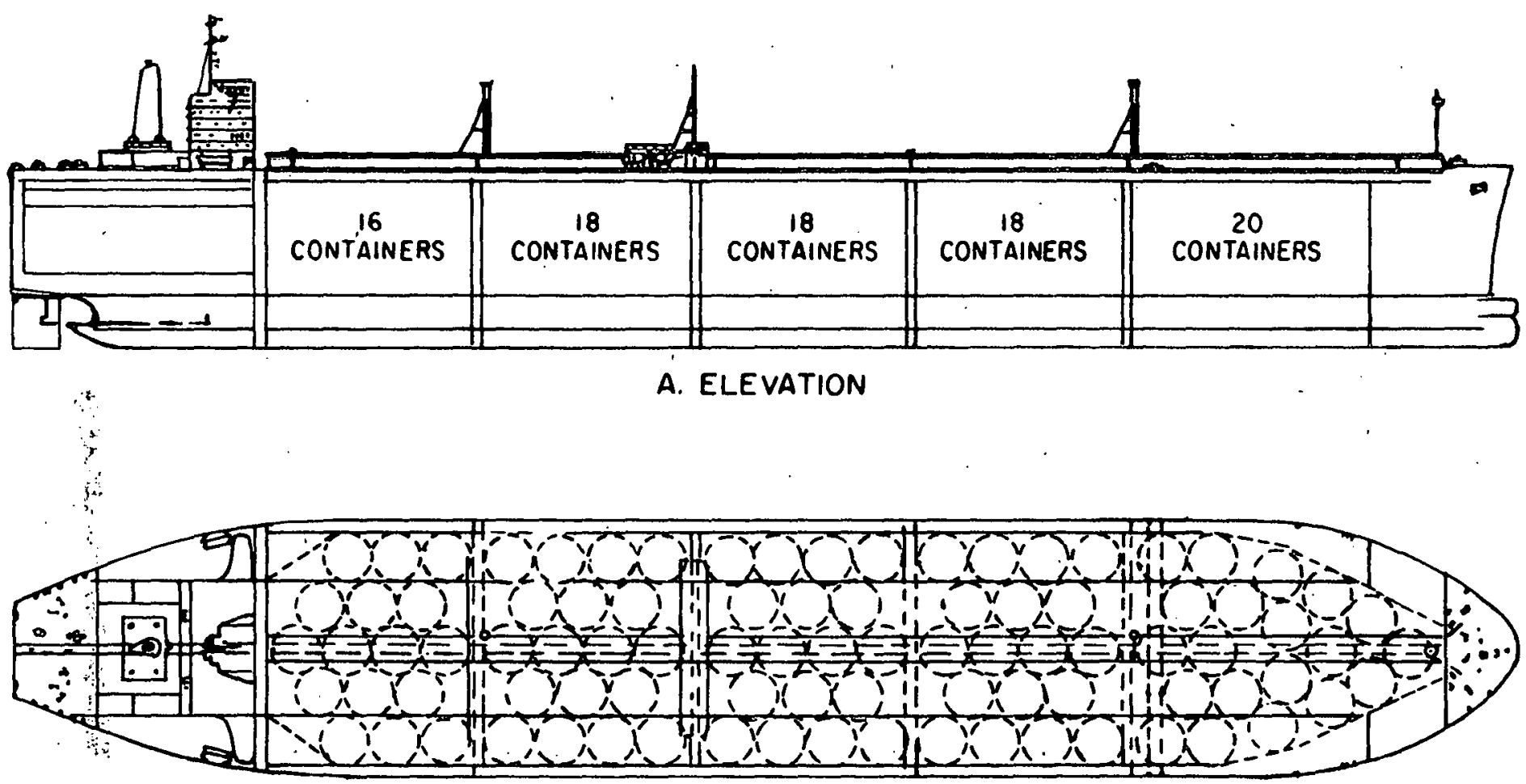

B. PLAN VIEW

FIGURE 4-17

VEROLME LIQUEFIED NATURAL GAS CARRIER 
Several advantages of such a multi-tank LNG vessel system have prompted the Verolme development. They include:

1. The individual tanks can be fabricated without any unusual tooling or manufacturing requirements in a number of plants specializing in pressure vessels and storage tanks.

2. A variety of ship sizes can be built, using the basic unit tank process, so that the capacity of the vessel can be tailored to particular trade routes, thereby minimizing transport costs.

3. With the insulated hold concept, inspection of the individual cargo tanks is a relatively simple matter.

4. Of special interest in this study is that the quantity of LNG which would be immediately spilled as a result of a major marine casualty would be limited to, at most, a few of the $3400-m^{3}$ tanks, and more likely would involve only one of these tanks.

The uncertainties of the Verolme system at this stage of its development are primarily related to the characteristics of the insulated hold," particularly in relation to major casualty events and to the economic aspects of this design relative to existing containment designs. For collisions which cause penetration of the sidewall above the waterline, the unstruck cargo tanks within the hold would heat up somewhat due to the loss of the integrity of the insulation, and depending upon the degree of damage to the piping network; and the characteristics and capacity of the venting/flaring system, would likely survive for relatively long periods.

For collisions involving structural damage to the sidewall below the waterline, sea water would enter the hold space and very rapid heat transfer and ouildup of internal pressure would develop with the remaining cargo tanks. It has been suggested that an ice layer would form on the container walls and act as an insulator to prevent rapid vaporization of the LNG: How quickly such a layer would form, the 
thickness it might reach, and its insulating efficiency under postcollision conditions with uncertain vessel motions and stability characteristics have not been studied in sufficient detail to determine its effectiveness in preventing further LNG releases from the intact containerśs.

One relatively simple design modification which could be effective in limiting the release of LNG would be a thin insulation on the lower part of the outer surface of each of the cylinders--up to a few feet above the waterline. The thermal effectiveness of this layer would be designed to match the venting capacity of the cylinder array, so that the vaporization rate in case of flooding of the hold could be controlled. Another possibility might be insulated bulkhead structures, extending from the base of the cylinders up above the waterline, separating groups of cylindrical containers along longitudinal lines within the insulated hold. Such an arrangement would confine the flooding problem to a portion of the cylinders, and prevent rapid vaporization of the interior cylinders. In any case, the multi-tank configuration would be effective in limiting the size of the initial spill of LNG, and might result in less severe spills when and if other containers failed sometime after the initial discharge.

The Verolme design has not as yet progressed to the point where the costs of the containment and, hence, of the vessel itself, can be reliably estimated. If one considers the principal characteristics of the proposed $125,000-\mathrm{m}^{3}$ designs, the major dimensions are comparable to the other $125,000-\mathrm{m}^{3}$ designs, generally somewhat shorter in length but greater in depth. The displacement is about the same as that of the General Dynamics spherical tank, Moss-design vessels (about 94,000 tons), suggesting that the greater amount of material used in the containers is compensated for by better use of the hull space by the smaller containers. On this basis, it would be expected that the overall cost of a $125,000-\mathrm{m}^{3}$ Verolme multi-tank vessel would not be much different from the cost of a Moss spherical tank ship of the same capacity. 
If LNG trade demands suggest that larger vessels are required, the Verolme design would appear to be in a favorable position relative to other current designs. The individual tanks of the membrane and Independent Type A designs are probably near their upper limit in size due either to eloohing effects, for membrane designs, or problems with the weight and handling of prefabricated tanks for the free-standing systems. The growth potential of spherical tanks would similarly appear limited for fabrication and logistical reasons to vessels with capacities in the range of 200,000 cubic meters. For vessels in the 300,000 to $400,000-m^{3}$ capacity range, the Verolme multi-tank system vould provide a relatively straightforward configuration and, most likely, would be very favorable in terms of costs.

\subsubsection{Other Multi-tank Designs and Concepts}

Marine transportation of LNG in other types of multi-tank containment systems has been investigated by several firms, including Linde AG, Liquid Gas Antagen Union GmbH (LGA), Dytam Tanker GmbH, and earlier, by H.M. Tiedemann Co. The Tiedmann concept was a multi-tank catamaran design with the entire hull fabricated of insulated $9 \%$ nicke1-steel. This design, which essentially consisted of a self-propelled segment storage tank configuration, to our knowledge, never got beyond the conceptual stage.

The Linde and LGA designs consisted of a large number of cylindrical pressure vessels. The LGA system, termed the Zellertank, was based on a horizontal array of such cylinders, fabricated of either aluminum alloy or $9 \%$ nickel-steel, while the Linde system utilized a vertical cluster of cylinders made of aluminum. Each of these systems conformed to IMCO Independent Tank Type $C$ (pressure vesse1) requirements and, as such, no secondary barrier would have been needed.

Neither of these multi-tank pressure vessel containment systems is being actively developed at this time. Information on the Linde system has been made available through papers and reports which suggest that a significant effort has gone into research and development studies on its multi-vesse1-tank (MVT) system. The basic containment vessel of this system is cylindrical with a diameter between 3 and 6 meters 
( 10 to $20 \mathrm{feet}$ ) and 27 meters ( $89 \mathrm{feet}$ ) high. These vessels would be grouped into batteries (the MVT) of 10 to 50 vessels, depending on the cylinder size and the overall ship capacity required, with the individual vessels connected at the top by a system of hor1zontal pressure vessels of similar design. Four suct. MVTs would be clustered into an insulated hold within an LNG ship. Sketches of an MVT unit and the configuration of such units within the ship are shown in Figures 4.18 and 4.19.

The advantages of such a containment system include the individual tank and MVT safety feature due to the degree of quality and reliability inherent in fabrication under pressure vessel shop facilities, the elimination of sloshing effects even under partial loading conditions, a more favorable hull utilization than large spherical containers (although not as good as prismatic or membrane tank systems), easy inspection and replacement, if necessary, of individual tanks, and the ability to load and unload these vessels with deck-mounted equipment.

The primary disadvantage (although no da.a in this regard have been made available) presumably is the capital costs of such a system relative to other containment system designs.

From the point of view of reducing LNG spillage and rate of outflow following a collision, such multi-tank systems would offer significant advantages. The contents of an individual tank of the Linde type would be less than 200 cubic meters for the 3-meter-diameter size. Breaching one to several such containers due to sidewall penetration would involve a relatively small initial spill, followed at a relatively slow rate by additional quantities up to the capacity of the MVT. Ultimately, depending on the location of the penetration relative to the waterline and on the specific venting and piping connections among the I.VTs, the entire contents of an insulated hold may be released. However, the feature of interest to the present study is that such systems would reduce the immediate sp1ll quantities to very small volumes and would also control the release of additional amounts to low outflow rates. 


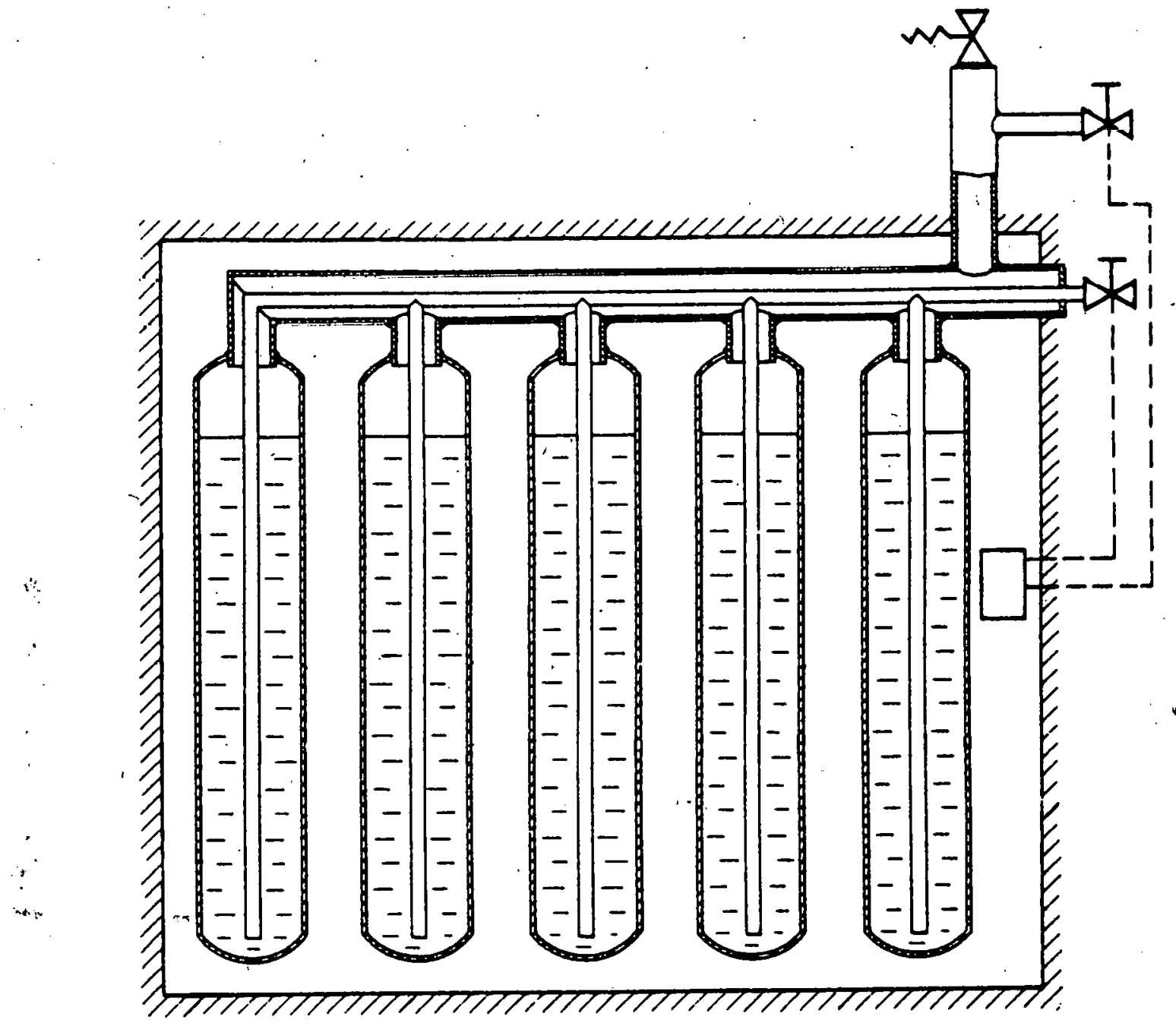

FIGURE 4.18: MULTI-VESSEL TANK SYSTEM (MVT)

(ARRANGEMENT OF CARGO TANKS) 

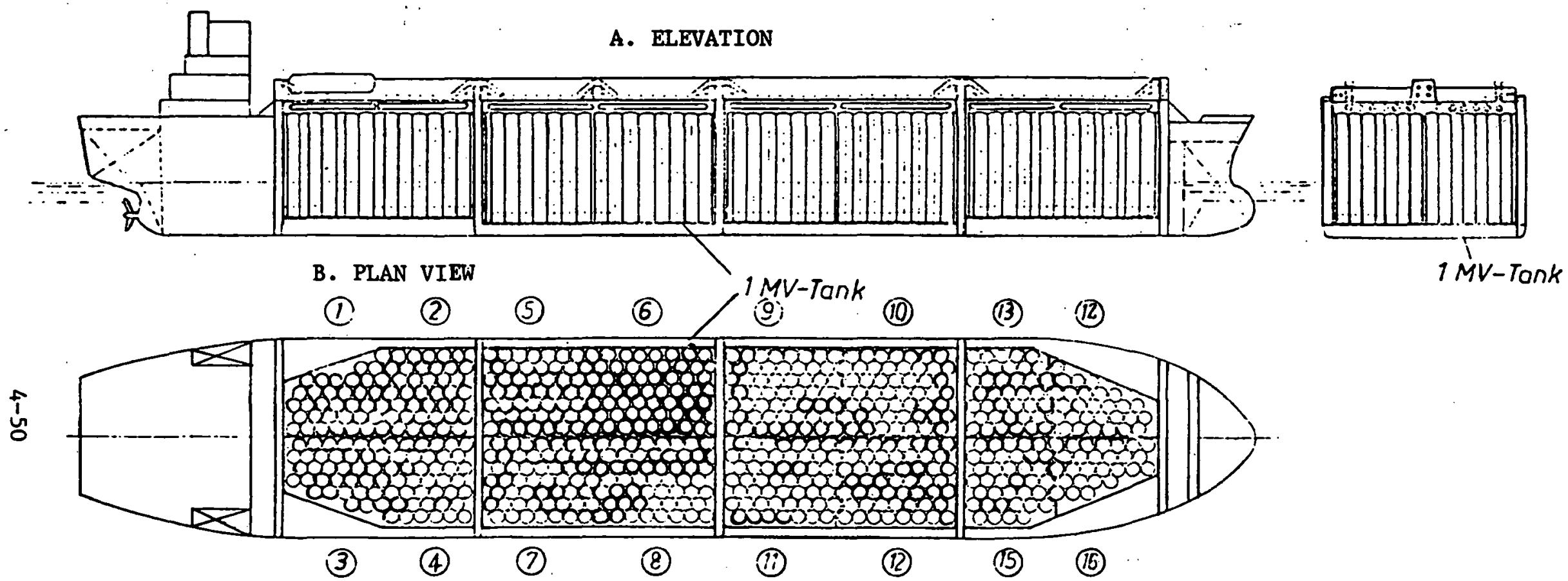

FIGURE 4.19: MULTI VESSEL TANK SYSTEM (MVT) 
The Dytam design, developed jointly by Tampimex. Tankers, Ltd. and Dyckerhoff and Widmann, is a multi-tank vessel of concrete construction throughout, with the cargo tanks (10 tanks in the proposed $125,000 \mathrm{~m}^{3}$ size) integral with the vessel's hull. Although certain cost advantages have been claimed for concrete as a structural and cryogenic tankage material for marine vessels, the development of such vessels has not proceeded beyond the design stage. It is likely that the concrete construction of the hull would provide a considerable resistance to collision damage, although the specific behavior of a prestressed concrete hull structure in this regard.has not been investigated. 


\subsubsection{Reduction in Spill Rate from LNG Cargo Tanks}

As developed in a previous section, the hazard associated with an LNG cargo spill can be effectively reduced if the rate of spill, following rupture of the cargo tanks due to a marine casualty, is less than the essentially "instantaneous" rate, or total immediate spill, generally assumed for major casualty events. The assumption of an instantaneous spill of the total quantity in a breached cargo tank is clearly conservative; the actual rate and amount would be governed by many factors, such as the vertical location of the rupture, the manner in which the cargo tank and the hull members are structurally deformed, and the degree to which they may spring back to reduce the opening; the manner in which the striking vessel engages the sidewall of the LNG ship (in the case of a collision), and whether it disengages following the casualty.

Notwithstanding such factors, there are positive approaches which might be used to reduce the outflow of LNG from a ruptured cargo tank. Two basic methods that appear to merit consideration are:

1. The filling of the cargo tank with some type of open cell or flow-through material, such as those in current use as flame arrestors in aircraft fuel tanks and in various liquid hydrocarbon fuel and chemical tanks; and

2. The use of single or multiple hanging curtains within the cargo tank which could be designed to be carried against the tank opening by the outflow of the liquid.

\subsubsection{Fillings for Cargo Tanks}

Several types of open-cell foam and modified honeycomb-type structures are available for use as fillers in cargo tanks. Such fillers have been used in various chemical and hydrocarbon fuel tanks to reduce or to control outflow'in case of puncture or rupture of tanks, to act as flame arrestors in case of spark ignition in the vapor space, to prevent sloshing, and for other useful functions. Although in the usual application of such fillers they occupy the entire volume of the 
tank, their design porosity is high enough so that they generally will use up only 1 or $2 \%$ of the actual tank volume. The principal materials that have been developed and are being utilized for these purposes are reticulated polyurethane foam and aluminum foil in a modiried honeycomb configuration. It is, however, unlikely that the open-cell foam materials, which are basically flexible foams, would have the necessary physical properties at cryogenic temperatures to be used for LNG cargo tanks. They would very likely become brittle and crack or abrade upon extended use at low temperatures. There are other non-metallic materials, such as fluorocarbon polymers, which might remain flexible enough at LNG temperatures, but the problems of fabrication and cost of their application as a cargo tank filler would likely be excessive.

An aluminum honeycomb material, manufactured under the trade name Explosafe ${ }^{\circledR}$, is presently finding increased use as a filler material in fuel containers, and in automotive, milttary, and aerospace applications. Currently, this material is being evaluated for use in tank trucks and railroad tank cars transporting hazardous materials. The effect of low temperatures on this material has not been established, although in terms of flexibility and maintenance of its physical properties, it "would undoubtedly be less adversely affected than the non-metallic materials. Its corrosion properties with LNG are not known, but they are not likely to be problems. The feasibility of supporting such a honeycomb material in large volumes and at heights of 100 feet or more has not been determined; it might be necessary to provide some supporting structure to prevent collapse of this material due to its own weight in such applications.'

Filling of the entire cargo tank with any type of porous material would add significantly to the cost of the containment systems. Even at projected mass production prices, the cost of the aluminum honeycomb material would be about $\$ 1.00$ to $\$ 2.00 / \mathrm{ft}^{3}$, corresponding to $\$ 1-$ million or more for a $25,000-\mathrm{m}^{3}$ cargo tank. The costs of non-metallic foam materials would not be significantly lower than these figures. 
Perhaps a more serious difficulty with the cargo tank filling concept is the limited accessibility to the interior of the tank. Periodic inspection of the primary containment system is required every few years under classification society rules. (Det Norske Veritas, for example, requires such inspections of the tank interior wall structure every four years.) Removal and replacement of the volume of filler material for such inspections or for repairs, even if a procedure could be developed for partial removal, would be a difficult and costly task.

Two other disadvantages of the porous filler system are its weight and the retention of liquid by the material. For the aluminum honeycomb material, assuming a fluid displacement of 1.5 percent, the total weight would be about 1000 tons per $25,000-\mathrm{m}^{3}$ tank, or about five times as much as the displaced LNG. The extremely high surface area of the filler material would, furthermore, retain some of the. LNG, reducing the effective volume transferred still further. The amount retained in this manner has not been quantified, however, and may well be small compared with the heel volume maintained for' thermal reasons.

In addition to the primary function of impeding LNG flow following a major casualty, the filler material would also eliminate sloshing effects which have been--and continue to be--a significant problem with the large-sized cargo tanks in current use.

An alternative to filling the entire cargo tank volume is to attach the material to the sidewalls of the cargo tank in some appropriate thickness, which might be of the order of 10 to $20 \mathrm{feet.} \mathrm{Attach-}$ ment in this manner, however, likely would mean that the material would be torn or damaged, along with the cargo tank wall, in a collision and thereby be of limited effectiveness in impeding the flow.

An extension of this partial.filling concept would be the filling of those smaller cargo tanks (in multi-tank containment systems) or, in the case of partitioned tanks, those portions closest to the sidewall. This may well be an appropriate strategy for cargo tank designs involving such smaller or partitioned tanks, although in such cases the 
total volume spilled in marine accidents would generally be substantially less than the quantities currently assumed in safety studies. The problems of cargo tank inspection and repair would remain, however.

Overal1, our conclusions at this stage are that the disadvantages of cargo tank filler systems in terms of costs and accessibility may outweigh the potential advantages, and that the hanging curtain approach described below represents a more promising solution to the problem.

\subsubsection{Hanging Curtain Inside Cargo Tank}

In this concept, a curtain or a series of curtains would be sus- pended along the sidewalls inside the LNG cargo tank to impede the flow of liquid following breaching of the cargo-containment system. Although this curtain configuration would not reduce the probability of an LNG spill following a major marine casualty, it could act to reduce significantly the rate of outflow of LNG following such a casualty. These curtain structures, which may be either liquid-tight or somewhat porous, would be required to be strong and flexible at cryogenic temperatures, with the idea that in case of penetration of the sidewall of the LNG vessel the curtains would maintain their structural integrity by moving away from the sidewall. Subsequently, the outflow of liquid would carry the curtain structures back against the tank opening to seal it off partially and thereby reduce the outflow rate. The hanging curtains would also allow access to the tank walls for inspection purposes. The primary considerations with regard to this curtain concept are related to its mechanical and structural design, and to the materials of construction. (Some sketches of possible single curtain arrangements are shown in Fig. 4.20). Nests of such curtains could provide multiple curtain arrangements.

\subsection{Design}

The design of the hanging curtain system would involve support of the curtains from the roof of the cargo tank, and possibly some type of restraint or support of the curtain by the cargo tank wall along the vertical side edges of the curtain. We foresee little difficulty in providing some means of support in this manner in any of the major cargocontainment systems presently in use (membrane or self-supporting types $A$ or $B)$, since the support need not be continuous or liquid-tight. 
RECTANGULAR-CURTAIN DESIGNS

SIDEWALL DESIGN

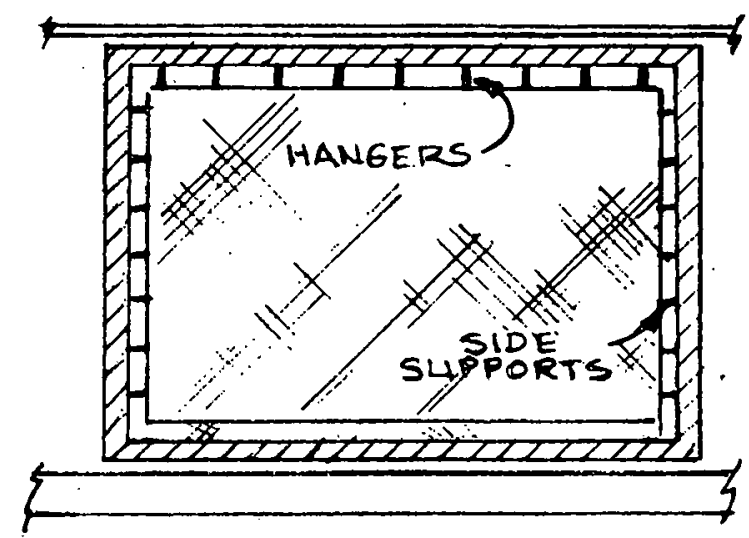

ELEVATION

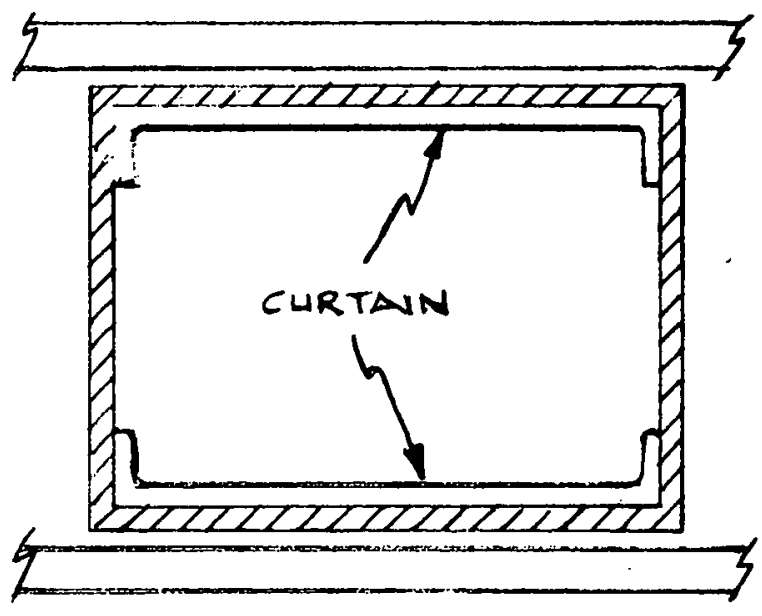

PLAN
CONTINUOHS DESIGN

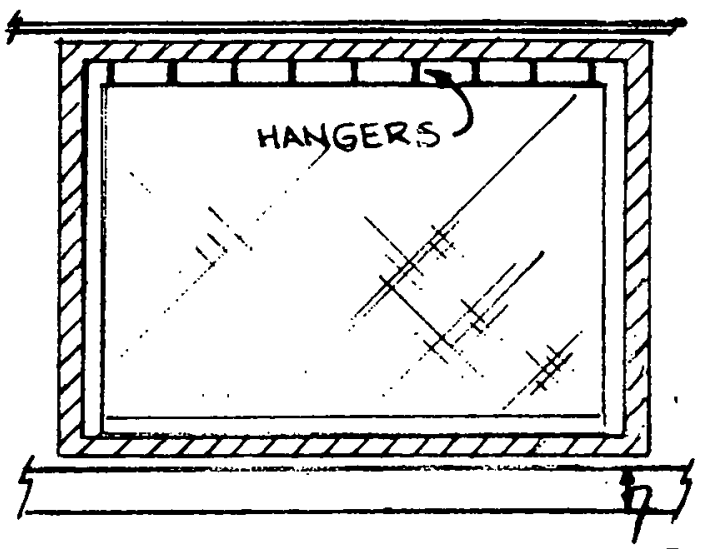

ELEVATION DOUBLE

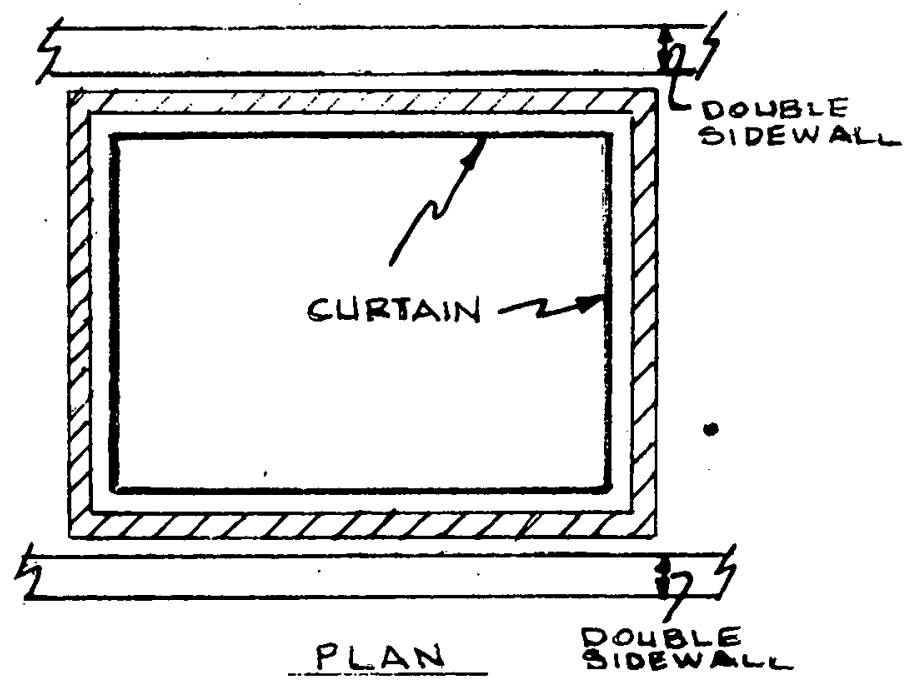

SPHERICAL-CURTAIN DESIGN
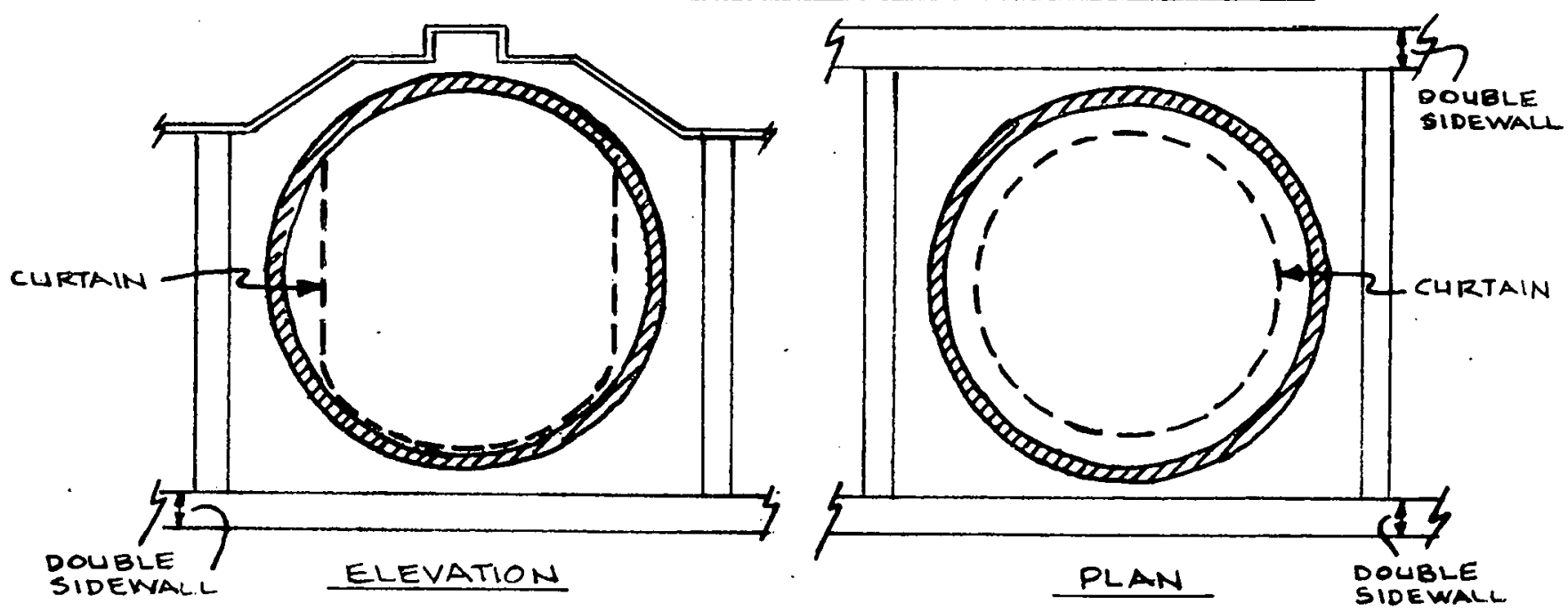

SINGLE CURTAIN BARRIER ARRANGEMENTS WITHIN LNG TANKS Fighre 4.20

$$
\text { 4-56 }
$$


Because of the height of the curtain structure, the weight involved could be significant. However, when the vessel is fully loaded, the buoyancy effects of the LNG would reduce the hanging weight. In spite of that fact, it might be necessary to have some type of structure of reinforcing cables or mesh in the curtains to assure the structural integrity of the hanging system. Of course it would be necessary to design the system to minimize stress concentrations on the hanging curtains and to prevent significant restraint on the tank wall at the points of attachment to the tank. We visualize that the hanging curtains would extend from the top and drape down across the bottom and along the sides for some distance laterally to assure that the curtains would be sufficiently large to block the outflow, even if the tank were ruptured near its base or close to a bulkhead. It may even be feasible for the curtain to be designed as a continuous structure around the interior periphery of the cargo tank walls. The system would have to be designed so that it did not affect the loading and unloading of the LNG; however, this consideration would not seem to present any unusual difficulties.

The mechanical design of the hanging curtains themselves could involve a number of variations. For instance, they might be metal foils, sintered metal mesh or fabric materials, or plastic films either alone or reinforced with some type of scrim or wire to improve tear resistance. They might be open-weave or close-weave fabric which would probably have greater strength and puncture resistance than either foil or film materials. The curtain might be of composite design; for instance, two fabrics with a fiber mat filler such that, when the curtain is pushed against an opening, the pressure decreases the porosity and automatically limits the flow. Another alternative would be a curtain designed as a type of modified honeycomb structure, or as a structure similar to a Venetian blind, which when pressed against a solid material would tend to close and cut off flow. Thinking along these lines leads to a structure which might utilize a porous filler material discussed earlier as a lining along the tank wall, but as a hanging material supported only from the tank roof instead of attached 
to the wall. Under these circumstances, the porous filler would be less likely to rupture when the tank wall is breached and, like other curtains, would simply be pushed back to the opening by the outflow.

\subsection{Costs}

Since these container structures are quite novel in both concept and materials, it is not possible to estimate implementation costs with confidence. Relative to the other structural arrangements and modifications discussed earlier, however, it is most likely that curtain structures of the type considered would be substantially lower in cost. On this basis, we believe that containers could be developed for installation in the current LNG containment designs for an incremental ship cost of the order of 1 to $2 \%$.

\subsection{Future Work}

To select the most appropriate material in terms of mechanical design, fail-safe performance, and cost, a significant additional effort would be required.

Such an effort would include a more detailed look at some of the non-metallic containment systems in recent development to assess the applicability of their technology of manufacture and installation requirements as barrier curtains. These systems would include, for example, elements of the Perm-Bar II membrane developed by OwensCorning (in particular, its FRP labyrinth; FRP membrane, and polyurethane core components); the fiberglass-reinforced polyurethane panel barriers that are part of the McDonnell-Douglas 3D system; the Triplex FRP material under development by Technigas as part of its Mark III containment system; and a fiberglass waffle barrier system under development in Spain. The membrane structure currently in use as primary containment barriers, inciuding the Technigas stainlesssteel waffle and the Gas Transport Invar lining may themselves be applicable as barrier curtain systems of the type described here. 
In summary, we believe that a hanging curtain system may well be a viable approach, both functionally and from a cost-effective viewpoint, to solve the problem of rapid outflow of liquid posed by potential rupture of LNG cargo-containment systems. 


\subsubsection{Summary}

The concepts and proposed designs for controlling the initial spill quantities and the rate of outflow following breaching of the LNG tanker cargo tank, as discussed in the previous sections are summarized in Tables 4.3, 4.4, and 4.5. As indicated in these tabulations, methods to control the initial amount spilled and the subsequent rate of outflow can be readily applied to the independent prismatic containment system design elther by retrofit to existing ships or in the construction of new ships. At the present time, however, the outlook for the construction of additional ships of this type is uncertain because of recent difficulties in fabrication of prismatic tanks of the sizes required, and the high costs associated with these difficulties.

The membrane containment system can be modified to control the quantity spilled by a design concept based on a larger number of fully-insulated tanks. Such a modification of the existing tank layout would not involve any new design or technological requirements, but would result in a somewhat higher inftial ship cost and slightly higher operating costs due to increased weight and operating equipment. Control of the rate of outflow by curtains of some type would appear feasible.

Penalties associated with spill control appear to be higher for the independent spherical tank systems. The concepts that have been considered are less adaptable to spherical surfaces than planar ones, and the introduction of internal structures may well involve reassessment of the basic containment type from one which requires only a partial secondary barrier (Type B) to one requiring a full secondary barrier (Type A). If a full secondary barrier must be used, then the spherical tank design offers no advantage over a prismatic design which would utilize the hull space with much greater efficlency. 
In terms of control of outflow rates, the use of porous materials in large quantities to fill the cargo space volumes would present cost and maintenance penalties, and for metallic materials, additional problems with weight. A more novel approach using flexible curtains along the sidewalls of the tank, however, may well be technically and economically attractive, although further study would be needed on materials and on mechanical design features to establish their feasibility. 
TABLE 4.3

\section{COMPARTMENTALIZATION OF EXISTING LNG CARGO CONTAINMENT DESIGNS}

\section{$\frac{\text { Maximum Single Tank Volume }}{\text { Technical Feasibility of Compartmen - }}$ talization as Retrofit Involving: \\ '. Insúlatèd Bulkheàds \\ Liquid-Tight Bulkheads \\ Swash or Non-Structural Bulkheads}

Technical Feasibility of Compartmentalization: of Ner Ship Construction,
Insulated Bulkheads

Liquid-Tight Bulkheads

Swash or Non-Structural Bulkheads

Adaptability of Existing Design to Possible Compartmentalization

Effect on Initial Ship Cost of Compartmentmentalization Modifications

Effect on Ship Weight and Operating Cost of Compartmentalization Modifications

Position of Classification Societies and Regulatory Authorities to Compartmentalization Modifications to New Ship Construction

\begin{tabular}{|c|}
\hline $\begin{array}{c}\text { Integrated } \\
\text { Membrane }\end{array}$ \\
\hline $25,000 \mathrm{~m}^{3}$ \\
\hline \\
Not Feasible \\
Not Feasible \\
Not Feasible
\end{tabular}

Not Feasible

Feasible
Not Feasible
Not Feasible.
Excellent
Intermediate
Intermediate

Independent

Prismatic

IMCO Type A

$25,000 \mathrm{~m}^{3}$

\begin{tabular}{r|r}
\hline & \\
\hline &
\end{tabular}

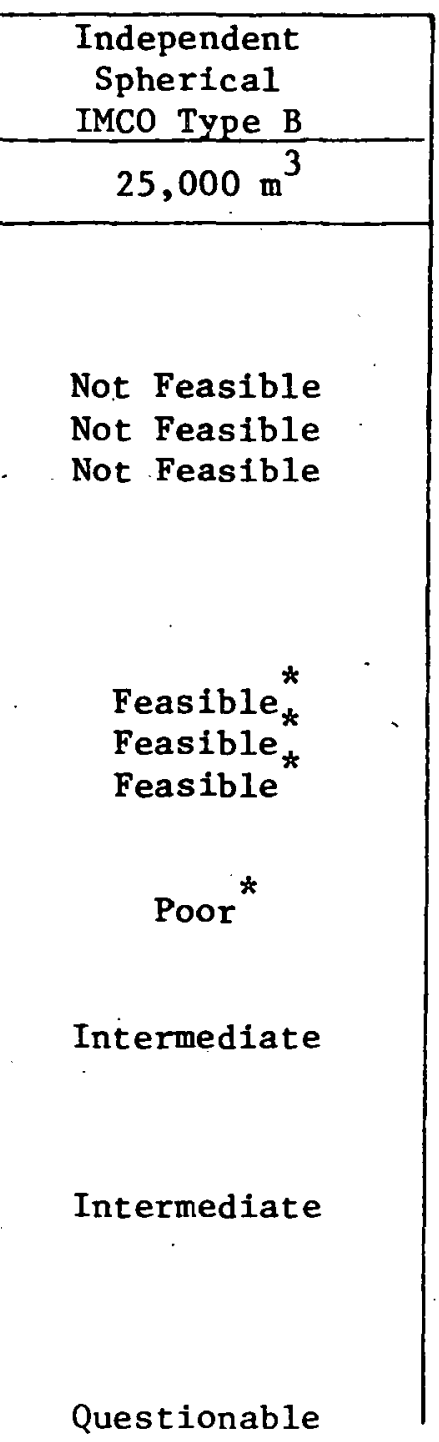

Modifications involving the addition of internal structures of any type may require reclassification of cargo-containment system to IMCO Type A which would necessitate the addition of a rull seconis r barrier. 
SPILL-RATE CONTROL IN EXISTING LUG CARGO-CONTAINIENT DESIGINS

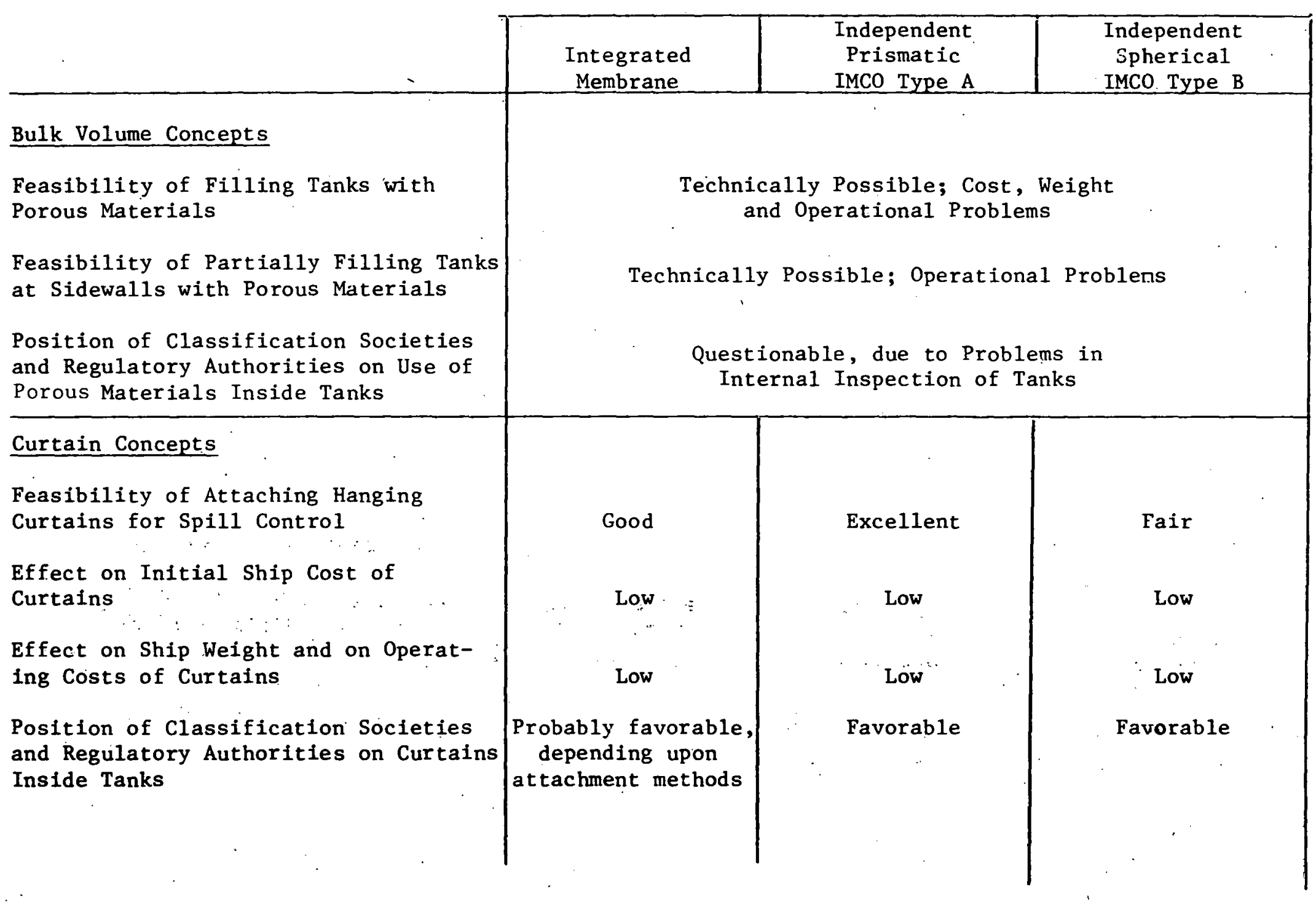


TABLE 4.5

PROPOSED LNG CARGO-CONTAINMENT DESIGNS

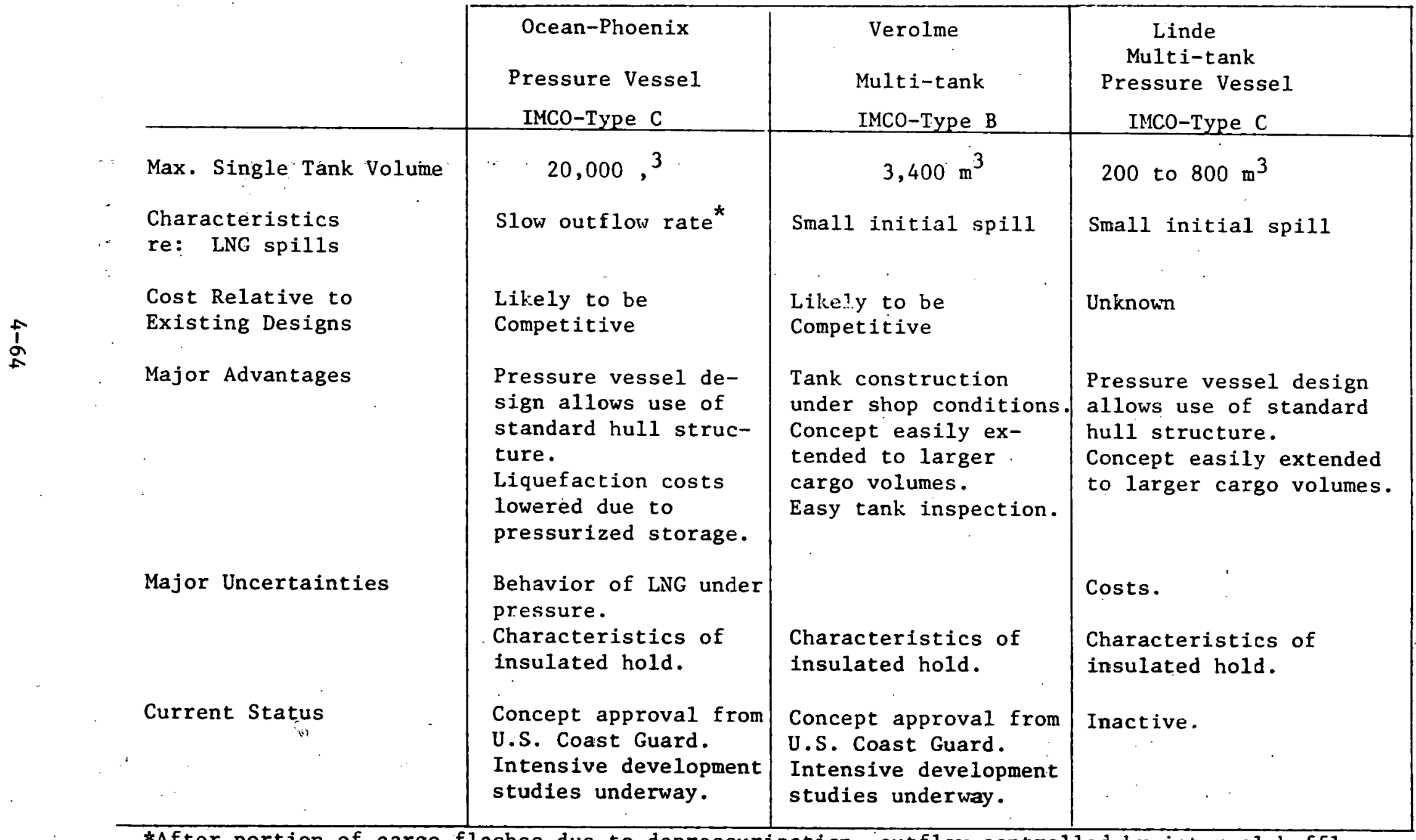

*After portion of cargo flashes due to depressurization, outflow controlled by internal baffles. 


\subsection{OTHER METHODS OF REDUCING LNG TANKER FIRE HAZARDS}

\subsubsection{General}

Other approaches to the reduction in the LNG tanker fire hazards that have heen examined in this study Include the gelling and solidification of LNG, conversion of LNG to methanol for shipping purposes, and the addition of flame suppressants to the cargo. Each of these methods is discussed in the following sections of the report.

\subsubsection{Gelled LNG}

\subsubsection{Background}

The gelling of LNG can reduce or inhibit the free flowing character of the liquid and, by so doing, potentially slow the outflow and decrease the rate of evaporation from a given amount that is accidentally spilled in the water. In concept, this could result in a reduction in the magnitude of a pool fire or of an unignited vapor cloud. The relative advantage of gelling, of course, depends upon the reduction in risk and the cost associated with its achievement.

Successful experiments with the gelling of cryogenic fluids were carried out many years ago, and the abllity to gel LNG was demonstrated by Vander Wall (1971) in 1970. The gelling of LNG as a means of reducing shipping hazards has been examined in considerable detail by Shanes (1977). In this latter work, the physics of gelation was examined, the rheological properties of the gel determined, and the bolling rates measured. Preliminary estimates were made as to the potential reduction in the hazard of unignited vapor clouds produced by accidental spills of LNG into water.

Most recently, work at Aerojet Energy Conversion Company (Rudnick1, 1980) characterized gelled LNG with respect to. rheology, confined and unconfined spill vaporization rates, leakage behavior, and heat transfer. A small scale gelator was built, and continuous production of gelled LNG was demonstrated.

\subsubsection{The Gelling Process}

There may be many agents capable of gelling LNG. However, the work 
to date has been concentrated on water and methanol as the gelants. These two materials may be separated from LNG with relative ease, and small amounts that might remain in the send-out gas would generally not interfere with its use, nor cause harmful environmental effects. Shanes' work and the recent studies at Aerojet are based on water and methanol as gellants.

The batch process of making gels employed in Shanes' experiments consisted of introducing methane gas containing a small amount of gelant vapor into the LNG at a vapor concentration and rate of injection that would provide the desired gel characteristics. The nucleation of the gelant and its particle growth within the liquid appeared to be controlling in forming the gel. The LNG that boiled off as a result of inserting warm gas would, of course, have to be reliquefied if this process were actually implemented in the transport of LNG. Experiments were performed in which LNG gels were formed using from 0.6 to 2.5 percent water by weight and from 1.5 to 7.8 percent methanol by weight. The structures of the gels that were formed were examined at some length, and it was concluded that the gels were, in fact, clathrates. A clathrate is a solid solution in which a cage-like host (e.g., $\mathrm{H}_{2} \mathrm{O}$ or $\mathrm{CH}_{3} \mathrm{OH}$ ) structure is formed by hydrogen bonding of the host molecules. This structure encages methane and the other constituents of LNG.

Gelling of LNG by Aerojet was also done with both water and methanol gelants; water was demonstrated experimentally to be the superior gelant. Gelled LNG for use in characterization studies was prepared in a batch process similar to that used in Shanes' work. A continuous process gelator development demonstrated the feasibility of an Aerojet proprietary process for introduction of the gelant directly into the process stream without separate carrier gas provision.

\subsubsection{Properties of LNG Gels}

\subsection{Rheological Characteristics}

The essential rheological behavior of gels is that they are nonNewtonian and time-dependent. If the gel, at rest, is instantaneously 
subjected to a constant rate of shear, the gel will initially react elastically and then, when a critical level of shear stress is reached (corresponding to the yield stress, of the order of $0.1 \mathrm{psi}$ ), the material will deform in a pseudoplastic manner. The shear stress will suddenly be reduced. As shear rate increases, the shear stress will continue to increase exponentia11y, approaching a steady-state value.

One measure of gelled LNG characteristics is the static yield stress. This property is directly related to the maximum height that a quantity of gel would sustain without flow. LNG gels may be prepared in a variety of consistencies, depending upon the gelant concentration used. Gelled LNG with high gelent content (say, $6 \%$ water) has to be scooped out of its container. Recent estimates of free standing height versus yield stress are given in Table 4.6. For a yield stress of $100 \mathrm{~N} / \mathrm{m}^{2}$, a free standing height of about 0.5 inches is indicated. Experimental work at Aerojet yielded heights of about 2 to 5 inches for the $100 \mathrm{~N} / \mathrm{m}^{2}$ gel, and roughly 6 inches for a $200 \mathrm{~N} / \mathrm{m}^{2}$ gel. Achieving relatively high yield stresses (hence, increased column height without flow) requires larger percentages of gelant and correspondingly increased energy investment.

Obviously, column heights of a few centimeters are insufficient to deter flow-out of a punctured tank where the liquid head may be of the order of tens of meters. The higher viscosity of the gel versus that of LNG would not be expected to significantly affect the rate of outflow through a large hole that might be caused by a tanker collision. Rather, it will be the inhibition of spread area and vaporization rate after the spill occurs which will be of interest in evaluation of LNG versus the gel.

Flow testing of the gelled LNG was conducted by Aerojet using precision bore tubes. Care was taken to stay within laminar flow conditions so that the calculation of shear rate would be valld. Thus far, the evaluation of shear stress versus shear rate for various gelant fractions has been done in only a limited range of shear rates (100 to $\left.10,000 \mathrm{sec}^{-1}\right)$. Shear stresses of roughly $10 \mathrm{~N} / \mathrm{m}^{2}$ were observed at $1000 \mathrm{sec}^{-1}$ shear rate. Future work is planned to extend the shear rate range and more fully 
Table 4.6

Yield Shear Stress and Free Standing Helght

of LNG Gels

From Shanes, 1977

Yield Shear Stress

$\mathrm{N} / \mathrm{m}^{2}$

Free Standing Height ${ }^{*}$

1

M

10

0.1

100

1.0

10.0

* The height that the LNG gel will sustain without flow. 
evaluate the effects of gelant concentration on dynamic behavior of the gel. This information is the key to understanding spill behavior and, ultimately, the safety/economic impact of using gelled LNG.

The Aerojet studies indicate that the gelled LNG structure remained stable even after repeated forced flows through capilary tubes used in shear stress/rate testing. Also, the stability of the gelled LNG was observed to be excellent in short term storage tests.

In the Aerojet work, tests were also run to observe the flow of LNG and gelled LNG through cracks. The gelled material would not flow through cracks through which LNG flowed profusely; this resistance to flow was observed even under elevated driving prëssures up to 30 psi).

\subsection{Spil1, Spread and Vaporization Characteristics}

The rate of vapor generation when an LNG gel is spilled on water has also been measured by Shanes, and it has been found that the boiloff behavior is significantly different from that of plain.LNG. The LNG gels boiled at a relatively low, steady rate (evaporation rate per unit area contacting water) which was, on the average, two to three times lower than for LNG. It appeared that film boiling governed the evaporation process rather than nucleate boiling, as in the case for LNG.

Unconfined spill testing on compacted earth was conducted by Aerojet at around $0.02 \mathrm{~m}^{3}$ scale, $1 . e$. about 5 gallons. It was demonstrated that, in these very small scale spills, gelled LNG displayed less extent of spread and substantially lower rate of vaporization than the LNG.

Confined spills on water, sand, and concrete were conducted by Aerojet with instrumentation provided to measure the instantaneous vaporization rates. All of the confined spill testing showed diminished vaporization rates for gelled LNG relative to LNG. Typically, maximum gelled LNG vaporization rates were found to be a factor of five lower than the corresponding maxima for LNG. 


\subsubsection{Hazard Reduction by Gelling}

From the preceeding results, the reduction in fire hazards resulting from gels rather than LNG spilling in water derives from a decrease in the rate of spreading of the fluid on the surface of the water, a greater thickness of the fluid layer when spreading ceases, and a lower evaporation rate per unit area of the fluid in contact with the water.

Utilizing a spreading model developed for gelled spills, Shanes estimated that - for one set of conditions - the maximum rate of vapor generation and the maximum travel distance of the vapor would each be reduced by a factor of four. Based on the Aerojet work, it can be estimated that roughly a five-fold reduction in area within the zone to the edge of the lower flammability limit would be achieved for gelled LNG when compared with LNG. If a pool fire were to occur (versus an unignited vapor cloud), then the significant dimensions of the pool.fire would be expected to be reduced, and the thermal radiation hazard would be appreciably lowered, although fire would continue to burn for a longer period of time. However, there is considerable uncertainty as to the application of these results to actual full scale spills. Scaling effects have not been determined so that it is not known whether the above estimated reduction in hazards would be similar if pool spreading and evaporation rates were derived from large rather than small scale experiments. Also, the nature of the spill and outflow rate has not been considered; for example; the falling of gelled LNG from some height Into the water (as during a tanker accident) might give different results than have been achieved in small scale experiments. Ultimately, large-scale comparative spill tests will be required to establish the relative advantage, if any, of gelation. However, study and experimental results to data are promising in terms of the use of gelled LNG to provide increased safety with benefits in siting of facilities and transportation of LNG.

\subsubsection{Cost of Gelling}

The added costs resulting from the gelling of LNG for water transport include those associated with the gelling process, the separation of the gelant from the natural gas at the receiving terminal, the 
increased pumping and compression requirements, the reduction in cargo volume in transit due to presence of the gelant, and the cost of gelant.

The additional energy requirements for a gel having a shear stress of $50 \mathrm{~N} / \mathrm{m}^{2}$, which seems reasonable for achieving a significant reduction in fire hazards, have been estimated by Aerojet (Rudnicki, 1980). Achieving this shear stress requires about $3 \%$ by weight gelant fraction, which corresponds to about $30 \%$ more energy than for liquefaction alone.

Energy, operating, equipment, and other facility costs were estimated in the Aerojet study for a typical LNG peakshaving plant to deliver gelled LNG instead of LNG. The total plant cost was increased by about $4 \%$ over that for the bastc, unmodifled peakshaving plant alone. This same cost factor can probably be applied to the larger baseload plants which serve LNG transport ships. The increment of cost associated with additionál cleanup and vaporization capacity required for gelled LNG will probably be less than $1 \%$ of total transport terminal plant cost. Costs associated with pumping and, more importantly; transport of the gelled material (with, say $3 \%$ of the LNG displaced by gelant) will add to the cost. It can be roughly estimated that gelling of LNG in tanker shipping would increase costs of natural gas at send-out by five to ten percent. 


\subsubsection{Methy1 Fue1}

\subsubsection{Introduction}

The importation of methyl fuel (fuel-grade methanol) made from natural gas has been considered in the past as an alternative to LNG. The greatest interest in this mode occurred during the early 1970's (Royal and Nimmo, 1973; Dutkiewicz, 1973), and the feasibility of several projects was evaluated. Since that time, the price of gas has increased substantially, and the interest in methyl fuel projects appears to have abated.

In these prior studies, 1ittle was done to compare the relative safety of methyl fuel and LNG and to evaluate a reduction in safety risks that might be achleved with methyl fuel. In general terms, the consequences of spills of methyl fuel would be expected to be much less than those for equal volumes of LNG, and hence the methyl fuel would probably be safer to ship.

Methyl fuel, thus, offers the potential for safer transportation (and storage) at perhaps an increased cost over that of LNG. In the following sections, the factors that affect both the relative risks and costs of methyl fuel as a substitute for LNG are considered.

\subsubsection{Transportation Hazards}

\subsection{Genera1}

Since no research on the hazards and risks of the water transport of methyl fuel has been reported, quantitative estimates of the $11 \mathrm{ke}-$ lihood of spills occurring and of their consequences are difficult to make. In this study we conslder methanol hazards in a qualitative fashion taking into account the known characteristics of methanol and the manner in which it may be shipped. 


\subsection{Characteristics of Methano1}

The characteristics that relate to the hazards associated with methanol spills are compared to those for LNG in Table 4.7. Methanol is about 80 percent as dense as water so that it floats on water, as does LNG. It also mixes with water in any proportion and becomes nonflammable when the water content is about 40 percent ${ }^{*}$ or greater. Thus, during a spill the methanol would spread on the surface with mixing taking place at the interface of the two liquids. When the methanol is sufficiently mixed with water, it no longer constitutes a fire hazard.

Since methanol has a vapor pressure of about 2 psia (at $70^{\circ} \mathrm{F}$ ), it also evaporates as it spreads and, depending upon ambient temperature, may create a flammable vapor cloud that would travel downwind. This would result in a fire hazard at some distance beyond the evaporating pool. Because methanol has about one-seventh the vapor pressure of LNG, it evaporates at a much slower rate; the governing rate mechanism, is diffusion. This is in contrast to LNG where heat transfer from the water to the liquid controls its rate of boiling. As with LNG, methanol vapor is more dense than air, and the vapor cloud that is formed w111 move downwind at sea (or ground) level.

The vapor cloud hazard is quite dependent on the temperature of the liquid, since its vapor pressure decreases when it is colder. Hazardous vapor clouds probably w1ll not occur at temperatures below the flash point $\left(54^{\circ} \mathrm{F}\right)$.

The heat of combustion of methanol is much lower than that of LNG, so that the amount of thermal energy that would be released in a spill of equal volumes of liquid would be much less for methanol. For example, a spill of $25,000 \mathrm{in}^{3}$ of methanol would be equivalent to only about $15,000 \mathrm{~m}^{3}$ of LNG on an equivalent energy basis.

Methanol is toxic both by ingestion and inhalation, where LNG, for all practical purposes, is not. It will also act as a pollutant in water and may pollute the atmosphere when spilled in large quantitles.

* Based on a vapor pressure of a water-methanol mixture (at $70 \mathrm{~F}$ ) that would result in a concentration in air less than that at the lower limit of flammability. 
TABLE 4.7

COMPARATIVE PROPERTIES OF LIQUEFIED NATURAL GAS AND METHANOL *

LNG

Shipping temperature, ${ }^{\circ} \mathrm{F}$

Specific gravity, liquid

Solubility in water

Saturated vapor pressure, psia

Specific gravity, vapor

Flammability limits in air, percent

Ignition temperature, ${ }^{\circ} \mathrm{F}$

Flash point, ${ }^{\circ} \mathrm{F}$ (closed cup)

Burning rate, mm/min

Heat of combustion, Btu/1b

Toxicity by inhalation (TLV), ppm

Toxiclty by Ingestion

Aquatic toxicity $\sim-258$

$0.415-0.45\left(-258^{\circ} \mathrm{F}\right)$

Insoluble

$14.7\left(-258^{\circ} \mathrm{F}\right)$

$0.55-1.0$

$5.3-14.0$

999

F1ammable gas

12.5

$-21,600$ to $-23,400$

Causes asphyxiation ${ }^{\star \star}$

when > 52.4\%

Not applicable

Not applicable
Methanol

Ambient

$0.792\left(68^{\circ} \mathrm{F}\right)$

Miscible in

a11 proportions

$2\left(68^{\circ} \mathrm{F}\right)$

1.1

6.0-36.5

867

54

1.7

$-8,419$

200

$50 ; 000$ may cause damage in 1-2 hours

5-15 g/kg (rat)

$250 \mathrm{ppm} / 11 \mathrm{hr}$ (goldfish)

*

CHRIS, Hazardous Chemical Data, Department of Transportation, U.S. Coast Guard, CG-446-2, January 1974.

**

Arthur D. Little, Inc., "A Report on LNG Safety Research, Volume II," AGA Project IU-2-1, American Gas Association, Catalog No. M19712, January 31, 1971. 
Fatal vapor concentrations for toxic effects by inhalation are about at the same level as flammable vapor concentrations; that is, methanol vapors may be fatal after a 1 to 2 hour exposure at a 5 percent concentration in air, whereas the lower flammability limit is 6 percent. The vapors may, however, cause permanent damage at concentrations of less than 2.5 percent so that harmful vapor clouds might extend well beyond those distances or areas where flammable clouds may travel.

Methano1 has a characteristic odor that can be detected at concentrations in air that are several orders of magnitude less than that at which it presents a toxic hazard. Thus, odor of methanol will provide some warning, but for large spills that may produce a substant1al vapor cloud, the ability to take evasive action after the odor is first noted may be quite limited. LNG, on the other hand, is odorless.

\subsection{Spreading of Methanol on Water}

Analytical models for the simultaneous spreading, evaporation, and mixing of methanol that has been spilled on the water have not been developed, and empirical data that would help to determine the size of pools of methanol do not exist. For a given volume spilled rapidly, it is difficult to say whether the maximum dimensions of the methanol pool would be either larger or smaller than that for LNG. Because methanol would mix with water, however, the extent of the surface layer capable of burning or generating vapor would be much smaller than for an equivalent amount of LNG spilled.

Spreading pools of methanol may also be much smaller than those for LNG, when the rate and quantity of spill are taken into consideration. Methanol most probably would be shipped in tankers of conventional design where much, if not most, of the cargo would be carried below the waterline. If the container were ruptured, as in a collision, the methanol that is stored above the waterline would flow freely onto the tanker and displaced the methanol. Methanol would take much longer to escape than LNG, most of which is contained above the waterline in tankers with relatively high freeboards. In addition, 
because water has to flow into the cargo compartments before the methanol will flow out, a significant amount of the methanol would probably be mixed with the water before and during its release. This mixing would tend to reduce both fire and vapor hazards as the methanol spreads further on the surface of the water.

A methano1 tanker would also be expected to have more compartments than an LNG tanker, so that the quantity that is spilled initially might be less. Methods of spill control might be more amenable to methanol shipments as well.

\subsection{Pool Fires}

In the event of a spill of methanol, both pool fires and vapor cloud propagation would depend upon the size of the pool that is formed on the water. Since the maximum pool size for methanol would be much smaller due to a reduced rate and quantity spilled in an accident and because of a smaller area of the effective surface layer, the pool fire would be expected to be very much smaller than that which may occur as the result of an LNG tanker accident. In addition, methanol might produce a smoky flame when burned in a large pool. The smaoke from the flame would obscure much of the thermal radiation is in gasoline and other petroleum fires.

The combination of smaller and slower spills, plus smaller flames and less radiation, would appear to make the thermal radiation hazards from methanol pool fires very much less than those for LNG and probably less than that from gasoline or other petroleum product pool fires.

\subsection{Vapor Cloud Dispersion}

The reduced pool size and lower vapor pressure of methanol would tend to result in much smaller flammable vapor clouds than with LNG. For example, models provided by CHRIs ${ }^{*}$ suggest less than one percent of the material spilled will evaporate whereas all of the LNG spilled evaporated. The maximum flammable vapor cloud distances for methanol may be an order of magnitude less than that for LNG and the maximum dimensions of the cloud also will be much less.

* CHRIS Hazard Assessment Handbook, Department of Transportation, U.S. Coast Guard, CG-446-3, January 1974. 
The toxic vapor cloud may be harmful at greater distances but most likely will still not extend as far as an LNG flammable vapor cloud.

It also should be noted that for shipments made in northern. latitudes vapor generation especially for spills during the winter months would be greatly reduced and the vapor cloud hazard might become almost non-existent.

\subsection{Water and Air Pollution}

The spilling of large quantities of methanol could harm aquatic life over a relatively large body of water. For example, if all of the methanol become uniformaly mixed with water at the level defined by one measure of its aquatic toxicity (e.g., $250 \mathrm{ppm}$ ) and the depth.of the water were 40 feet, the radius over which the mixture would be toxic would be about one mile. Thus a large spill might be capable of polluting a large area within a harbor or estuary. Methanol would tend to be non-persistent, however, for the diluting, and washing action of tides and currents would tend to completely remove it from harbors and estuaries fairly quickly. It also may be metabolized by numerous organisms with little ill effect.

The potential for methanol to pollute the atmosphere has not been evaluated; however, the quantity evaporated during an infrequent and rare spill might be insufficient to cause significant harm.

\subsection{Overa11 Shipping Risks}

The risks associated with the transport of methyl fuel may be more similar to those for gasoline than LNG. The probability of spills may be similar to that for gasoline and higher than that for LNG, because tankers carrying these cargoes may be more vulnerable. On the other hand, the consequences of spills, especially in terms of potential harm to humans, would appear to be very much less for methanol than for LNG. The overall risks to people would be expected to be lower. Pollution from methanol spills needs further evaluation. 


\subsubsection{Methano1 as a Substitute for LNG}

\subsection{General}

Unlike LNG, there is no experience with the large-scale Industrial importation of methyl fuel. Facilities have neither been designed nor built. However, a number of studies have been made in the past, and two projects reached an active level of negotiation--Houston Natural Gas In Saudi Arabia and Transco in Iran. The Houston Natural Gas Project was originally planned to provide methyl fuel, both for SNG manufacture and as a fuel in itself, but it was gradually reduced in size and eventually changed in scope to a chemlcal grade methanol project. The Transco Project was undertaken to furnish base load synthesis gas as an alternative to LNG, but was eventually dropped because of economics and problems with securing a gas supply in Iran.

The increase in the gas price at the supply point has pretty much removed the potential economic advantage of methyl fuel in recent years, and activity on these projects and other feasibility studies appears to have been stopped. In this section we discuss the process by which natural gas may be converted to methyl fuel, transported, and used by the importer. This is followed by a discussion of the relative cost of delivering energy by the methyl fuel and LNG routes.

\subsection{Methanol from Natural Gas}

The conversion of natural gas to methanol requires a molecular change in contrast to the state change incurred in the liquefaction of LNG. The primary steps involved in the conversion process include the purification of the gas to remove sulfur, reforming at elevated pressure and temperature to make synthesis gas, heat recovery, compression, synthesis at an elevated pressure and temperature, and then methanol condensation and dehydration. The production of methyl fuel in this manner differs from that employed in making a chemical-grade product primarily in plant size and in a reduction in the extent of the purification. Plant capacitles would have to be much larger than those that have been built to date to make methanol for chemical use. 
Because of the thermal inefficlencies in this process, the converston to methanol is more costly than 1lquefying natural gas. However, some cost savings might be achieved by locating the process plant Inland near the wellheads and transporting the methanol to the export terminal by pipeline. In any event, water requirements are large and could create problems in the desert-like areas of the Mid-East. 1.

- The technology required to make methanol from natural gas does exist, however, although there may be some risk in building the first large-scale production facility.

\subsection{Water Transport of Methy1 Fuel}

Methyl fuel projects that have been studied relied on the use of VLCC's to transport the product. However, the cost of tankers would be much less than the cost for those used to transport LNG. In fact, cost savings in transport was the primary factor in considering the economic feasibility of substituting methyl fuel for LNG in the first place.

Methyl fuel would not be much more difficult to transport than crude ofl and gasoline, except that it might be degraded by accidental seepage of water into the containment tanks. Transfer operations during loading and unloading might be similar to those for gasoline.

The VLCC's, of course, do not have double hulls as do the LNG tankers, and would therefore be more vulnerable to accidental spills from rammings and collisions. On the other hand, the VLCC's have more compartments, and much more of the fuel would be contained below the waterline so that the rate and quantity, of spill might be much less for a "conventional" methanol tanker versus an LNG ship.

The drafts of the large ships that might be used, however, are so great that they could not be received in any existing U.S. port. E1ther off-loading to smaller ships or to off-shore terminals would be required, if the economies of large vessels were to be realized. 


\subsection{Use of Methyl Fuel at the Receiving Terminal}

The land storage of methanol would be similar to that for the storage of gasoline. Conventional storage tanks could be employed (reducing storage costs relative to $L N G$ ), and with adequate diking and fire protection, they might present much less of a hazard than would LNG in storage. For example, much lower rates of evaporation due to the lower volatility of methyl fuel would greatly reduce the vapor cloud hazard.

In past projects, the conversion of the methy 1 fuel back to a synthesis gas (SNG), which could then be sent out through existing natural gas transmission and distribution systems, has been considered. This conversion process would utilize more energy and require a larger capital investment than LNG gasification systems, thus increasing the relative cost of the SNG versus that of LNG. The technology for this conversion has not been commercialized, but no adverse problems are expected other than those associated with scale:

Methyl fuel might also be used directly as a fuel rather than converting it to a synthesis gas. There should be no inherent difficulty. in firing it in conventional boilers, nor in using it as a fuel for turbines at peaking facilities. It might be mixed with gasoline as an automobile fuel ("gasohol"), and processes have been developed for converting methanol to a synthetic gasoline.

\subsection{Economics of Methy1 Fue1}

The economics of methyl fuel.hinges on the cost of its preparation, shipping, and conversion to synthesis gas. Studies that have been reported (Royal and Nimmo, 1973; Dutkiewicz, 1973) compare the costs of LNG as a function of the shipping distance, since the savings in tanker costs have the greatest influence on the competitiveness of methyl fuels. * At the time of the analysis, it was shown that methyl fuel would be about 40 percent more expensive on an equivalent

\footnotetext{
* At the time these studies were made, it was estimated that a methanol tanker would cost some $\$ 35$ million. It was estimated that this would result in a saving of about $\$ 270$ million for one project.
} 
energy basis than LNG for shipments from Algeria to the United States. For longer shipments involving one-way distance of 6,000 miles or so, methyl fuel becomes competitive. Since 1973, the price of gas has increased substantially so that the relative savings in shipping do not have as much influence on the cost of gas at the receiving end, probably to the extent that methyl fuel would not be competitive at any practical shipping distance today.

To approximate the incremental costs associated with the substitution of methyl fuel for LNG, we have used data from Reference 2 on the relative delivered costs, of energy (MM Btu) as a function of shipping distance. These costs are shown as solid lines in Figure 4.21 and are assumed to be based on gas prices prior to 1973. This data indicates that the cost of delivered energy was lower for methyl fuel once the one way shipping distance approached 4,000 miles. This break-even distance would be greater; however, if the cost of converting methanol to synthesis' gas were taken into account.

The present cost of gas at the shipping point for our baseline (see Table 2.2) is now estimated to be about $\$ 1.35$ per MM Btu. If the cost of methyl fuel were also increased in the same proportion and the shipping costs were to remain the same, a second set of curves as shown (as dotted 1ines) in Figure 4.21 are derived, Here the shipping distance at the cross-over point is almost doubled.

Actually the cost of shipping of both LNG and methyl fuel will have increased above that used in the 1973 data so that the difference may not be as large as shown. If, however, one uses these values and selects a 5,000 mile transit (as in our baseline data), methyl fuel would cost some $\$ 0.15 / \mathrm{MM}$ Btu more than LNG at the point of delivery. If the cost of converting methyl fuel to synthetic gas is then assumed to be equal to the cost of converting the gas to methyl fuel in the first place, say $\$ 0.40 / \mathrm{MM}$ Btu, then the total incremental cost of methyl fuel converted to synthesis gas might be some $\$ 0.55 / \mathrm{MM}$ Btu or 20 percent greater than LNG. 


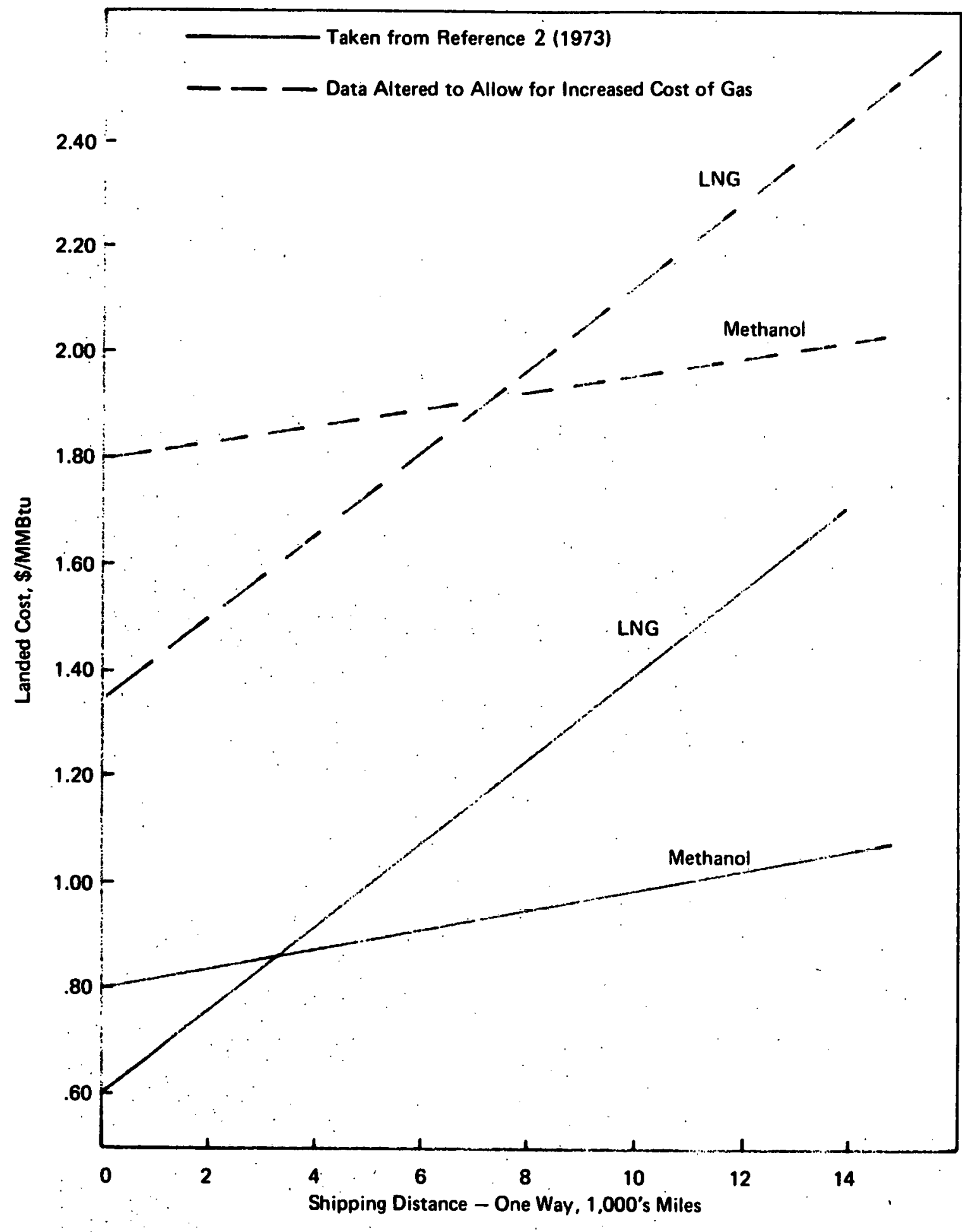

FIGURE 4:21

Cost of Energy Delivered for Different Shipping Distances 
This of course is a gross approximation but does Indicate that the increased costs associated with achieving improvements in safety by the methyl fuel route may be substantial.

4-83 


\subsubsection{Addition of Flame Suppressant}

\subsubsection{Concepts}

In concept, the use of a fire suppressant either to eliminate or reduce the burning of vapor from an accidental sp111 might involve efther:

- An intimate mixture of the suppressant with the LNG (with subsequent removal prior to its dispatch from the import terminal); or

- Separate storage of the suppressant aboard ship and a means of applying it in the area of the accidental spill.

Both methods present severe problems, not the least of which are the very large quantities of suppressant required, even for the most effective extinguishing agents.

Typical extinguishing or inerting agents for which there are data on the concentrations required to prevent burning are presented in Table 4.8. Nitrogen and carbon dioxide, both inerting agents, are effective in that they reduce the oxygen concentration avallable for reacting with LNG vapor. Relatively large quantities are needed to reduce the oxygen concentration to the point where combustion of LNG vapor and air will not occur. The halons, on the other hand, chemically inhiblt the reaction of methane (Creitz, 1972), and the heavier hydrocarbons and air. Because of this characteristic, much smaller quantities are needed.

\subsubsection{Mixtures of Extinguishants and LNG}

The most common method of expressing the extinguishing ability for gaseous reactants is the percent by volume of the suppressant necessary for flame extinguishment. Thus, nitrogen must be added to a1r in an amount equal to 42 ; percent by volume. Halon 2402 needs to be added in an amount equal to about 0.8 percent by volume. In the case of an LNG tanker carrying sufficient suppressant to extinguish 
TABLI: 4.8

- Characteristics of Some Extinguishants

\begin{tabular}{|c|c|c|c|c|c|c|c|c|}
\hline Agent & $\begin{array}{l}\text { Molecular } \\
\text { Weight }\end{array}$ & $\begin{array}{l}\text { Boiling } \\
\text { Point } \\
\quad(1) \\
\end{array}$ & $\begin{array}{c}\text { Melting } \\
\text { Point } \\
(\text { ( } \mathrm{F}) \\
\end{array}$ & $\begin{array}{l}\text { Liquid } \\
\text { Density } \\
\left(1 \mathrm{~b} / \mathrm{ft}^{3}\right) \\
\end{array}$ & $\begin{array}{l}\text { \% by Volume } \\
\text { Added to A1r } \\
\text { for Extingutshmer.t }\end{array}$ & $\begin{array}{l}\text { \% by Volume } \\
\text { Added to Methane } \\
\text { for Extinguishment }\end{array}$ & $\begin{array}{l}\text { Rat 10 fo Extinguishant } \\
\text { to I.NG for Ext1nguishment } \\
\text { by Volume }\end{array}$ & $\begin{array}{l}\text { Ratio of Extinguishant } \\
\text { to I.NG for Extinguishment } \\
\text { by Welght }\end{array}$ \\
\hline Nitrogen & 28 & -320 & - & 50.6 & $42^{(4)}$ & 618 & $5.6 / 1$ & 10.8 \\
\hline Carbon Dioxide & 44 & -109 & $-170^{(2)}$ & 68.7 & $28^{(4)}$ & 318 & $3.4 / 1$ & 8.8 \\
\hline Halon $1301^{*}$ & 149 & -72 & $-270^{(3)}$ & 46.5 & $2^{(3)}$ & 20 & $1 / 1$ & 1.8 \\
\hline Halon $2402^{*}$ & 300 & 117 & - & 136 & $0.8^{(5)}$ & 8 & $0.3 / 1$ & 1.5 \\
\hline Methane & 16 & -258 & - & 26.6 & - & - & - & - \\
\hline
\end{tabular}

Bromotrifluoromethane

* Dibromotitrifluoroethane

(1) Chemical dictionary

(2) Perry's handbook

(3) Standard on Halogenated Fire Extingulshing Agent Systems - Halon 1301, NFPA No. 12A-1973, National Fire Protection Association, Boston, Massachusetts.

(4) Zabatakis. (1965)

(5) Rainaldi (1970) 
the vapor from a given amount of LNG, however, the ratio of liquid volumes (and weights) of extinguishant to LNG becomes important. It can be seen from the last two columns of Table 4.8 that even the most effective agent will occupy some 30 percent of the space, or 150 percent of the weight, of the LNG being shipped. Obviously these are excessive amounts.

There are little data on potential extinguishants other than the inerting gases or halons. Screening tests with hydrogen and air have indicated ${ }^{*}$ that there are many other agents that may be effective but none appears to offer very much improvement over those listed in Table 4.8 .

Most all suppressants, when added in lesser amounts than required to cause extinguishment, reduce the flammability limits and flame speed. In so doing; they may alter the burning characteristics of the LNG turbulent diffusion flame; that is, if there is sufficient wind and turbulence, extinguishment may occur with lesser concentrations: of the additives. The reduction in the required quantity, however, would be expected to be relatively small.

Other drawbacks to the use of suppressant-LNG mixtures include:

1. Difficulty in achieving and maintaining uniform mixtures of the desired concentrations in the ship's cargo tanks.

2. The potential health effects of the suppressants; e.g., In low concentrations they are non-toxic, but in larger concentrations they may at least cause asphyxiation.

3. The halons decompose when exposed to the heat from a fire, forming toxic products such as hydrogen fluoride, hydrogen bromide, bromine, carbonyl fluoride, and carbonyl bromide.**

4. Trace quantities of halons that may be uneconomical to remove from the natural gas might eventually pollute the atmosphere (as do fluorocarbons). Either the halons themselves or their decomposition products would be vented to the atmosphere after the natural gas is burned in most any end-use that is made to it.

*Chemical Inhibition of the Hydrogen-0xygen Reaction, Technical ** Documentary Report No. ASD-TDR-62-10.42. Standard on Halogenated Fire Extinguishing Agent System - Halon 1301, NFPA No. 12A, National Fire Protection Association, Boston, MA. 
5. Most importantly, the agent will not $\mathrm{mix}$ with LNG vapor in the proportion needed for extinguishment, if it is originally mixed with LNG in the required concentration. The discrepency in boiling points for the agent and LNG will cause most of one to evaporate before significant concentrations of vapor from the other are emitted.

\subsubsection{Separate Containment of Extinguishants}

In concept, extinguishants could be stored in separate tanks aboard ship and used to extinguish fires or inert vapors resulting from accidental spills of LNG. Only that quantity necessary to control the spill of LNG from one shipborne container might be required, and a significant, reduction in the fire hazard might result, even if only a portion of the vapor from a spill were exposed to the extingulshant.

The ability to apply the extinguishant in the proper area quickly enough when an accidental spill of LNG occurs (as, for example, during a ship collision) appears to be difficult to achieve. The app1ication of the extinguishant would have to be controlled at the time of the spill, so that it could be applied in one of many different 1ocations, depending upon the particular tank that is ruptured and the direction of the wind. In addition, since spill times may be of the order of a few minutes, very prompt decisions and action on the part of the crew would be required.

Other drawbacks include:

1. The loss of cargo space taken up by the extinguishant;

2. The difficulty in achieving good mixing of the agent with LNG vapor in a vapor cloud; The potential for increasing the hazard by extinguishing a.pool fire, but not sufficiently inerting the vapors emitted subsequent to extinguishment.

However, provision for carrying substantial quantities of extinguishant on board an LNG vessel, along with appropriate methods of applying it, might reduce the hazards from spills where the rate and quantity of spill are reduced by compartmenting or otherwise altering the containment of the cargo. 


\subsubsection{Suppressing LNG Explosions}

Information developed to date indicate that an explosion of natural gas air mixtures is not likely - at least, not with the concentrations of methane normally found in natural gas. The detonation of mixtures of heavier hydrocarbons, such as propane and air, however, has been experienced when the fluids have been released accidentally. The propensity for an LNG/air explosion to occur will be expected to increase during the late stages of an evaporating pool of spilled LNG because of the increased concentrations of the heavier hydrocarbons. Extinguishing agents, such as the halons, might be utilized much more effectively in reducing the likelihood of an explosion of this kind than in eliminating the fire hazards from a large spill. 


\subsubsection{Solid Natural Gas}

\subsubsection{Introduction}

The transportation of natural gas in the frozen state will minimize and may well eliminate, for all practical purposes, spills caused by accidents which cause rupture of the carrier's tanks. The technology for implementing systems which transport natural gas on the high seas in the frozen form is available from prior research with small quantities of the material. The questions that remains $1 s$ : Is the added cost attendant to the transport in this form worth the reduction in risk?

Any system for solid transport must: 1) produce the solid at point of origin, 2) maintain the solid during transit, and 3) meit the solid. to liquid at the destination point for subsequent distribution. The solid form can be produced by pumping the ullage of a shipboard LNG tank below the triple-point pressure and, thereby, evaporating liquid which, gets its heat from the remaining liquid which eventually freezes. The solid can also be produced by cooling LNG by heat transfer with a cooler fluid, which, for practical purposes, can be a nitrogen or hellum stream within a closed-cycle refrigerator.

The natural gas transport economics basically reduces to two ques-. tions: 1) which of two methods of producing the solid is cheaper; and 2) what is the added cost of the cheapest method. The comparisons to be made are based on solidification and maintenance of the transported material all in the solid form. Finally, a baseline system consisting of a $125,000 \mathrm{~m}^{3}$ tanker with five spherical tanks transporting LNG from Algeria to Texas is chosen for subsequent comparative evaluations. For concepts involving solidification by evacuation of the ship's tanks, the spherical tank configuration is selected because it can be more readily strengthened to withstand an internal vacuum than can membrane constructions. The propertles of pure methane are assumed in the thermodynamic calculations. All technical evaluations are first order and all cost evaluations are approximations to give a preliminary perspective. 


\subsubsection{Production of Solid}

\subsection{Onboard Evacuation Process}

This concept for producing the solid. by evacuation envisions filling the cargo tanks with LNG and subsequently pumping the ullage to reduce its pressure below the triple-point pressure ( 1.7 psia, or 88 torr). In this process, $23.3 \%$ of the original liquid is evaporated, leaving $76.7 \%$ as solid. One filled $25,000 \mathrm{~m}^{3}$ tank has $23.6 \times 10^{6}$ lb of liquid, from which $5.5 \times 10^{6} 1 \mathrm{~b}$ of gas are evacuated from the ullage, leaving $18.1 \mathrm{x}$ $10^{6} 1 \mathrm{~b}$ of solid.

The capacity and power requirements for the vacuum pumping system depend inversely on the period allowed to produce the solid. A period of 24 hours is selected for the baseline. With this period a total of $2.54 \times 10^{6} \mathrm{cfm}$ of cold gas from the five tanks must be pumped through a pressure ratio of approximately 10 to 1 . To reduce the pumping power, size and loss of refrigeration, pumping could best be carried out with cold compression equipment.

Five 6000-hp., two-stage centrifugal pumps driven at $1800 \mathrm{rpm}$ would meet the requirements. Two additional vacuum pumping modules are added to provide uninterrupted service in the face of failures and maintenance. A 7-ft-diameter pumping port into the tank ullage would be required to keep pressure losses up to the vacuum pump inlet within a reasonable range. In our investigation, we have not attempted to locate a commercial product meeting these specifications, but smaller ones (by Rotoflow Corporation, for instance) have been in service. Assuming the availability of an appropriate compressor at $\$ 50 / \mathrm{hp}$ and a gas turbine drive at $\$ 150 / \mathrm{hp}$, the installed cost of one pumping unit is $\$ 1.2$ million and the total installed cost of 7 units is $\$ 8.4$ million. The operation and maintenance costs figured at $2 \mathrm{c} / \mathrm{kW}-\mathrm{hr}$ for continuous operation of 5 pumping modules for one year would total about $\$ 4$ million.

In addition, $27.5 \times 10^{6} \mathrm{lb}$ of gas at. $-140^{\circ} \mathrm{F}$ must be either returned to storage or reliquefied almost concurrently with the evaluation process. This penalty can be viewed simply as reducing the 
effective plant capacity in terms of transportable product by $23.3 \%$, or the cost of liquefaction is increased by a factor of 1.30 .

\subsection{Onboard Refrigeration Process}

The concept for producing the solid by refrigeration includes the use of a large refrigeration plant that provides a cold fluid, nitrogen or helium, to be circulated in pipes welded to the walls of the tanks. The temperature of the cooling fluid must be below the triple-point temperature $\left(163.2^{\circ} \mathrm{R},-296^{\circ} \mathrm{F}\right)$. Nitrogen would be introduced into the ullage to prevent an internal vacuum. A retrofit of the tanks to install pipes to carry the refrigerant stream is estimated to cost $\$ 2 \times 10^{6} /$ ship.

For a cooldown period of $24 \mathrm{hr}, 89,000 \mathrm{kw}$ of heat would have to be extracted to solidify the contents of the five tanks in the tanker. A refrigeration plant of conventional design which provides cooling at - $300^{\circ} \mathrm{F}$ would have a power input of $620,000 \mathrm{kw}$ and an installed cost of about $\$ 200$ million; not including its power supply. Its operation and maintenance costs computed at $0.5 \mathrm{c} / \mathrm{kw}-\mathrm{hr}$ for continuous operation for one year would amount to $\$ 25$ million. A large power plant would need to be added to supply power to the refrigeration plant. The capital expenditure, computed at $\$ 1000 / \mathrm{kw}$, would amount to $\$ 6.2 \times 10^{8}$, and yearly $O \& M$ costs, figured at $1 \mathrm{c} / \mathrm{kw}-\mathrm{hr}$, would be $\$ 50 \times 10^{6}$. These cost figures, which must be considered to be a minimum, assume that the tank's internal thermal resistance to cooling does not prevent solidification of its contents in 24 hours. If solidification in 24 hours requires a cooling fluid at $-370^{\circ} \mathrm{F}$ or at $-424^{\circ} \mathrm{F}$, the costs for the refrigeration and power plant would increase by factors of approximately 2.1 and 5.6 , respectively.

A non-conventional refrigeration plant which uses cold gas compression and LNG for cooling at the exit to the compression process would reduce the power required to $190,000 \mathrm{kw}$ and the costs by a factor of about 4. However, during operation it would vaporize $63.8 \times 10^{6} 1 \mathrm{~b}$ of LNG, which is $54 \%$ of the çapacity of the tanker, so that the effective capacity of the plant would be only $46 \%$. 


\subsection{Maintenance of the Solid during Transit}

In a 5000-mile voyage, without refrigeration about $2 \%$ of the solid would be liquefied by heat leakage through the conventionally insulated tanks. This amounts to $19,000 \mathrm{ft}^{3}$, or $500 \mathrm{~m}^{3}$ per tank. The solid could be maintained by pumping to keep the tank evacuated, but, in this case, a tank rupture would cause afr to flow into it and cause a very hazardous condition. Without cooling, keeping an inert gas blanket over the solid to avoid this circumstance would not prevent melting. However, conventional operations use the boil-off as a source of cheap fuel. About $85 \%$ of the boll-off is used in this way. In accordance with this economic practice, the solid which melts would be pumped from the bottom of the tanks, stored and vaporized as appropriate, and largely used as fuel. The addition of the necessary fuel-handling system (piping, pumps, holding tanks and vaporizers) to accomplish this function is estimated to cost $\$ 0.5$ million per sh1p.

\subsection{Cargo Warm-Up}

When the tanker reaches its destination, the solid must be warmed to liquid prior to off-loading. The most apparent practical way to accomplish the warm-up is to introduce warm natural gas into the tank through a suitable internal piping system. The total amount of warm $\left(70^{\circ}\right)$ gas required to liquefy the solid cargo is $14.2 \times 10^{6} \mathrm{lb}$, which amount is reduced to the liquid form. This amount is about $12 \%$ of the 1iquid capacity of the tanker, so the transported solid acts as a liquefier producing useful liquid product at its destination.

The warm-up time will be controlled by complex heat transfer processes. These processes involve condensation of gas on the solid and the melted solid and depend on the configuration of the gas injection system, internal fluid flows, mixing, etc. Quantitative estimates have not been made of these processes to determine the time for warm-up, however, related experience indicates that a warm-up perfod of 24 hours could be readily achieved. A 12-hour warm-up period is assumed in this analysis. 
The warm-up systems would be additional and thus add costs. Additional internal tank plumbing (of a design to be developed) would be required. Modifications to the regasification plant at the delivery port to include the plumbing and pumping system used for warm-up would also be required. The additional capital costs would be about $\$ 1$ million/ship and $\$ 1$ million for shore facilities, respectively.

\subsection{Vacuum Tank Structure}

To withstand an internal vacuum, a 60-ft-radius tank constructed to ASME Code of material having a yleld strength of 30,000 to 38,000 psi would have a wall thickness of 2.2 inches and weigh $4 \times 10^{6} 1 \mathrm{~b}$. Such a spherical vessel would have about twice the thickness and weigh about twice as much as the current design. The additional weight add about $\$ 2$ million to the cost of the tank, or $\$ 10$ million to the cost of the vessel.

\subsection{Ecconomic Evaluations}

For the economic evaluation we assume that a baseline economic enterprise is transporting LNG from Algeria to Texas in amounts averaging $1 \mathrm{BSCF} /$ day distributed as a gas at a cost of $\$ 2.762 / \mathrm{MSCF}$. If the gas is sold for $\$ 2.762 / \mathrm{MSCF}$, this enterprise returns $\$ 2.762 \times 10^{6}$ / day, or $\$ 1.01 \times 10^{9} / \mathrm{yr}$. Also $1 \mathrm{BSCF} /$ day translates to $15.2 \times 10^{9} \mathrm{lb} / \mathrm{yr}$ and, with each vessel having a cargo of $10^{8} \mathrm{lb}$, the delivery calls for 152 landings per year, or one landing every 2.4 days. Assuming that a round trip, including time for loading and discharge, takes 24 days, 10 ships must be dedicated to the enterprise. The assignment of 12 ships is assumed, to give a margin for maintenance, bad weather, etc. Table 2.2 in the Summary shows the breakdown of costs for the baseline case, i.e., the transportation in liquid form.

Shipment of the material in the solid form increases the cost, because of additional capital expenditures, increased operation and maintenance costs and a direct fractional increase in liquefication and shipping costs due to the decrease in the effective liquefaction plant capacity, and the reduction of the weight of cargo carried per vessel 
(in the case of solid production by on-board evacuation only). The additional costs attendant to the two methods of solidification are reduced to presentations parallel to Table 2.2 so that comparative costs are revealed in Tables 4.9 and 4.10 .

The cost effects of additional capital expenditures are taken into account as follows: The total capital cost of the expenditure is simply depreciated linearly in five years. The amount of the yearly depreciation is expressed as a fraction of $\$ 1.01 \times 10^{9}$ (corresporiding to $\$ 2.762$ ) MSCF) and a surcharge equal to this fraction times $\$ 2.762$ is added to $\$ 2.762$. For instance, in the case of solld production by refrigeration, the yearly depreciation on the $\$ 200 \times 10^{6}$ plant cost is $\$ 40 \times 10^{6}$. This depreciation is 0.04 times $\$ 1.01 \times 10^{9} / \mathrm{yr}$ and adds to cost in the amount of $0.04(\$ 2.762)$, or $\$ 0.110 / \mathrm{MSCF}$. Sim1larly, the capital expenditure for the power plant needed to supply power to the refrigeration plant would add $\$ 0.338 / \mathrm{MSCF}$.

The added costs for operation and maintenance are similarly computed. These yearly costs are expressed as a fraction of $\$ 1.01 \times 10^{9} / \mathrm{yr}$ multiplied by $\$ 2.762 / \mathrm{MSCF}$.

The added shipping costs attendant to the transportation of the solid when produced by evacuation are simply computed as a decimal .767, or 1.30 times the shipping costs given in Table 2.2. These additional costs result from the fact that each ship transports only $76.7 \%$ of its liquid capacity in the solid form.

The cost of liquefaction increases in the case of solid formation by evacuation by virtue of $23.3 \%$ reduction in its effective capacity as a result of the evaporated return stream. Producing the solid by refrigeration does not change the liquefaction costs.

The added costs due to the time required for the warm-up and solidification processes are incurred mainly through the extension of the turn-around time. This reflects on the need for additional vessels to deliver a given amount of product per year. Assuming that the warm-up takes half a day amounts to a $2 \%$ increase in round trip time, or a $2 \%$ 
increase in the number of ships to deliver the same yearly amount of product. Of course, $2 \%$ of 12 vessels does not amount to an integer, but to give some value to the added cost for warm-up we add $2 \%$ to the capital charges (vessel) for shipping as appearing in Table 2.2. Similarly, the assumption of an additional period of one day needed for solidification adds $4 \%$ to the capital charges (vessel).

\subsection{On-Shore Solidification}

It may not be practical to entertain solld natural gas transport unless existing transport vessels can be modified reasonably to serve this purpose. The retrofit of freestanding prismatic or membrane tanks to withstand an internal vacuum appears to be impractical, and strenthening of the existing spherical tanks could involve major rework. Accordingly, a system for on-shore solidification, and ship loading is considered.

The concept involves a separate, on-shore chamber where solidification of the LNG introduced into it takes place. The same two methods for solidification (refrigeration and evacuation) can be applied. Thereafter, the solid must be transported from this chamber into the ship's tanks. The implementation of this concept requires inaginative design concepts and development. A major problem confronting the achlevement of a practical design is the production of a load within the ship's tanks which approaches the density of LNG in a system free of interruptions as a result of plugging or other malfunctions of the solidification chamber-to-ship tank solị handling systems.

\subsection{Summary}

Tables 4.9 and 4.10 11lustrate the results of economic evaluations for the costs of shipping natural gas in the solid phase where the solidification is produced by refrigeration and evacuation respectively, of the ship's tanks. A comparison of the results shows that solid formation by refrigeration is apparently the less costly method but entalls large additional capital expenditures; and the estimates are sensitive to assumptions relating to the coolling fluid temperature, 
Table 4.9

ESTIMATED COSTS FOR SOLIDIFYING,

TRANSPORTIÑG AND REGASIFYING LNG

(Solidification by Sh1p Tank Refrigeration; Algeria to Texas Route)

1 BSCF/Day

Cost (\$)

Cost of Gas

$0.500 / M \cdot S C F$

Liquefaction

0.840

Shipping

Fuel

0.030

Boil-off

0.092

Capital Charges (Vessel)

0.837

Fixed Costs

$\underline{0.225}$

1.184

Receipt and Regasification

0.285

Additional Capital Charges

Refrigeration Plant

0.110 (min)

Power Plant

$0.338(\mathrm{~min})$

Spherical Tanks (Cooling Coils)

0.014

Warm-up System

(In-tank and Onboard)

0.007

Fuel Handling System

0.004

0.473

Additional $0 \& M$ Charges

Refrigeration Plant

0.068 (min)

Power Plant

0.137 (min)

$\underline{0.205}$

TOTAL

$3.487 / M$ SCF (m1n) 
Table 4.10

ESTIMATED COSTS FOR SOLIDIFYING,

TRANSPORTING AND REGASIFYING LNG

(Solidification by Ship Tank Evacuation; Algeria to Texas Route)

1 BSCF/Day

Cost of Gas

Liquefaction

Shipping

Fue1

Boil-off.

Capital Charges (Vessel)

Fixed Costs

Recelpt and Regasification

Additional Capital Charges

Evacuation System

Spherical Tanks (for Vacuum)

Warm-up System

(In-tank and Onboard)

Fuel Hand1Ing System

Additiona1 $0 \& M$ Charges

Evacuation System
$0.500 / \mathrm{M} S \mathrm{SCF}$.

1.092

0.039

0.120

1.092

0.293

1.544

0.285

0.064

0.007

0.004

0.131

$\underline{0.011}$

0.011

TOTAL

$3.563 / \mathrm{M} \mathrm{SCF}$ 
capital costs, depreciation'rates, etc. The supply system based on solidification by in-tank refrigeration is estimated to increase the cost of gas for distribution by a minimum of $26.2 \%$. The supply system based on solidification by in-tank evacuation is estimated to increase the cost of gas for distribution by $29.0 \%$, mostly due to a $30 \%$ increase in liquefaction and shipping charges that results from reduced utilization of the liquefaction plant and cargo capacity. The uncertain cost elements in the estimate amount to only about $4 \%$ of the total cost. In principle, the full cargo capacity could be utilized in this case by alternately topping-off and evacuating the tanks during the loading process; however, the care and time, with their attendant costs, required for this operation may not warrant the effort.

The technology for implementing a solid natural gas supply system based on the formation of the solid within the ship's tanks is available except (perhaps) for commercially available, cold gas, vacuum compression equipment in the size range most desired, and the design of the tank's internal piping for the warm-up process would have to be developed and tested. Also, the most practical techniques for reducing the cargo to solid would have to be proof-tested on a large scale. In this study, heat transfer within the ship tank was assumed to be great enough not to limit the time for solidification or warm-up. This assumption is questionable, particularly in the process for producing the solid by refrigeration. It may be unrealistic to assume the solidification of the tank's contents in 24 hours by simply cooling the tank walls at a temperature only slightly below the triple-point temperature. To solidify the tank's contents within 24 hours may require cooling at temperatures much lower than the triple-point temperature and, therefore, the cost of the refrigeration plant and its attendant power plant may well cost considerably more than the minimum estimates given in Table 4.9. This issue requires more study.

The acceptability of any scheme for transporting natural gas in the solid form would be enhanced if the existing fleet could be retrofitted for the service without mafor modifications to the present 
vessels' designs. Accordingly, a system which forms the solid on shore and, thereafter, transports $1 t$ to and loads it into the cargo tanks of existing vessels is worth further consideration. The implementation of such a concept requires new design concepts. Because of the leverage that cargo packing density has on total costs, a major problem confrontIng the realization of a practical design is the achievement of a loading density within the ship's tanks which approaches that of LNG in a trouble-free solid handling system. The minimum cost of delivered product packed to a density $76.7 \%$ of LNG would be $\$ 3.432 / \mathrm{MSCF}$, which figure results from subtracting the costs of the evacuation system and upgraded spherical tanks to withstand vacuum from the total given in Table 4.10. This figure would be increased by the capital and operating cost of the on-shore solidification and solid handling systems. On the other hand, this base figure would be reduced by a factor nearly inversely proportional to the packing density of the solid in the ship's tanks.

Another approach that has been considered (Strumbus, 1974) is the utilization of an insulated conventional single-hull tanker for transporting the solid. Since the shipping of the material in the solid phase could eliminate the potential occurrence of a large cargo spill during a collision accident, there might be little incentive to provide a double hull and, possibly, two cryogenic barriers for cargo containment. This could reduce the cost of transporting the solid, but, of course, the concept requires additional research before its feasibility can be established. 


\subsection{VULNERABILITY OF LNG TANKERS AND CREWS TO FIRE}

\subsection{INTRODUCTION}

The effecl of a large-scale fire on an LNG ship caused by a collision accident and resulting in spill and ignition is not well understood. To provide additional fire protection for the ship and its crew, it is essential to understand the extent to which the ship and its structures are vulnerable to a massive fire. Once the critical components are identified and the thermal effects of fire on these components are established, suitable modifications to minimize the hazards can be considered.

In this chapter we have analyzed the important construction details of an LNG ship and identified the types and locations of various materials (including flammable materials), and vulnerable and critical structures. We have also analyzed the thermal response of the structures and the effects of fire. Finally, we have identified the normal crew positions during entry into a port and during transfer of cargo, and discussed the possible protection from large accidental fires that can be provided to members of the crew and ship components. 


\subsection{CRITICAL SHIP COMPONENTS AND THEIR LOCATION}

\subsubsection{LNG Tankers in Genera1}

Because of the extremely low temperature of the cargo and the nature of the hazards associated with natural gas, LNG carriers have special construction features. These include substantial insulation for the cargo tanks - to inhibit a heat leak into the liquid - and special designs of the tanks (1) to accomodate large variations in temperature, for conserving the total amount of heat that reaches the cargo, (2) to withstand the dynamic loadings imposed during ocean transits, and (3) to reduce the likelihood of liquid leaks (e.g., by the use of two cryogenic barriers).

All LNG vessels are built with double hulls and double bottoms with cryogenic containment provided by barriers separate from the hulls. Currently, there are two common cargo tank/vessel designs, both of which will be described in greater detail later in this section.

Some of the features and the occupancy profile of a typical LNG tanker are illustrated in Figure 5.1. The foc'sle area, located at the bow, contains the anchor windlass and the mooring winches. Located below the foc'sle are the peak (fuel) tanks and the bow thrusters. Storerooms are also frequently found in this area. The main deck, which is intersected by the cargo tanks and their covers, generally contains the following:

- Cargo (liquid and vapor) transfer lines, valves, associated sensing equipment, and the flanges for transfer to or from shoreside;

- Machinery such as mooring winches, davits, and 11 feboats;

- Fire protection equipment such as dry chemical systems; and perhaps

- Tanks of carbon dioxide, nitrogen, and/or propane.

This equipment and the cargo tanks and covers limit the movement of the crew. 


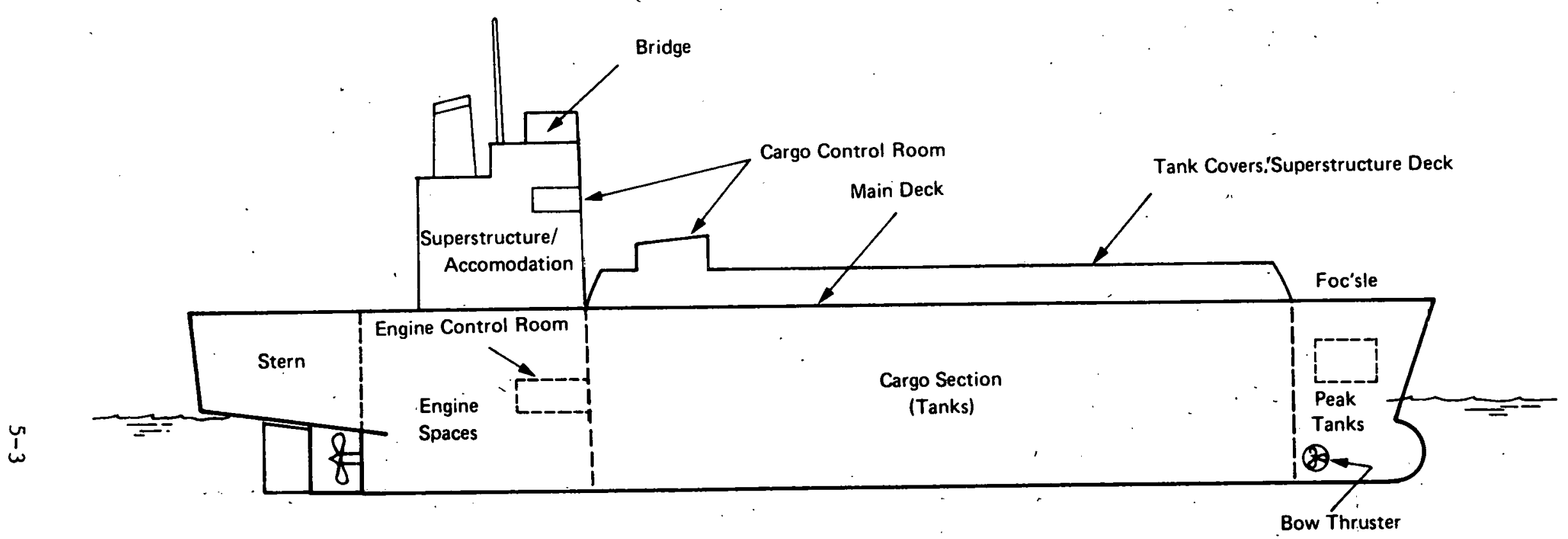

FIGURE 5.1 SCHEMATIC OF SHIP AREAS 
The control center for monitoring and transferring cargo may be located either aft in the superstructure or at an elevated position in the area of the cargo tanks. Many vessels are equipped with water sprays that may be applied to cargo tank covers with the water draining across the deck to provide fire protection and to protect the deck from spills or leaks of the cryogen. Vent stacks are provided for emergency venting of cargo.

The superstructure contains the bridge, the primary control center for ship operation, and the crew's quarters. Engineering spaces and the power plant are located below the superstructure. The power plant includes the boilers, turbines, appropriate controls, and some of the fuel supply. The stern area contains such equipment as the steering engine, the aft anchor windlass, and mooring winches.

The machinery on the foc'sle and on the deck as well as the submerged cargo pumps are operated electrically. The power and control cables for the machinery and lighting run the entire length of the ship, usually just under the deck plate. A general list of the electrical machinery and equipment and its location aboard ship is presented in Table 5.1.

\subsubsection{Pertinent Features of Two Types of LNG Carriers}

Although there are some 15.existing tanker designs, two basic types are most common: (1) the membrane or Integrated tank system; and (2) the free-standing or self-supporting tank system. Membrane tanks utilize a relatively thin liquid-containment liner, which is supported through insulation, and a secondary barrier, supported by the hull and bulkheads. Free-standing tanks, on the other hand, are self-contained and spherical or prismatic in shape. They are elther welded to special supports or to the ship structure itself.

Both of these common tanker designs are considered in this analysis. Examples of the membrane-type tank system are those designed by Technigaz, such as are. found on the LNG carrier DESCARTES $\left(50,000 \mathrm{M}^{3}\right)$ and four ships operated by She11. The Kvaerner-Moss spherical tank system is 
TABLE 5.1

Location of Machinery on LNG Ships - General

\section{Electrical Circuits and Distribution}

Foc'sle area:

Anchor windlass power supply

Bow thruster (if fitted), power supply, and control

Navigation lights

Peak tank bilge/ballast pump (if fitted)

Mooring winches

Main deck Including cargo section and cargo control room:

Lighting, deck

Cargo tank pumps, power supply, and controls

Instrumentation

Sensors (tanks, holds, volds, cofferdams)

Remote controls, power supply, and controls for valves, etc.

Mooring winches

Superstructure:

Hotel services for accomodations (1ight, heat, galley, sanitary, recreational)

Bridges, controls, and instrumentation

Communications, external

Safety and navigation (lights, radar, davits)

Engine room and spaces:

Main turbo-generators and busses

Main and auxillary switchboards

Propulsion plant auxiliaries, electrically driven

Lighting, ventilation

Controls and instrumentation in engine control cubicle

Ballast system pumps

Stern:

Steering engine

Aft anchor windlass

Mooring winches

Navigation lights

General:

Internal communication and alarm system circuits throughout the ship. Principal cable runs, fore and aft, are led below the main deck, either in a passageway fust below the main deck or in a continuous trunk such as available elsewhere, depending upon the particular design of the ship. 
representative of the free-standing concept. Examples of the latter include the NORMAN LADY, the VENATOR $\left(116,000 \mathrm{~m}^{3}\right)$ and the General Dynamic vessels $\left(125,000 \mathrm{~m}^{3}\right)$.

\subsubsection{LNG Ships Equipped with Technigaz Membrane Tanks}

A longitudinal sectional view of an LNG carrier equipped,with Technigaz membrane tanks is shown in Figure 5.2. the carrier has six tanks, with tank 非 1 having the smallest volume. The containment system consists of a stainless-steel primary barrier. The insulation panels are constructed of laminated balsa layers faced with Douglas fir plywood on the warm side and maple plywood on the cold side. The plywood can be considered the system's secondary barrier and is sealed by a bonded PVC joint. A final layer of balsa provides a flat surface upon which the membrane is fastened, and it maintains the secondary barrier at a temperature above that of LNG. All vold spaces are filled with mineral wool. A section through the midship of the DESCARTES is shown in Figure 5.3, and the details of the insulation are shown in Figure 5.4 .

\subsubsection{LNG Ships Equipped with Kvaener-Moss Free-Standing Spherical Tanks}

A longitudinal view of an LNG ship equipped with Kvarerner-Moss free-standing spherical tanks is shown in Figure 5.5. These ships generally have five tanks of equal capacity. The basic design consists of a spherical LNG tank supported by a cylindrical skirt welded to the tank equator and to the bottom of the ship structure. As the spherical tank is essentially a pressure vessel, the customary secondary barrier has been replaced by a drip tray and a splash barrier. A crosssection through a spherical tank is shown in Figure 5.6. Several types of insulation techniques employed by such vessels consist of different materials and generally are in the form of multi-layered systems. The LNG ships are designed so that the ship will still float even if one compartment in the hull (between bulkheads) is flooded with water."

U.S. Coast Guard regulations 46 CFR-93 and 46 CFR-42.20. Also see (1) "Safety of Life at Sea Convention (SOLAS) 1974," (1i) International Load Line Convention (ILLC), 1966, and (iii) IMCO Gas Code, 1975. 


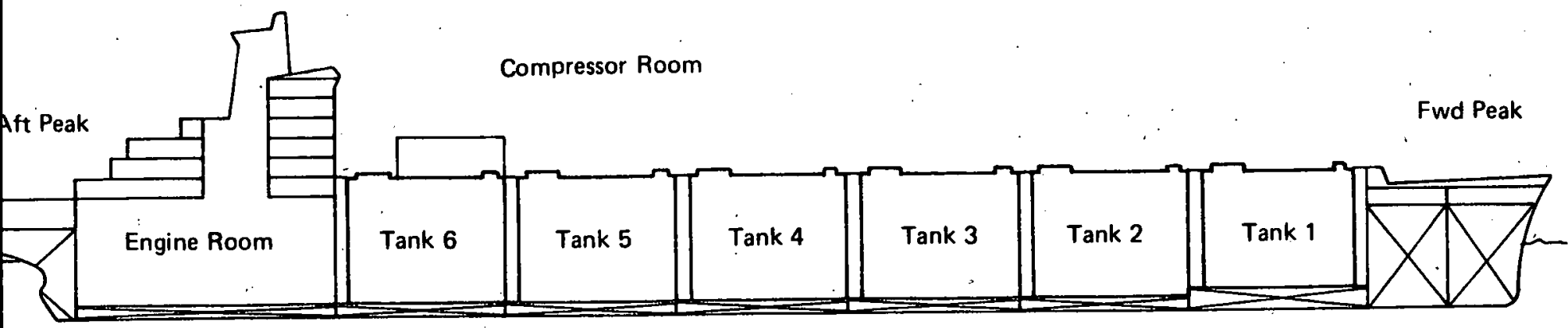

Deep Tank

Storage capacity $-50,000 \mathrm{~m}^{3}$.

Overall length $-220.4 \mathrm{~m}$

Freeboard (fully loaded) $-7.9 \mathrm{~m}$

Mass of freeboard steel in hull one side (fully loaded) $-44.3 \mathrm{~m}^{3}$

Total amount of insulating materials $-764.1 \mathrm{~m}^{3}$

Fuel oil (Bunker C) storage $-3000 \mathrm{~m}^{3}$

Diesel oil storage - 179 metric tons

Lube oil $-65 \mathrm{~m}^{3}$ 


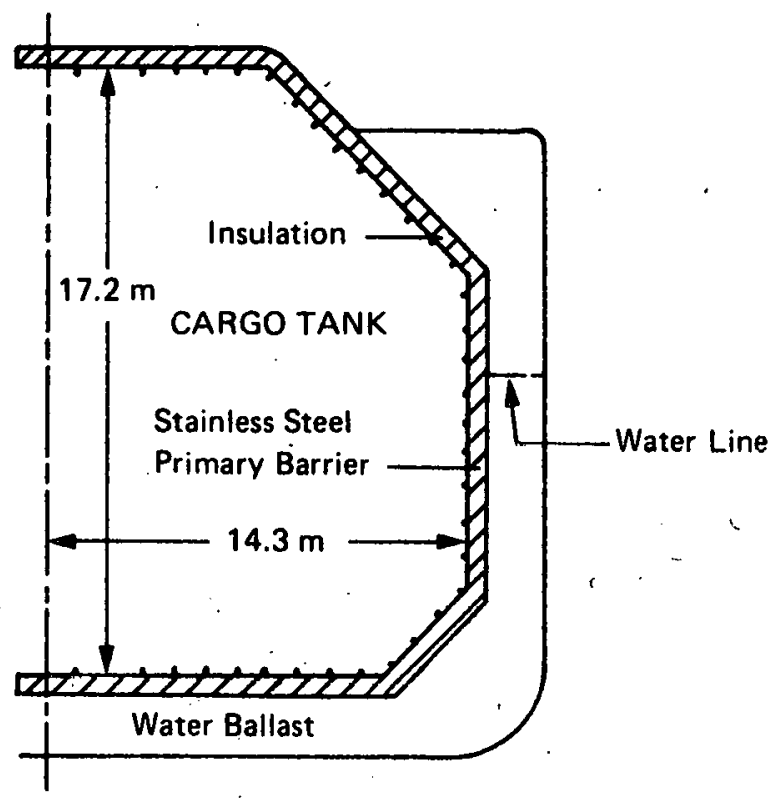

\section{FIGURE 5.3 SECTION THROUGH MIDSHIP OF THE DESCARTES} SHOWING DETAILS OF THE CARGO TANK

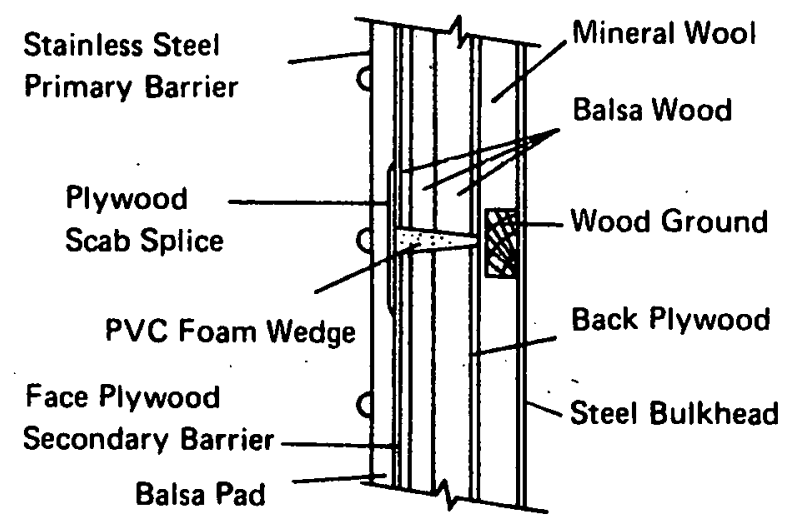

FIGURE 5.4 DETAILS OF INSULATION FOR A MEMBRANE TANK DESIGN 


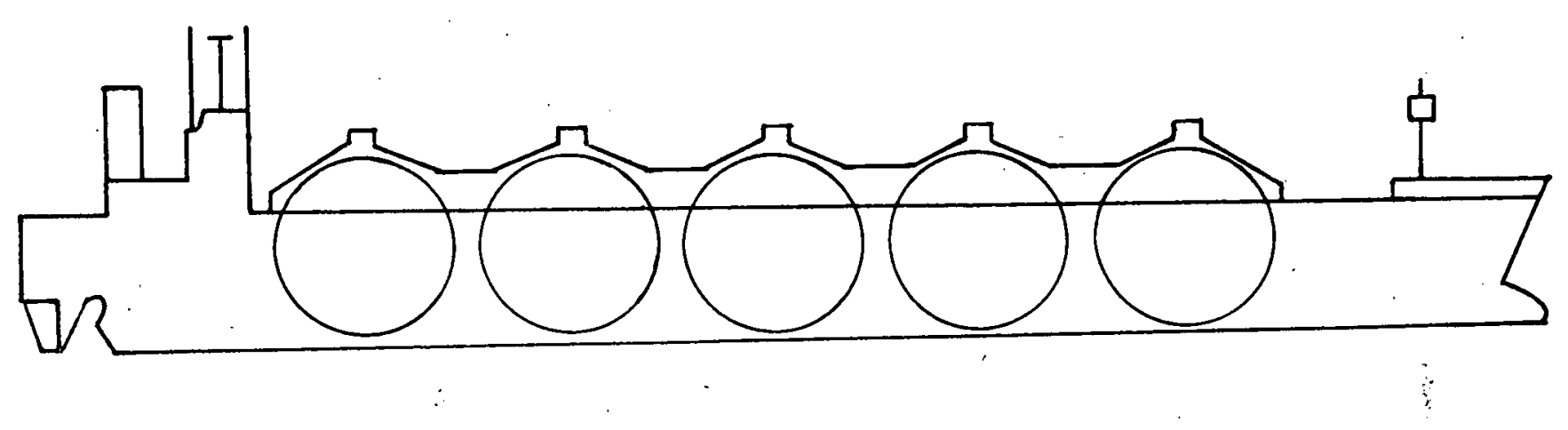

Storage capacity - $125,000 \mathrm{~m}^{3}$

Overall length $-285.3 \mathrm{~m}$

Freeboard (fully loaded) $-14.0 \mathrm{~m}$

Mass of freeboard steel in hull one side (fully loaded) $-101.9 \mathrm{~m}^{3}$

Total amount of insulating materials (spheres) $-4265.4 \mathrm{~m}^{3}$

Fuel oil storage - 6078 metric ton capacity, customary maximum 3629 metric tons

FIGURE 5.5 LONGITUDINAL SECTION OF FREE-STANDING SPHERICAL TANK LNG SHIP

! 


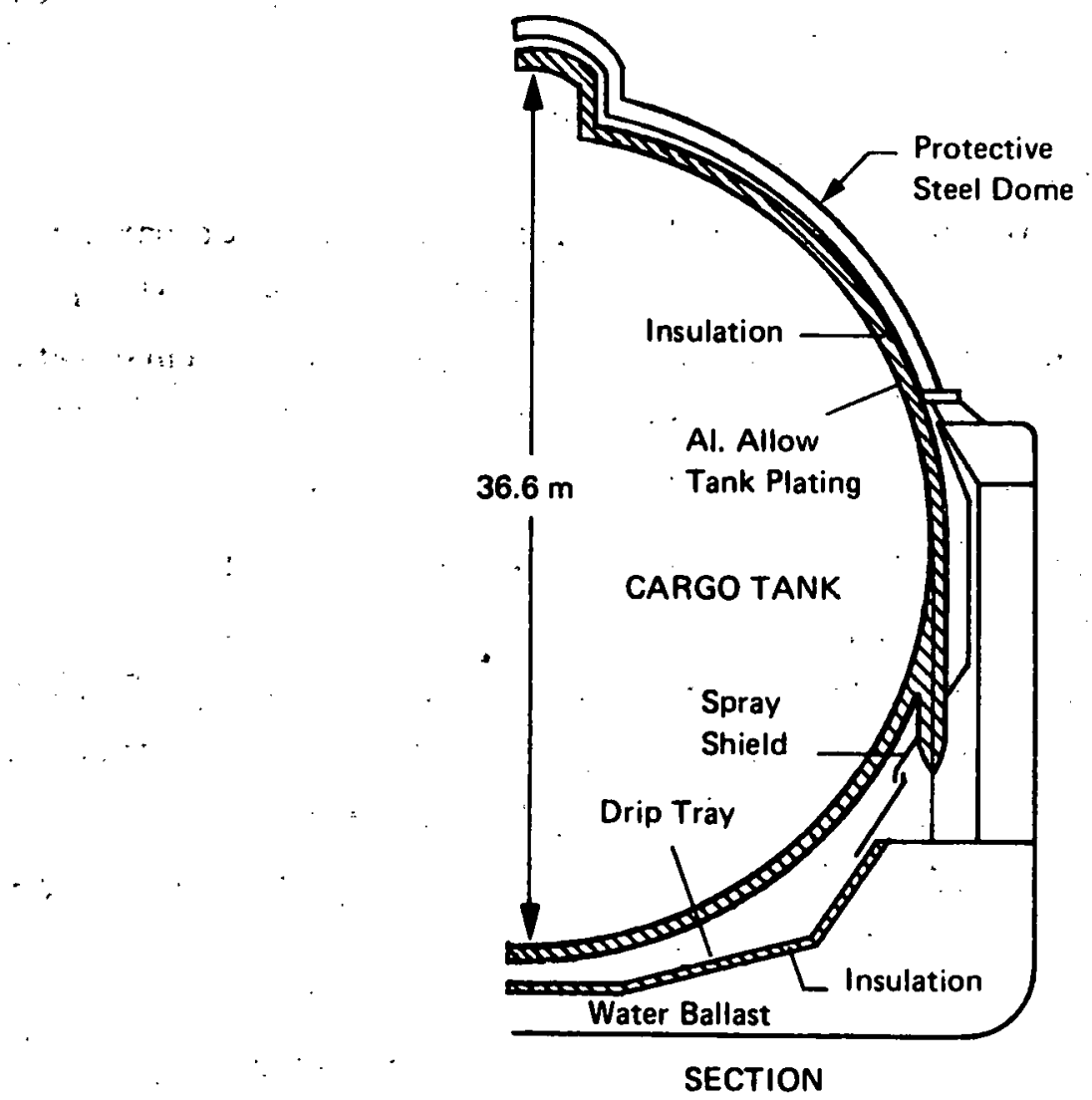

FIGURE 5.6 CROSS-SECTION THROUGH A SPHERICAL TANK

$5-10$ 


\subsubsection{Fire Protection System in an LNG Ship}

The fire protection system in an LNG ship is provided primarily to combat an on-board fire and is not intended to fight fires resulting from an accident caused by spills of large quantities of LNG onto water. The protection system consists of dry chemical agents and water deluge systems, and its design is guided by various code requirements.

Codes and standards which govern the fire protection of LNG ships include the Code of Federal Regulations, Title 46, 1974 (CFR); Rules for Building and Classifying Steel Vessels, American Bureau of Shipping, 1974 (ABS); the Tentative Guide for the Review of Liquefied Flammable Gas Carriers, U.S. Coast Guard, April 1971; the Code for the Construction and Equipment of Ships Carrying Liquefied Gases in Bulk, InterGovernmental Maritime Consultative Organization, 1976 (IMCO); and the rules developed by the International Convention for Safety of Life at Sea, 1960 (SOLAS-60) $^{*}$. These codes and standards include specific requirements for the dry chemical equipment and fire water systems - both the primary equipment required on LNG ships.

Dry chemical agents are typically used to fight electrical fires and small LNG fires that may result from spills during transfer operations.' Their effectiveness depends on wind conditions and application rates. The location of the dry chemical agents is governed by the IMCO code that requires installation to "fight fires on the deck, in the cargo area, on the bow and stern cargo areas." The exact specifications are included in the code for quantities, discharge times, and methods of application.

Water (which cannot effectively extinguish large LNG fires) is used for cooling equipment that may be exposed to fires. Application of this cooling or fire water can be effected through water deluge systems or, manually, by hose lines. The IMCO guidelines recommend that a water spray system be installed to protect: -

(a) Exposed cargo tank domes and any exposed parts of cargo: tanks;

\footnotetext{
*University Engineers, Inc., "Fire Safety Aboard LNG Vessels," Report to the U.S. Coast Guard.
} 
(b) Exposed on-deck storage vessels used to hold flammable or toxic products;

(c) Cargo liquid and vapor discharge and loading manifolds, as well as the area of their control valves, and any other areas where essential control valves are situated; and

(d) Boundaries of superstructures, deck houses, and cargo control rooms facing the cargo areas.

The recommended water application rates for these four areas is at least $10 \mathrm{l} / \mathrm{m}^{2}$ per minute for horizontal projected surfaces and $4 \mathrm{l} / \mathrm{m}^{2}$ per minute for vertical surfaces. Further details pertaining to the installation of transfer lines, valves, nozzles, and pumps can be obtained from the codes. Water sprinkler systems are also generally provided in the living areas of the superstructure.

At present the effectiveness of on-board fire suppressing systems to combat large fires is uncertain. While the system is probably adequate for small fires, it would not be expected to provide enough protection against a massive fire, such as a pool fire on water caused by the spill of $25,000 \mathrm{~m}^{3}$ of LNG. In addition, the fire protection system on the ship would depend, to a large extent, on the availability of electrical power, but this power might not be avallable in a large fire situation. In a collision elther, or both, water and dry chemical systems and associated controls could be damaged to the extent that they would be inoperable or, in some way, become inadequate.

\subsubsection{Characteristics and Susceptibility of Materials to Fire}

\subsubsection{Equipment Overview}

Most of the structural materials on an LNG ship are made of steel. The cargo tanks are generally made of stainless-steel or aluminum. The cargo insulation on many ships will burn, but it is generally protected by a steel covering which must be damaged before the insulation will gain access to air (and thus be ignited by an external fire). In general, there are no flammable materials present on the deck on an 
LNG ship, except for minor items such as rope, lubricating oil, 11feboats, and paint. The bridge is constructed entirely of steel and all interconnecting doors, and much of the furniture and the walls are also made of steel. The only flammable materials within the "hotel" would be wooden furniture, wooden veneer on the walls, linen, and carpets. The living quarters are protected by sprinkler systems and other firefighting equipment used to smother any small-scale fires. The "fire load" provided by the flammable materials in the "hotel" is very small, and would not be expected to influence the fire threat to the ship significantly.

The steel hull and deck plates are about $2.5 \mathrm{~cm}$ ( 1 in.) thick. These plates are backed by stiffeners (angle beams) in two normal directions and are also stiffened by bulkheads. The significant heat-transfer characteristics of the steel plates, as well as other critical materials, are presented in Table 5.2. In general structural steel loses it strength (by a factor of 3) at about a temperature of $700 \mathrm{~K}^{*}$ In the case of constrained structures, such as hull plates and deck plates, heating by fire may result in substantial warping and buckling. It is not possible to state whether fracture of the plate would result. The effect of steel contacting cryogenic LNG may, in fact, be more serious, as this occurrence may result in brittle fracture of steel.

We were unable to determine whether any structures made of aluminum or its alloys are used in the construction of the superstructure of LNG ships. Because of the light weight, high durability, and low cost of structural aluminum (an alloy \#3003 containing 99\% aluminum and $1.0 \%$ manganese), it is concelvable that it may be used for such app11cations as room partitions, staircase steps, rallings, doors, etc. This alloy melts at about $810 \mathrm{~K}$. Aluminum reacts with oxygen at ordinary ambient temperatures, forming aluminum oxide which, under normal circumstances, protects the virgin metal from further oxidation. However, under a fire environment with direct flame impingement, aluminum (or its alloy) not only melts, but also burns, producing heat. At a temperature of $650 \mathrm{~K}$, the yield strength of the aluminum alloy decreases

\footnotetext{
*"Petroleum Refinery Piping," ASA B31.3-1966, American Standards

Code for Pressure Piping, published by ASME, NY, Table 302.2.1A, p.60.
} 
TABLE 5.2

Thermal Characteristics of Structural Materials and Insulation

\begin{tabular}{lccc}
$\begin{array}{c}\text { Thermal } \\
\text { Densithy } \\
\left(\mathrm{kg} / \mathrm{m}^{3}\right)\end{array}$ & $\begin{array}{c}\text { Conductivity } \\
(\mathrm{W} / \mathrm{mK})\end{array}$ & $\begin{array}{c}\text { Ignition } \\
\text { Temperature }\end{array}$ & $\begin{array}{c}\text { Heat of } \\
\text { Combustion } \\
(\mathrm{MJ} / \mathrm{kg})\end{array}$ \\
\hline
\end{tabular}

\section{INSULATION}

\begin{tabular}{|c|c|c|c|c|}
\hline $\begin{array}{l}\text { Balsa } \\
\text { Plywood } \\
\text { Polyurethane }\end{array}$ & $\begin{array}{r}- \\
288 \\
32\end{array}$ & $\begin{array}{l}\text { e } 303 \mathrm{~K}, 0.055^{(1)} \\
\text { Not Ava1lable (3) } \\
0.035-0.052\end{array}$ & $\begin{array}{l}\text { Not Avaj } 1 \text { able } \\
465-530(2) \\
590-650(2)\end{array}$ & $\begin{array}{l}19.8-23^{(2)} \\
19.8-25 \\
46.5\end{array}$ \\
\hline
\end{tabular}

(1) Brown and Marco (1958).

(2) Obtained in a private telephone conversation with Factory Mutual

(3) Research conducted at Arthur D. Little Research Corporation.

\begin{tabular}{cc} 
Thermal \\
Density & Conductivity \\
$\left(\mathrm{kg} / \mathrm{m}^{3}\right)$ & $(\mathrm{W} / \mathrm{mK})$ \\
\hline
\end{tabular}

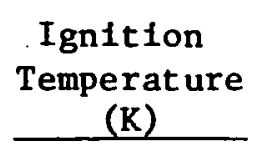

Heat of Combustion $(\mathrm{MJ} / \mathrm{kg})$

SHEET STEEL

Stee1, AISI $8025^{(1)}$

304 (sheet)

(1)

Baumeister (1967).
$16.3^{(1)}$
$1700^{(1)}$
Thermal Conductivity (W/mK)

$$
\begin{array}{r}
\text { Density } \\
\left(\mathrm{kg} / \mathrm{m}^{3}\right) \\
\hline
\end{array}
$$

ALUMINUM
Aluminum
(1) Eshback (1952).
${ }^{(2)}$ Hansen (1960).

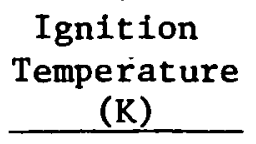

Heat of Combustion $(\mathrm{MJ} / \mathrm{kg})$ 
by a factor of about 3. The use of aluminum may, however, be restricted to non-load bearing structures.

\subsubsection{Fuel Oil and Propane}

Significant quantities of luel o1l are carried in LNG ships. This oil is used as standby fuel for primary power in the ships. The fuel oil tanks are located. in the bow of the ship under the storage area below the main deck. Because of the structural protection provided by deckplate and.huil, the hazard to the fuel ofl' in the tank by thermal radiation from an LNG fire is small. However, if the bow were damaged in a collision, the ofl might also be spilled and, in fact, might burn.

Several LNG ships (for example, the DESCARTES) carry propane in tanks on the deck, but these tanks are not large (typically $30 \mathrm{~m}^{3}$ ). The propane is used primarily to generate (by combustion) burnt products to be used for inerting insulation spaces. If this propane tank is exposed to an external fire, two phenomena may occur: (1) Initial heating may result in venting of the gas which itself may catch on fire; and (2) intense heating of the propane tank by fire engulfment may result in a bolling liquid expanding vapor explosion (BLEVE), resulting in severe damage to other structures. 


\subsection{HEAT TRANSFER FROM FIRE TO STRUCTURES}

When a fully laden LNG ship is involved in a collision accident, the LNG cargo may leak if one or more tanks is punctured. The rate and the quantity of the leak or sp111 w111 depend on the severity of the accident; that is, on the size of the hole and its location on the tank wall. However, if the tank is punctured at all, it is most probable that the hole will be of sufficient size for the contents to spill within a matter of minutes.

It is generally believed that there is a $90 \%$ probability that the spilled LNG will be ignited immediately, resulting in pool fire. If the fire is large, it can create potentially serious damage to the ship's structures and possibly to her hull and deck plates. In this section, we discuss the effects of fires on the ship's structures and Identify potentially serfous problems in terms of the survivability of the ship.

\subsubsection{Scenarios of Fires, Their Sizes, and Locations}

The size of the pool fire depends on the spill quantity and mode of spill (instantaneous, continuous). Table 5.3 shows the expected diameter, height, and duration of fire for several spill sizes and durations of spill considered in the analysis. Since it is difficult to predict the location of holes in the sh1p (caused by the accident), we have chosen two arbitrary collision impact locations and have assumed that LNG would leak from these positions. The assumed location of the leaks is shown in Figure 5.7 for a typical $125,000 \mathrm{~m}^{3}$ ship. These positions have been chosen so that the fire would have maximum thermal impact on the bridge and on the front of the ship.

It is very difficult to predict the exact way in which spilled LNG will spread and burn. The spill may be deflected by the colliding ship, or carried away from the ship by surface water currents. It may also spread along the length of the sh1p if the surface current runs parallel with the ship's axis. In effect, the location of a fire and its base geometry depend on many factors; hence, a universal description of the pool fire cannot be made. To calculate the effects of fire on the ship's 
TABLE 5.3

Fire Size and Duration

\begin{tabular}{clccc}
$\begin{array}{c}\text { Spil1 } \\
\text { Size } \\
\left(\mathrm{m}^{3}\right)\end{array}$ & $\begin{array}{c}\text { Duration } \\
\text { of Spil1 } \\
(\mathrm{sec})\end{array}$ & $\begin{array}{c}\text { Maximum Fire } \\
\text { Diameter } \\
(\mathrm{m})\end{array}$ & $\begin{array}{c}\text { Fire } \\
\text { Height } \\
(\mathrm{m})\end{array}$ & $\begin{array}{c}\text { Duration } \\
\text { of Fire } \\
(\mathrm{sec})\end{array}$ \\
\hline 25,000 & Instantaneous & 760 & 863 & 218 \\
25,000 & 180 & 525 & 667 & 180 \\
25,000 & 600 & 290 & 442 & 600 \\
10,000 & Instantaneous & 495 & 641 & 173 \\
10,000 & 180 & 330 & 483 & 180 \\
10,000 & 600 & 185 & 323 & 600 \\
1,000 & Instantaneous & 210 & 353 & 98 \\
1,000 & 180 & 105 & 218 & 180
\end{tabular}

* Total burning rate of LNG on water $=6.35 \times 10^{-4} \mathrm{~m} / \mathrm{sec}$ ** Fire height is determined by using Thomas' equation.

Source: Raj and Kale1kar (1974). 


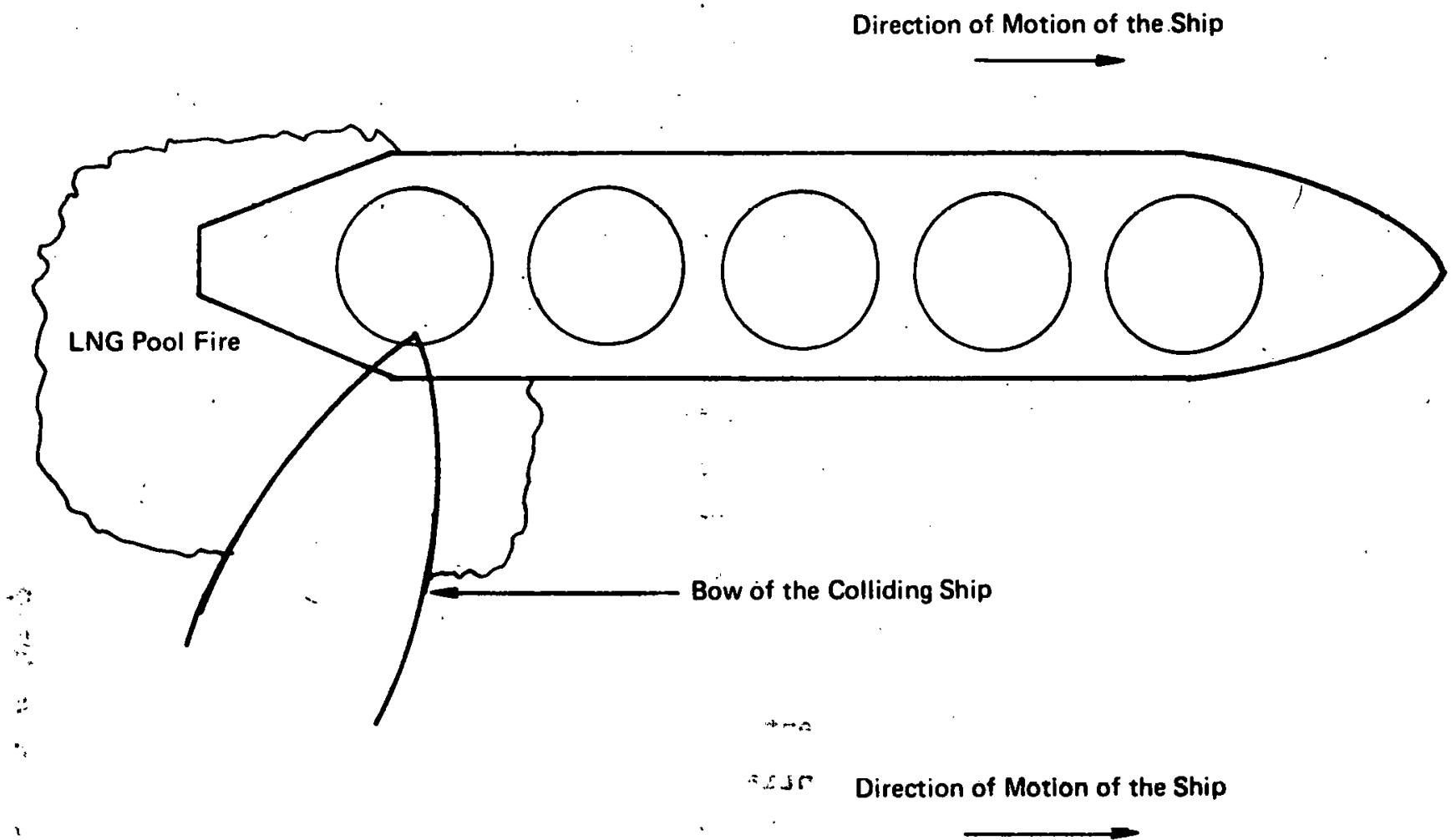

\section{SCENARIO 2}

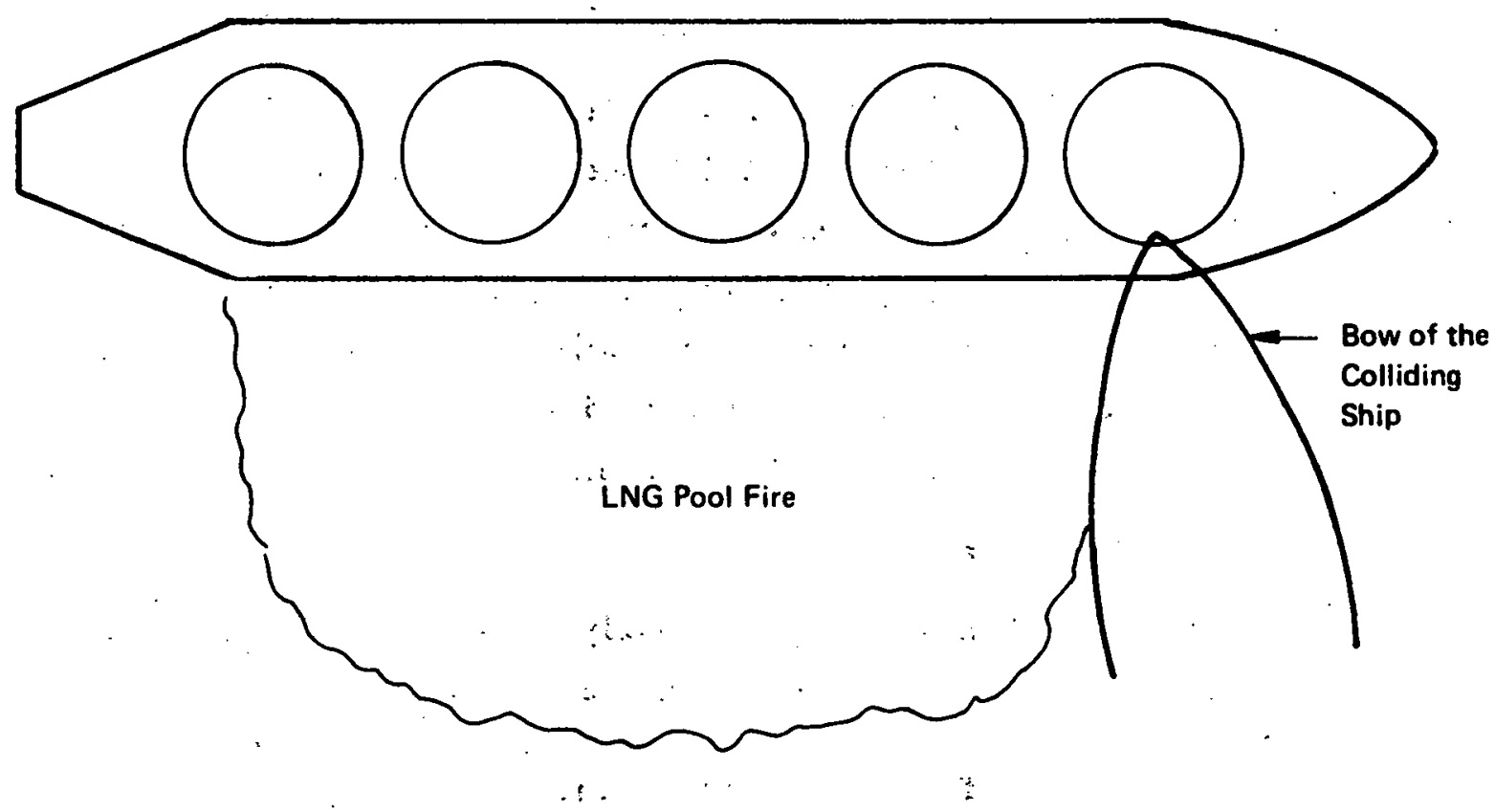

FIGURE 5.7 SCHEMATIC REPRESENTATION OF TWO POSSIBLE SPILL-FIRE SITUATIONS CAUSED BY SHIP COLLISIONS 
structures, we assumed that the fire base area would be the same as that which results when the liquid spreads radially and unhindered on a calm ocean. However, to be conservative, we assumed that the LNG pool was touching the hull of the ship. The results of thermal calculations and analyses of the effects of fire on varfous structures are-discussed below.

\subsubsection{Heat Transfer to Various Components and Their Temperature History}

\subsubsection{Hull Plate}

The structure that vill be very close to an LNG pool fire is the hull plate of the ship on the side of the spill. The length of a 125,000 $\mathrm{in}^{3}$ class sh1p ranges between 285 in (free-standing spherical tank -.G.D. type) and $260 \mathrm{~m}$ (double hul.1 - Technigaz, type). The approximate diameter of the pool of LNG (Table 5.3) for sp111s of $10,000 \mathrm{~m}^{3}$ is of the order or magnitude of the ship's length. Should a pool fire occur notwithstanding the possible movement of the ship after the collision and spill - this implies that a substantial part of the hull would be exposed to the fire. Exception to this scenario might occur if the tank nearest to the bridge were punctured, and if during the spiling of LNG, the tanker moved a significant distance. *

The calculations of Appendix $C$ indicate that the hull of an LNG ship exposed to a fire for 500 to 600 seconds could possibly sustain severe structural damage. Our calculations do not include the possibility of plate buckling or failure. - If fallure due to thermal stresses, metal softening, or some other causes should occur, the ballast area between the inner and outer hull could likely become flooded with sea water: The consequences of such a scenario have not been investigated.

\subsubsection{Deck P1ate}

The decks of an LNG ship are usually made of about $2.5 \mathrm{~cm}$ ( 1 in.) thick steel plates anchored to the hull of the ship and to the tank

* At $4 \mathrm{~m} / \mathrm{sec}$ speed of the ship and assuming a 10-minute spill, the ship would move about. 2400 m. 
structure. An external LNG fire on water could heat up the plate, either by direct impingement of the fire on the plate or by the radiated heat from the fire. The former scenario is more detrimental because of the very high heating rates. The flame sizes (heights) estimated in Table 5. 3 indicate that in almost all cases, they are larger than the freeboard - the distance between the deck and the waterline (generally about $15 \mathrm{~m}$ ). Because of this relatively low freeboard height compared to the heights of the fire, relatively low winds across the bow could deflect the fire, resulting in flame impingement of the deck plate as well as heating of the outer covering of the LNG tank. Since the construction of the deck plate is similar to that of the hull plate, with stiffeners and cross mombers used, the results indicated in Appendix $C$ are also applicable to deck plate. The conclusion from such a calculation is that direct flame impingement exposure of deck plate to an LNG fire for a period longer than 10 minutes could result in serious structural damage, buckling, or both.

\subsubsection{Outer Structure of.LNG Tank}

The two general types of LNG tanks have already been described. Both types of tanks protrude above the deck level. The part of the tanks that protrudes above the deck is covered by a steel barrier which protects the tank insulation from the destructive effects of the weather. The thickness of the protective shield may be less than that of the deck. We have assumed a thickness of $1.25 \mathrm{~cm}(0.5 \mathrm{in.})$.

There are two fire scenarios in which the outer structure of tanks may be impacted. The first is an LNG pool fire on the water with the flames impinging on the part of the tanks that protrudes above the deck plate. The second scenario is a fire on a neighboring tank. Such a fire was observed in the case of the YOYU MARU. *

Calculations have been made (Appendix D) to determine the effect of exposure of the protective dome of the tanks to a fire. To be on the conservative side, we assumed direct flame impingement (and hence maximum

\footnotetext{
*

"Report on the Collision between Japanese Tanker YOYU MARU No. 10 and Liberian Freighter PACIFIC ARIES (November 1974)," Japanese Maritime Safety Agency, Proceedings of the Atlantic International Air and Surface Search and Rescue Seminar (April 1975), pp. 116-119.
} 
rate of heat transfer). We estimated that, under these circumstances, the protective cover would probably fall in about 3 to 4 minutes. We were unable to determine whether this failure would be in the form of buckling of the steel plates or a collapse of the structure, exposing the lank insulation to the fire. Under less severe conditions of fire on a neighboring tank and heating of the protective steel shroud by thermal radiation from the fire, the protective cover would last considerably longer and, in fact, might not attain the fallure temperature of $700 \mathrm{~K}$. (This is because the conductive and convective transfer of heat from a localized hot spot would probably be significant.) The fire on the YOYU MARU reportedly raged for two days without any apparent damage to the outer structure of tanks that were not damaged by the collision.

The fallure of the protective steel cover would expose the LNG tank insulation to the fire (or to the thermal radiation). Depending on the extent of damage to the outer cover, several events could occur. If a major part of the protective cover were destroyed, exposing substantial areas of the insulation to the fire, it is concelvable that the insulation itself would burn. " In addition to the rapid depletion of insulation, the effect of this fire would be to transfer heat to the LNG, resulting in rapid boil-off and consequent venting of vapors. These vapors, in turn, would likely lgnite and result in a vent fire.

In Appendix E, calculations of the thermal response of the insulation (on the spherical tanks) to an external fire engulfing the insulation are presented. The conclusion from the very conservative calculation is that the insulation of the tanks will burn off in about 2 minutes after the outer, protective shroud is lost. This calculation was made on the assumption that the nitrogen in the space between the protective shield and the tank would be 1ost. Realistically, because of the diffusion times necessary for air to occupy. the nitrogren space, the damage

In the case of General Dynamic-designed ships, the Insulation consists primarily of closed-cell polyurethane panels; in the case of membrane-type tanks, the Insulation contains mineral wool and balsa wood. 
to the insulation would take appreciably longer than the 2 minutes estimated.

\subsubsection{Piping and Machinery on Deck}

On the main deck, extensive exposure to direct flame impingement would result in significant damage to machinery, such as mooring winches and lifeboat davits. It is not possible to estimate, with any degree of certainty, the thermal response of the machinery to a fire. Lubricating oils would vaporize, and the differential thermal expansion might result in broken bearings, twisted metal, and inoperable machines. However, these would not incapacitate the ship, but might result in difficulties in anchoring or mooring.

The deck also has extensive piping for interconnecting tanks, headers for transferring LNG to the articulated loading arms, vapor return lines, fuel oil lines, and others. A major fire might destroy some of the piping insulation and possibly cause bending or mechanical failure of piping.

Another 1mportant structure on the deck - the cargo control room would, in a11 probability, be severely damaged by a large LNG pool fire. The cables and the sensitive control equipment might be damaged, and, In addition, the compressors and gassifiers could be made Inoperable.

Large, short-duration fires on the deck might result in continuing fires in the store rooms that are commonly located in the bow area (foc'sle) for stores such as paints and cordage. These store rooms are, however, fitted with steam or $\mathrm{CO}_{2}$ smothering systems.

\subsubsection{Superstructure (Bridge)}

The superstructure (hotel) contains the crew accomodations and the bridge and is almost entirely constructed of steel. The bridge forms the nerve center of the ship, and contains all of the control equipment for navigating the ship and performing other vital functions. Thus, it is the most sensitive area of the ship.

Depending on the size and location of the LNG fire, two possible effects on the bridge and superstructure can be expected. If the rate 
of spill of the LNG is low (resulting in a relatively small pool fire) and the spill is near the bow, then the principal hazard to personnel and equipment in the bridge would be from the thermal radiation of the fire. Under these circumstances, the bridge and superstructure could be adequacely protected by the water curtaln provided in front of the bridge (currently regulations require the provision of water spray on the front of the superstructure). If, on the other hand, the pool fire is very large and very close to the bridge (see Figure 5.7), heat would be transferred to the bridge structure by both radiation and convection. * The plate glass windshield on the bridge would crack in a very short time, admitting the hot (combustion) gases into the bridge control room. Also the control room would be subjected to thermal radiation from the fire. The combined result of convective and radiative transfer of heat from the fire might be the destruction of sensitive control eqipment, burning of cable insulation, and injury or fatality to bridge personnel. The effectiveness of water spray in preventing damage to the bridge under the conditions of a massive fire (which may envelop the superstructure) is uncertain at best. Because of the requirement of an essentialiy 350-degree view from the bridge and because the bridge, of necessity, contains large plate glass windows, it may. be impossible to protect the bridge from damage from a very large LNG poo1 fire.

In the event that the bridge is incapacitated by the fire, however, several alternatives are available to maintain limited operations of the ship. Steering can be performed from an after-steering station or from an emergency steering station in the steering engine room; the main propulsion plant can be operated from the engine control room within the engineering space section of the hull. Loss of internal communications and loss of central control would limit severely the capabilities of the ship.

* The bridge is about $30 \mathrm{~m}$ above the waterline in the $125,000 \mathrm{~m}^{3}$ class ships. The flames are expected to be significantly higher than $30 \mathrm{~m}$. 
The living areas in the superstructure are less prone to direct damage from an external fire because they are made of steel and also because they are located in the interfor of the superstructure. However, it is possible that the glass on the port hole windows (on the side of the ship where the fire is burning) would break due to heat from the flames, admitting combustion products into the living areas. Also the loss of electrical power caused by the burning of cables, short circuits, or deliberate shutoff could result in a shutdown of ventilation and alr conditioning systems. This may, in itself, lead to injury to people in the living quarters - elther from the rapid increase in the ambient temperature of from toxic fumes (from combustion products) or both. 


\subsection{CREW POSITIONS AND SURVIVABILITY}

\subsubsection{Crew Functions}

Manning of U.S. flagships is determined by the officer in Charge of Marine Inspection of the U.S. Coast Guard and is established in the Certificate of Inspection. The minimum requirement is established in view of the physical characteristics of the ship, but actual numbers result from agreements between the owner and unions. CFR 46, Chapter I, Part 157 of Subchapter P, concerns manning, and establishes the basis for use of three watches and an eight-hour day, which means that crew members may stand two four-hour watches per day or "four on and eight of $\mathrm{f}^{\prime \prime}$.

CFR 46, Chapter I, Subchapter D, "Tank Vessels," contains further pertinent requirements. Paragraph 35.10-1 concerns the assignment of crew members to specific stations and the maintenance of muster lists; Paragraph 25.20-20 concerns the Master's responsibility for maintianing a lookout at all times; Paragraph 25.25-20 specifies inspections required before transfer of cargo is permissible. Part 38 contalns further technical details applicable to LPG/LNG carriers.

CFR 33, Chapter I, Subchapter P, "Ports and Waterways Safety," contains the following pertinent spectfications:

Paragraph 164.11 - General responsibilities for navigation underway; 164.15 - Requirement to keep the engine room manned and to have personnel avallable for anchoring;

164.25 - Tests before entering port or getting underway, which include primary and secondary steering gear; internal control communications and control alarms; emergency generators; storage batteries for emergency light and power in propulsion and control spaces; main propulsion untts ahead and astern. 
Furthermore, the requirement for a lookout is specified in Rule 29 of the International Rules (33USC147a); Article 29 of the Inland Rules (33USC221); and Rule 29 of the Great Lakes Rules (33USC293).

\subsubsection{Typical Manning Positions when Underway}

On the bridge, when underway, the minimum personnel will include the officer of the Watch and a helmsman. During port entry, a quartermaster may also be present and a pilot. The Master will probably be on the Bridge at such a time.

At sea, the lookout may be shifted to a protected position (on the bridge or similar location), but during port entry he will be stationed in the bow. Visibility of the sea directly in front of the bow is impossible from the bridge, which, moreover, is some 700 or 800 feet from the bow. Particularly in congested port waters, when approaching terminals, or when being approached by pilot vessels or tugs, visual coverage of this area is essential.

In the constricted waters, such as during port entry, use of the ship's anchors would constitute an emergency option. For this purpose, the windlass is energized and manned. Once the anchor chains have been released from the stoppers applied at sea, manning may consist of one officer or petty officer and a windlass operator. Together with the lookout, this totals three persons on the foc'sle.

Other personnel above the main deck will include the cargo officer (usually one of the mates) and any assistants who may be preparing the above-decks cargo control room and compressor room for checkout and operation.

Random operations will also be performed by the Deck Department; e.g., organizing mooring lines, checking deck machinery, and rigging gangways and pilot ladders. Cargo personnel may be Involved in checking and preparing topside cargo piping for operation.

Even on fully automated ships, during the maneuvering involved in port entry the engine control room would be manned by the Engineering Watch officer and his assistant(s), whether the enginers are under 
bridge or local control. Intermittent checks and inspections may be made throughout the engineering spaces during this time. It is expected that no more than a total of three persons would occupy the engineering and control spaces under normal cunditions.

Off-duty, communications, and administrative personnel will be located in the various areas of the superstructure below the bridge in their respective accomodation spaces and work areas. Engineering personnel and this latter group will be situated in enclosed spaces dependent, nevertheless, upon a fresh air supply and upon protection from indirect or long-term thermal effects.

\subsubsection{Typical Manning Positions during Cargo Transfer}

The requirement for operating the cargo-transfer equipment, as well as the requirements for having the ship in readiness for immediate departure in the event of an emergency, governs the manning positions during the transfer period. Typical manning profiles during port entry and cargo tran'sfer are presented in Table 5.4.

The cargo control space will be occupied by the Cargo officer and his assistants and possibly by a Coast Guard observer. The engine control room will be in the charge of a watch Engineer who may have personnel periodically checking the fire room and the turbo-generators. The foc'sle will not be manned. The bridge does not have to be manned, but there will be a Watch Officer, in overall charge, either on the bridge or in its close vicinity. A gangway watch may be stationed in the vicinity of the head of the gangway to control access to and from the ship. Members of the deck force will periodically make the rounds of the main deck to check mooring lines and winches. Off-duty personnel will be concentrated in the accomodation superstructure, if remaining on board.

Even though the cargo-transfer operation concerns principally the Cargo Officer and the Engineering Department, the requirement - usually included in the Captain of the Port's regulations - concerning readiness for immediate departure from the pier necessitates that a complete bridge watch and deck watch be held on standby duty during this period. 
TABLE 5.4

Typical Manning of an LNG Ship During Port Entry and Cargo Transfer

$\begin{array}{ll}\text { Bridge } & 4 \\ & \text { Master } \\ & \text { Watch offic } \\ & \text { Helmsman } \\ & \text { Quartermast } \\ \text { Forecastle } & 3 \\ & \text { Lookout } \\ & \text { Boatswain } \\ & \text { AB }\end{array}$

Engine Control Room "2

Engineering Watch officer Fireman/watertender

1 Engineering Watch Officer Watch Officer Helmsman
$-$

(1)

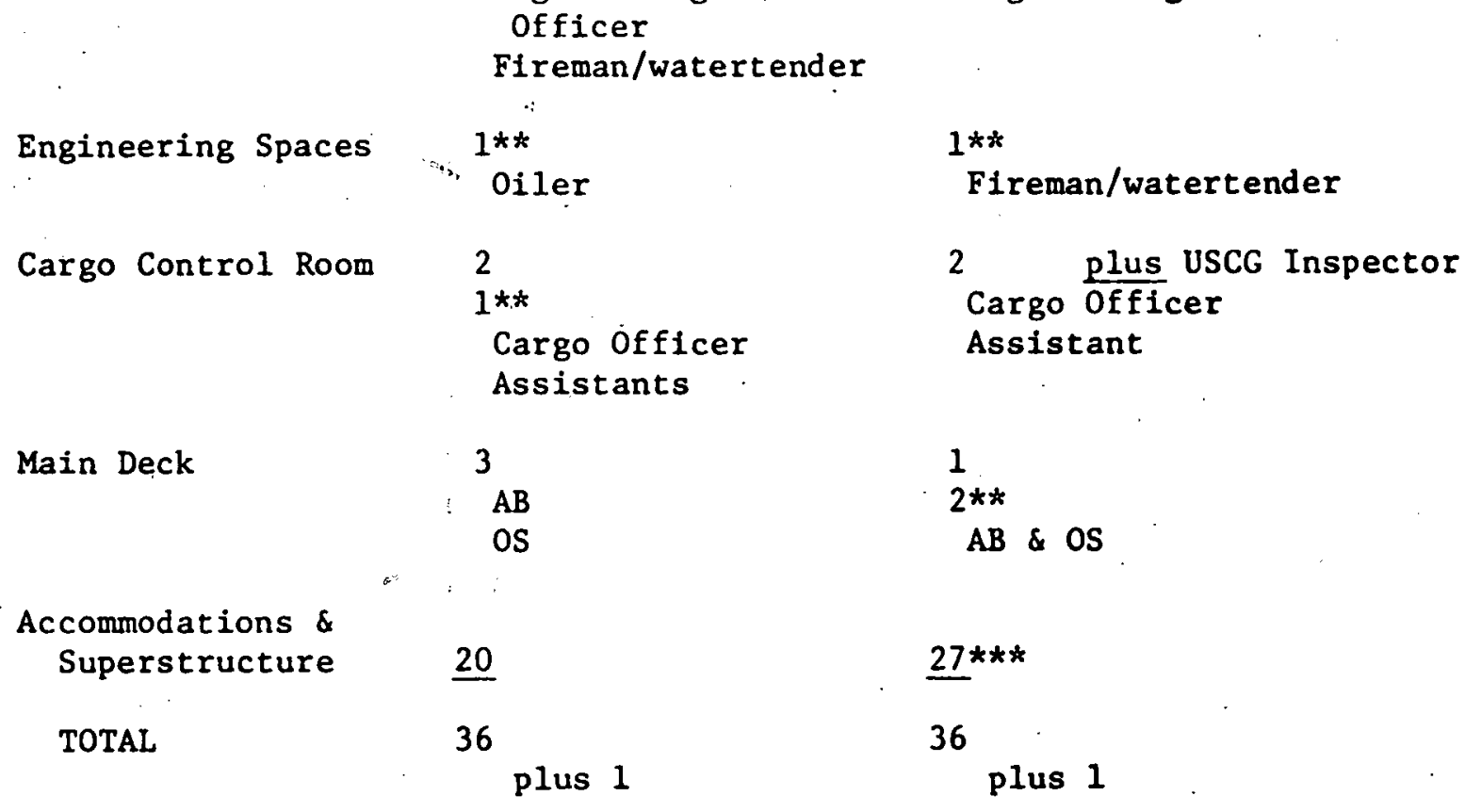

NOTE: * In the vicinity of and accessible to

** Intermittent

$\star \star \star$ Includes some crew possibly ashore 
This implies that they are not necessarily at their exact duty station for getting underway, but are somewhere in the vicinity and prepared to assume that station. The layout of the ship and the policies of the Master will affect the distribution of these personnel at any specific time.

\subsubsection{Fire Threat}

From the previous discussion of the heat transfer from large LNG spill fires to ship structures and the dimensions of fires as given in Table 5.3, it is evident that many of the crew may be exposed to the thermal effects of these large fires. Of particular importance to the crew is the time lag between occurrence of the Initial causalty and the ignition of the LNG. This cannot be predicted very well, even in statistical terms, at this time, but it may be small. An even shorter time, perhaps a few seconds, may occur between when the crew senses the magnitude of severity of the accident and when the thermal effects of the fire overwhelm them. It is these short-time intervals which strongly influence the alternatives of action open to an individual crew member, and the type of additional safety measures or devices which might be provided for his survival.

\subsubsection{Exposures and Access to Protective Enclosures}

The crew positions, which do not differ greatly between the port entry and cargo transfer activity, except in distribution of numbers, can be divided into the following principal areas:

- Bridge and accomodations, both in the superstructure, usually aft;

- Engine control room, within the engineering spaces;

- Cargo control room;

- Main deck; and

- Foc'sle.

Each of these areas or spaces is examined in terms of direct exposure to fire, radiation exposure, air supply, and access/egress in the following paragraphs. 


\subsubsection{Bridge}

Except for its height above the waterline, the bridge is exposed and vulnerable. Air is supplied to its ventilation system from intakes aft of the bridge itself. The only entrance or exit is into the lower levels of the superstructure. The visual requirements of the control functions normally carried out on the bridge are not compatible with the extensive protection which might be necessary to permit the space to survice a short-duration, high-intensity external fire. A separate ready-access protected space could be provided immediately below the bridge.

\subsubsection{Accommodations}

The accommodations consist of an internally insulated metal superstructure, the front of which is coverable by a water spray. Air is supplied by forced ventilation fans with intakes at a high level. There is access from the superstructure to the lower hull levels of the ship in the region of the engineering spaces - and to the main deck. The entire structure is of sufficient size that, even without an emergency air supply, personnel within the space could survice for an extended period, provided there is sufficient water spray to maintain a survivable temperature and provided the ventilation system can be shut down and sealed off immediately upon outbreak of an external fire. Ports and doors, likew1se, would have to be shut and sealed immediately to isolate the structure at all levels.

\subsubsection{Engine Control Room}

This cubicle usually is burled within the engineering spaces, is sound-proofed and air-conditioned, and has an overview of the main grating level. It is not directly exposed to external ship fires. It may have a separate access from the main engineering spaces, but usually has a communication opening with the latter. The room may contain several people at any one time and is dependent upon a continuous fresh air supply, without which temperatures would build up rapidly, even under normal operating conditions. If an emergency air supply 
were provided, the space could form a satisfactory temporary shelter for engineering personnel at or close to their normal station, even though there were severe temperature increases in the engineering spaces.

\subsubsection{Engineering Spaces}

The engineering spaces are generally not subdivided and contain the boilers, main engines, auxiliaries, turbo-generators, and work/ storage spaces. The space is fed by a forced ventilation system, while the boiler air is derived from a separate system. Fore and aft areas are usually blocked by bulkheads and the principal entrance/exit route is vertical into the superstructure. The engineering space, when 10cated in the stern of the ship, may be in a single-hulled portion of the vessel and would be uninsulated. Some heat transfer through the shell might be expected in the event of a fire external and contiguous to the ship. Manning for limited short-term operation of these spaces would not be required, but it would be necessary to avoid the entrance of combustion gases. The spaces are large, volumetrically, and it is not considered feasible to cool them or provide them with an emergency air supply. The air intakes are usually located high up in the superstructure; automatic shutdown and the fitting of alternative intakes may be possible and would require further investigation. It should be noted that if boiler air is cut off, the ship would lose power within a very short period (both main propulsion and electrical), and emergency diesel generators may not start up in a severely contaminated atmosphere. Loss of power may subject the ship - and consequently its crew - to further hazard.

\subsubsection{Cargo Control Room}

On some ships, the cargo control room is located on the main deck and, hence, it is quite vulnerable both to direct flames and thermal radiation. Being relatively small in volume, it would require an emergency air supply, as well as additional thermal protection, to provide for survival. It could be protected by a water spray deluge system if operable after an accident had occurred. In most designs it is 
reached via the main deck. Being in the proximity of the topside cargo piping and the main transfer headers, it is expected that any personnel in the space would not be able to leave it, once a casualty and a large conflagration had occurred; therefore, if it is to provide protection from a massive fire, it would require both an exceptional thermal barrier and an emergency air supply.

\subsubsection{Main Deck}

The weather deck is completely exposed. Personnel on deck at the outset of a casualty could either make their way aft into the superstructure or forward into the lower foc'sle levels. But it is questionable whether there would be sufficient time for such actions. It is possible, for example, for a crew member to be working at a distance of 300 or 400 feet from the closest protective closure on the main deck level. Generally, there is no access amidships to safer areas below; however, protection might be provided by installing shelters at intermediate locations on the weather deck. Fireproof, jettisonable floating capsules, such as those fitted on some offshore platforms, may represent another approach. In efther case, an emergency air supply and very efficient thermal protection would be required.

\subsubsection{Foc'sle}

Although the foc'sle is most vulnerable in the event of a collision or ramming, it has several advantages over the main deck. Underway it is upwind, and therefore in the event of a fire remains clear longer. Second, it is further removed from the cargo system on deck, and, third It has habitable spaces below the main deck. A personnel refuge may be considered for this area; however, there 1s the option of furnishing means of quick access to protected regions below deck.

\section{4 .6 Summary}

None of the ship's critical operating positions are fully protected from the effects of the postulated fire. However, the installation of special protective systems and possibly restricting crew exposure, particularly during more vulnerable phases of transit (e.g., during 
port entry and unloading operations) offer the opportunity of reducing the number and severity of injuries significantly during an unlikely, but possible, large spill accident. Thermal protection may also be considered for vulnerable ship components such as cargo tank covers, transfer lines, valves, controls, and electrical systems to avold further escalation of the fire and to enhance later salvage and disposal procedures and actions. 


\subsection{CREW PROTECTION FROM FIRE}

Methods of protecting crew members from a large spill fire are presented in the following sections. In discussing these concepts, we have selected an interval of one hour as that needed for protecting the crew on the basis that fires lasting longer than this period of time are expected to be small and exposure at deck level and above would be minimal.

\section{$\underline{5.5 .1}$ Air Systems}

Since a fire from a major spill can envelop large sections of the ship, there is a reasonable probability that hot gases and flames would enter air intakes and other openings within ship enclosures. The entry of the hot inert gases into the combustion air systems could cause shutdown of the power plant due to oxygen starvation. In addition, back-up diesel generators might not function, for the same reason. The accompanying loss of electrical power would, in turn, render water deluge systems inactive. The entry of hot gases from the LNG fire into living spaces might also cause asphyxiation of the occupants.

To prevent damage to equipment and injury to the crew, therefore, would require a facility be provided for quickly (and perhaps automatically) closing all air-intake ducts, shutting down the main power plant, and providing standby temporary air for breathing within protected spaces. Provision for a back-up power generating system would also ald in maintaining the function of fire protection systems, controls, and communications. Options include batteries, redundant intake systems that would allow the selection of those intakes not exposed to the hot gases, or an on-board emergency reservoir of air.

The normal air consumption rate of an adult is about $6 \mathrm{l} / \mathrm{min}$, increasing to $250 \mathrm{l} / \mathrm{min}$ under severe stress and physical exertion. Emergency air then would be needed for each crew member at this rate over a period of about one hour.

\subsubsection{Thermal Protection Shelters}

Where existing enclosures are remote from crew positions or inadequate in themselves for serving as protective shelters, special 
thermally protected structures or enclosures appropriately located on or within the ship may be needed. Enclosures of this type are being considered, for example, as a means of protecting crews on offshore ofl plat forms.

The basic requirements that would have to be met for shelters of this kind are that the shelters be:

- Accessible (i.e. near) to the crew which they are to serve;

- Equipped with self-contained breathing apparatus or an emergency air supply for the room;

- Capable of being sealed against entry of hot gases from the LNG fire and from the decomposition of the shelter's insulation;

- Fitted with means of. communication to other refuge areas aboard ship and to rescue craft external to the ship; and

- Designed to provide tolerable temperatures within the shelter of about $310 \mathrm{~K}$ (100 F [124 C]) for at least one hour of exposure to an LNG fire.

Potential shelter locations include the following:

- Either on, or one deck below, the bridge and readily accessible to bridge personnel. This shelter would have to be large enough to accomodate four to six people. One might contemplate protecting the bridge itself, using thermal shields or shades that could be lowered or ralsed to cover windows. It may not be feasible, however, to design and construct such a system that would function satisfactorily under the very severe thermal environment that may be present.

- Engineering spaces and the engineering control room. Since these areas recelve considerable protection from the ship itself, the thermal barrier requirements may be minimal.

- Cargo transfer control room. If this is located above the main deck, consideration may be given to either protecting the entire room or providing a sheiter within it. 
- Foc'sle area. Crew members (approximately three) during port entry are particularly vulnerable in the foc'sle area, since they will be out on the open deck. An emergency shelter might either be located on deck or just below it, depending upon available space and the needs for accessibility. If the shelter were placed on deck and designed with windows so that the crew could perform its lookout function, then they would already be partially protected if an accident should occur. This, of course, would require that thermal shades be provided which could be drawn over the windows quite quickly. Again the design of such a system might be beyond the current state-of-the-art.

\subsubsection{Thermal Construction Features of Protective Shelters}

The requirement that the inside temperature of the room not exceed $310 \mathrm{~K}$ during one hour of exposure of the room to an LNG fire imposes severe demands on the thermal insulation. In fact, we are not aware of any standard or conventional insulation systems that would meet these requirements, at least within a reasonable weight and volume. Consider for example, the two commonly used thermal insulating materials; namely, polyurethene foam and fiberglass. Polyurethene burns when exposed to the fire. It is shown in Appedix $D$ that a $0.3 \mathrm{~m}$ ( $1 \mathrm{ft}$ ) thick polyurethene insulation will burn up in about 2 to 3 minutes. If the insulation is protected from fire by say a metal layer on the fire side, it is expected that in a duration of time of about 3 to 5 minutes full temperature gradient will be established in the insulation leading to significant heat fluxes into the room. * While water fackets can be provided to minimize the rate of heat flux into the room, the possibility that insulation can catch on fire should preclude the use of polyurethene insulation. Thermal transmission calculations performed assuming a $0.15 \mathrm{~m}$ thick (6:) fiberglass insulation cover for the room also indicate that the room air temperature can increase significantly in about 6 to 10 minutes. In addition, the mechanical integrity of * Estimated heat flux into the room $=160 \mathrm{w} / \mathrm{m}^{2}$. If this heat flux comes only from one side wall $(4 \mathrm{~m} \times 4 \mathrm{~m}$ ) in a typical room ( $4 \mathrm{~m} \times$ $4 \mathrm{~m} \times 4 \mathrm{~m}$ ), the air temperature will increase by $20^{\circ} \mathrm{C}$ in about 10 minutes. 
fiberglass at flame temperature is questionable. Glass fibers soften at about $1100 \mathrm{~K}$ and melt at $1350 \mathrm{~K}$ (flame temperature $1500-1700 \mathrm{~K}$ ). Therefore, if fiberglass insulation is used, there is a potential for the mechanical loss of the insulation and hence the loss of protection.

The required insulation characteristics should be high mechanical integrity in fire situations, low thermal conductivity and non-flammability. In addition, the insulating material(s) used should be able to weather, without thermal and mechanical property deterioration when exposed to severe sea conditions. Finally, the physical thickness and weight of the insulation should not be excessive. These requirements are met by intumescent, ablative types of insulation materials. Some of the commonly available mastic coatings for passive fire protection are reviewed in Appendix E.

The most promising wall construction for thermal protection seems to be a sandwich construction involving an intumescent, low thermal conductivity substance (such as CHARTECK), mineral wool Insulation and steel wool. A possible design is shown in Figure 5-8. It is similar to the design discussed in Appendix $E$. The surface temperature of the room side wall does not exceed $100^{\circ} \mathrm{F}(310 \mathrm{~K})$ when the outer wall is exposed to a fire even for 1 hour. * We foresee two problems in the design. First, it is not known whether the intumescent material (CHARTECK) gives off toxic fumes when heated. Even though the temperature at which the material intumesces is $500 \mathrm{~K}$ and this temperature is not attained within 1 hour on the in-room side intumescent material, It is not certain whether small amounts of toxic gases are liberated even at low temperatures. Secondly, because of the closed room condition being different than that investigated in the small scale experiment, the air inside may get hot resulting in a temperature greațer than $100^{\circ} \mathrm{F}$ in less than one hour. Both these aspects need further experimental investigation. However, by adding a water jacket

\footnotetext{
* These are based on sma11-scale test results of exposing panels to furnaces and fires with the colder face cooled by natural convection in an infinite medium. However, when all of the walls of a completely enclosed room are exposed to the fire, the internal air temperature may rise somewhat more rapidly than indicated by above small-scale experiments.
} 


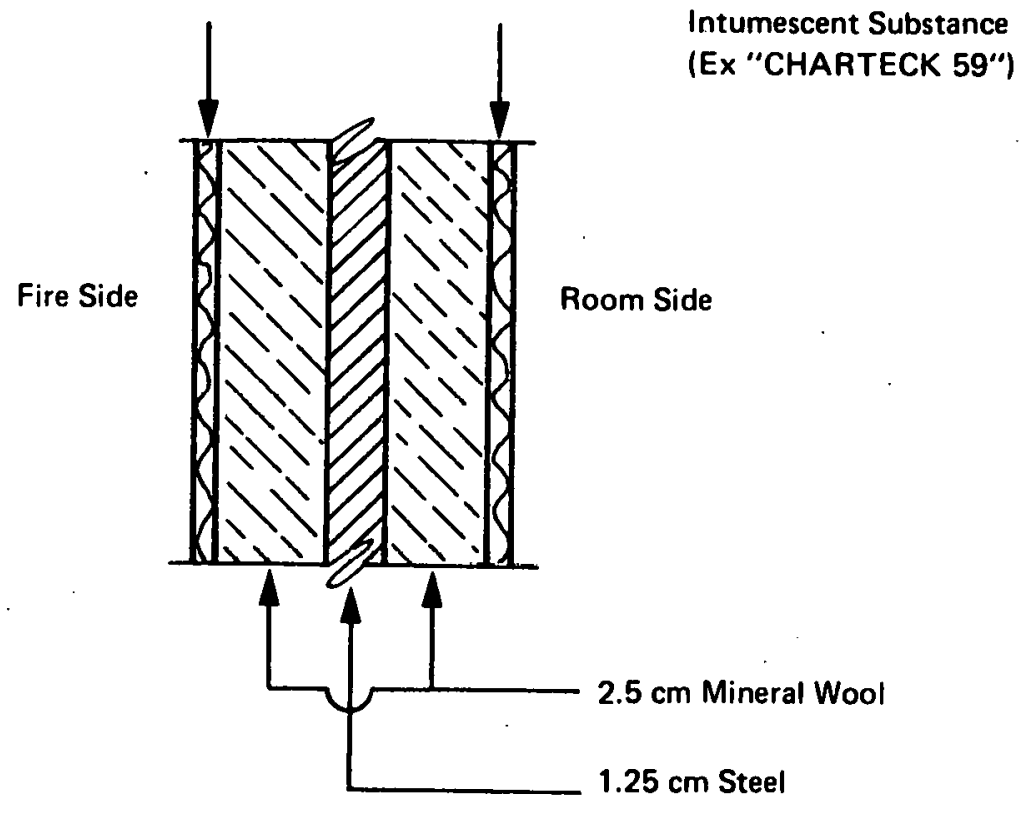
FIGURE 5.8 POSSIBLE ARRANGEMENT OF INSULATION ON THE WALLS
OF THE THERMAL ISOLATION ROOM

0
$\vdots$
$\vdots$
$\vdots$
$\vdots$
$\vdots$
$\vdots$
$\vdots$

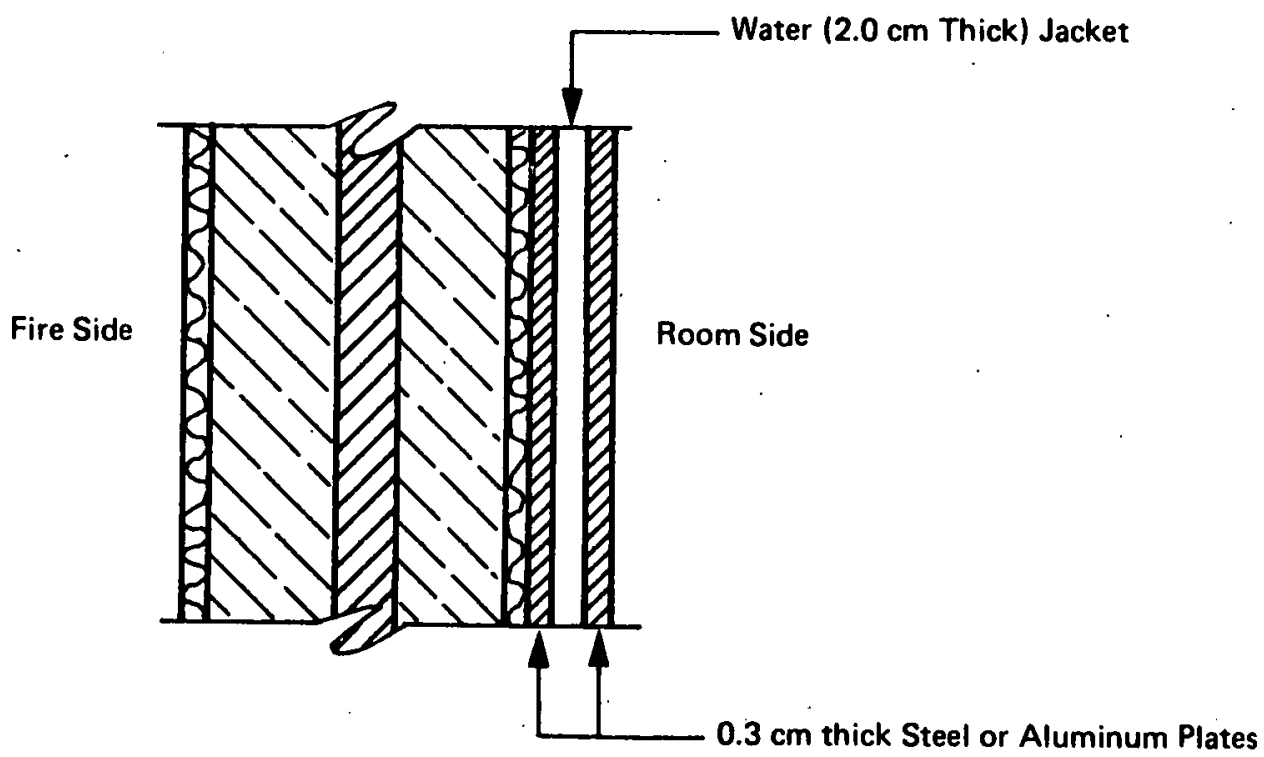

FIGURE 5.9 ADDITIONAL PROTECTION WITH WATER JACKET ON COLD SIDE 
of about $2 \mathrm{~cm}$ thick on the room side as shown in Figure 5.9, the temperature environment as well as the quality of the air, can be maintained within required limits for one hour. In this case the water temperature may increase by about $15 \mathrm{~K}$ in one hour.

The cotal area density of materials (mineral wool and CHARTECK) for the design indicated in Figure 5-8 is about $61 \mathrm{~N} / \mathrm{m}^{2}\left(4.21 \mathrm{~b} / \mathrm{ft}^{2}\right)$ and with the water jacket indicated in Figure 5.9, the density is about $550 \mathrm{~N} / \mathrm{m}^{2}$. The allowable weight per unit area on horizontal roof steel is about $6500 \mathrm{~N} / \mathrm{m}$ (taking into account the reduction in yield strength of steel by a factor of 3 due to possible elevated temperature - $700 \mathrm{~K}$ ). Therefore, structurally the insulation and the water jacket do not add a significant load to the walls of the room.

\subsubsection{Crew Motivation and Training}

The concept of a fully isolated and thermally protected refuge is feasible from a technological standpoint; however, consideration must also be given to the crew's attitude toward the refuge system, particularly their motivation to use it properly during an emergency. If the crew cannot be relied upon to utilize the facllity so that they would remove themselves from danger, then the potential of the shelters would be significantly degraded.

Courses of action that the crew might take, if not adequately motivated and trained, include taking an excessive amount of time in seeking shelter and in securing themselves within it, selecting more hazardous alternatives, such as jumping overboard or opening up the enclosure prematurely. We believe that the success of shelters, if they are to be provided, will be highly dependent upon how well human needs and reactions are integrated with the design of the shelters, on adequate training, and on equipping the shelter with a means for the crew to obtain information and communicate. The latter might include, for example, means for monitoring the status of the fire, the ship, and the shelter itself. In addition, the ability to communicate with other shelters and rescue personnel external to the ship would be important. 


\subsubsection{Other Crew Protection/Escape Systems}

In this study we have also identified other approaches to protecting the crews of an LNG vessel from a massive LNG fire. None of them appears to be as effective or as feasible as the thermal shelter approach. Other methods and problems assoclated with them include:

- Provision for escape capsules that might be launched either from the main deck or at lower levels. The development of such capsules that can be adequately launched, directed to a safe location, and which would provide the necessary thermal protection would require an Inordinate development expenditure and may be less rellable than fixed shelters.

- Protective clothing and personal breathing apparatus which would allow more time for crew members to seek shelter. We know of no protective clothing that would significantly increase the time that personnel could be exposed to the thermal effects of the fire without injury.

- Escape chutes that would allow crew members to enter the water safely at locations distant from the flame. Depending on the location of the fire and the crew, many of the ship's complement may not be able to reach the least exposed areas of the ship without suffering severe, if not fatal, burns.

- Water deluge systems that would protect existing enclosures as well as shelters so as to reduce the need for special insulations. These systems would be inactive during power outages and an, alternate system using pressurized reservoirs of water on the ship would occupy excessive space and be subject to fallure due to ship damage.

- One-man capsules or shelters located close to crew positions. The total volume or space required for many individual shelters would be much greater than that needed for a few shelters, each capable of holding several crew members. 


\subsection{THERMAL PROTECTION OF THE SHIP}

Although our attention has been focused on the protection of the crew from a massive fire in the unlikely event of a large accidental spill of LNG, measures may also be taken to protect components of the ship from thermal effects so as to deter the escalation of the fire, to enhance the management of the vessel once the fire has died down, and to make salvage or disposal of the cargo more tenable. The cost of these measures might be compensated, at least to some degree, by reducing the damage suffered by the ship.

The most critical components that might be protected include the cargo tank covers, cargo transfer 1ines, valves, controls, and electrical cabling. The protection of deck plates, the extertor of the superstructure, and other components might significantly increase the salvage value of the vessel, but might contribute only in a minor way to reducing the magnitude of the threat to the crew and the surroundings, or to inhibiting the response to the accident.

Insulation systems of the type described for personnel shelters could be constdered for tank covers and perhaps electrical cabling. The protection of cargo transfer lines and assoclated equipment might best be achieved by integrating both the cryogenic and the fire insulations. 


\subsection{CONCLUSIONS}

An LNG ship is constructed essentially of non-flammable materials, mainly steel. With the exception of exterior paint and possibly some minor items of limited quantity, there are no mafor flammable materials on the exterior of the ship. There are no flammable ttems or structures that would, on burning impair the ability of the ship to survive a major fire.

A Large LNG pool fire along side the ship w111 heat the hull plate, resulting in buckling, warping, or failure of the plate. The extent of failure has not been evaluated.

The steel shield protecting the cargo tanks may not withstand a direct impingement of fire (or thermal flux in excess of $100 \mathrm{~kW} / \mathrm{m}^{2}$ ) longer than, say, 2 or 3 minutes. Fallure of this shield might result in the deterioration of the tank insulation which could, in turn, lead to a high rate of venting of cargo. Vent gases would, in all probability, be ignited.

The extensive glass panels (windshield) on the bridge are liable to break when exposed to flames. The water curtain in front of the bridge may provide some initial protection if it remains operable. The fire may destroy the sensitive equipment and control panels on the bridge once the windows are destroyed.

The piping, deck machinery (windlasses, winches, davits, etc.), and safety equipment such as life boats, communications and navigation equipment (radio and radar antennas, lights, etc.), are likely to be destroyed by a fire which impacts the deck. However, the loss of any or all of these would not completely disable the ship.

The availability of primary electrical power on the ship after an accident resulting in a major LNG leak and ignition is uncertain at best. The boilers may be shut down and the back-up diesel generators may not be operable because of lack of oxygen (air). 
The crew could be protected against thermal effects from the fire by providing shelters at strategic places in or on the ship: These rooms would have to be unusually well-insulated to provide an . Inside theximal environment of less than $310 \mathrm{~K}\left(100^{\circ} \mathrm{F}\right)\left(122^{\circ} \mathrm{C}\right)$ for about one hour of exposure to fire. Ease of accessibility of these shelters will be critical to their success.

While the concept of completely isolated thermal shelters is technically feasible, its acceptance by the LNG ship crew would depend on crew motivation and confidence.

Thermal protection of critical ship components, such as cargo tank covers, cargo transfer equipment, and electrical cables, may decrease the overall hazards and, if combined with more extensively applied insulation, increase the salvage value of the ship. 


\subsection{CARGO DISPOSAL}

\subsection{BACKGROUND}

An additional factor in reducing the overall consequences of an LNG tanker accident is the emergency removal of cargo from the vessel when it is unable to unload at its designated receiving terminal, either because it is immobile or it is deemed to be unsafe to do so. It is most likely that in any LNG tanker accident - from the mildest fallure to the severest impact (e.g., a collision) - a major portion of the cargo will remain on board after the initial event has taken place. If, for some reason, the ship cannot then proceed to its unloading terminal, this large quantity of fuel may present some level of danger to populated areas, shipping, and to those charged with managing the damaged vessel. Emergency off-loading, if it can be conducted in a reasonably safe and timely manner, may very significantly reduce the overall risks presented by a disabled tanker.

Studies of potential collisions of LNG tankers with other ships have shown that only those LNG tanks that are in the direct path of the impacting ship may be damaged sufficiently to release their contents. Hence, only one or two tanks, at the most, out of the usual five for the large $125,000 \mathrm{~m}^{3}$ vessels might lose their contents under the most severe of credible events. Although there have been no such accidents with LNG vessels, a considerable number of examples of accidents involving other types of tankers do exist. The collision of an LPG carrier (Yuyo Maru) In Tokyo Bay resulted in the loss of its secondary cargo and a large fire. The LPG containers, however, retalned their integrity so that the disabled ship with its LPG cargo presented, at least, a large (percelved) threat to nearby populated areas. It took several days and created considerable anxiety before a successful solution was implemented (which, in this case, resulted in the destruction of the ship in a remote location). Oil tankers also typically retain much of their cargo after a major accident, as, for example, was the case with the Torrey Canyon and the Argo Merchant. In both instances, large quantitles of oil remained on board immediately after the inftial incident. If the cargo 
could have been transferred to another vessel at that t1me, extensive pollution of the sea could have been prevented.

To date there has been little or no analysis made, or at least available, in the literature of the salvage problem for LNG tankers. Analysis of the risks of tanker accldents has not been carried out in sufficient detail to provide an adequate base for designing or evaluating the cost/effectiveness of salvage concepts, nor have potential methods for salvage or disposal been delineated or evaluated. To our knowledge, little or no response planning dealing with LNG tanker accidents has been performed to date.

In this study a preliminary review is made of the conditions that might warrant salvage or disposal of the LNG cargo, potential salvage methods, and response planning. Emphasis is placed on salvage or disposal concepts. 


\subsection{CONDITIONS REQUIRING SALVAGE/DISPOSAL OF CARGO}

\subsubsection{General Considerations}

The events that might lead to the necessity of removing cargo from a disabled vessel are expected to be rare. Such events would require that a vessel present efther too great a hazard to be unloaded at its designated receiving terminal or, for some, reason (e.g.; too large a draft caused by flooding), that it actually be unable to proceed to the terminal on its own. They represent major system fallures for which unprecedented measures to mitigate against them have already been taken.

Nevertheless, accidents are possible and, given the potential threat of the cargo that may remain on a ship after an accident has occurred, it is only prudent to consider methods of eliminating the hazards presented by a damaged or disabled vessel.

A complete examination of the events that may result in a ship not being able to off-load at the receiving terminal and of the various conditions of the vessel that may influence emergency off-loading procedures would require a formalized fallure analysis in which such techniques as failure modes and effects analysis, fault trees, and event trees, would be utilized. Here, however, in this preliminary survey, only generic failure modes and primary effects of the failures are considered. This provides a base on which the essentlal needs of salvage or disposal systems may be considered, and on which preliminary emergency response plans may be developed. This study, however, does not provide information in sufficient detail to design these systems, nor to completely evaluate their cost/effectiveness.

\subsubsection{Primary Fa1lure Modes and Causes}

Primary failure modes which might individually or collectively create a hazardous situation in which salvage or disposal may have to be considered are presented in Table 6.1 and the principal causes of these fallures are 11sted in Tab.le 6.2. Attempts have been made to estimate the probability of occurrence of some or most of these causes 
Table 6.1

PRIMARY FAILURE MODES

\section{Control Failures}

Steering

Propulsion

Navigation

Ballasting

Cargo monitoring and transfer system.

\section{Electrical Power Fallures}

Electrical distribution fallure Alternator/generator fallure

\section{Propulsion Fallures}

Prime-mover failure'

Fuel deflciency

Drive train damage

\section{Crew Failures}

Absence

Incapacitation

\section{Containment Fallures}

Insulation fallure

Leak in primary barrier

Leak in primary and secondary barrlers

Leak in vapor transfer system

Catastrophic failure of one or more containers

\section{Vessel Structural Failure}

Damage of free-standing container supports

Perforation of two hulls wth flooding 
Table 6.2

\section{PRIMARY CAUSES}

Internal Abnormal Events

Operating/maintenance deficiencies

Equipment/materials deficiencies

Internally caused fires or explosions

Illness/injury to crew

Inadequate crew training and/or information

External Abnormal Events

Collision

Grounding

Ramming

Sabotage/vandalism

Aircraft/missile Impact

Other More Rare Events

Meteorite impact, tsunami, and tornado 
In risk studies conducted for specific import projects. In general, collisions present the greatest (although very sma11) risk of a major spill accident.

\subsubsection{The Need for Emergency off-loading}

of the various possible accidents, grounding and/or structural failure, are probably most likely to require emergency off-loading of cargo.

Past shipping experience shows that it is possible for an LNG tanker to $r$ un aground, although its occurrence might be quite rare due to the extra precautions taken by the operators, the high level of competence of the crew, improved navigation systems, and the extraordinary control exercised by the U.S. Coast Guard. Groundings might occur due to combinations of events such as the simultaneous loss of steering and propulsion controls, the occurrence of a severe wind storm and a propulsion fallure, and the fallure of navigation, along with severe maneuvers taken to avold' a collision.

Groundings unaccompanied by collisions, rammings, or other damaging events may, in the majority of instances merely require that the ship either by itself or with assistance be refloated, perhaps at the next or several high tides later. In some instances, however, the refloating of the vessel may be difficult and time-consuming. The benefits of off-loading some of the cargo to lighten, the vesse1, along with a real or perceived urgency to remove the potential threat of a spill may be sufficient to require some discharge of cargo within a relatively short-time after the incident.

If a major structural failure, accompanied by a massive spill of LNG, were to occur, as in a very exceptional collision, a large fire would most likely take place severely damaging and disabling the ship. LNG containers not in the direct path of the impact might maintain their integrity, and thus, very large quantities of LNG might remain on the damaged ship. Depending on the damage assessment made after the fire has been brought under control, a decision that it might be prudent to off-load the remaining cargo at a safe location might be made. 
Other less severe accidents might also necessitate off-loading. The structural damage of a ship in a grounding, ramming, or collistion, for example, could jeopardize the LNG container by weakening the supporting structure, the bolluin of a membrane, or some free-standing tanks, or even the spheres of the Kvaerner-Moss ships. Assessment of the damage might indicate that movement of the vessel to a pier or wharf at the receiving terminal might be too risky. Instead it may be decided that the cargo should be off-loaded at a remote and relatively safe location. A potential inability to assess damage adequately may also lead to the same decision.

Other structural damage might involve loss of insulation, failure of primary and secondary LNG containment barriers where damage assessment may be difficult, and fires or explosions aboard ship. In some of these instances, it may also be wise to off-load at a safe location.

A major failure at the recelving terminal during a ship-to-shore operation might, also, in some way damage the LNG vessel so that it would have to be removed to a safe location for cargo off-loading. 


\subsection{URGENCY OF OFF-LOADING}

As in most emergencies, the sooner the threat can be removed, the less the-risk. The emergency removal of cargo from an LNG vessel, however, will be time-consuming. It is more than likely that emergency off-loadings of entire cargo will greatly exceed the 10 hours or more that is required during normal ship-to-shore operations. Added to the time for transfer will be the movement of the ship to a safer location (if it is not grounded), the delivery of unloading equipment at the site, and the rigging of the equipment. Hence, it might take several days to unload cargo from a disabled ship.

If the off-loading is to be accomplished when the ship is grounded at a location near to a populated area, the urgency of the operation may be much greater. Given that such a condition is credible, there will be a major need to remove cargo as quickly as possible. Assuming current technological limitations, this might be of the order of a day or more.

Another case may involve a ship that is so badly damaged that it is deemed too risky to remove the remaining cargo. If such a case existed, the authority in charge might order that the ship be towed to sea and destroyed. This is a drastic measure, and it is conceivable that $1 t$ might be completely avoided if proper salvage and disposal plans and procedures are developed and made available prior to the incident. 


\subsection{SUMMARY OF OFF-LOADING REQUIREMENTS}

The results of this preliminary survey of the need to emergency

off-load cargo from an LNG tanker are presented in Table 6.3. The fallure modes listed serve as the basis for identifying and evaluating emergency off-loading systems and procedures. 
Table 6.3

\section{ACCIDENTS REQUIRING EMERGENCY LNG OFF-LOADING}

$\begin{array}{ccc} & \text { General Location } & \text { Earliest } \\ \text { Accident Type } & \text { at } & \text { off-Loading Need } \\ \text {-Off-Loading } & \text { after_Incident }\end{array}$

(1) Grounding

- Partial off-loading (no damage, but At site of grounding

$<$ day need to lighten.ship)

- Complete off-loading (ship damage

At site of grounding

$<$ day severe; too risky to move loaded ship)

(2) Structural Damage (complete of f-Loading).

- Severe damage, including a release of LNG

- LNG containment in jeopardy, but no spill

- LNG containment may be in jeopardy, but unable to assess damage

\section{(3) Receiving Terminal Failure}

- LNG tanker undamaged

- LNG tanker damaged
Remote area or at sea

Remote area or at sea

Remote area or at sea

$>$ day

$\because$ day

$>$ day

At a secondary receiving terminal

Several days

Remote area or at sea 


\subsection{SALVAGE AND DISPOSAL}

\section{5 .1 General}

Salvage or disposal of the cargo implies that it is removed from the ship under abnormal conditions and usually during an emergency. The conditions undei whlch salvage or disposal may be required can range from off-loading at a terminal when there is a major systems failure to the removal of cargo from a damaged immobile ship located near a populated area.

Major systems failures that might cause emergency conditions at terminal off-loadings include, for example, loss of ship power without provision for shoreside electrical connections, damaged transfer lines, and loss of transfer monitoring systems. Most of these problems and the hazards associated with them can be taken care of with adequate contingency planning and provision for equipment and skills necessary to solve them.

In this study we focussed on the more difficult problems associated with cargo disposal when the ship either cannot be berthed at a terminal, or it is deemed unsafe to do so. In addition, we considered generic problems common to the $125,000-\mathrm{m}^{3}$ vessels. Details of design and operational procedures were left for further study.

In this chapter, we consider the potential off-loading rates and their implications, existing methods of removing cargo, problems with getting LNG out of the shipborne containers and working with a disabled ship, and potential methods of cargo removal.

\section{$\underline{6.5 .2}$ Rate of Disposal}

Table 6.3 indicates that emergency off-loading times required to remove a perceived threat may vary from less than a day to perhaps scveral days, depending upon the type of accident and the resulting fallure modes. The shortest possible time, of course, is that determined by the pumping capacity of the on-board immersion pumps. The longest period of time 
required to implement off-loading procedures, and the overall emergency as determined by those in charge of salvage.

The rates of discharge and the hazards resulting from the release of the LNG at these rates for different total discharge times are presented In Table 2.1 of the Summary section of this report. These data provide an indication of the potentlal hazards from jetting liquid, venting vaporized cargo, and flaring, as well as from falled lines during emergency transfer.

\subsubsection{Removal of Cargo from Shipborne Containers}

\subsubsection{Pumping of Cargo}

Al1 shipborne LNG cargo tank systems use submerged cryogenic pumps for discharging LNG at the receiving terminal. The pumps are submerged so that a net positive suction head can be maintained. Since the LNG is contained at near atmospheric pressure, it is not possible to transfer the LNG with pumps located external to the tanks.

These electrically driven pumps constitute the sole method of emptying the tank. There are no bottom penetrations that would allow draining of the tanks by gravity, nor generally can the tanks be adequately pressurized to' force cargo out of the top discharge lines.

To drive the cargo from the tanks by gas pressure requires a pressure of about 0.195 psi per foot of tank height $(62.4 \times 0.45 / 144)$. Thus, a 90-foot-deep prismatic tank would require 17.55-psi plus the pressure to overcome friction and flow losses. A 120-foot-diameter sphere would require $23.4 \mathrm{psi}$ of pressure minimum. The spherical tanks might be stressed to this degree in case of emergency, but no other existing containment system can accept this type of loading. The safety valves are set at 3 -psi on at least some spherical tank systems. They cannot be reset remotely, and it may be very difficult, if not impossible, to set them at higher values under emergency conditions.

With a 3-psi permissible overpressure, LNG could be lifted about 15 feet above the liquid surface, which would allow very little of the 
LNG to be removed. Membrane designs may not withstand much more than this overpressure; however, the spherical tanks may be able to withstand much more. If the relief valves for spherical tanks were set at 10 psig, for example, some 50 feet of cargo depth could be removed, which is about 13 pcreent of the total tank depth and corresponds to about 45 percent of the cargo volume.

Partial emptying (or loading) of an LNG tank does not necessarily improve the safety of the situation. In fact, the membrane tanks must be operated under normal conditions within the under $5 \%$ or over $95 \%$ full range, due to problems stemming from sloshing loads in the intermediate range. The self-supporting tanks are less susceptible to the hazards of these dynamic loads; the spherical tanks present different geometries and may be operated in the $10 \%$ to $90 \%$ range.

The most difficult problem with achieving cargo discharge during an emergency may be the loss of power to the submerged pumps. Typically each tank on a $125,000-\mathrm{m}^{3}$ vessel has two $300-\mathrm{HP}$ submerged pumps. The power requirements, then, are relatively large and would require exceptional sources of power to supply the needed energy. Facility is provided in all ships for pump replacement.

\section{$\underline{6.5 .3 .2}$ Ship Transfer Lines}

In present ship designs, the discharge lines from the storage tanks are manifolded, and discharge is made at one or more flanges amidship. An articulated (e.g., CHIKSAN) system located on shore is connected to this flange at the time of off-loading. Some ships can off-load on either side while others are designed for connections to be made to only one side of the ship. Redundant shipborne transfer systems are not usually provided.

In an accident, the transfer 1ines, manifolds, valves, and/or controls may be damaged so that major components may have to be replaced before off-loading could proceed. Once this is done, then a system must be provided to transfer the LNG to another vessel or to a vent, flare, or combustion system external to the ship (that is, if the LNG is not to be jettisoned or efther vented or flared from the ship itself). 
Transfer from the ship during an emergency might be accomplished with flexible metallic hoses, articulated piping systems, or a combination of both. Ship-contained flexible metallic lines were employed for off-loading cargo from the LNG barge MASSACHUSETTS, while most ships use a shore-based articulated arm arrangement. The flexible hose offers the advantage of accommodating a variety of off-loading conditions, whereas use of the articulated rigid-pipe system is more 1imited. Because greater spans and vertical heights than are experienced in normal off-loadings most probably will be required, the design of either system would be expected to stretch the state-of-the-art and the actual devices would be very.costly. In addition, special handling and support systems (e.g., booms and cranes) on board the ship would also be necessary. Moreover, if high rates of off-loading are to be employed, vapor would have to be provided to the vessel's cargo tanks to prevent the occurrence of sub-atmospheric pressure within them.

Concepts for articulated transfer lines that might be used in shipto-ship transfer are shown in Figure 6.1. To provide freedom of motion, a minimum of two swivel joints in the horizontal plane and four swivel joints in the vertical plane are required between the connecting flanges of the two ships. If each ship carried half such a link as standard on-board equipment, each ship-set most probably would have two horizontal and three vertical swivels, as indicated in Figure 6.1. A support system from an elevated point would be required for the weight of the piping, joints, and cargo flow. Unless the systems are permanently installed on both sides of the ship, they would have to be backed up by a handling capability for shifting from side to side and to stowages and header flanges.

The lower part of Figure 6.1 shows an arrangement that is analogous to the use of one CHIKŞAN arm on each sh1p. Such a permanent arrangement would require one arm on each side of the ship, plus permanent valving and piping to permit its use, when needed, alternatively to the normal discharge flanges. With a portable arrangement, only one unit has to be carried and it can be rigged where and when desired. However, cost analyses indicate that the expense of the kingpost and 


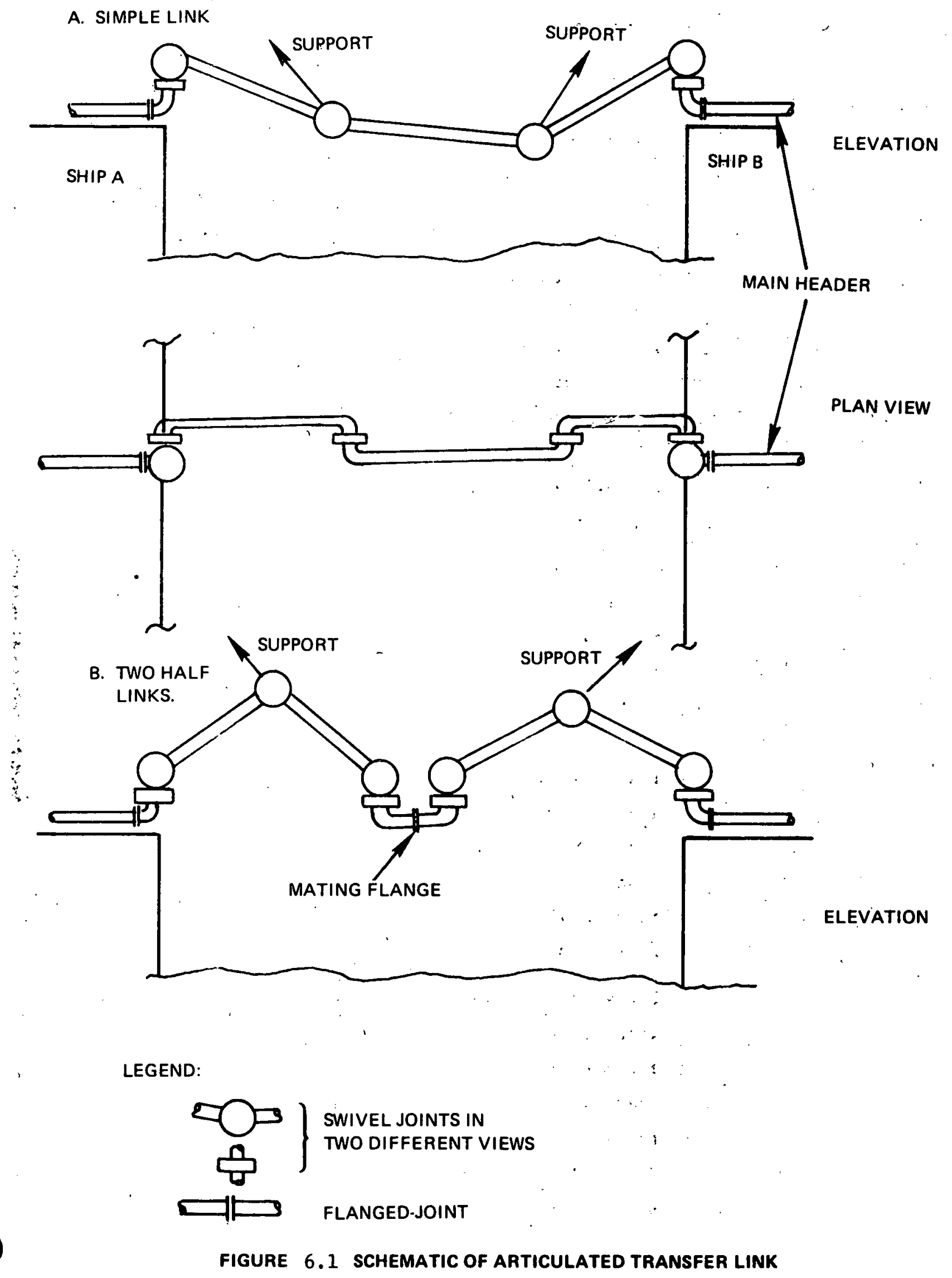


boom arrangements might be greater than that incurred using two installations. The other factor which remains somewhat unresolved at this time is the outreach required, and the CHIKSAN arms are known to have a limited capability in this respect.

Since the entire problem under discussion deals with a rare event, and the equipment under consideration may rarely be used, if ever, the matter of cost, weight, and space is most important, and substantial analysis and testing would be required before a concept could be chosen and implemented.

\subsubsection{Transfer from Damaged and Disabled Ships}

A badly damaged LNG tanker, as could conceivably occur as the result of it being impacted by another ship in a harbor or channel, may pose special problems in salvage or disposal of the cargo. In a severe collision, the entire contents of one or more of the cargo tanks could be spilled in a very short time. This would result in an exceptionally large fire with severe thermal exposure of the ship and its crew. Transfer lines and valves, electrical power cables, and control systems might be damaged and broken and the crew might be incapacitated. Furthermore, damage to the insulation and structural supports of cargo tanks that remain fully loaded after the accident could result in emergency venting (with the corresponding hazard from fire) and a threat of further releases due to failure of one or more of the remaining tanks. The ship could also trim, making it difficult to gain access to the ship's deck and to work on it.

Before off-loading can be considered in a specific accldent situation, a thorough damage assessment would have to be made and the risks of off-loading evaluated. Off-loading problems such as the following would have to be considered:

- Adequate descriptions of the cryogenic system aboard ships. Access to sufficient information about the system might be difficult and time-consuming, unless specific measures were taken to make this information accessible to potential salvage personnel prior to the accident. 
- Availability of skilled personnel who can engineer the repairs and implement salvage procedures.

- The inability to perform any work on board while the cargo system is ruptured and leaking gas into the atmosphere around the ship.

- The difficulty associated with raising large pieces of equipment from low lying vessels to the deck of the LNG tanker. The decks of the $125,000-\mathrm{m}^{3}$ tankers can be as high as 70 feet or more above the water line.

- Disconnecting and/or cutting large diameter insulated lines that may contain flammable vapor and attaching new temporary systems.

- The availability and means of providing auxiliary electrical power if the tanker's electrical system is inoperable.

- Providing adequate protection and emergency escape for salvage personnel.

- Preparing for and accommodating sudden shifts in the vessel's orientation.

- Motion of the ship.

- Fendering of salvage and other vessels.

\subsubsection{Salvage and Disposal Methods}

\subsubsection{Present off-Loading and Vapor-Handling Systems}

The design off-loading times at receiving terminals for the 125,000$\mathrm{m}^{3}$ ships is generally of the order of 12 to 48 hours. Hence discharge rates of the order of 2,500 to $10,000 \mathrm{~m}^{3} / \mathrm{hr}(11,000$ to $45,000 \mathrm{gal} / \mathrm{min})$ are attainable under normal circumstances. Vapor must be provided from the shore side to replace liquid taken from the tanks, thus maintaining a positive pressure. Also, since the LNG tankers generally operate at a constant draft (whether loaded with cargo or empty), water ballast must be pumped into ballast tanks at a rate commensurate with the offloading of the LNG. The ballast system has a weight capacity equal to the cargo load and a volumetric capacity of about $44 \%$, which for a $125,000-\mathrm{m}^{3}$ ship would be $55,000 \mathrm{~m}^{3}$. 
The normal cargo boil-off while the ship is in transit is about $0.25 \%$ per day. This is about $140 \mathrm{~m}^{3} / \mathrm{min}$ and is normally used for propulsion while the ship is in transit. Boil-off may also be burned in the ships' boilers when the main turbines are not in operation by use of the "steam dump" system. Current U.S. Coast Guard rules"do not allow vapor to be vented to the atmosphere when the ship is in port. Emergency vents are provided, however, and they would be expected to handle somewhat in excess of the normal boil-off in the event that other vapor-handling systems fail.

\subsubsection{Disposal from the LNG Tanker}

Potential methods of removing cargo without transferring it to equipment or facilities external to the ship include venting and flaring, the use of combustors, and jettisoning overboard. Each of these methods is discussed below.

\subsection{Venting and Flaring}

The venting of vapor from vent stacks aboard ship at the high rates of discharge that might be required during an emergency is hazardous and probably impractical. There is a finite probability that vapor would be ignited by static discharge or by some other source so that in effect, venting might be considered to be similar to flaring. In addition, at high rates of venting, the unignited vapor cloud may travel far enough to endanger surrounding areas.

High rate flaring would be difficult to achieve without causing thermal damage to shipborne systems from the thermal radiation emitted by the large flames that would be produced.

A $25,000-m^{3}$ LNG tank is the equivalent of about 503 million cubic feet of gas at ambient temperatures To flare such a gas volume within 24 hours requires a rate of $165 \mathrm{~m}^{3} / \mathrm{sec}$. This would release about $6.7 \mathrm{MM} \mathrm{Btu/sec.} \mathrm{Even} \mathrm{when} \mathrm{the} \mathrm{flaring} \mathrm{period} \mathrm{is} \mathrm{stretched}$ out over several days, the entire design and ship protection problem remains formidable. It may be noted that the combustion of $165 \mathrm{~m}^{3} / \mathrm{sec}$ is equivalent to about 10 million hp or 7.7 million $\mathrm{kW}$. 
Either a vent or flare system will require a vaporization system to convert the liquid to gas before it is sent to the vent. Based on a comparison with shore-based vaporizers, the placing of an installation having a capacity of $165 \mathrm{~m}^{3} / \mathrm{sec}$ or more aboard an existing ship would appear tó be dlfficult indeed and utilize a significant amount of space on a newly designed ship.

\section{$\underline{6.5 .5 .2 .2 \quad \text { Combustors }}$}

An alternative which may be more attractive than flares is development of a combustor which can be fueled directly with liquid LNG. Only a small gasifier to provide start-up heat and pilot fuel would be necessary, or normal boil-off may serve this purpose. Major weight and space requirements, as well as capital investment, would be greatly reduced. An installation capable of burning $17.3 \mathrm{~m}^{3}$ of LNG per minute remains a major, sophisticated and expensive system. Excess air would be required to eliminate the large flame developed during flaring. The size of the equipment again might be excessive for instailation on the tanker.

\subsection{Jettisoning}

The jettisoning of large quantities of LNG over an extended period generates specifically those hazards in inshore areas which it is desired to ameliorate. In addition, there is a finite probability that the vapors would ignite and the resulting thermal effects could jeopardize the whole operation.

Experiments have been made with jettisoning of LNG from ships. Tests were madewith the METHANE PIONEER in 1959, and more recently (1973) Shell Research Ltd. and Shell International Marine Ltd. conducted tests on the $75,000-m^{3}$ GADILLA in jettisoning LNG. This latter ship, engaged in the Indonesian trade, is designed for a port which requires loading over the stern. The cargo manifolds are located on a sponson projecting over the transom. A discharge nozzle was fitted and supplied with sufficient pressure so that the LNG stream struck the water surface well clear of the hull, which also was sluiced with water. 
Tests conducted with the ship both underway and stopped were considered a successful demonstration of the feasibllity of the technique. The stern discharge arrangement is peculiar to this class of ship; most large carriers discharge amidships and have no cargo installation aft of the forward bulkhead of the deckhouse, except for the gas fuel lines passing to the engine room via a double-walled conduit. The GADILLA tests demonstrated the feasibility of jettisoning LNG cargo at high rates at sea where the vapor cloud presented a hazard to no land areas and where no danger of ignition from non-ship sources existed. Even under these conditions, however, one might question whether there may be some probability of ignition due to static discharge or by some other mechanism.

\subsubsection{Ship-to-Ship Transfer}

The salvage of the cargo by transferring it to another vesse]. has great appeal in that it could save an expensive cargo - an estimated value of $\$ 8$ million at the terminal's sendout. The primary limitation, however, is the availability of a cooled-down empty carrier.

The present density of LNG traffic is insufficient to expect a carrier to be avallable within a short period. For example, at a U.S. receiving port which is geared for one ship arrival every 10 days, if an outbound ship has a casualty within 24 hours of its expected in-port arrival time; the next scheduled ship can advance its ETA by two days due to the emergency; and, if the next ship required one day for unloading and one day to approach the transfer, the waiting period of the damaged ship is 11 days $(1+10-2+1+1=11)$. Diversion of an empty ship from another port might abbreviate such a waiting period. When terminals such as Lake Charles, Elba Island, Everett, and Cove Point are all in full or expanded operation, such inter-port cooperation may be feasible.

The provision of stand-by ships at the various ports for this purpose is feasible, but cannot be justified economically; the sole U.S. LNG barge (MASSACHUSETTS) is of small capacity and moreover is not in commission. 
It may also be noted that the presently completed, but laid-up LNG tonnage is no solution to this situation; a receiving ship must be fully mannel and operable and must be cooled down to be of use. The expense of the LNG ships prohibits, under current economics in which even a laid-up ship costs on the order of $\$ 90,000$ per day and an operating ship well over $\$ 100,000$ per day, the stand-by of an operable ship in unemployed manner for contingency use could cost over $\$ 30$ million per year, per ship.

A storage barge would be somewhat less expensive for standby use, but could still represent a large investment since the cargo system is the largest portion of the vessel's cost. General Dynamics currently offers its $25,000-\mathrm{m}^{3}$ spheres for a price in the $\$ 6$ million range each. A seaworthy $125,000-\mathrm{m}^{3}$ barge would cost well over half the cost of an equivalent ship, since the cargo system, including al1 safety and instrumentation features, would be similar to those of an equivalent sized ship.

Another option would be to provide a $25,000-\mathrm{m}^{3}$ barge sufficient to offload one tank at a time. This would extiend the total offloading time and thus might not be practical, but it would be appreciably less costly. Such a barge could be fitted with any number of different tank systems. The barge, MASSACHUSETTS, with four horizontal cylindrical tanks, has a capacity of on $1 \mathrm{y} 4,700 \mathrm{~m}^{3}$ (30,000 bb1).

Ship-to-ship transfer also requires flexible or articulated transfer lines that would be difficult to design so they could be readily used and would stand up under the unusual dynamic loads to which they might be subjected.

\subsubsection{Disposal of LNG with Equipment External to the Ship.}

The use of equipment to flare or otherwise burn the LNG vapors under controlled conditions at sufficient distance from the LNG tanker offers the advantage of not having to equip every ship with the necessary systems. This would reduce the amount of retrofit required and elfminate the need to sacrifice cargo space for the disposal system. 
Potential concepts for burning LNG under controlled conditions remote from the tanker include the following:

- Burning LNG on the Water Surface

Perhaps the simplest concept is to pipe the liquid a safe distance from the tanker, discharge it onto the water surface, and ignite it. This might require long flexible lines to keep the flame at a safe distance from the tanker. There might be areas where it would not be possible to find a safe location for the pool fire where the thermal radiation would not cause damage to built-up areas near the shipping channel. Nevertheless, the simplicity of the system warrants further evaluation.

- Submerged Combustion

Some vaporizers employed at LNG plants burn natural gas and air. under water; the heated water is then employed in a heat exchanger arrangement to warm up or gasify the liquid. A similar system might be devised to dispose of the LNG at a distance from the tanker. This concept, however, would require a barge-mounted vaporizer system and large blowers to force air into the water, along with the natural gas, for combustion purposes. This system would appear to be inordinately expensive because of the large blowers needed to achieve sufficient pressure differential to force the gases well below water level. It does, however, eliminate thermal radiation hazards from open flames.

- Gas Turbine Combustors

In this concept a bank of jet engines would be used to convert the energy of combustion to mechanical energy which might then be dissipated by one of several different means, Including some form of thermal dissipation in the water. The cost of such a system, however, would appear to be cxcessive compared to other potential concepts. Gas turbines basically contain a level of sophistication far above that deemed necessary for merely disposing of the heat of combustion. 
A typical large gas turbine, the J79-GE-10, burns about 10,000 pounds of fuel per hour. It would thus take close to 100 days for a single engine to absorb the contents of one $25,000-m^{3}$. tank.

- Waste Heat Boilers

Waste heat boilers are much less expensive than gas turbines and could conceivably provide for the disposal of the LNG cargo within a day or two. It is estimated that with 10 boilers to a barge and 4 barges, a high rate of disposal could be achieved. Each boiler of conventional design capable of $500 \times 10^{6} \mathrm{Btu} / \mathrm{hr}$ would be expected to cost about $\$ 200,000$. A preliminary estimate would indicate that a waste heat boiler system might cost between $\$ 10$ and $\$ 20$ million.

The problem of utilizing sea water in these bollers and dumping steam overboard requires further evaluation of this concept.

- Open F1ares

Barge-mounted flares would be similar.to pool burning, but can be controlled better and provide a means of reducing the size of the flame and, hence, the thermal radiation hazard. A concept using a large matrix of off-the-shelf flares or burners is illustrated in Figure 6.2. This one large barge would be capable of disposing of the contents of the remaining cargo on the tanker within a day or two. Not shown are the vaporizers necessary to convert the LNG to vapor before being transferred to the flares. Preliminary estimates indicate that the cost of this system might be in the range of $\$ 6^{\circ}$ to $\$ 10$ million. 


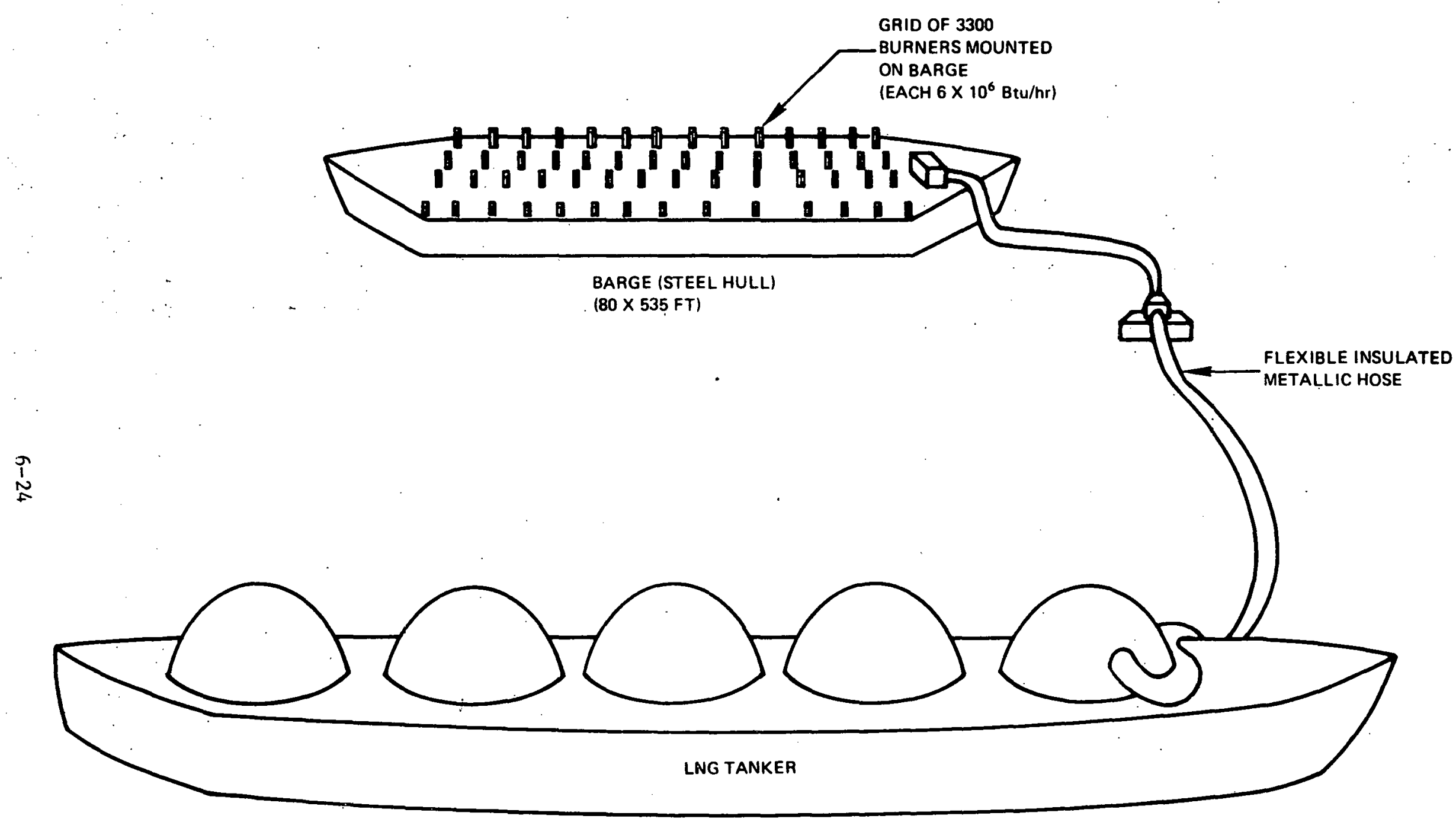

FIGURE 6.2 FLARE SYSTEM CONCEPT 


\subsection{CONCLUSIONS AND RECOMMENDATIONS RELATING TO CARGO DISPOSAL}

\subsubsection{Conclusions}

It is unlikely, but possible, that an LNG tanker would become grounded, disabled, and/or damaged to the extent that off-loading of LNG at other than receiving terminals would be the preferred response to the accident.

Emergency off-loading times of less than a day to several days, depending upon the condition of the tanker, may be necessary to. adequately remove a perceived threat to the surroundings.

It is unlikely that the cargo could be off-loaded from a tanker within these periods of time (at other than the terminal itself) with existing equipment and plans, short of scuttling the ship.

The most desirable method of off-loading cargo is to transfer it to another vessel(s) since this would allow the expensive cargo to be salvaged. But because of the avallability of existing and planned vessels that could receive this cargo, only rarely would the conditions be right for transfer within the interval of time that is required for removal of the perceived or real threat.

Shipboard methods of disposing of cargo (e.g., by flaring or utilizing specially designed combustors) appear to be either too hazardous or require equipment that may call for an inordinate amount of space on the ship.

The transfer of cargo through flexible lines to a barge(s) located at a reasonable stand-off from the ship would provide the means to dispose of it by a matrix of flares or by the use of waste heat boilers. This system appears to be both feasible and safe for use in relatively sheltered waterways, but might present severe problems when and where sea states may be high.

A compromise, or perhaps an interim measure, that needs more evaluation is the pool burning of cargo by releasing and burning it on the water at a sufficient stand-off from the ship and vulnerable 
surroundings. Again flexible transfer lines would be used to carry the LNG to the site of pool burnings.

\subsubsection{Recommendations}

Criteria for equipment and methods needed to dispose of or salvage LNG cargo from a damaged or disabled tanker should be defined more accurately.

Depending upon the risks presented by LNG shipping, an analysis should be considered for each LNG project so as to:

- Characterize potential fallure modes and their consequences in detall as a function of possible ship location for the specific ships and for the specific waterways being traversed;

- Establish risks to the surroundings from these accidents;

- Determine when and under what conditions salvage or disposal may be necessary, define required offloading times; and

- Establish criteria for the design and use of salvage or disposal equipment and methods.

Salvage or disposal methods should be developed and made available for use, as defined by the above criteria and needs.

As an interim measure, the development of a portable system for the pool burning of LNG at safe stand-off distances should be evaluated, in detail and the necessary equipment should be developed and deployed if such an evaluation concludes that the system would be cost-effective.

Equipment should be developed and made available (where it does not now exist) for handling emergency offloadings (at LNG terminals) from damaged or failed LNG tankers. 


\section{E. 7 CONTINGENCY PLANS}

\section{7 .1 General}

All U.S. import projects have been subjected to extensive safety evaluations. Primary focus on shipping accidents has been placed on ship collisions for they appear to be the most likely mode by which a large spill could occur, even though the likelihood of the event occuring is extremely small. Little has been done, however, to determine or outline the response that should be taken once a severe accident has occurred. At least in the open literature, there is little or no commentary on what to do with a damaged (fully or partially loaded) ship in an emergency.

Without having identified all of the credible events that can occur and planning ahead-of-time for response to them presents the risk that inadequate response will cause unacceptable casualties over and above that resulting from the early phase's of the accident.or failure. In addition, indecision, vacillation, and delay that may occur are the result of the lack of detailed and appropriate contingency plans and may cause undue alarm, forcing imprudent responses, acticns requiring excessive expenditures of labor and money, and unfounded restrictions on further shipping of LNG. It appears that it would be prudent to develop or improve upon contingency plans for responding to shipping accidents even though their occurrence is expected to be rare and, perhaps, never happen.

In this study we have outlined the items that may be considered in the development or improvement of contingency plans that relate to salvage or disposal of the cargo. The content of such plans, of course would change if and when more definite salvage and disposal measures are developed.

\subsubsection{Components of a Contingency blan}

The components of contingency plans described here derive from the preliminary assessment of conditions that may possibly require salvage or disposal of cargo from the LNG tanker. The following items are 
deemed to be important whether or not new salvage and disposal methods are developed in the future.

\subsubsection{Plans for Damage Assessment}

Once an accident has taken place and events begin to evolve, the assessment of the condition of the ship and its cargo system becomes critical to the implementation of adequate response. Plans need to be developed that would allow appropriate assessment to be made, taking into account possible crew incapacitation, lack of normal communications with the ship, inability to board the vessel, and other restrictions introduced by the acciderit and its consequences.

of particular importance is the monitoring of the onboard cryogenic system. This includes the integrity of the insulation and the LNG containment and its structural support as well as the condition of transfer lines, valves and the cryogenic control system. Tank pressure build-up, adequacy of relief, and pending venting of vapors or tank failure are also, of course, critical to implementing pertinent and timely response actions.

The ability to assess the condition of the ship itself will also play a significant role in the response decision process. Flooding, seaworthiness, risk of further damage, ship motion, grounding, listing and other factors must be considered and evaluated.

Plans should be made for appropriate engineering drawings, operating procedures, and personnel with the necessary skills to be made. accessible so that the condition of the ship may be assessed as events occur following the accident.

Plans should also contain basic responses that may be necessary, depending upon the possible outcomes of damage assessment.

\subsubsection{P1ans for Response Action}

There are generally two somewhat distinct response phases that apply to hazardous chemical shipping accidents, as described and employed in the development of the Chemical Hazards Response Information 
System (CHRTS). The first phase is associated with the early part of the accident sequence where only limited response may be taken before there is time to make a more complete assessment of the condition of the ship and its contents and before longer term responses can be initiated. In this first plase, free fighting, rescue, and protection of surrounding areas and activities will be carried out. In addition, acquiring information for damage assessment and the reporting on the course of events to those that are trained to evaluate them must be performed.

Detailed plans, based on assessments of the potential accidents and subsequent events, for the initial or first-phase responses should be developed for specific import projects where they do not now exist.

The second phase of response actions consists of preparing for and implementing damage assessment procedures, providing manpower and equipment, assigning responsibilities, making appropriate response decisions, and carrying out the necessary active measures as needed. It is this second phase where much additional planning could help to ensure appropriate responses that may result in the saving of lives, a reduction in losses to property, and a general mitigation of concerns as to the overall response.

\section{7 .2 .3 Planning, Responsibilities, and Incentives}

The U.S. Coast Guard is in control of LNG ship movements in U.S. waters and regulations are issued under the authority of the local Captain of the Port. In the event of a casualty to an LNG carrier, the Coast Gurad representative remains as On-Scene Commander (OSC), who may draw upon Coast Guard, commercial, or governmental resources. Under current procedures, the Coast Guard has one or more patrol boats or cutters present at each ship movement, and is in charge of the communication network which links together the entire operation. In the event of a casualty, the immediate need may be for fireboats and tugs.

As OSC, the Coast Guard will be responsible for approving or disapproving further methods of cargo disposal in the light of the risks 
involved to the port and the surrounding shore areas, as well as instituting any shoreside alerts or evacuations.

If the ship is damaged or disabled, but the cargo system remains intact, the responsibility for determining repair and salvage measures rests with the ship's owners, subject only to approval or disapproval of the Coast Guard in respect to the interference such measures may cause to the operation of the port. In such an instance, it is highly probable that a decision will also have to be reached concerning disposition of cargo or extended boll-off.

If ship-to-ship cargo transfer is possible, the nearest terminal w11l be the organization best qualified to determine availability of ships and to arrange for this use. If the LNG carrier which has been damaged is in a "safe" condition, the terminal must be brought into the planning for cargo. unloading to shore immediately, if the ship can be moved to the terminal.

Other than tugs or fireboats, there is little material or equipment which is of use in the event of an LNG ship casualty, other than the actual ship repair or spare parts which may be needed if sufficient to place the ship in operation again. The OSC would be the contact point for all other agencies and organizations which might be involved in the effects or potential effects of an LNG ship casualty.

Present Captain of the Port plans for LNG ship movement and the ship's own emergency plans cover much of the above. However, it appears that more attention to the detailed actions (based on real accident scenarios) that may be taken after a major failure should be considered. If salvage or disposal methods are developed, then the contingency plans would have to be expanded to provide technical Information on these systems and to provide policy and guidelines for their implementation. 


\subsection{IGNITION OF SPILLED CARGO}

\subsection{Introduction}

The effectiveness of methods of reducing spill rate and quantity to minimize LNG tanker fire hazards depends upon which of two possibilities occurs in a collision followed by a spill. One is immediate ignition and a subsequent pool fire; the other is no ignition at the site of the spill, and a vapor traveling downwind and, perhaps, entering a populated area. For example, in the former situation, using spill control methods, the maximum potential harmful distance from a pool fire may be reduced from about 2100 meters for an "Instantaneous" release of 25,000 cubic meters of LNG to 120 meters for a spill of 1,000 cubic meters that takes place over a period of 30 minutes (Table 2.1). On the other hand, the maximum travel of an unignited vapor cloud under the same spill conditions would be reduced from 20 kflometers to 1.4 kilometers. Thus, the hazard distances for the unignited vapor cloud remain much larger than those for the pool fire.

A reduction in the rate and quantity of spill may also reduce the probability of ignition after a collision because of a decrease in the likelihood that the ignitable vapor cloud near the accident will propagate to the potential sites of ignition (i.e., the ignition sources might be at tens of feet above the water level and be well above the maximum height of the near-field flammable vapor cloud).

In past evaluations of potential tanker hazards, it has generally been assumed that there is a high probability (e.g., in excess of a 90 percent chance) of ignition at or near the spill site very soon. after the discharge has started. In essence, it has been postulated that the risks from pool fires resulting from early ignition are greater than those from "unignited" vapor clouds because of the improbability of the latter.

Although the assumption of early ignition may be valid, it has not been very well supported by either analytical or empirical data on the potential ignition processes that might take place. In effect, a lack of knowledge as to the existence of ignition sources under conditions that may be experienced during accidents introduces considerable 
uncertainty as to the casualties or losses that may be experienced in accidents involving LNG and other liquefied energy fuels.

In this portion of the report, we discuss our attempt to derive the information necessary to provide. more insight as to the likelihood of ignition. We consider the occurrence of ignitions in past accidents involving tankers carrying flammable liquids, review the potential physical mechanisms for ignition; report on ignition experiments conducted at $\mathrm{ADL}$, and make a preliminary assessment of the potential for flammable vapors to reach sites of ignition. 


\subsection{Ignition Occurrences in Tanker Accidents}

\subsubsection{Background}

One source of Information that has been used by others to assess the likelihood of ignition is past events where tankers carrying flamwable cargos have been involved in collisions. Of course, this information relates to collisions of ships other than LNG tankers in as much as, to date, there have been no collisions resulting in LNG spills. However, it has been implied that if there were a high proportion of petroleum tanker collisions that resulted in immediate ignition, one might also expect this to be the case for LNG tankers.

The pertinent information on past shipping accidents revealed by a search of the literature is discussed in this section.

\section{2 .2 U.S. Coast Guard Data}

The U.S. Coast Guard compiles data on all U.S. flag tanker casualties that occur anywhere in the world and for all tanker casualties within U.S. waters (as well as data on other types of vessels). These data have been examined (E1 Paso, 1977) for the years FY 1973.and FY 1974 (these data being the most accessible at the time). The records show that.for these years, there were 81 collisions involving tankers of greater than 1,000 gross tons. Of these collisions, there were only two cases where cargo tanks were penetrated by the striking ship. In both incicients, fire occurred almost instantly upon collision.

We have verified these results by an independent search of the USCG Commercial Vessel Casualty File. In so doing, however, we also tabulated tank barge collisions over the same period. Of 250 barge collisions, six resulted in spills of cargo, none of which ignited. Seven of the collision reports were missing from the file and might possibly have contained cases where Ignition took place. We did not determine whether the six spills involved significant penetration of the cargo tanks by the striking ship or merely resulted in cracks or minor hull damage that resulted in some leakage. 
The active files of the U.S. Coast Guard Marine Boards of Investigation were also searched (E1 Paso, 1977) for pertinent data. These reports covered the perfod June 1966 to January 1975. In seven cases cargo containers were penetrated; and in all but one case, the cargo was ignited immediately upon collision. The one exception was a tanker carrying heavy bunker fuel with a flash point greater than $150^{\circ} \mathrm{F}$. Apparently, there was not enough vapor to create a sufficient quantity of flammable mixtures to engage one or more of the potential ignition sources present during the collision. In those cases where ignition took place, the cargos were reported to be crude oil, naphtha, and gasoline.

In addition, U.S. Coast Guard Marine Boards of Investigation reports were surveyed (E1 Paso, 1977) for years prior to 1965. Nine other cases were found where there was a significant penetration of the struck ship's cargo containment area. In all cases, it was reported that ignition occurred immediately on penetration of the tanker. Cargos such as crude oil, gasoline, JP-4, acrylonitrile, and diesel oil were involved.

In all of these cases, there was insufficient information to indicate whether flammable mixtures of cargo vapor and air were present in the cargo spaces of the struck ships at the time of collision.

\section{2 .3 Lloyd's Data}

Another source of data on tanker casualties derives from Lloyd's Casualty Reports as completed by the Maritime Data Network, Ltd. of Stamford, Connecticut. At our request, the Maritime Data Network analyzed the data for the period 1964 through September 1979 for all reported tanker collisions throughout the world involving tankers of more than 4,000 gross tons (Table 7.1).

of some 852 collisions over the 15-year period, there were 83 spills of cargo and 12 ignitions upon collision and spill. The data do not specify quantity spilled nor whether there was a significant penetration of the cargo containment area by the striking ship. Given 
a spill, the lower percentage of ignitions compared to that indicated by U.S. Coast Guard data may be attributable to either insufficient impact or the absence of ignitable vapors. In the former case, there would be little or no penetration to create ignition sources, such as by frictional impact; whereas in the latter case, the cargo spaces in the struck tankers may not contain a flammable mixture of vapor and air.

In comparing the U.S. Coast Guard and the Lloyd's data; we found discrepancies in the two data bases. Lloyd's data reported casualttes that would have been expected to be in the U.S. Coast Guard compilation, and vice versa. We made little attempt to resolve these discrepancies, because they did not affect the proportion of ignitions that took place. However, these discrepancies may indicate that both data bases are incomplete.

\subsubsection{Liverpool Casualty Returns}

The potential for ignition during tanker collisions was also examined (Sharp 1975) using data compiled by the Liverpool Underwriters Association. Data for a 127-month period were analyzed. Of 105 collisions where a tanker was struck by another ship, 34 resulted in ignition of the cargo. However, it was noted that:

"There is no record available concerning how many, if any, of the struck tankers were inerted in the cargo spaces and if so, what the casualty rate for inerted tankers was: It is expected that fires and explosions would be reduced drastically by such a precaution."

\subsubsection{Summary of Tanker Accident. Data}

Our analysis.indicates that tankers transporting flammable hydrocarbons are quite likely to have their cargo ignited when they are struck by another ship. But a substantial collision impact may be required for ignition, because the high percentage of fire was realized when there was a significant penetration of the cargo containment area of the struck ship. 
Table 7.1

Tanker Collisions, Worldwide

$(1964$ - present $)$

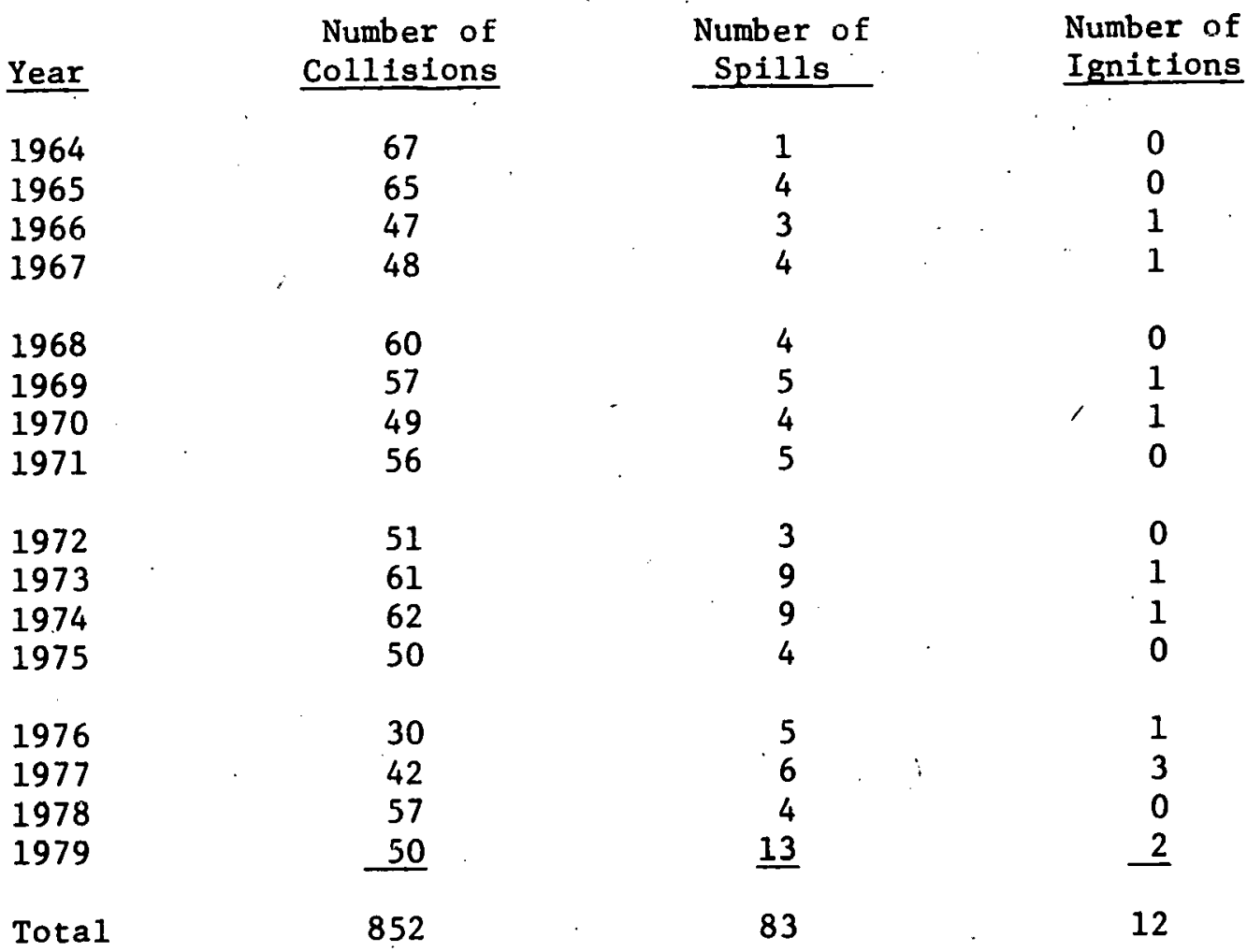

Lloyd's Data from Maritime Data Network, Ltd. 
This would imply that in LNG tanker collisions, where the impact must be quite severe for the striking ship to penetrate two hulls and the cargo containment, it may be very likely that ignition sources will be present. However, from these data alone, one cannot conclude that ignition would be highly likely in the event that another ship penetrated an LNG tanker's cargo tanks, since the relative flammability of the material in the cargo spaces for the two types of tankers could be quite different. 


\subsection{A Review of Fundamental Mechanisms Pertaining to Immediate}

Ignition of Accidental LNG Spills

In this section, we review and analyze literature results pertinent to those ignition sources most capable of causing LNG fires upon ship impact. As we are concerned with ignitions coincidental with LNG tank penetration, we do not consider, for example, open flames or electrical sparks in nearby tugboats, home furnaces or bollers. We assess immediate ignition potential through development of a collision scenario. The three most probable ignition sources are found to be frictional heating, frictional sparking and electrical sparking. Fundamental mechanisms are discussed for al1 three sources with major attention given to frictional heating and ignition.

\subsubsection{Collision Scenario}

The basic beam-on collision scenario is shown in Figure 7.1. LNG tank rupture requires penetration through both the outer and inner hulls plus whatever insulation surrounds the tank itself. Upon rupture, natural gas liquid and vapor flow from the LNG tank. Above the water line, the ballast space is filled with air. Entrainment of air by turbulent jets of vaporizing. LNG may create flammable mixtures in this region. Hot surfaces and sparks arise wherever the bow of the striking ship rubs the hull of the struck tanker. Thus, a potential ignition source occurs where the outer hull of the struck ship meets the bow of the striking ship. Ignition is not likely along the inner hull because of the lack of a flammable mixture.

In our review of accidents involving crude oil tankers and cargo ships carrying flammable hydrocarbons, we found that in a high proportion of collision-penetration accidents, ignition occurred upon impact if the ambient temperature was greater than the flash point of the cargo. There is considerable uncertainty in applying such statistics to LNG tankers, however, since immediate ignition would be almost certain for many of the past accidents where the impacted ships probably had premixed fuel-air mixtures. in the ullage space above the cargo. In these instances any sparks or hot spots created by the collision 


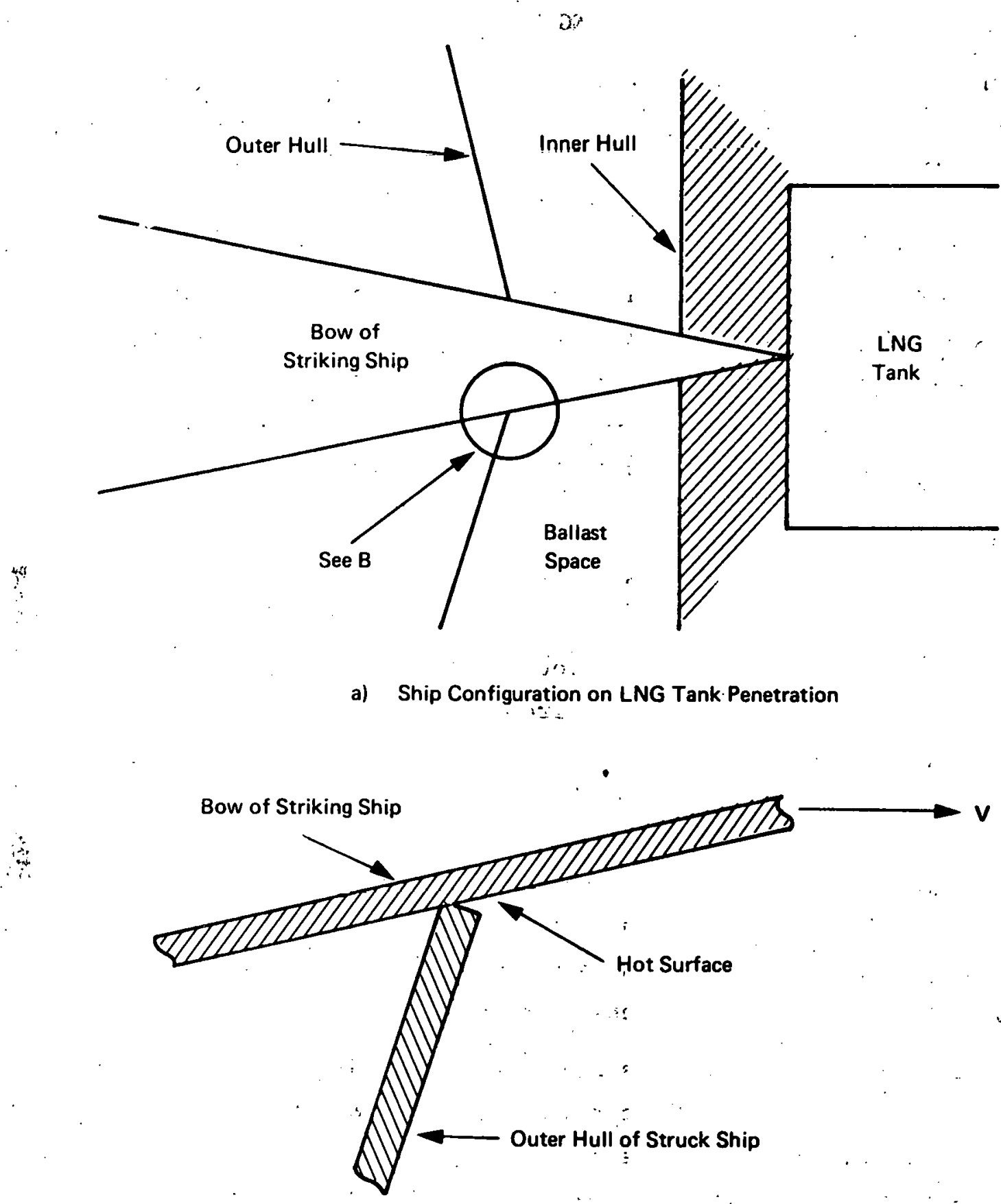


would have immediate access to a flammable mixture. LNG tanks, on the other hand, are controlled so that air.cannot enter and mix with vapor. Hence, mixing of LNG vapor and air in the ballast space between hulls or outside the tanker is required to form a flammable mixture. Because LNG tankers are double-hulled while most crude oil tankers have a single hull, we would expect then that collision-penetration accidents involving LNG tankers may be less likely to lead to immediate ignition than for crude oil tankers. Given a flammable mixture, however, similar ignition sources are expected for both types of tankers.

\subsubsection{Characteristics of Anticipated Fuel-Air Mixtures}

The composition and properties of various LNG's are listed in Table 7.2. Properties of the major constituents relevant to ignition are shown in Table 7.3. Since methane is the lowest boiling point component, flammable mixtures created by LNG vaporization and mixing will tend to be enriched in $\mathrm{CH}_{4}$ compared to the compositions given in Table 7.2. T'e spontaneous ignition temperatures in Table 7.3 are determined using large induction times and heated volumes of premixed gas. For forced ignition by sparks or heated surfaces, the local ignition temperature is much larger than the spontaneous ignition temperature. Methane, for example, requires surface temperatures greater than $1000^{\circ} \mathrm{C}$.

The flammability limits denote mixtures capable of undergoing ignition. For pure methane fuel, mixtures having 5.3 to 15.2 percent methane support combustion. Flammability limits for mixtures void of hydrogen or carbon monoxide can be calculated using Le Chatelier's rule (Penner and Mullins 1959),

$$
L=100\left[\sum_{i=1}^{n} \quad x_{i} / L_{i}\right]^{-1}
$$

where $\mathrm{L}_{i}$ and $\mathrm{L}$ are the flammability limits in volume percent for the $i^{\text {th }}$ fuel and the mixture of $n$ combustibles, respectively, and $x_{1}$ is the volume percent of the $i^{\text {th }}$ combustible gas in air. Using equation (1.1), the lower and upper flammability limits for Algerian LNG are found to be $4.8 \%$ and $14.5 \%$, respectively, or in terms of equivalence ratio, 0.55 and 1.7. Little difference is noted as compared to the flammability limits for methane-air mixtures. 
Table 7.2

Composition and Properties of LNGs

from Different Sources*

\begin{tabular}{|c|c|c|c|c|c|c|c|}
\hline : & $\mathrm{CH}_{4}(\%)$ & $\mathrm{C}_{2} \mathrm{H}_{6}(\%)$ & $\mathrm{C}_{3} \mathrm{H}_{8}(\%)$ & $\mathrm{C}_{4} \mathrm{H}_{3}(\%)$ & $\begin{array}{l}\text { Boiling. } \\
\text { Point }\left({ }^{\circ} \mathrm{C}\right)\end{array}$ & $\begin{array}{l}\text { Specific } \\
\text { Gravity }\end{array}$ & $\begin{array}{c}\text { Heating } \\
\text { Value } \\
\text { (BTU/scf) }\end{array}$ \\
\hline U.S. & 96.6 & 2.7 & 0.4 & 0.3 & -162 & 0.44 & 1040 \\
\hline Algeria & 88.8 & 8.1 & 2.3 & 0.8 & -165 & 0.47 & 1115 \\
\hline Libya & 69.1 & 24.4 & 4.5 & 2.0 & -160 & 0.54 & 1380 \\
\hline
\end{tabular}

* Approximate composition at saturation ( $P=1$ atm) neglecting molecular nitrogen $\mathrm{plus} \mathrm{C}_{5}$ and heavier hydrocarbons. Compiled from Chatterjee and Geist (1972). 
Table 7.3

Hydrocarbon Properties Relevant to Ignition*

$\begin{array}{lccccc}\begin{array}{c}\text { Stoichio- } \\ \text { metric } \\ \text { Rat1o }(\mathrm{v} / \mathrm{v})\end{array} & \begin{array}{c}\text { Lower } \\ \text { Flamma- } \\ \text { bility } \\ \text { Limit }\end{array} & \begin{array}{c}\text { Upper } \\ \text { Flamma- } \\ \text { bility } \\ \text { Limit }\end{array} & \begin{array}{c}\text { Spontaneous } \\ \text { Ignition tem- } \\ \text { perature }\left({ }^{\circ} \mathrm{C}\right)\end{array} & \begin{array}{c}\text { Boiling } \\ \text { Point }\left({ }^{\circ} \mathrm{C}\right)\end{array} \\ \mathrm{CH}_{4} & 9.5 & 0.56 & 1.6 & 630 & -162 \\ \mathrm{C}_{2} \mathrm{H}_{6} & 5.7 & 0.53 & 2.2 & 470 & -89 \\ \mathrm{C}_{3} \mathrm{H}_{8} & 4.0 & 0.55 & 2.4 & 505 & -42 \\ \mathrm{C}_{4} \mathrm{H}_{10} & 3.1 & 0.61 & 2.8 & 430 & -1\end{array}$

*Flammability limits expressed as equivalence ratios for room temperature and one atmosphere. Spontaneous ignition temperature for one atmosphere and stoichiometric conditions. Compiled from Lewis and von E1be (1961) and Murty Kanury (1975). 
The initial temperature of fuel-air mixtures produced by LNG tank rupture can be estimated assuming adiabatic mixing, i.e.,

$$
T_{m} \simeq\left(1-x_{f}\right) T_{a}+x_{f} T_{f}
$$

where $T_{m}$ is the mixture temperature, $T_{a}$ the ambient air temperature, $\mathrm{T}_{f}$ the LNG vapor temperature and $\mathrm{X}_{\mathrm{f}}$ the LNG vapor mole fraction. For $\mathrm{T}_{\mathrm{f}}=-160^{\circ} \mathrm{C}$ and $\mathrm{T}_{\mathrm{a}}=0-25^{\circ} \mathrm{C}$, the initial temperature-equivalence ratio regime for potential Algerian LNG ignition is approximated in Figure 7.2. Note that we have neglected the effect of temperature on the flammability limits.

\subsubsection{Summary of Ignition Sources}

Given a flammable mixture, we require a sufficiently energetic ignition source for immediate ignition. Based on the work of Affens and Lange (1979), the scenario depicted in Figure 7.1 and the discussion to follow, we classify the potential ignition sources as follows:

1. Most probable

2. Probable

3. Unlikely

4. Most Unlikely
Adiabatic shear Frictional "sparks" electrical sparks

Adiabatic compression, electrostatic sparks.

Metal fracture, plastic deformation

Adiabatic shear refers to frictionally induced hot surfaces whose temperatures are greater than $1000^{\circ} \mathrm{C}$. As shown in Figure 7.1 , such surfaces are available throughout the collision process; moreover, their size and temperature should promote ignition of flammable methane-air mixtures. Adiabatic shear is a more probable ignition source than frictional sparks since discrete non-pyrophoric particles are too small to ignite methane-air mxitures. Electrical break sparks could occur along light (100 V, $60 \mathrm{~Hz})$ and power $(450 \mathrm{~V}, 60 \mathrm{~Hz})$ lines in both the striking and struck ship. Navigational and anchor lights on the striking bow are the most obvious sources. Electrical sparks are deemed less probable than adiabatic 


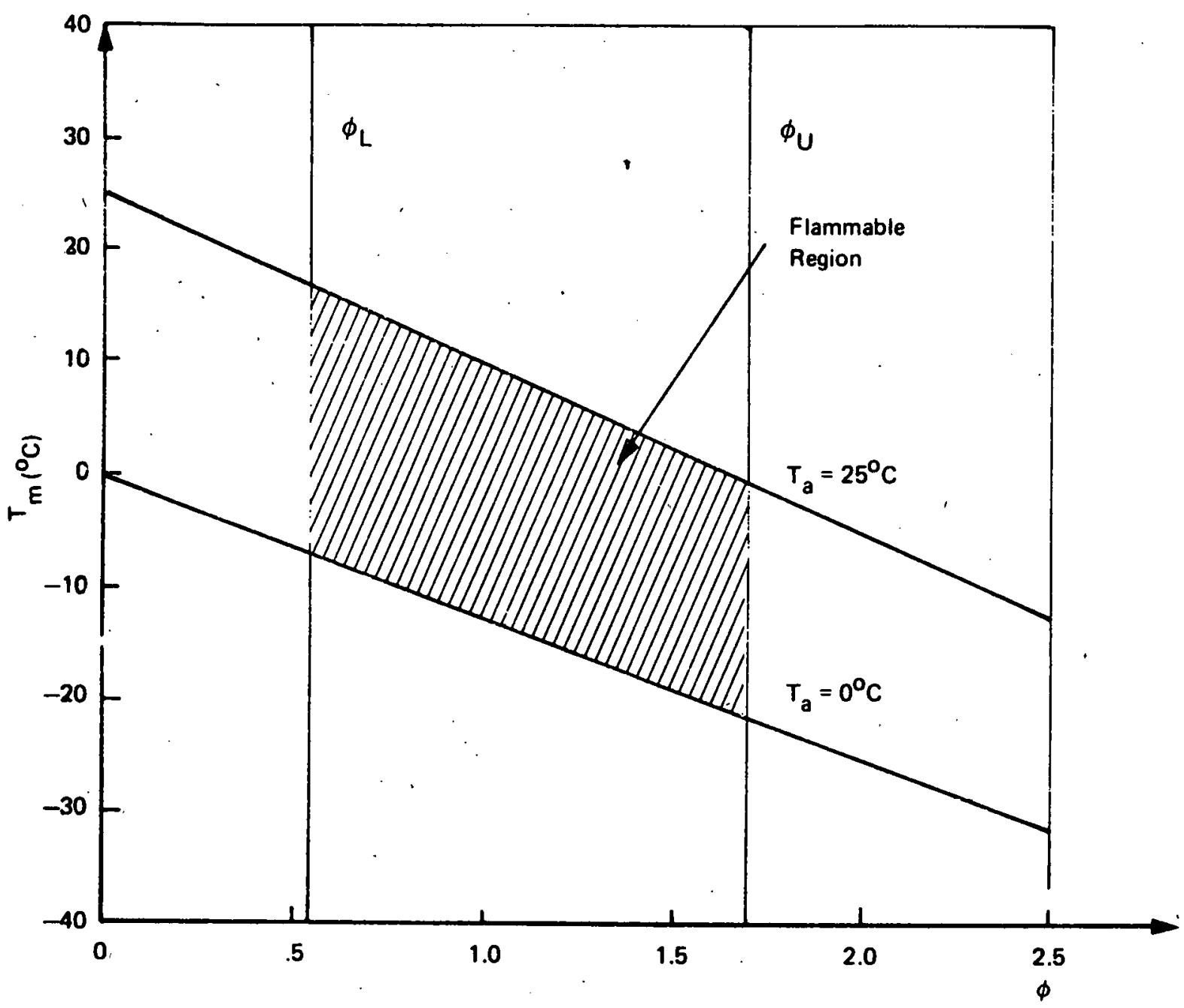

FIGURE 7.2 INITIAL TEMPERATURE-EQUIVALENCE RATIO REGION FOR FLAMMABLE ALGERIAN LNG MIXTURES. INITIAL LNG VAPOR TEMPERATURE ASSUMED TO BE $-160^{\circ} \mathrm{C}$. AMBIENT AIR TEMPERATURES ASSUMED TO BE $0-25^{\circ} \mathrm{C}$. STOICHIOMETRIC CONDITIONS FOR LNG VAPOR GIVEN BY $8.6 \%$ V/V. THE EQUIVALENCE RATIO $\phi$ IS GIVEN BY [FUEL/AIR] ${ }_{\text {ACTUAL/ }}{ }_{\text {[FUEL/AIR] }}^{\text {STOICH. }}$ 
shear since electrical wires are usually placed under the centerline of the forecastle and main decks and the bow of the striking ship usually receives less structural damage than the hull of the struck ship (Porricel1i, 1977; Marine Casualty Report, 1975, 1977; Minorsky, 1959).

For crude o1l tankers, porricelli (19/7) finds that (1) welds created by adiabatic shear during collision suggest temperatures greater than $770^{\circ} \mathrm{C}$, (2) frictional sparks are often reported during collision and (3) some ignitions are caused by rupture of electrical lines (Affens and Lange, 1979). Thus, the experimental evidence and collision scenario suggest that adiabatic shear, frictional sparks and electrical sparks are the most likely ignition sources. We will review frictional and electrical sparks in the next section. As adiabatic shear has been judged most likely, we will analyze, in detall, data and theories relevant to frictionally induced ignition and ignition by hot surfaces.:

As discussed by Affens and Lange (1979), ignition by electrostatic sparks and adiabatic compression cannot be ruled out but appears unlikely, while ignition by metal fracture or plastic deformation is essentially impossible. An electrostatic potential could be set up by flowing LNG depending on the rate of charge relaxation along the flow stream. The physics of electrostatic sparks do not differ substantially from electrical sparks as discussed in the next section.

\subsubsection{Ignition by Frictional and Electrical Sparks}

\subsubsection{Frictional Spark Ignition}

Frictional spark ignition has been reviewed previously by Titman (1955), Powell (1969), and Desy, et al. (1975). Little quantitative work is available; the principal qualitative results that have been obtained for methane-air mixtures are as follows:

1. Ignition by discrete non-pyrophoric. frictional sparks is highly unlikely.

2. A high density of non-pyrophoric sparks, particularly if arrested by a nearby surface, can produce a."compact flash" leading to ignition. 
3. Hard gritty surfaces produce higher spark number densities, thus fostering ignition.

4. Ignition by discrete pyrophoric sparks is highly likely.

5. Methane-air mixtures ignite most easily at equivalance ratios near $\phi \simeq 0.7$.

Information on non-pyrophoric sparks comes mainly from the work of Burgess and Wheeler (1928, 1929) Bowden and Lewis (1958) and Tolson (1972). Burgess and Wheeler (1929) found it nearly impossible to ignite an $8 \% \mathrm{CH}_{4}$-air mixture with sparks generated by steel-steel friction. Ignition became more probable if the sparks were retained near the source. Higher frictional loads and speeds also promoted ignition, but it is difficult to say whether higher spark densities, higher spark temperatures or a hotter, more accessible surface was responsible. Burgess and Wheeler (1928) also found it very difficult to ignite 6.5 $9.0 \% \mathrm{CH}_{4}$ mixtures via steel-rock friction. Harder stones promoted spark generation and ignition, but again, the influence of higher surface temperatures cannot be discounted. Restricted geometries tended to produce a localized yellow flash over the area of contact at the moment of impact rather than a shower of sparks. The probability of ignition in such cases was approximately $1 \%$. Higher incendiary behavior due to compact sparks has also been observed by Desy, et al. (1975).

Typical metal sparks are roughly 100 um in diameter. Bowden and Lewis (1958) found that iron particles near this size at $1100^{\circ} \mathrm{C}$ could not ignite methane-air mixtures. Similar results were found by Tolson (1972) for white-hot $\left(21400-1600^{\circ} \mathrm{C}\right)$ iron particles in an $8.5 \% \mathrm{CH}_{4}$-air mixture. These observations are consistent with the work of Silver (1937) who found that a. "non-catalytic" platinum sphere at $1200^{\circ} \mathrm{C}$ must be $6.5 \mathrm{~mm}$ in diameter to ignite an $8 \% \mathrm{CH}_{4}$-air mixture. Hot particles in this size range are ejected during rock-rock friction and have been found to easily ignite methane-air mixtures (Burgess and Wheeler, 1928). 
Powel1 (1969) and Desy, et al. (1975) give much evidence showing that the probability of ignition increases with increasing material hardness. Bowden and Lewis (1958) and, Hillstrom (1978) find that high spark densities are-more probable for harder metals. Thus, it would appear that hard gritty surfaces foster ignition by generating more sparks. Rusty steel, for example, has been found to be more incendiary than clean steel in methane-air mixtures due to the creation of more frictional sparks (Powe11, 1969; Desy, et al., 1975; Affens and Lange, 1979).

We have seen that inert particles must be large and relatively stationary to promote ignition of methane-air mixtures. Pyrophoric sparks, on the other hand, can easily cause ignition in the $10-100 \mu \mathrm{m}$ size range (Bowden and Lewis, 1957; Tolson, 1972). It is for this reason that friction of magnesium and aluminum, for example ignites methane-air mixtures easily compared to steel (Titman, 1955; Desy, et al., 1975). The incendiary nature of pyrophoric sparks arises from their reaction with atmospheric oxygen. Flame temperatures near $2700^{\circ}$ have been measured for cerium and titanium sparks (Rae, 1961). Such temperatures duplicate flame front conditions in a methane-air deflagration and thus, serve as an ideal ignition source (Mullins and Penner, 1959)

Pyrophoric metals are characterized by (1) high heats of combustion, (2) a high Gibbs free energy of formation per oxygen atom in the metal oxide and (3) a linear oxidation rate (Hillstrom, 1978; Kubaschewski and Hopkins, 1962). Aluminum, magnesium, zirconium, titanium and cerium are the most common pyrophoric metals. Tolson (1972) produced metal sparks by exploding wires via a capacative discharge and then passing the products through a $\sim 1 \mathrm{~mm}$ hole to a chamber housing an $8.5 \%$ methane-air mixture. Using Schlieren photography, he obtained direct evidence of ignition by aluminum particles. Non-pyrophoric particles such as iron, copper, tin, tungsten, and zinc did not produce ignitions.

Bowden and Lewis (1958) have carried out the most quantitative study of ignition by stationary pyrophoric sparks. Small particles were heated by a nichrome tape to $1100^{\circ} \mathrm{C}$, in $5-9 \% \mathrm{CH}_{4}$-air mixtures. 
Preliminary tests showed that the nichrome tape was incapable of causing ignition. Non-pyrophoric particles such as carbon, platinum or iron also provided no ignition. However, pyrophoric particles readily ignited $\mathrm{CH}_{4}$-air mixtures as shown in Figure 7.3 . As might be expected, metals with the highest heats of combustion were the most effective igniters. Aluminum and magnesium are so effective that only a $1 \mathrm{\mu g}$ particle caused ignition throughout the $5-9 \% \mathrm{CH}_{4}$ range. Figure 7.3 also shows that ignition is most probable for $6.8 \% \mathrm{CH}_{4}$-air mixtures. Burgess and Wheeler (1929) found that friction between aluminum or magnesium alloys is most probable at $6.4 \% \mathrm{CH}_{4} \cdot$ Desy, et al. (1975) suggest that fuel lean $\mathrm{CH}_{4}$-air mixtures ignite easier due to the availability of excess oxygen for combustion of pyrophoric particles. We will see later, however, that ignition of methane-air by hot surfaces is also promoted by fuel-lean conditions.

\subsubsection{Electrical Spark Ignition}

Conceivable electrical ignition sources upon collision include (1) AC or DC inductive break sparks, (2) AC or DC capacitance sparks or, (3) electrostatic sparks. In each case, the ignition process proceeds through three relatively well distinguished regimes of space and time (Hill, 1979; Barreto, et al., 1974). First spark heating occurs in a channel $30 \mu \mathrm{m}$ in. radius for approximately $40 \mathrm{~ns}$. Successful ignition requires a critical electron density $\left(10^{17} \mathrm{~cm}^{-3}\right)$ for stoichiometric propane-air) so that the discharge channel can change from a cold streamer to a hot incipient arc (Barreto, et al., 1974). For metal electrodes, this charge is instantaneously absorbed by the surface and thus the work done in the procurement of the critical value defines precisely a minimum ignition energy. Second, the heated channel grows hydrodynamically. to a quasisteady radius of a few tenths of a mm in roughly $10 \mu \mathrm{s}$. Third, heat transfer generates a critically-sized nucleating volume which provides transition to stable hydrocarbon burning. This stage is achieved in approximately I $\mathrm{msec}$ with a nucleating sphere of radius $\sim 1 \mathrm{~mm}$ and temperatures close to the adiabatic flame temperatures. 


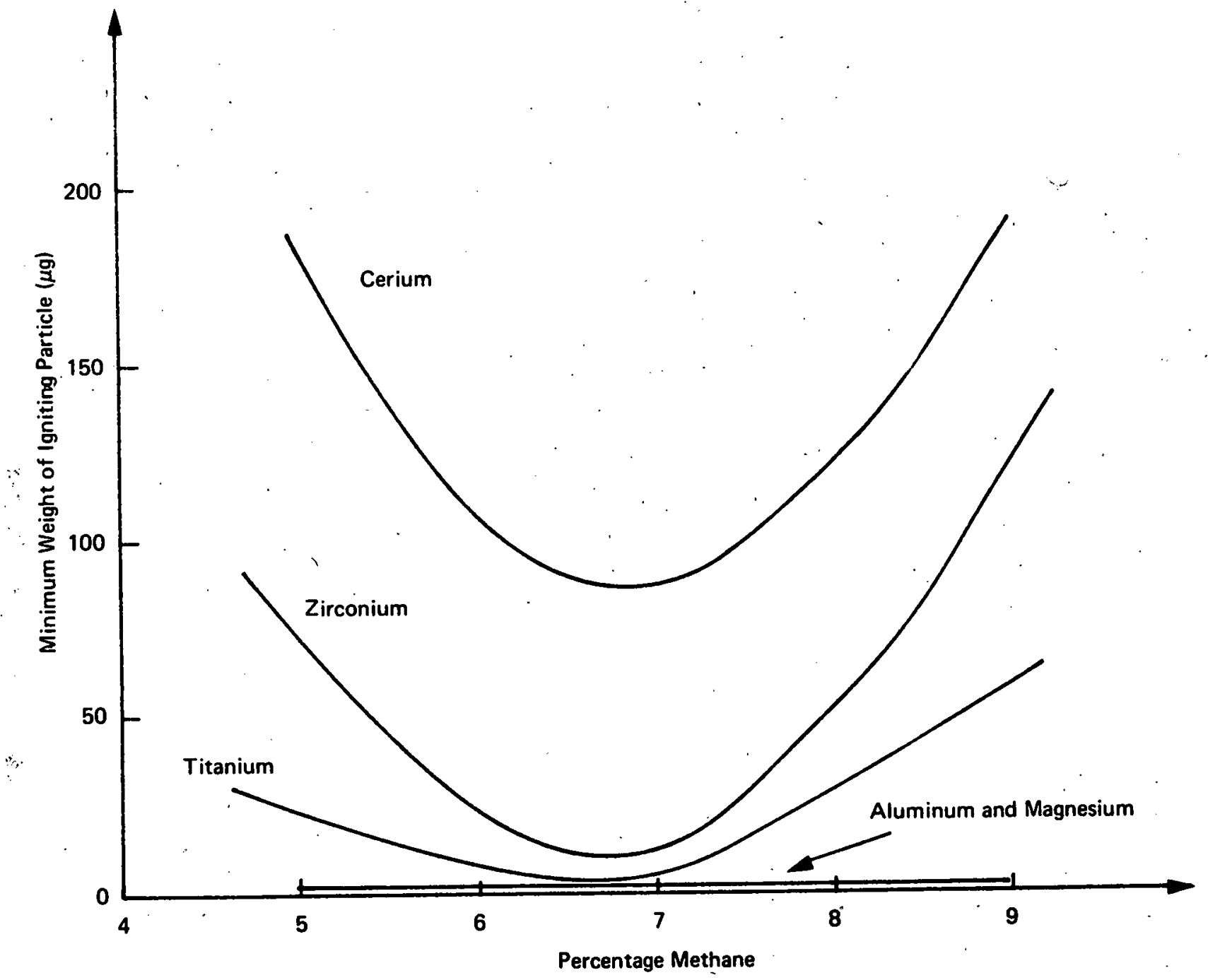

FIGURE 7.3 THE MINIMUM WEIGHTS OF STATIONARY PARTICLES NECESSARY TO IGNITE METHANE-AIR MIXTURES. THE PARTICLES ARE INITIALLY AT $1100^{\circ} \mathrm{C}$ (BOWDEN AND LEWIS, 1958) 
Figure 7.4 demonstrates the basic characteristics of capacitance sparks using flanged electrodes (Lewis and von Elbe, 1961; Ballal and Lefebvre, 1975). A minimum ignition energy $E_{\min }$ is observed at intermediate values of the spark gap. Higher spark gaps require greater ignition energies since a larger gas volume must be heared; lower spark gaps promote extinguishment due to excessive heat losses to the electrodes. The smallest spark gap corresponding to $E_{\min }$ is called the quenching distance, $d_{q}$. For a flowing mixture, both $E_{\text {min }}$ and $d_{q}$ are minimized at stoichiometric conditions (Ballal and Lefebvre, 1977). Table 7.4 lists minimum ignition energies and quenching distances for stagnant fuel-air mixtures. The equivalence ratio for minimum $E_{m i n}$ and $d_{q}$ differs from unity due to diffusional stratification (Lewis and von Elbe, 1961). Based on Table 7.4, we would expect a stagnant LNG mixture to have $E_{\text {min }} \simeq 0.3 \mathrm{~mJ}$ and $d_{q} \simeq 2 \mathrm{~mm}$ under worst case conditions.

The $\mathrm{E}_{\text {min }}$ values in Table 7.4 were measured for a $\mathrm{DC}$ capacitive discharge. However, similar values have been reported for AC capacitive disčharges (Kono, et al., 1976), inductive break sparks (Berz, 1959), and switching sparks (Kravchenko, 1973). Moreover, an optimum discharge duration exists which provides the smallest values of $\mathrm{E}_{\mathrm{min}}$ and is found to be $\sim 100 \mu \mathrm{s}$ in all cases. This critical duration probably corresponds to the time period for initial heating by combustion at the edge of the spark channel (Hill, 1979). The agreement among measurements of minimum ignition energy and critical discharge duration for various spark sources suggests a basic similarity in spark physics independent of the means used to generate the spark.

Practical circuits possess distributed inductance, resistance and capacitance and thus provide damped discharges, either oscillatory or aperiodic. Only a portion of the electrical energy released at the spark gap takes part in the ignition process. The gap geometry has a significant influence on loss mechanisms such as shock formation and heat transfer to the electrodes. Hence, even for spark gaps greater than the quenching distance, variations in circuit conditions and gap 


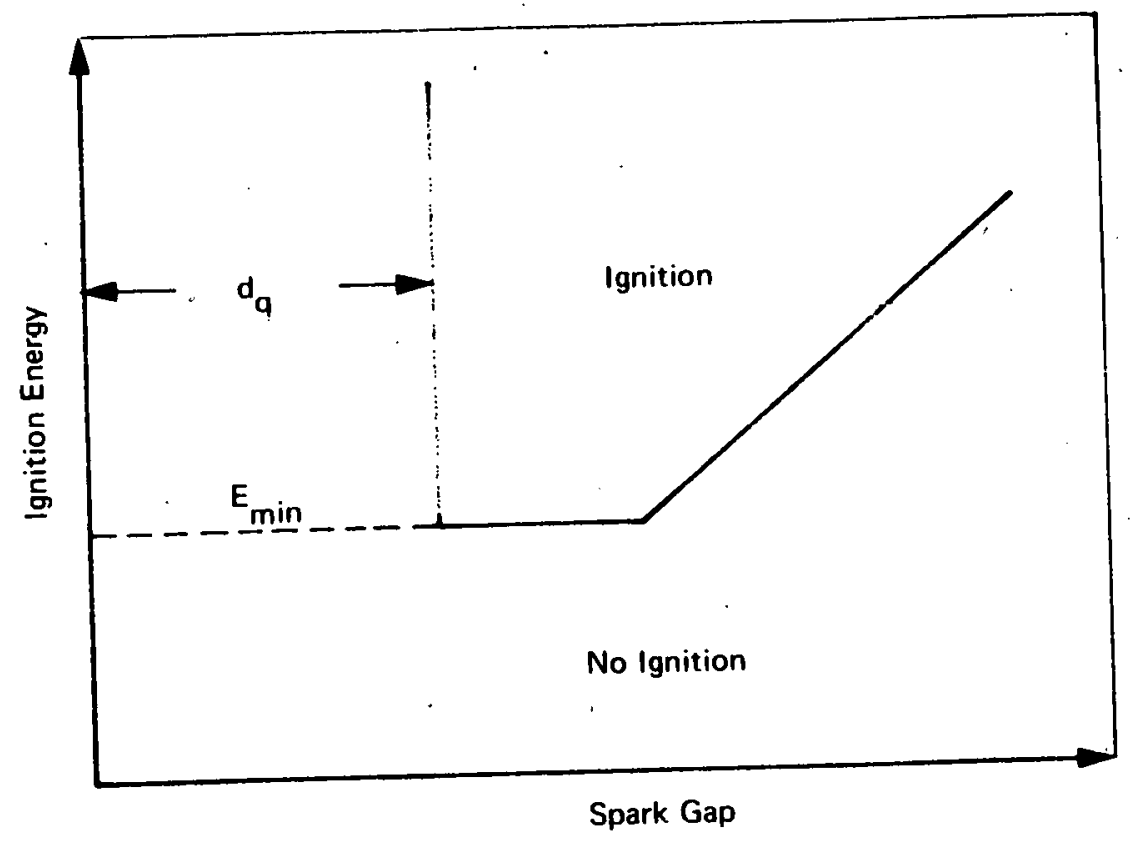

a) Ignition Energy vs. Spark Gap

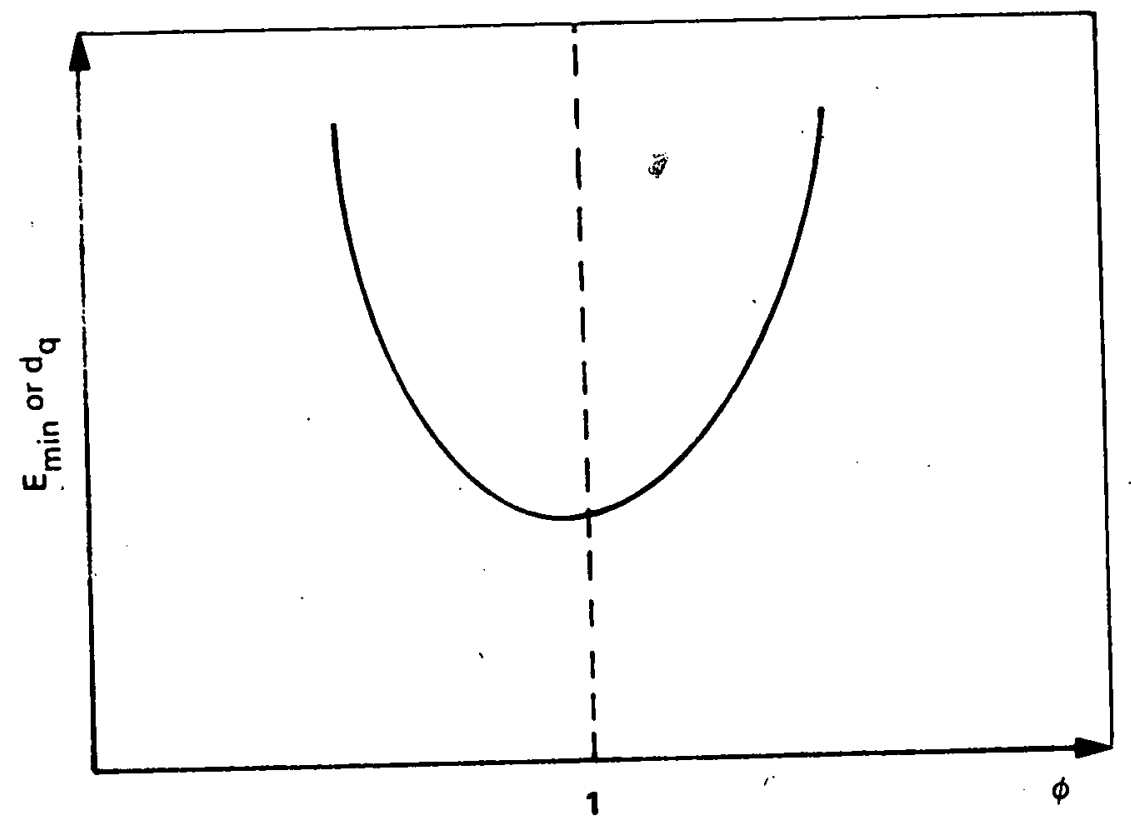

b) Minimum Ignition Energy or Quenching Distance vs. Equivalence Ratio. FIGURE : 7.4 CHARACTERISTICS OF SPARK IGNITION
FOR FLANGED ELECTRODES 
Table 7.4

Minimum Ignition Energy and Quenching Distance

For Stagnant Fuel-Air M1xtures at STP Conditions ${ }^{*}$

Fue1

$\mathrm{CH}_{4}$

$\mathrm{C}_{2} \mathrm{H}_{6}$

$\mathrm{C}_{3} \mathrm{H}_{8}$

$\mathrm{C}_{4}{ }^{\mathrm{H}}{ }_{10}$
Equivalence

Ratio

0.9

1.2

1.3

1.5
Minimum Ignition

Energy (mJ)

0.30

0.25

0.25

0.25
Minimum Quenching Distance (mm)
2.0
1.8
1.8
1.8

5

* Lewis and von Elbe (1961); standard temperature, $25^{\circ} \mathrm{C}$, standard pressure, 1 atm. 


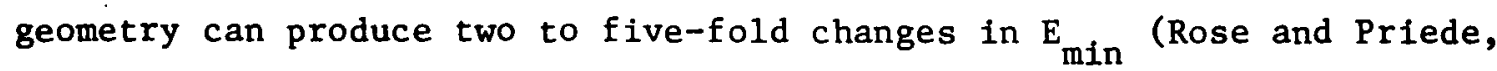
1959). For example, significant reductions in $E_{\min }$ (and $d_{q}$ ) occur as the electrode size is reduced or the circuit resistance is increased (Rose and Priede, 1959; Ballal and Lefebvre, 1975). For break sparks, the Ignition energy approaches values listed in Table 2.1, even for spark gaps below $d_{q}$, due to the fact that broken wires present electrodes which are very small compared to the flame kernel (Litchfield, 1960). Thus, it is prudent to assume that ignition energies as low as $0.3 \mathrm{~mJ}$ may be sufficient to ignite flammable mixtures produced via rupture of LNG tanks.

The most useful data for ignition in flowing gases has been developed by Ballal and Lefebvre $(1975,1977)$. They find that the optimum spark duration for minimum ignition energy is unaffected by turbulence, but decreases with an increase in velocity. The highest values of optimum spark duration were obtained with stoichiometric mixtures. The ignition energy was found to be linearly proportional to gap width above $d_{q}$ and rose only slightly with increases in pressure and velocity. However, further evaluation of $\mathrm{E}_{\min }$ and $\mathrm{d}_{\mathrm{q}}$ measurements showed that velocity per se has little effect on $E_{\text {min }}$ except insofar as it changes the turbulence intensity $u^{\prime}$. Correlation of the data showed that

$$
\mathrm{d}_{\mathrm{q}}=\frac{\mathrm{Aa}}{\left(\mathrm{S}_{\mathrm{L}}-\mathrm{B}_{1} \mathrm{u}^{\prime}\right)}
$$

for low intensity turbulence and

$$
d_{q}=\frac{A \alpha}{\left(S_{T}-B_{2} u^{\prime}\right)}
$$

for high intensity turbulence, where $S_{L}$ is the laminar flame speed, $S_{T}$ the turbulent flame speed, $\alpha$ the thermal diffusivity and $A, B_{1}, B_{2}$ constants equal to $10,0.16$ and 0.63 , respectively. För stagnant $\mathrm{m} 1 \mathrm{x}-$ tures, $u^{\prime}=0$ and thus

$$
\mathrm{d}_{\mathrm{q}}=\mathrm{Aa} / \mathrm{S}_{\mathrm{L}}
$$


which shows, as expected from thermal ignition theory, that the quenchIng distance is directly proportional to flame thickness $\delta_{f}\left(\delta_{f} \propto \alpha / S_{L}\right)$ and inversely proportional to flame speed (Mullins and Penner, 1959).

The minimum ignition energy may be obtained by recognizing that $E_{\min }$ is the energy required to heat a spherical volume of gas, of diameter equal to the quenching distance for that mixture, up to the adlabatic flame temperature, i.e.,

$$
E_{\min }=\rho C_{p}\left(T_{f}-T_{o}\right)\left(\frac{\pi}{6} d_{q}^{3}\right)
$$

Equation 2.4 has been verifled experimentally by Ballal and Lefebvre (1977). Hence, for a stagnant mixture, we have

$$
E_{\text {min }}=\frac{\pi}{6} \frac{k A^{3} \alpha^{2}}{S_{L}^{3}}\left(T_{f}-T_{o}\right)
$$

where $k$ is the thermal conductivity, $T_{f}$ the adiabatic flame temperature and $\mathrm{T}_{0}$ the ambient temperature.

Using equation (2.5) for stoichiometric methane-air, we find $E_{m i n}$ $\simeq 0.3 \mathrm{~mJ}$ thus conffrming the data of Table 7.4. No doubt this minimum ignition energy would be available if any break sparks formed during the collision process. However, as indicated earlier, most electrical lines are placed along the centerline of the ship and would not be damaged by tanker 1mpact. Hence, we conclude that ignition via frictionallyinduced hot surfaces is more likely than ignition via electrical sparks.

\subsubsection{Frictional Heating and Ignition}

\subsubsection{Mechanism of Frictional Heating}

One of the most well-known features of frictional ignition is that the probability of ignition increases for higher frictional contact forces and relative velocities. An obvious correlation is that higher loads and velocities will increase the temperature of the contact surface. The relevant mechanisms are discussed in detail in Appendix $F$. In general, experimental work has demonstrated the following important results (Bowden and Tabor, 1950): 
(1) Surface heating is confined to a thin layer at surface asperities where rubbing actually occurs.

(2) The maximum surface temperature is limited by the lower of the melting points of the rubbing materials.

(3) Below the melting point, the steady state surface temperature is proportional to $\mathrm{p}^{1 / 2} \mathrm{~V}$ where $\mathrm{P}$ is the normal surface force ( $n t)$ and $V$ the relative velocity of the two surfaces $(\mathrm{m} / \mathrm{s})$.

At moderate forces and speeds, surface temperatures greater than $1000^{\circ} \mathrm{C}$ are easily reached. Temperature rise times for a single asperity range from 0.5 to $5.0 \mathrm{msec}$. As each asperity undergoes plastic deformation, the load shifts to other asperities thus creating a hot surface over the entire contact area.

For the case of colliding tankers, heating at the contact area leads to the formation of a hot surface immediately preceding the contact region on the sliding bow (see Figure 7.1). At longer contact times, the hull of the struck ship near the point of penetration may also reach temperatures greater than $1000^{\circ} \mathrm{C}$. The size of the hot surface is determined by the rate of heat conduction into the metal and the relative velocity and shape of the two impacting bodies. The hot surface will remain a potential ignition source as long as motion between the two metal surfaces continues to create a hot spot of sufficient size and temperature.

\subsubsection{Temperature, Size and Duration of Hot Surface}

The method of Holm (1948) has been employed to estimate the surface temperature and size produced by broadside impact of an LNG tanker by the bow of either a cargo vessel or a crude oil tanker. Vaporization and mixing of LNG and air are assumed rapid enough to provide a flammable mixture at the hot surface during its lifetime. A simple momentum analysis for a completely inelastic collision is used to calculate frictional load. Constant deceleration is assumed in order to calculate velocities at various times before and after LNG tank penetration. 
Reaction to the impact force is supplied solely by the interfaces between the striking bow and the outer and inner hulls of the LNG tanker, as shown in Figure 7.1.

Surface temperatures during and following the contact period are determined by modeling surface asperities as a stationary contact to which a source of heat is suddenly applied or taken away (Holm, 1948). Both steady state and non-steady state temperatures are considered. The steady-state temperature ' $\mathrm{I}_{\mathrm{s}}$ ' is given by

$$
T_{s}-T_{0}=\frac{\sqrt{3 \pi Y} Q}{8 k \sqrt{P / n}} .
$$

where $T_{0}$ is the initial surface temperature, $Y$ the elastic 1 imlt, $Q$ the heat production rate due to friction, $k$ the thermal conductivity, $P$ the normal contact force and $n$ the number of asperities. The heat production rate is related to the contact force and relative velocity $\mathrm{V}$ by

$$
Q=\mu \frac{P V}{n}
$$

where $\mu$ is the coefficient of friction which is assumed equal to unity based on friction machine experiments. Combination of equations (3.1) and (3.2) shows that the surface temperature is indeed proportional to $\mathrm{P}^{1 / 2} \mathrm{~V}$. Frictional load $\mathrm{W}_{\mathrm{p}}$ is related to the contact force $\mathrm{P}$ by $\mathrm{W}_{\mathrm{p}}=\mathrm{P} / \mathrm{A}_{\mathrm{a}}$ where $\mathrm{A}_{\mathrm{a}}$ is the apparent contact area, assumed to be $2 \mathrm{~mm}$ in width and $50 \mathrm{~mm}$ in length (Figure F.4). Further details of the methodology for calculating frictional load, relative velocity and surface temperature are presented in Appendix $F$.

For loads $\left(W_{p} \simeq 10^{7} \mathrm{nt} / \mathrm{m}^{2}\right)$ and velocities $\left(v_{p} \simeq 2-4 \mathrm{~m} / \mathrm{s}\right)$ typical of tanker collisions, both the steady and non-steady state surface temperatures proved to be significantly greater than the melting point of steel. Hence, the peak temperature of the surface can be estimated very well by 1 ts melting point, which is approximately $1500^{\circ} \mathrm{C}$.

The size of the hot surface is determined by the rate of heat transfer into the metal downstream of the contact region. A conservative estimate of surface width can be obtained by assuming a minimum surface temperature of $1200^{\circ} \mathrm{C}$. Thus, the surface temperature is 
defined to vary from $1500^{\circ} \mathrm{C}$ at the contact point to $1200^{\circ} \mathrm{C}$, furthest away from the contact region. For such surfaces, the width is found to be $0.2-13 \mathrm{~mm}$, giving an area of $10-650 \mathrm{~mm}^{2}$. As we will see later, previous work and our own experiments show that surfaces of this size and temperature are sufficient to ignite methane-air mixtures.

Based on the time required to reach zero relative velocity, we estimate that after LNG tank rupture, the hot surface will be accessible to methane-air mixtures for 0.5-5.0 s (Append1x F). However, higher gas velocities or momentary contact could decrease the gas-solid contact time to as little as one msec. Estimates of gas velocities during LNG tank rupture are not available; we judge that gas-solid contact times of 0.5-5000 msec are not unlikely. Contact times are also influenced by the local gas flow pattern and boundary layer disruptions. The existence of recirculation zones, for example, promotes quasi-stationary regions which could "see" the surface for the entire 11fetime of the hot spot. In this investigation, we sought to establish whether ignition would occur during a ship collision with maximal surface temperatures, surface areas, and duration. We thus consider the "worst reasonable!" case--a $1200-1500^{\circ} \mathrm{C}$ hot surface, 1 - 10 m in width and 1 - 5 sec in duration.

\subsubsection{Ignition by Frictional Heating}

Nearly all work on ignition by frictional heating is so qualitative or device-specific as to be almost worthless with respect to the development of a fundamental ignition criterion. Two basic problems characterize most work of this nature: (1) ignition by a hot surface has not been clearly distinguished from ignition by frictional sparks, and (2) surface temperature, size and duration induced by frictional heating before ignition has not been measured, except for the recent study by Blickensderfer. (1975). The reviews by Powell (1969) and Desy et al. (1975) suggest the following conclusions for methane-air mixtures: 
(1) Ignition by steel-steel friction is possible but difficult. The probability of ignition increases with Increasing load and relative velocity due to higher surface temperatures and larger heated areas accessible to flammable mixtures.

(2) Ignition is favored by materials of high melting point.

(3) Methane-air equivalence rattos near $\phi \simeq 0.7$ are most conducive to ignition.

(4) For heated surfaces, temperatures greater than $1000^{\circ} \mathrm{C}$ are required for ignition at all equivalence ratios.

Steel-steel impact experiments have shown that rubbing is essential to ignition. High loads or velocitles alone are not sufficient. Rae (1966), for example, found that for two $25 \times 25 \mathrm{~mm}$ steel surfaces, ignition of methane-air mixtures is possible at a relative velocity of $4.6 \mathrm{~m} / \mathrm{s}$ only for loads above $2000 \mathrm{nt}$. At $9.2 \mathrm{~m} / \mathrm{s}$, loads above $1300 \mathrm{nt}$ were sufficient. Powell (1969) and Desy et al. (1975) report that methane-air ignition for rock-rock systems is more probable for rocks of higher quartz content. This result is to be expected since the melting point of rock increases with quartz content and the surface temperature is limited by the material melting point. Rae (1966) finds that methane-air ignition for rock-metal friction is favored by metal melting points above $1000^{\circ} \mathrm{C}$. Bowden and Lewis (1958) and Rae et al. (1964) find that methane-air ignition by hot surfaces requires temperatures greater than $1000^{\circ} \mathrm{C}$, thus confirming Rae's (1966) observations. This temperature is larger than the spontaneous ignition temperature due to convective currents and the relatively small size of the heated surface. The ignition probability, in general, will depend on temperature, surface size and orlentation, time at temperature, fuel, stoichiometry and gas velocity.

Blickensderfer (1975) has conducted the most fundamental study of methane ignition by frictional heating. Rock-metal impact was simulated by pushing a metal rod into a sandstone flywheel. Impact energies in 
an air-7\% natural gas mixture were measured by determining the angular velocity of the flywheel just before and after impact. The 1mpact zone was analyzed using high speed photography and two-color optical pyrometry. The temperature, 11fetime and area of the hot surface were investigated using a non-steady conductive heat transfer analysis.

The experiments were plagued by reproducibility problems; however, several consistent patterns emerged from the many tests performed. Ignition was always accompanied by a bright yellow flash in the impact region and the formation of a molten metal smear on the rock surface. High speed photography suggested association of ignition with the hot surface rather than the yellow flash (an intense spark shower?). This conclusion was corroborated by two-color pyrometry of a $1 \mathrm{~cm}^{2}$ area behind the impact zone which showed an average surface temperature of $\sim 1420^{\circ} \mathrm{C}$, rough $1 \mathrm{y}$ equivalent to the melting point of mild steel. The measured impact energy decreased just prior to ignition, again indicating surface melting of the steel.

Previous studies had shown that ignition probability increases with higher relative velocity. This result was invariably explained by the existence of higher surface temperatures. However, Blickensderfer (1975) points out that higher velocities will also increase the area of the metal smear since less time will be available for heat transfer to the underlying sandstone. Hence, for loads and velocities sufficient to achieve melting of the metal, the biggest effect of velocity is the development of enough area for ignition. The probability of ignition will then depend on the exact area and lifetime of the smear. For steel or sandstone, Blitckensderfer (1975) finds a hot streak length of $2-8 \mathrm{~mm}\left(\mathrm{~A}^{*}=250-800 \mathrm{~mm}^{2}\right)$ at velocities of $1.5-4.6 \mathrm{~m} / \mathrm{s}$ and 1 ifetimes of $\sim 2 \mathrm{msec}$, as determined by both theory and experiment. The lifetime is mainly controlled by metal freezing; an additional $1 \mathrm{msec}$ is possible if oxidation of steel is significant. The important conclusion is that at $1500^{\circ} \mathrm{C}$, such areas and lifetimes are sufficient for methane-air ignition. Similar areas at even larger lifetimes will be available during tanker collision. 


\subsubsection{Ignition by Hot Surfaces: Experimental}

We have seen that the ignition of stagnant methane-air mixtures during frictional heating should depend on the temperature, size and lifetime of the hot surface. For a moving mixture, the influence of surface orientation and velocity will also be important. In this section, we verify and quantify these effects by reviewing studies concerned with ignition by hot surfaces. Theoretical approaches to this problem are then considered in order to develop suitable correlations and predictive procedures.

\subsection{Stagnant Ignition}

We consider first ignition in relatively stagnant mixtures. No mixture is of course truly stagnant due to the buoyancy driven convection caused by a heated surface, particularly in a closed vessel. As might be expected, the ignition process has been studied using heated rods, spheres and plates. However, no definitive study varying temperature, size and lifetime in a systematic fashion has been performed.

Coward and Guest (1922) studied ignition of natural gas $\left(93.2 \% \mathrm{CH}_{4}\right.$, $3.3 \% \mathrm{C}_{2} \mathrm{H}_{6}$ )--air mixtures in a large explosion chamber. Horizontally mounted strips $1 \mathrm{~mm}$ thlck, $12.5 \mathrm{~mm}$ wide and $100 \mathrm{~mm}$ long were electrically heated and the maximum temperature monitored by affixing a thermocouple to the center of the strip. The results using nickel and platinum are shown in Figure 7.5. The nickel temperatures proved to be reproducible; the platinum temperatures varied considerably but were always higher than the former and exhibited a maximum at stoichiometric conditions. Similar results were obtained by coating the nickel strip with platinum or palladium. These observations show that nickel is inert while platinum is catalytic, a conclusion substantiated by $\mathrm{CO}$ and $\mathrm{CO}_{2}$ measurements in the chamber prior to ignition. The results for nickel demonstrate two important features: ignition temperatures greater than $1000^{\circ} \mathrm{C}$ for large surface areas $\left(\sim 1250 \mathrm{~mm}^{2}\right.$ ) and higher ignition probabilities for fuel lean conditions. 


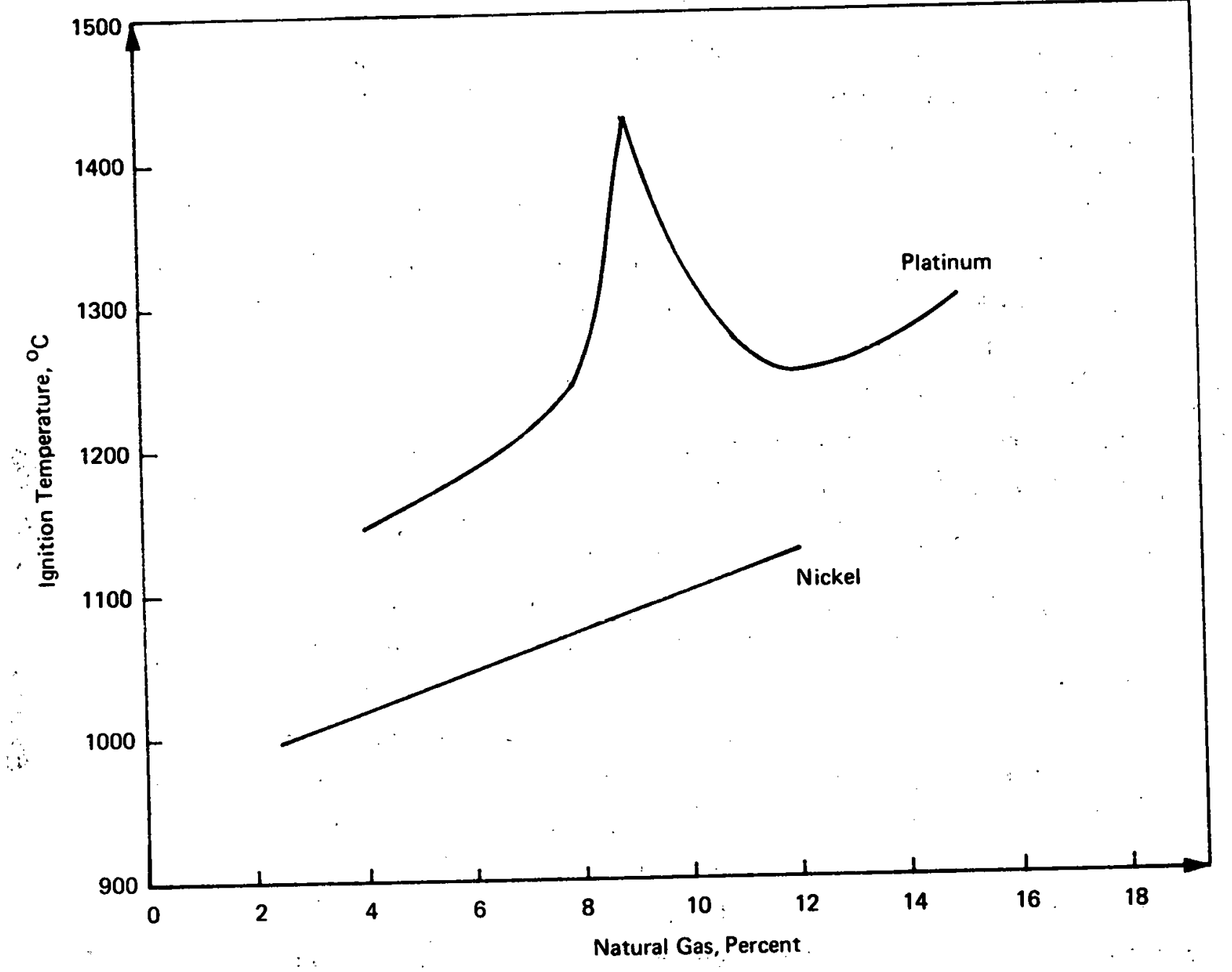

FIGURE 7.5 IGNITION OF NATURAL GAS-AIR MIXTURES BY HEATED STRिIPS OF NICKEL AND PLATINUM ICOWARD AND GUEST. 1927) 
The early work of Stout and Jones (1949) suggests that higher ignition temperatures are required under conditions of rapid heating and cooling since the lifetime of the hot surface is too short to provide sufficient heat transfer unless large temperature gradients are available. Cutler (1974) has provided recent evidence to support this conclusion. A strip of tungsten foll was rapidly heated by capacitive discharge. The temperature-time profile was followed by two-color pyrometry. The typical profile showed heatup at $\sim 275^{\circ} \mathrm{C} / \mathrm{msec}$ to a peak temperature of $1700-2000^{\circ} \mathrm{C}$, followed by immediate cooldown at $\sim 2.5^{\circ} \mathrm{C} /$ msec. Figure 7.6 demonstrates the influence of methane composition and surface area on the peak temperature required for $50 \%$ ignition probability. Note that the ignition temperature is a minimum at $7 \%$ methane $(\phi \simeq 0.7)$ and decreases in a linear fashion with increasing strip size. The $1700-2000^{\circ} \mathrm{C}$ range is considerably higher than the results of Coward and Guest (1927) or Rae et al. (1964) which are obtained for much larger 1ifetimes. The influence of surface lifetime near peak temperature is also demonstrated by the fact that Cutler (1974) observed higher ignition probabilities for slower heatup or cooldown rates.

The influence of surface size is best demonstrated by the work of Silver (1937), Paterson (1940) and Rae et al. (1964). Silver (1937) and Paterson (1940) simulated ignition via frictional sparks by injecting small spherical pellets at a known temperature into a chamber containing explosive gas. A narrow range of pellet temperatures was found below which no ignition occurred and above which ignition occurred instantly on pellet injection. The pellets were introduced to the chamber by dropping them from a fixed height or shooting them down an entrance tube via a short air blast. The ignition temperature of methane-air mixtures was too high for these experiments and thus extensive use was made of an available coal gas of composition $50.1 \% \mathrm{H}_{2}$, $18.8 \% \mathrm{CH}_{4}, 19.4 \% \mathrm{CO}, 6.5 \% \mathrm{~N}_{2}, 3.4 \% \mathrm{CO}_{2}, 2.3 \% \mathrm{C}_{\mathrm{n}} \mathrm{H}$ and $0.5 \% \mathrm{O}_{2}$. Identical results were obtained with spheres made from quartz and platinum "aged" in the coal gas at $1000^{\circ} \mathrm{C}$. Data from low speed experiments for coal gas-air and pentane-air are shown.in.Figure 7.7 (Lewis and von Elbe, 1961). The ignition temperature decreases sharply with decreasing 

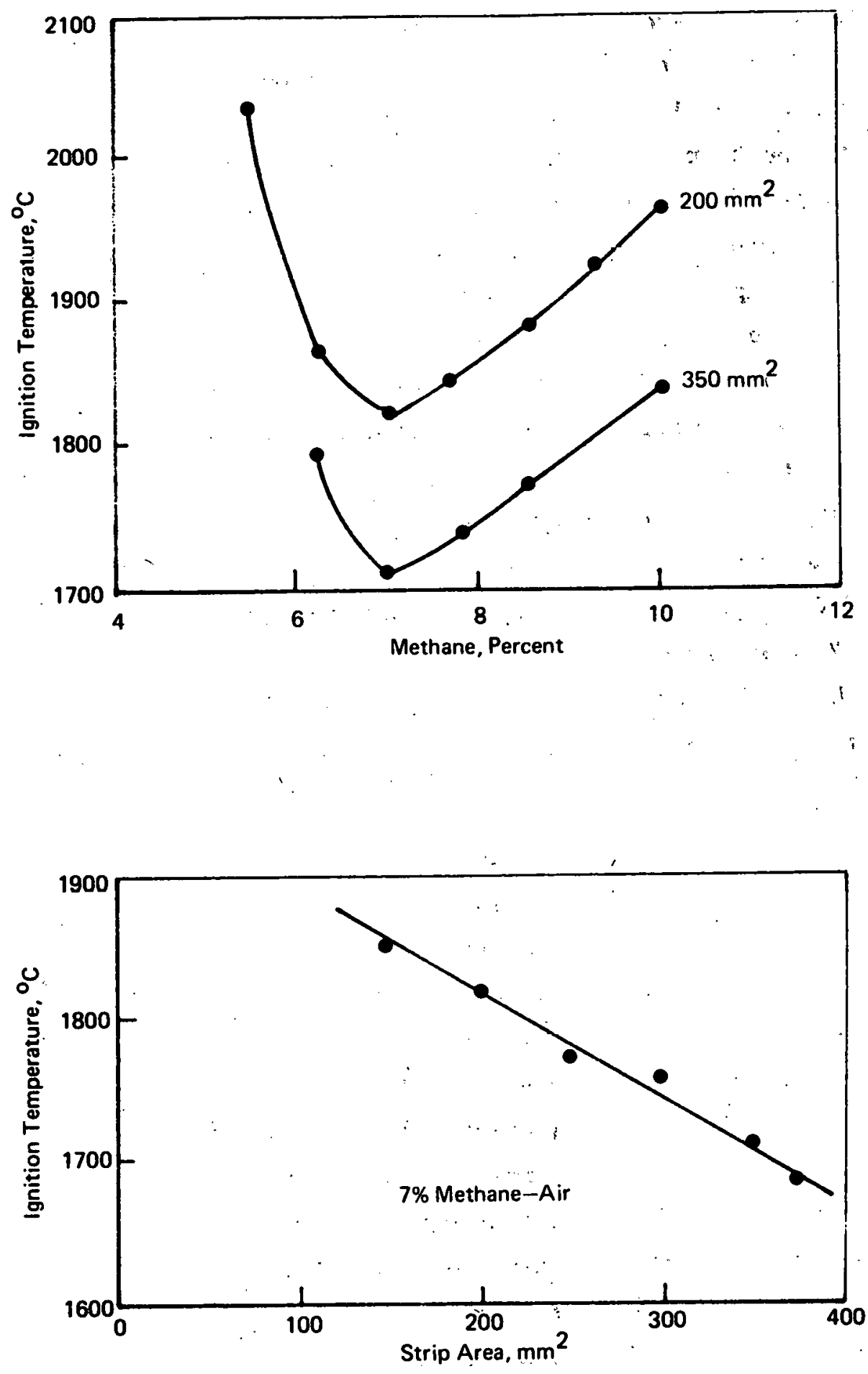

FIGURE 7.6 VARIATION OF IGNITION TEMPERATURE WITH METHANE COMPOSITION AND AREA OF TUNGSTEN STRIP (CUTLER, 1974) 


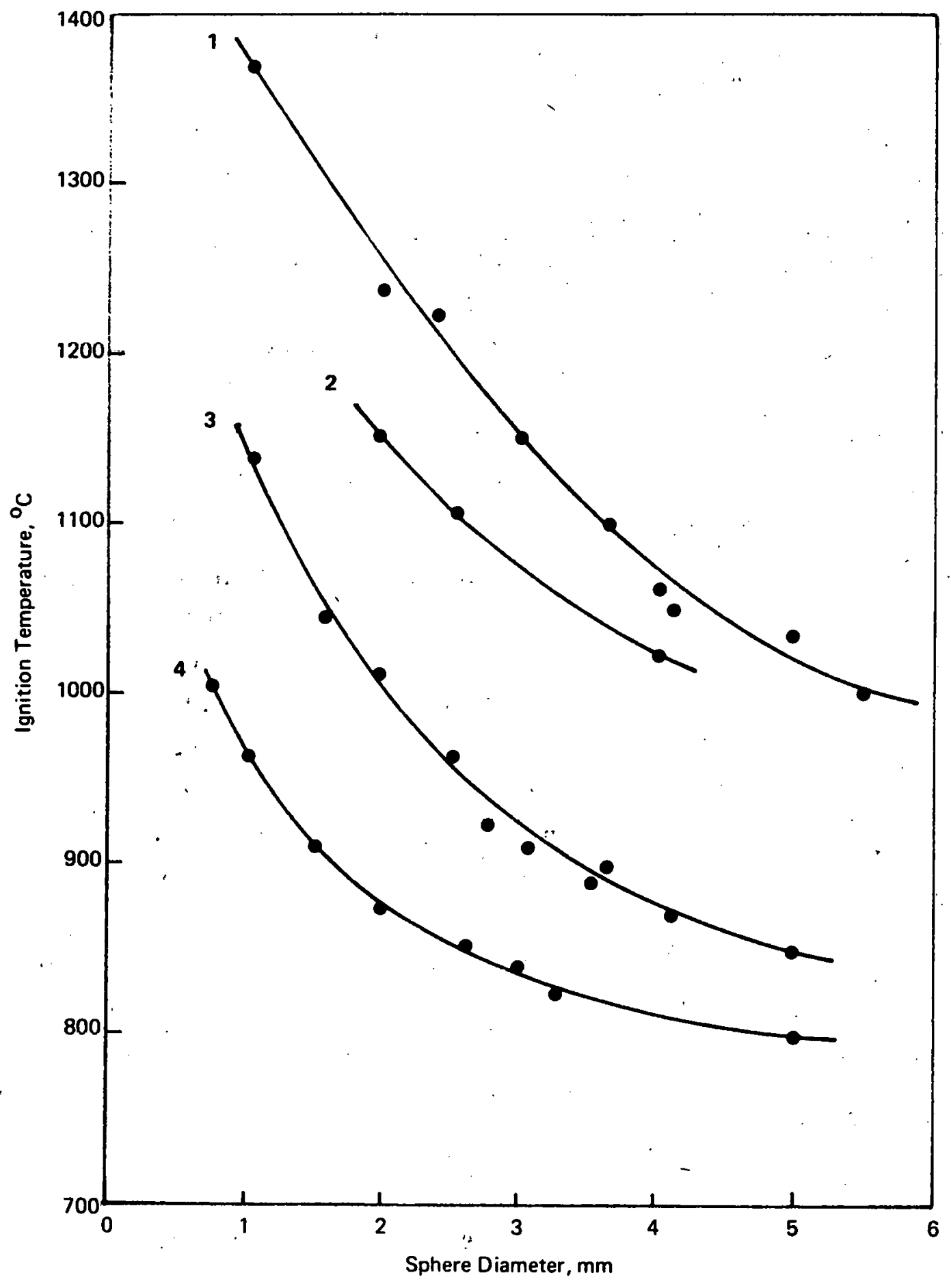

FIGURE 7.7 IGNITION TEMPERATURES FOR SPHERES OF VARYING DIAMETER PASSING THROUGH FUEL-AIR MIXTURES. LEGEND: (1) 3\% PENTANE @ 4m/s; (2) 3\% PENTANE @ $1.2 \mathrm{~m} / \mathrm{s} ;$ (3) 10\% COAL GAS @ $\sim 4 \mathrm{~m} / \mathrm{s} ;$ (4) 10\% COAL GAS @ $1.2 \mathrm{~m} / \mathrm{s}$ (SILVER, 1937; PATERSON, 1940). 
pellet diameter; the effect of velocity is demonstrated by the difference in ignition temperature between runs at $\sim 4$ and $1.2 \mathrm{~m} / \mathrm{sec}$.

Rae et al. (1966) have made the most complete study of the influence of surface area and orlentation on the ignition of methane-a1r mixtures. Small electrically heated square areas of platinum covered with $0.5 \mathrm{~mm}$ of alumlna were set flush with one wall of an explosion box. The heated surface was covered before being suddenly exposed to flammable mixtures. The surface temperature was measured by optical pyrometry and the minimum ignition temperature was defined as that surface temperature giving an ignition delay time greater than one second. The influence of natural convection was studied by placing the hot surface in the center of the roof, wall and floor of the explosion box.

Typical experimental results are shown for a $6 \%$ methane-alr mixture in Figure 7.8. The surface size necessary for ignition increases rapidly for temperatures below about $1100^{\circ} \mathrm{C}$; the surface temperature necessary for ignition increases rapidly for areas below $10 \mathrm{~mm}^{2}$. At $1500^{\circ} \mathrm{C}$, ignition is not possible for surfaces less than about $7 \mathrm{~mm}^{2}$. For areas greater than $100 \mathrm{~mm}^{2}$, the ignition temperature decreases nearly linearly with increasing surface area, as in Figure 7.6 (Cutler, 1974). As expected, convective effects become unimportant as surface area decreases; for areas greater than $\sim 100 \mathrm{~mm}^{2}$, the ignition temperature is least for the floor position, with a $50^{\circ} \mathrm{C}$ increase for the roof position and another $50^{\circ} \mathrm{C}$ rise for the wall position. Data at other stoichiometries indicates a shift in ignition temperature of about $20^{\circ} \mathrm{C}$ upwards for each percent concentration increase from 6 to 12 percent methane in a manner similar to Coward and Guest (1927). Thus, we again have the highest ignition probability at $\phi \underline{\simeq} 0.7$.

\subsection{Influence of Veloctty and H1gher Hydrocarbons}

The effect of surface orfentation with respect to buoyancy-driven convective currents is demonstrated by Figure 7.8 (Rae et al., 1964). As the strip orientation is changed with respect to the moving gas, the average velocity past the heated strip can undergo significant variation. As the velocity decreases, more heat is transferred to the gas 


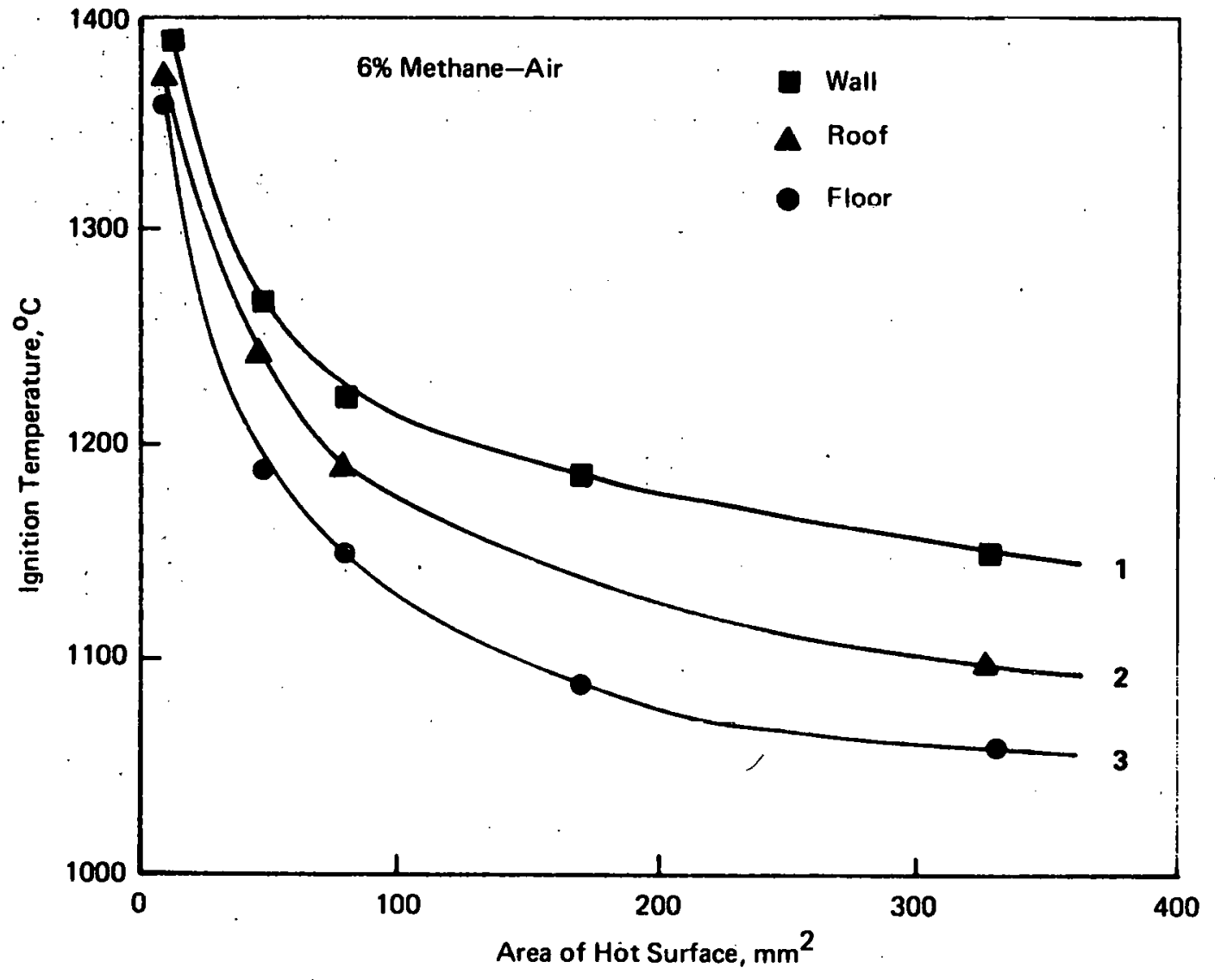

FIGURE 7.8 IGNITION TEMPERATURES FOR PLATES OF VARYING SIZE AND POSITION IN AN EXPLOSION BOX CONTAINING 6\% METHANE (RAE et al., 1964). LEGEND: (1) WALL; (2) ROOF; (3) FLOOR. 
and the ignition temperature decreases. If shields are mounted near the strip or a small gas flow is directed against the convective flow, for example, the ignition temperature will decrease; for higher gas flows, the ignition temperature will of course increase (Lewis and von Elbe, 1961). Figure 7.7 demonstrates the latter for relative velocities of 1.2 and $\sim 4 \mathrm{~m} / \mathrm{s}$ past spherical pellets (Silver, 1937; Paterson, 1940).

Higher velocities have been investigated by Mullen et al. (1949), Paterson (1940) and Toong (1957). No results are, however, available for methane because, of the inconveniently high ignition temperatures. Mullen et al. (1949) studied the ignition of fuel-air streams passing over electrically heated cylindrical rods. The typical, rod was about $6 \mathrm{~mm}$ long and its temperature was measured by optical pyrometry. High speed photographs showed that ignition develops, as expected, In the stagnant gas near the downstream face of the heated cylinder. Systematic measurements of rod temperature and stream velocity were made to determine the ignition threshold. The typical upward concavity of ignition temperature vs stream velocity is shown in Figure 7.9.' Mullen et al. (1949) suggest that this trend reflects the temperature dependence of the chemical reaction rate. Higher stream velocities shorten the residence time in the wake, thus requiring higher temperatures to complete chemical reaction. Mullen et al. (1949) also found higher ignition temperatures at higher turbulence levels, lower rod diameters, higher initial gas temperature and higher gas pressure. Minimum ignition temperatures were found on the fuel lean side for hydrogen and on the rich side for pentane. Lewis and von Elbe (1961) ascribe this result to diffusional stratification, i.e., the lower molecular weight gas diffuses more rapidly, thus giving stoichiometric conditions in the wake at the minimum ignition temperature.

Results similar to those of Mullen et al. (1949) have been obtained by Paterson (1940). and Toong (1957). Paterson (1940) 1gnited coal gasair mixtures using 2 and $3.5 \mathrm{~mm}$ diameter spheres at $10-65 \mathrm{~m} / \mathrm{s}$. Toong (1957) ignited ethanol-air mixtures moving at $10-20 \mathrm{~m} / \mathrm{s}$ using a $50 \mathrm{~mm}$ long strip fitted into a $12 \mathrm{~mm}$ I. D. steel tube. Paterson's (1940) 


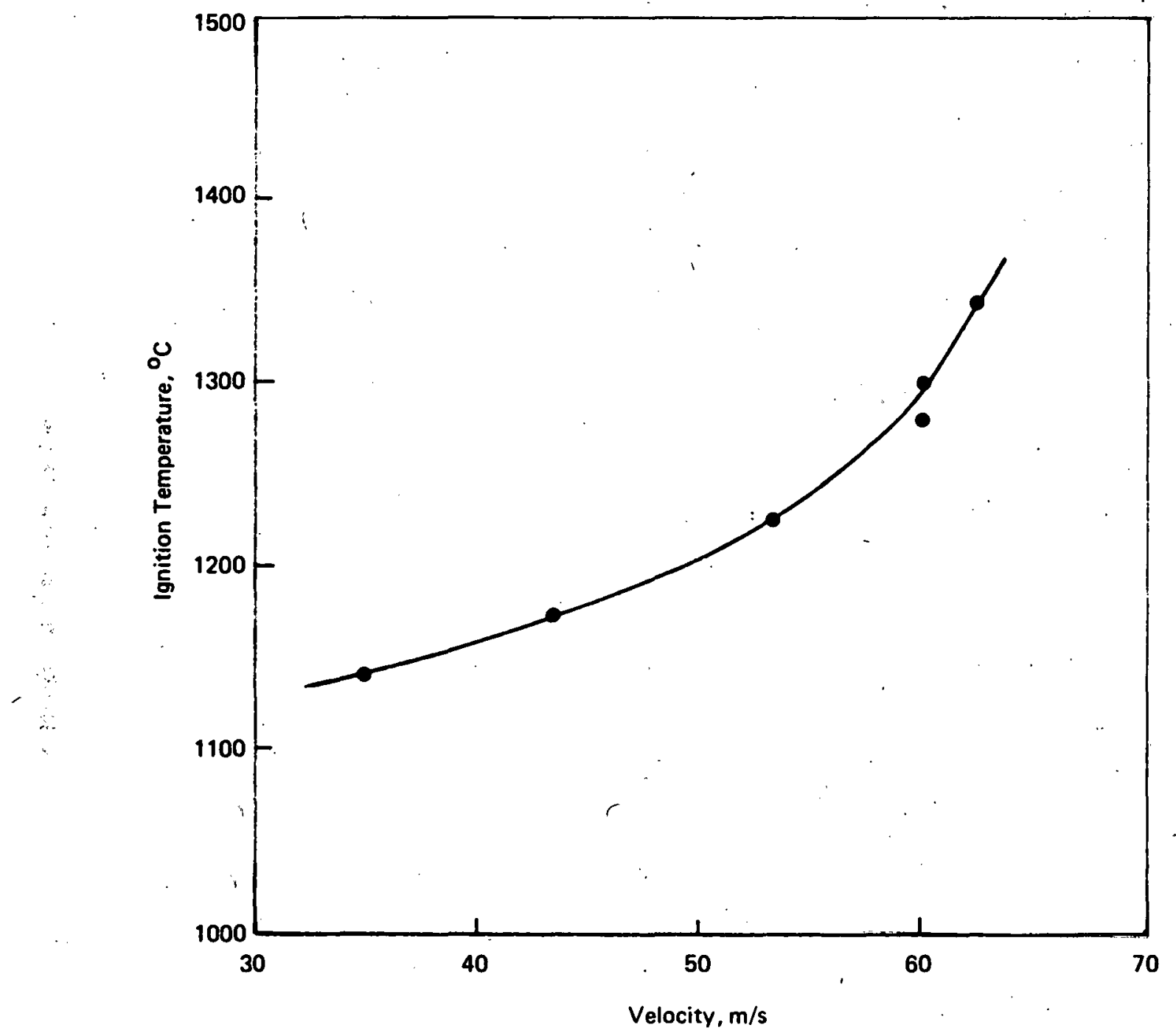

FIGURE 7.9 IGNITION TEMPERATURE VS. STREAM VELOCITY FOR $6 \mathrm{~mm}$ DIAMETER HEATED ROD. STOICHIOMETRIC PENTTANE-AIR AT $70^{\circ} \mathrm{C}$ AMBIENT TEMPERATURE (MULLEN et al., 1949)

$7-3 n$ 
results demonstrate curvature similar to those of Mullel et al. (1949) while those of Toong (1957) are more nearly linear.

The influence of higher hydrocarbons on methane ignition is of great importance to the question of LNG ignition. Evaporation of LNG favors methane-air mixtures due to the low boiling point of methane, but small. quantities of higher hydrocarbons could lower the ignition temperature significantly. No direct measurement of the influence of hydrocarbon additives on methane-air ignition by heated bodies is available in the literature. However, indirect evidence suggests that ignition probability is favored by such additives. The spontaneous ignition temperature of higher hydrocarbons is $\sim 150^{\circ} \mathrm{C}$ lower than that for methane (Table 7.3). Ignition temperatures measured by Coward and Guest (1927) for natural gas appear to be lower than comparable data obtained by Rae et al. (1964) for pure methane-air at the same stoichiometry (compare Figures 7.5 and 7.8 ). In initial tests using $3 \%$ propanealr, Cutler (1974) found an ignition temperature of $\sim 1100^{\circ} \mathrm{C}$ rather than the $1700-2000^{\circ} \mathrm{C}$ range measured for methane-air mixtures.

Corroborative evidence comes from the shock tube work of Lifshitz et al. (1971), Crossley et al. (1972) and Tsuboi and Wagner (1974). Both Lifshitz et al. (1971) and Tsuboi and Wagner (1974) find that methane induction times can be correlated by

$$
\tau_{i}=A\left[\mathrm{CH}_{4}\right]^{1 / 3}\left[\mathrm{O}_{2}\right]^{-1} \exp (\mathrm{E} / \mathrm{RT})
$$

where $\tau_{1}$ is the induction time in seconds, A a frequency factor, $E$ the activation energy and concentrations are expressed in moles/cc. At $\phi=0.5-2.0$ and $T=1225-1875^{\circ} \mathrm{C}$, Lifshitz et a1. (1971) found $A=3.6$ - $10^{-14}$ and $E=195 \mathrm{~kJ}$; at $\phi=0.2-2.0$ and $\mathrm{T}=925-1825^{\circ} \mathrm{C}$, Tsubo $\mathrm{I}$ and Wagner (1974) found $A=2.5 \cdot 10^{-15}$ and $E=222 \mathrm{~kJ}$. Both results give induction times in the $10-1000 \mu \mathrm{sec}$ range.

Crossley et al. (1972) and Lifshitz et al. (1971) determined induction times for stoichiometric methane-oxygen-argon mixtures with and without hydrocarbon additives. Ethane, propane, butane and pentane were added such that the volumetric ratio of additive to methane was 
approximately 5\%. For all additives, induction times were reduced by a factor of two to three. Comparable reduction with hydrogen as the additive required seven times more hydrogen than hydrocarbon. This result suggests a kinetic coupling of oxidative reactions involving the methyl radical. However, for small additions, the induction time data could be formally correlated by simply assuming à thermal effect based on the greater heat of combustion of the higher hydrocarbons. For our purposes, a reduction in induction time suggests lower ignition temperatures; however, the precise influence of additives depends on the extent to which ignition is controlled by molecular transport vs. chemical kinetics.

\subsubsection{Ignition by Hot Surfaces: Theoretical Interpretation}

In this section, we develop a simple correlation for data on forced ignition by hot surfaces. Numerical solution of the conservation equations, as developed by Sharma and Sirignano (1969, 1970), was not pursued due to lack of chemical kinetic data required to make this approach profitable. Moreover, the formulation developed here offers insights into the ignition process of ten overlooked when dealing with the intricacies of numerical techniques.

Our steady-state analysis expands on the original work of Khitrin and Goldenberg (1957) and similar contributions by Adomeit (1965), Alkidas and Durbetak1 (1973b) and Ono et a1. (1976). The basic premise of this development is the so-called Van't Hoff ignition criterion as shown in Figure 7.10. Curve 1 represents conductive heat transfer into the surrounding boundary layer before ignition, while Curve 3 represents heat transfer to the surface from the hot combustion products after ignition. Curve 2 portrays the ignition criterion, -

$$
(\mathrm{dT} / \mathrm{dx})_{\text {wall }}=0
$$

which simply says that at ignition, the rate of heat loss to the surroundings is equal to the rate of heat gain by chemical reaction. 


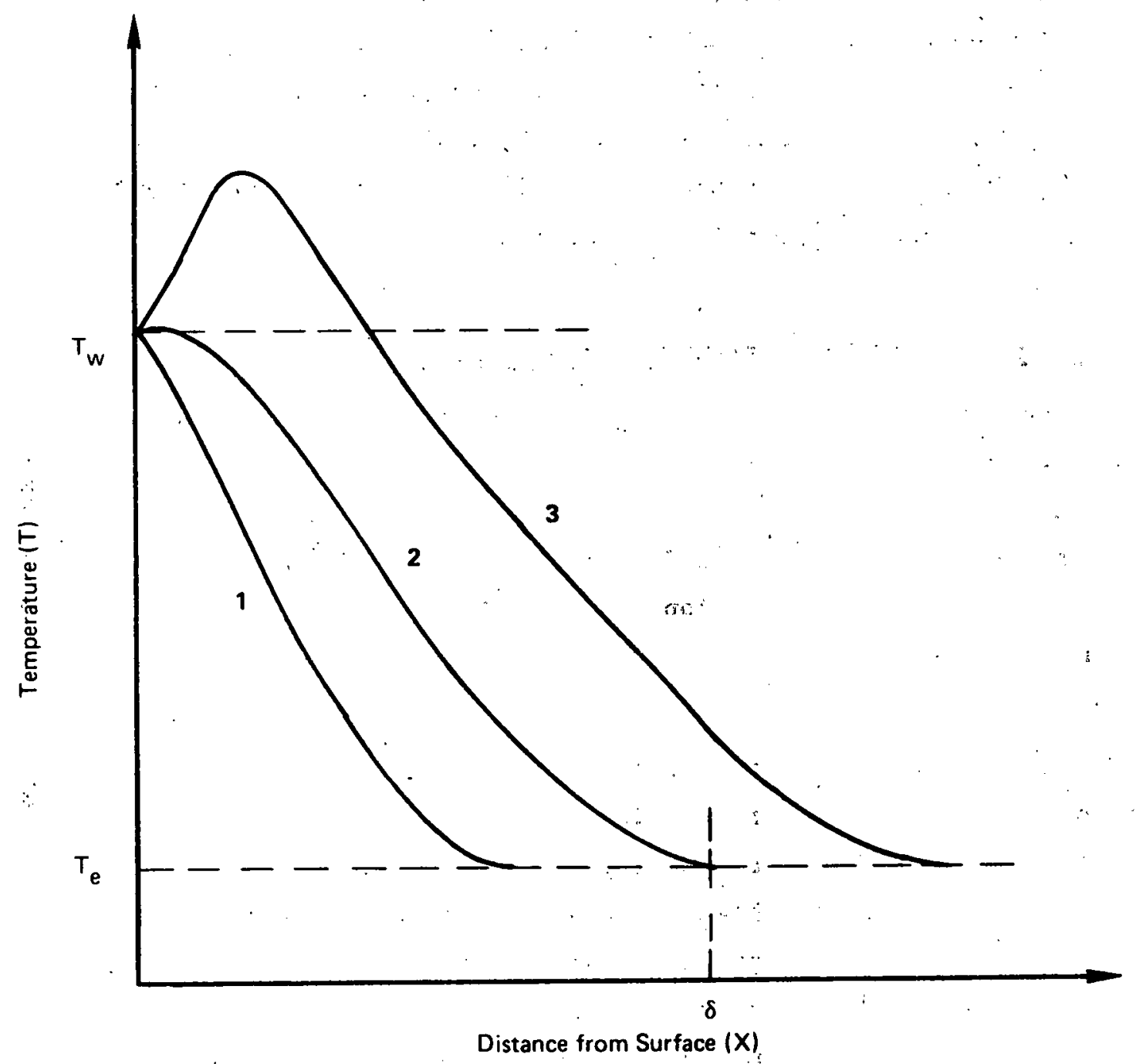

FIGURE $\%$. 10 TEMPERATURE PROFILES NEAR HEATED SURFACE

SURROUNDED BY FLAMMABLE MIXTURE. LEGEND:

(1) BEFORE IGNITION; (2) IGNITION; (3) AFTER IGNITION. 
The applicability of the Van't'Hoff criterion has been verified by Alkidas and Durbetaki (1971, 1973a) and Law (1978a, 1978b). Alkidas and Durbetaki (1971) applied the full conservation equations to the forward stagnation region of a flat plate. The Shvab-Zeldovich formulation and one-step overal1 kinetics were used to simplify the governing equations. The ignition temperature was found by creating an eigenvalue problem via introduction of equation (3.4) as an extra boundary condition. Alkidas and Durbetaki (1973a) subsequently found good agreement between the Van't Hoff approach and numerical results obtained by examining steady state solutions to the conservation equations in the transition region between frozen and equilibrium flow. Law (1978a, 1978b) developed an analytical steady-state solution for both stagnation point ignition and ignition by a stationary particle using the Shvab-Zeldovich formulation combined with a matched asymptotic analysis in the limit of large activation energy. In both cases, the flowfield surrounding the particle could be divided into two regions, an inner diffusive-reactive zone and an outer diffusive-convective zone. A Damkohler number ignition criterion was developed which proved to be independent of the momentum equation and thus applicable to both stagnant and convective flowfields. The Damkohler number criterion was found to imply zero heat transfer between the surface and the gas and hence to be equivalent to the Van't Hoff criterion.

Adomeit (1965) measured the temperature field surrounding a rapidly heated ( $\mathrm{T}_{\max }$ within $10^{-4} \mathrm{sec}$ ) $3-4 \mathrm{~mm}$ diameter chromium-nickel rod using a Mach-Zehnder interferometer. Temperature profiles immediately before, during and after ignition were similar to those shown in Figure 7.10, again verifying the Van't Hoff profile. Until the moment of ignition, the temperature field could be described by simple non-steady conduction with little or no effect due to combustion. Thus, ignition delay was controlled primarily by molecular transport and not chemical kinetics. For stoichiometric pentane-air, ignition delay times of 1-60 ms were found at $950-1200^{\circ} \mathrm{C}$ while the ignition event occurred in $\sim 0.5$ ms. At the lower rod temperatures, pre-ignition fuel consumption was nearly negligible. 
Based on the above, our simple analysis makes use of the following major assumptions:

(1) Ignition can be described by the Van't Hoff criterion.

(2) No reactant depletion occurs until ignition.

(3) Chemical reaction occurs in a stagnant film in the immediate vicinity of the heated body.

(4) Heat transfer is independent of chemical reaction.

(5) Chemical kinetics can be described by a one-step overall chemical reaction, $F+\nu_{0} O x \rightarrow \nu_{p} P$, where $F, O x$ and $P$ represent the fuel, oxidizer and products, respectively, and $v_{o}, v_{p}$ are the molar stoichiometric coefficients for the oxidizer and products.

(6) Physical properties are constant with evaluation occurring at the geometric mean temperature.

Heat transfer at the surface due to chemical reaction can be assessed by integrating the energy conservation equation at the moment of ignition (curve 2 of Figure 7.10). We thus have

$$
k \frac{d^{2} T}{d x^{2}}+Q r_{f}=0
$$

where $k$ is the thermal conductivity of the gas $(\mathrm{J} / \mathrm{m} \cdot \mathrm{k}), Q$ the heat of combustion ( $\mathrm{J} / \mathrm{mole}$ ) and $\mathrm{r}_{\mathrm{f}}$ the molar reaction rate (moles/m $\mathrm{m}^{3} \mathrm{~s}$ ) given by

$$
r_{f}=-X_{F}^{m_{f}} x_{0}^{m_{0}} \rho^{n} A e^{-E / R T} .
$$

where $X_{F}$ and $X_{0}$ are the amblent mole fractions of fuel and oxidizer, $\rho$ the density (moles $/ \mathrm{m}^{3}$ ), A the frequency factor, $E$ the activation energy, $m_{f}$ and $m_{o}$ the partial orders with respect to fuel and oxidizer and $n=m_{f}+m_{0}$ the overall reaction order. The appropriate boundary conditions are given by: 


$$
\begin{array}{ll}
\mathbf{x}=0 & \mathbf{T}=\mathrm{T}_{\mathrm{w}} \\
\mathbf{x}=\delta & \mathrm{T}=\mathrm{T}_{\mathrm{e}}
\end{array}
$$

where $T_{w}$ is the surface temperature and $T_{e}$ the amblent temperature. Evaluating the density $\rho$ at the geometric mean temperature,

$$
\rho=P / R \sqrt{T_{e} T_{w}}
$$

where $P$ is the total pressure, and integrating Equation (3.5) with respect to temperature, we have

$$
k \int_{0}^{\delta}\left(\frac{d T}{d x}\right)\left(\frac{d^{2} T}{d x^{2}}\right) d x=A x_{F}^{m_{f}} x_{0}^{m_{f}} Q \rho_{e}^{n}\left(\frac{T_{e}}{T_{w}}\right)^{n / 2} \cdot \int_{T_{w}}^{T} e^{-E / R T} d T
$$

where

$$
\rho_{\mathrm{e}}: \mathrm{P} / \mathrm{RT}_{\mathrm{e}}
$$

Since

$$
\frac{d T}{d x}\left(\frac{d^{2} T}{d x^{2}}\right) d x=\frac{1}{2} \frac{d}{d x}\left(\frac{d T}{d x}\right)^{2} d x
$$

we have

$$
k\left(\frac{d T}{d x}\right)_{w}^{2}=2 A x_{F}^{m_{f}} x_{0}^{m_{0}} Q p e\left(\frac{T_{e}}{T_{w}}\right)^{n / 2} \int_{T_{e}}^{T} e^{-E / R T} d T
$$

To a good approximation (Kanury, 1975),

$$
\int_{T_{e}}^{T} e^{-E / R T} d T \simeq \frac{R T_{w}}{E} e^{-E / R T_{w}}
$$

and hence the heat transfer due to chemical reaction is given by 


$$
q_{c h e m}=k\left(\frac{d T}{d x}\right)_{w}=\left\{2 k A x_{F}^{m_{f}} x_{0}^{m_{0}} Q_{e} \rho_{e}^{n}\left(\frac{T_{e}}{T_{w}}\right)^{n / 2}\left(\frac{R T_{w}^{2}}{E}\right) e^{-E / R T}\right\}^{1 / 2}
$$

Heat loss from the surface is given by

$$
q_{\text {loss }}=\frac{k N u}{L}\left(T_{w}-T_{e}\right)
$$

where $\mathrm{Nu}$ is the Nusselt number and $\mathrm{L}$ the characteristic size of the heated surface. According to the Van't Hoff criterion,

$$
q_{\text {chem }}=q_{\text {loss }}
$$

Thus, combining equations (3.14), (3.15) and (3.16), our ignition criterion becomes

$$
\left(\frac{\theta_{w}-1}{\theta_{w}}\right)^{2} \theta_{w}^{n / 2} e^{E^{*} / \theta_{w}}=\frac{2 D_{1} D_{2}}{E^{*}}
$$

where $D_{1}, D_{2}, E^{*}$ and $\theta_{w}$ are non-dimensional parameters given by

$$
\begin{aligned}
D_{1}=A\left(P / R T_{e}\right)^{n-1} x_{0}^{m^{o}} / N u^{2}\left(\alpha / L^{2}\right) \\
D_{2}=x_{F}{ }^{m_{f}} Q / C_{p} T_{e} \\
E^{*}=E / R T_{e} \\
\theta_{w}=T_{w} / T_{e}
\end{aligned}
$$

where the thermal diffusivity $\alpha$ is given by

$$
\alpha=k / \rho_{e} C_{p}
$$

and $C_{p}$ is the specific heat at constant pressure.

Equation (3.17) demonstrates that the ignition temperature is determined solely by the Damkohler numbers $D_{1}$ and $D_{2}$ and the nondimensional activation energy $E^{*} . D_{1}$ is a Damkohler number of the first kind and physically represents the ratio of convective-diffusive time to kinetic time. $D_{2}$ is a Damkohler number of the second kind and

$$
7-45
$$


represents the ratio of heat generated by reaction to that provided by the ambient fluid. Equation (3.17) shows that the ignition temperature increases as $E^{*}$ increases or $D_{1}$ and $D_{2}$ decrease, as shown previously by Alkidas and Durbetaki (1971). Since higher convective velocities decrease $D_{1}$, we might expect that an upper velocity exists beyond which ignition will not occur irrespective of the value of $T_{w}$; this conclusion has also been verified by Alkidas and Durbetaki (1971). Equation (3.17) duplicates to within a constant of order unity the Damkohler number criterion developed by Law (1978a, 1978b) using a matched asymptotic analysis. Alkidas and Durbetaki (1973b) find that a similar correlation, corrected for reactant depletion, compares favorably with numerical methods and the flat plate data of Toong (1957). However, successful correlation requires $G_{W} \leq 5$ and $E^{*} / S_{W} \gg I$ since use of heat transfer correlations for frozen flow become problematic under high reactivity conditions.

For most hydrocarbons, $m_{f}=m_{0}=1$ and $n=2$ to a reasonable approximation. Thus equation (3.10) becomes

$$
\frac{\left(\theta_{W}-1\right)^{2}}{\sigma_{W}} e^{* / \sigma_{W}}=\frac{2 D_{1} D_{2}}{E^{*}}
$$

For a given fuel, composition and ambient temperature, we then have

$$
\frac{\left(T_{w}-T_{e}\right)^{2}}{T_{w}} e^{E / R T w} \propto \frac{P L^{2}}{N u^{2}}
$$

where we have used equations (3.18-3.21). The dependence of the ignition criterion on characteristic size $L$ and approach velocity $U_{e}$ depends on the relevant Nusselt number correlation:
(1) stagnant
$\mathrm{Nu}=$ constant
(2) free convection : Nu $\propto L^{3 / 4}\left(T_{w}-T_{e}\right)^{1 / 4}$
(3) forced convection $\mathrm{Nu} \propto \mathrm{L}^{1 / 2} \mathrm{U}_{\mathrm{e}}^{1 / 2}$ 
We then have:

(1) stagnant

$\frac{T_{w}}{\left(T_{w}-T_{e}\right)^{2}} P L^{2} \propto e^{E / R T}{ }^{\prime}$

(2) free convection

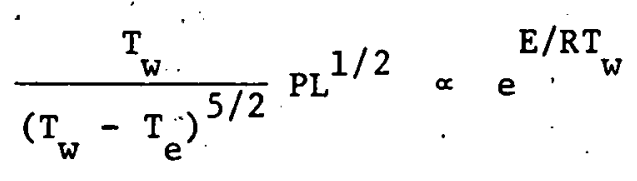

(3) forced convection

$$
\frac{T_{w}}{\left(T_{w}-T_{e}\right)^{2}}\left(\frac{P L}{U_{e}}\right) \propto e^{E / R T}
$$

Most experimentalists have assumed the area of the hot surface to be a primary determinant of ignition temperature. Equations (3.28-3.30) show that this assumption is only applicable to symetric bodies under stagnant conditions; in most cases, the characterist1c length for heat transfer is the relevant correlation parameter. Since the exponential dominates the temperature effect, equations $(3.28-3.30)$ can be approximated as follows:
(1) stagnant
$\ln \left(L P^{2}\right) \propto E / R T_{W}$
(2) free convection$$
\ln \left(P L^{1 / 2}\right) \propto E / R T_{W}
$$
(3) forced convection

$$
\ln \left(P L / U_{e}\right) \propto E / R T_{w}
$$

where $T_{W}$ is the critical wall temperature for ignition.

Application of equations (3.31-3.33) to the data of Figures 7.6 7.10 is shown in Figures 7.11-7.14. Figure 7.11 portrays ignition temperatures measured by Cutler (1974) under rapid heating conditions in a "stagnant" medium. Lifshitz et al. (1971) and Tsuboi and Wagner (1974) found $E / R \simeq 25,000$ for methane-air mixtures. On this basis, we see that stagnant conditions were maintained at lower temperatures whereas free convection obtained at higher temperatures. Such difficulties are not surprising considering the influence of temperature on free convection and the variation from $\mathrm{L}^{1 / 2}$ to $\mathrm{L}^{2}$ demonstrated by 


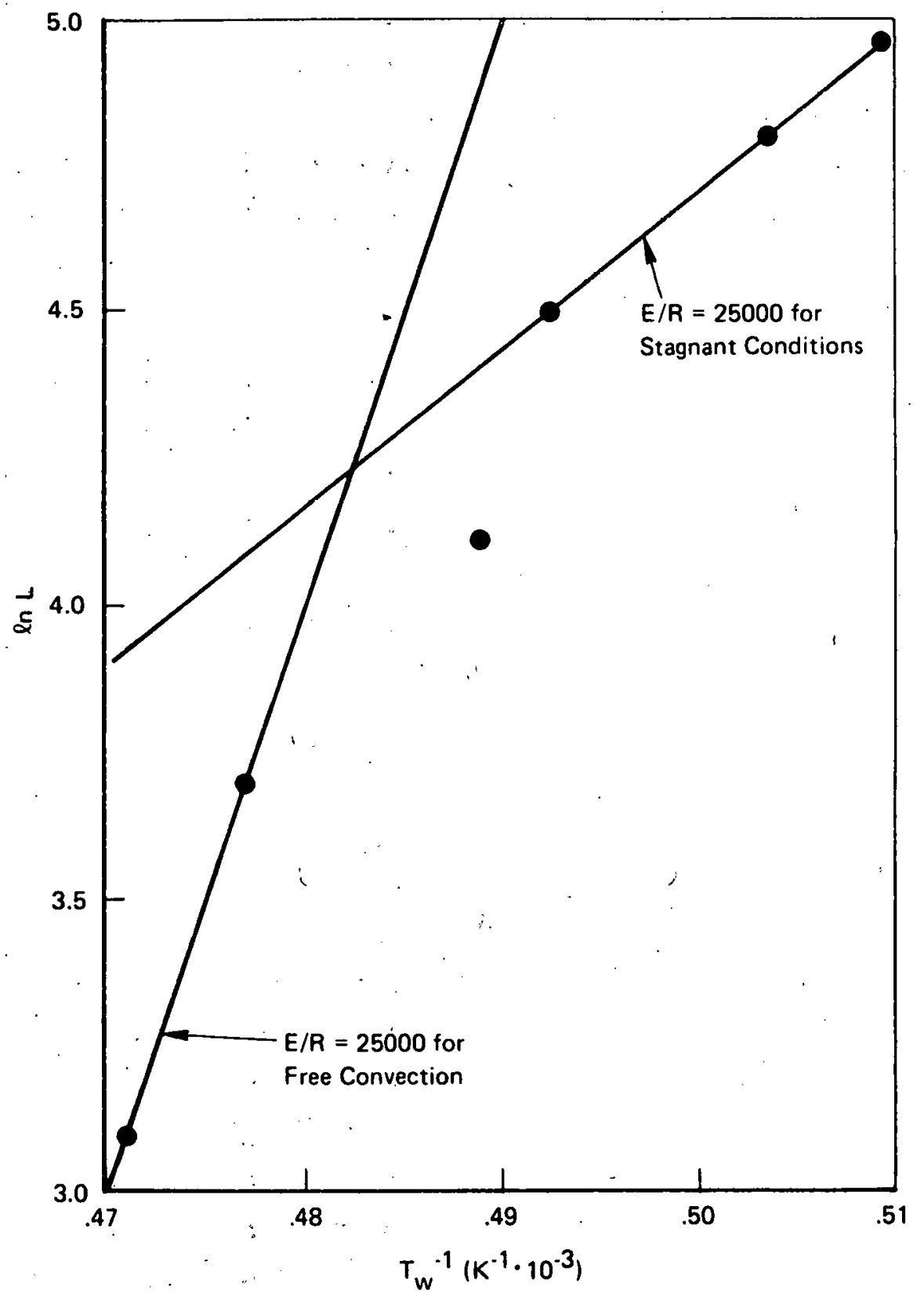

FIGURE 7.11 INFLUENCE OF STRIP SIZE ON IGNITION TEMPERATURE FOR RAPID HEATING IN 7\% METHANE-AIR. STRIP WIDTH-31.7mm; LENGTH $-4.8,6.4,7.9,9.5,11.1,11.9 \mathrm{~mm}$ (CUTLER, 1974). 
equations (3.31) and (3.32). Care has not been taken to isolate such influences in most of the previous literature. Stagnant conditions are more likely to hold in the lower temperature work of Rae et al. (1964) where an already heated surface was suddenly exposed to methane-air mixtures by itemuling a cover plate. Indeed, Figure 7.12 demonstrates the expected E/R of $\sim 25,000$ for heated surfaces placed on the floor and roof of the explosion chamber. The $E / R$ value for the wall is. higher, as might be anticipated, due to the more intense development of free convection currents.

Figure 7.13 demonstrates the validity of equation (3.33) for spheres of varying diameter and velocity of $10 \%$ coal gas-air mixtures (Silver, 1937; Paterson, 1940). Considering the uncertainty in the $4 \mathrm{~m} / \mathrm{s}$ data and the fact that the data were obtained in two different investigations, the agreement shown is quite remarkable. Figure 7.14 demonstrates that the correlation breaks down at high velocities due to the effects of turbulence and wake recirculation.

The most impressive demonstration of the correlation procedure developed here is the recent experimental work of Ono et al. (1976). Vertical steel plates, $0.3 \mathrm{~mm}$ thick, $40 \mathrm{~mm}$ long and 5-30 mm wide, were used to ignite stoichiometric mixtures of $\mathrm{CH}_{4}, \mathrm{C}_{3} \mathrm{H}_{8}, \mathrm{C}_{2} \mathrm{H}_{5} \mathrm{OH}$ and $\left(\mathrm{C}_{2} \mathrm{H}_{5}\right)_{2} \mathrm{O}$ in air. Dominance by free convection was assured through slow heating; hence, ignition always took place at the trailing edge of the flat plate. Equations (3.17) and (3.26) show that at a given ignition temperature, $\mathrm{L}^{1 / 2} \mathrm{P}^{\mathrm{n}-1}=$ constant; this conclusion was verified by ono et a1. (1976) giving $\mathrm{n}=1.7$ for $\mathrm{CH}_{4}, \mathrm{C}_{2} \mathrm{H}_{5} \mathrm{OH}$ and $\left(\mathrm{C}_{2} \mathrm{H}_{5}\right) \mathrm{O}$ and $\mathrm{n}=2$ for $\mathrm{C}_{3} \mathrm{H}_{8}$. Figure 7.15 shows the excellent agreement between experiment and theory (equation 3.32) for stoichiometric methane-air. Ignition temperatures of $1100-1350^{\circ} \mathrm{C}$ are obtained for this size range. Some deviation from the theory can be seen at the highest temperatures owing to the use of frozen flow heat transfer data and the assumption of no reactant depletion. These concerns are especially pertinent at low values of $L$ and $P$ which could hinder proper boundary layer development. Figure 3.11 gives $E / R=21,000$, in good agreement with the $E / R=25,000$ recommended by Lifshitz et al. (1971) and Tsuboi and Wagner (1974). 


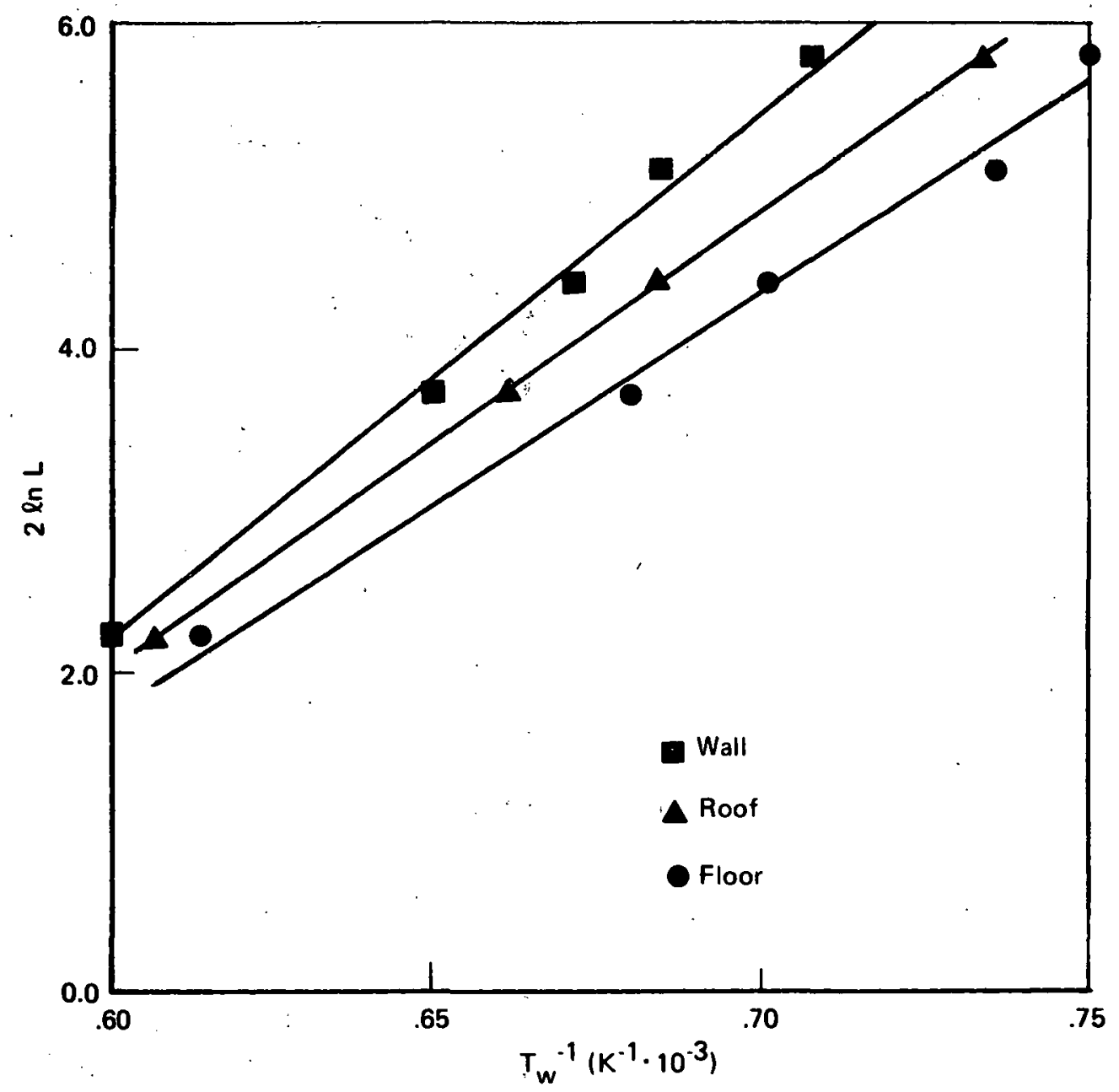

FIGURE 7.12 INFLUENCE OF PLATE AREA ON IGNITION TEMPERATURE FOR 6\% METHANE-AIR (RAE et al., 1964). E/R: WALL-33000; ROOF-28000; FLOOR-26000. 


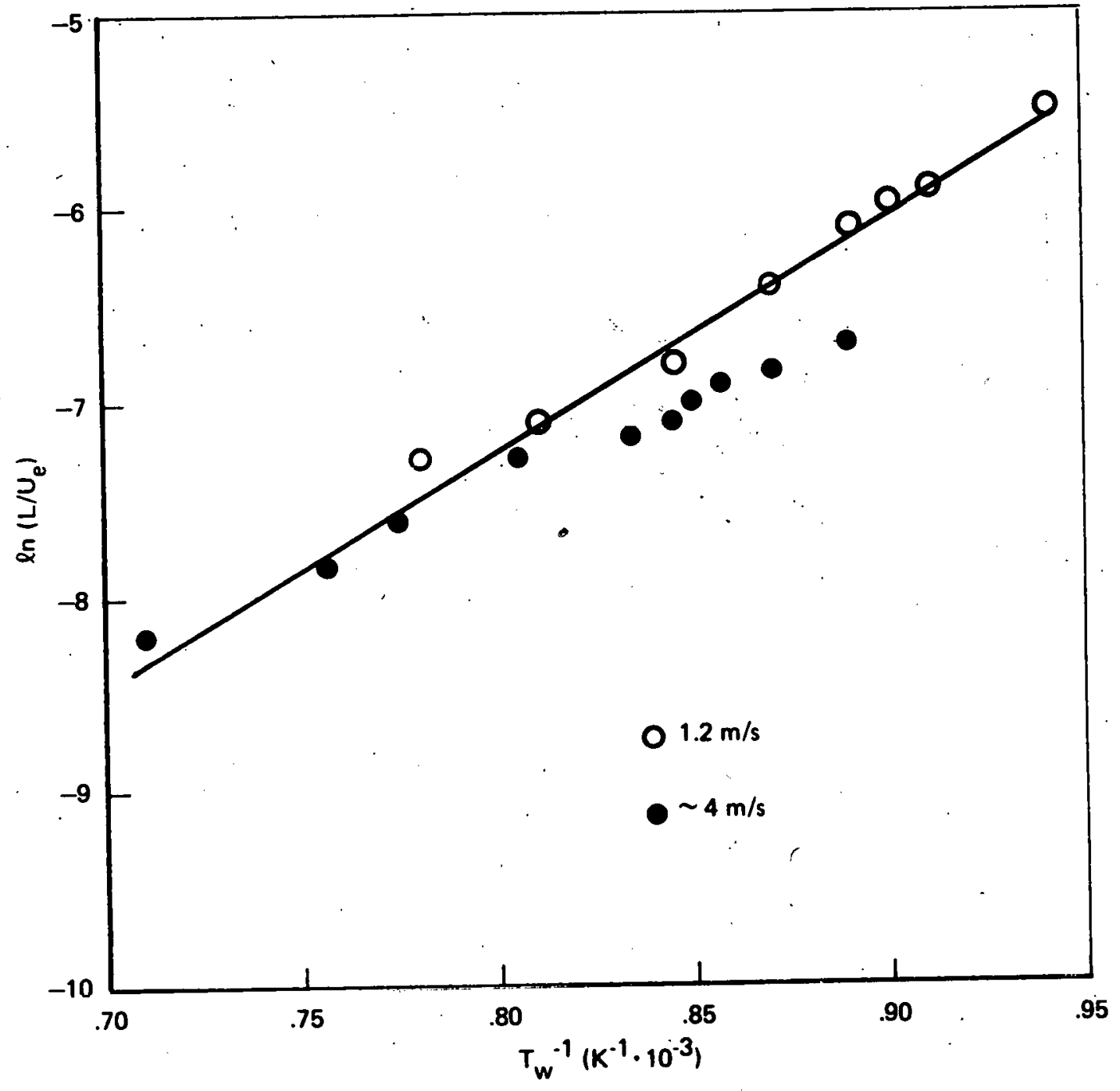

FIGURE 7.13 IGNITION TEMPERATURES FOR SPHERES.OF VARYING DIAMETER AND VELOCITY IN 10\% COAL GAS-AIR (SILVER, 1937; PATERSON, 1940). 


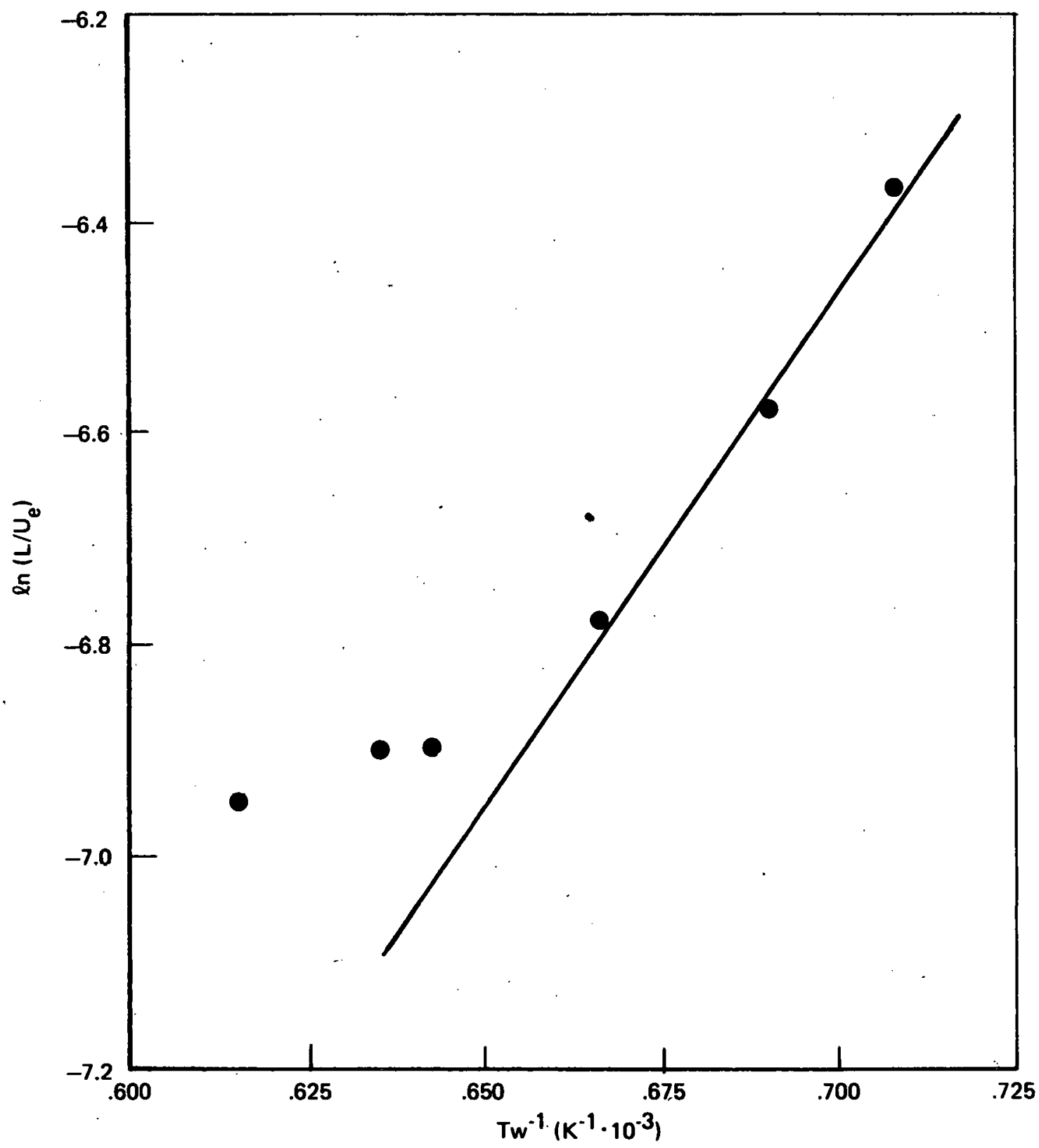

FIGURE 7.14 IGNITION TEMPERATURE AS A FUNCTION OF STREAM VELOCITY FOR $6 \mathrm{~mm}$ HEATED ROD IN STOICHIOMETRIC PENTANE-AIR (MULLEN at al., 1949) 


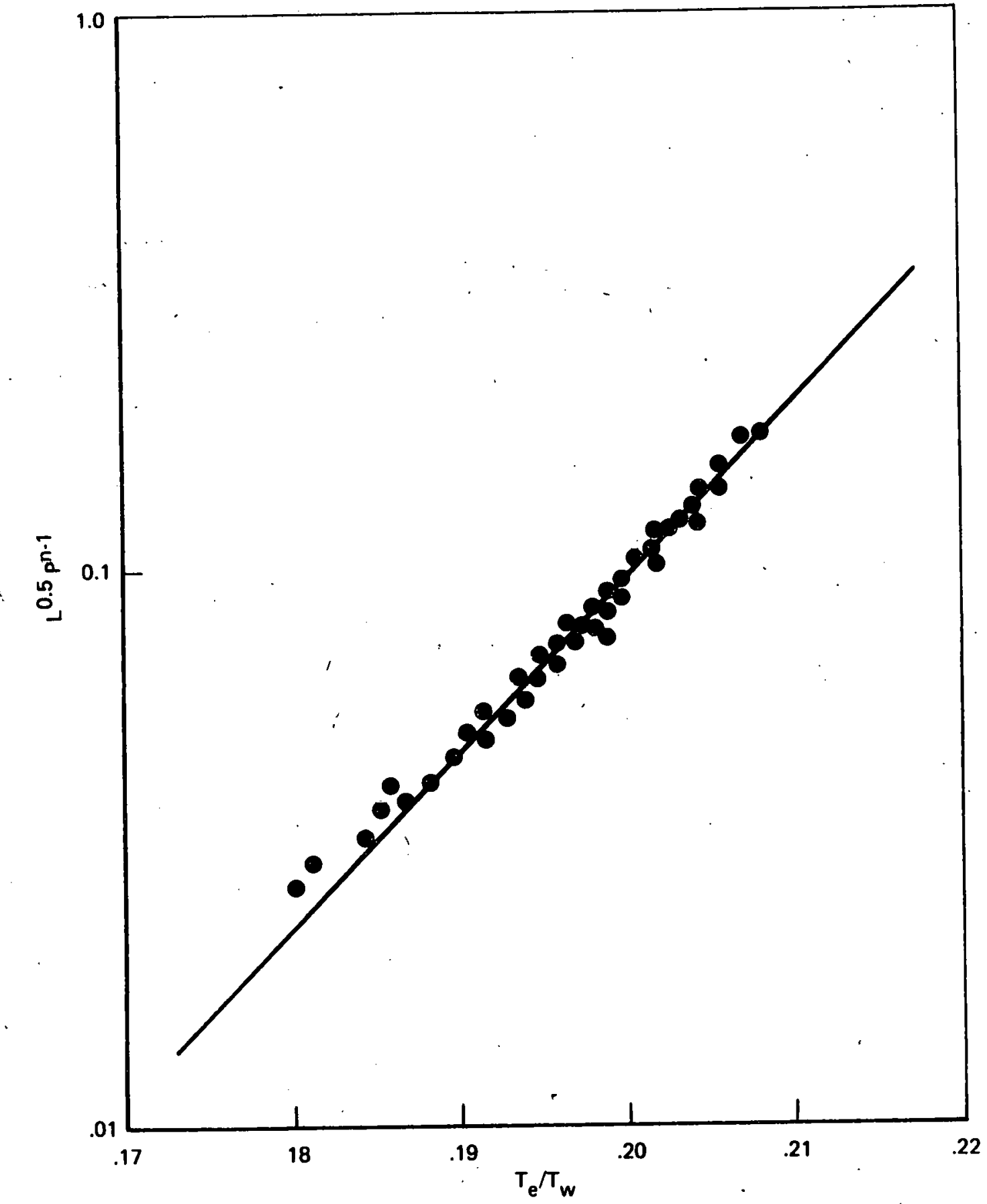

FIGURE 7.15 CORRELATION OF METHANE IGNITION DATA FOR VERTICAL FLAT PLATES UNDER FREE CONVECTION. $L=5-30 \mathrm{~mm}$; $T_{e}=293 K ; n=1.7 ; L$ AND P NON-DIMENSIONALIZED BY $L_{0}=$ $1000 \mathrm{~mm}$ AND $P_{0}=760 \mathrm{~mm}$, RESPECTIVELY (ONO et al., 1976). 
The foregoing analysis is a steady state treatment of ignition by a hot surface. However, in many instances, we are interested instead in the time required for ignition. Would a momentary hot spot generated by frictional heating, for example, be of sufficient duration to ignite a nearby. flammable mixture? Recently, Law (1979) applied the ShvabZeldovich/matched asymptotic technique to transient ignition by a stationary hot surface. He found that the flowfield could be divided into a locally similar reactive-diffusive region plus a non-similar transientdiffusion region. The ignition process was found to be essentially independent of body geometry. The ignition delay time was controlled solely by thermal diffusion, in agreement with the experimental results of Adomeit (1965). An explicit transient Damkohler number condition for ignition delay was developed which corresponded, once again, to. the Van't Hoff criterion.

Based on the above, the transient temperature proftle prior to ignition can be estimated by the result for a hot slab (Bird, Stewart and Lightfoot, 1960):

$$
\frac{T-T_{e}}{T_{w}-T_{e}}=1-\operatorname{erf}(x / 2 \sqrt{\alpha t})
$$

Hence, the heat loss rate is given by

$$
q_{10 s s}=-k\left(\frac{d T}{d x}\right)_{w}=\frac{k\left(T_{w}-T_{e}\right)}{\sqrt{\pi \alpha t}}
$$

Combining equations (3.14), (3.16) and (3.35), we obtain our transient ignition criterion

$$
\left(\frac{\theta_{w}-1}{\theta_{w}}\right)^{2} \cdot \theta_{w}^{n / 2} e^{E^{*} / \theta_{w}}=\frac{2 \pi D_{t} D_{2}}{E^{*}}
$$

where $D_{2}, E^{*}$ and $\theta_{w}$ are given by equations $(3.19-3.21)$ and the transient Damkohler number $D_{t}$ is given by

$$
D_{t}=A(P / R T)^{n-1} x_{0}^{m_{0}} \tau
$$


where $\tau$ is the ignition delay time.

Equation (3.36) duplicates the transient ignition criterion developed by Law (1979) except for a constant factor of two. Note that for a sufficiently reactive system, the ignition delay $\tau$ is independent of the characteristic size $L$ of the heated surface. Comparison of equations (3.17) and (3.36) shows that the steady state and transient ignition criteria are equivalent if

$$
\pi \mathrm{D}_{\mathrm{t}}=\mathrm{D}_{1}
$$

Hence, the criteria differ only by a characteristic thermal diffusionconvective time $\left(\mathrm{L}^{2} / \alpha \mathrm{Nu}^{2}\right)$.

For a second order reaction $(n=2)$, we have

$$
\frac{\left(\theta_{w}-1\right)^{2}}{\theta_{w}} e^{* / \theta_{w}}=\frac{2 \pi D_{t} D_{2}}{E^{*}}
$$

For a given fuel, stoichiometry and ambient temperature, we then have

$$
\frac{\left(T_{w}-T_{e}\right)^{2}}{T_{w}} e^{E / R T_{w}} \propto P \tau
$$

and hence for a given pressure,

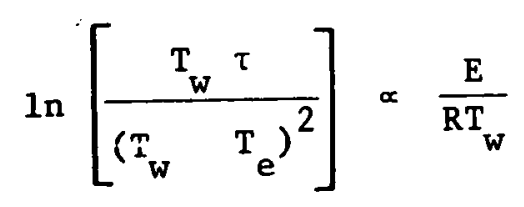

Adomeit (1965) has obtained the only transient ignition data applicable to the present problem. Figure 7.16 shows ignition delays measured for stoichlometric pentane-air mixtures, plotted in the original manner of Adomeit (1965) and in recognition of the correlation shown by equation (3.41). The agreement between theory and experiment is excellent, particularly in light of the fact that the $E / R$ for pentane from Figure 7.16 is 24,000 while that for the similar hydrocarbon propane, as measured by Ono et al. (1976), is 27,000 . 


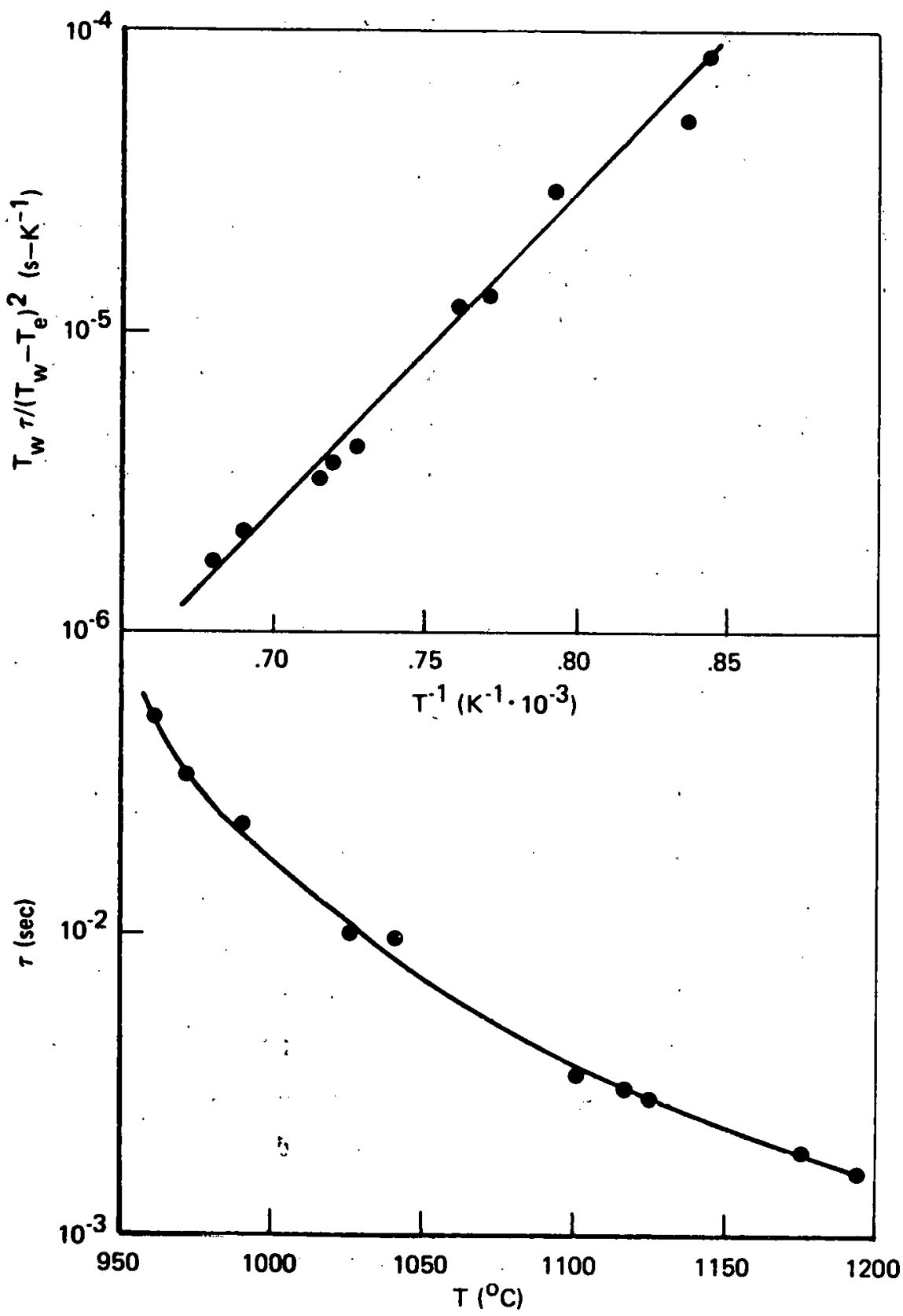

FIGURE 7.16 DEPENDENCE OF IGNITION DELAY ON ROD TEMPERATURE FOR STOICHIOMETRIC - PENTANE-AIR MIXTURES AT ROOM TEMPERATÚRE AND PRESSURE. STAGNANT CONDITIONS: ROD DIAMETER-3.5mm (ADOMEIT, 1965) 


\subsection{Experimental Investigation of Ignition by Hot Surfaces}

The work of Rae et al. (1964) and Cutler (1974) strongly supports the feasibility of methane-air ignition during ship collision. However, further confirmation is required since no previous investigation has considered the combination of experimental conditions appropriate to frictional heating by tanker impact. In particular, proper attention must be paid to heating rate, maximum temperature, surface size and orientation' and flow velocity. Furthermore, accurate determination of the temperature-time profile of the hot surface is needed for meaningful comparison among the results of different investigators: In the present work, we have developed an experimental procedure consistent with the above goals and demonstrated our ability to obtain,we11defined ignition temperatures for a particular set of experimental conditions. Although our results are preliminary in nature, they give conclusive proof that a flammable methane-air mixture can be ignited by the $1500^{\circ} \mathrm{C}$ peak temperature anticipated during ship collisions.

\subsubsection{Experimental Facility}

An overview of the experimental facility is presented in Figure 7.17. The system consists of four components: the reactor, designed to contain methane-air under atmospheric conditions; the electrical system, which is capable of heating the foil with a controlled timetemperature history; the flow system, used to mix the methane-air purge through the reactor; and the temperature monitoring system, which provides a known time-temperature trace for the heated foil. This system has a number of distinct advantages:

- Independent control of heating rate and time at final temperature.

- Known heat transfer characteristics.;

- Accurate measurement of time-temperature hîstory $\left(1500 \pm 5^{\circ} \mathrm{C}\right)$

- Ability to study different sizes and orientations of the hot surface. 


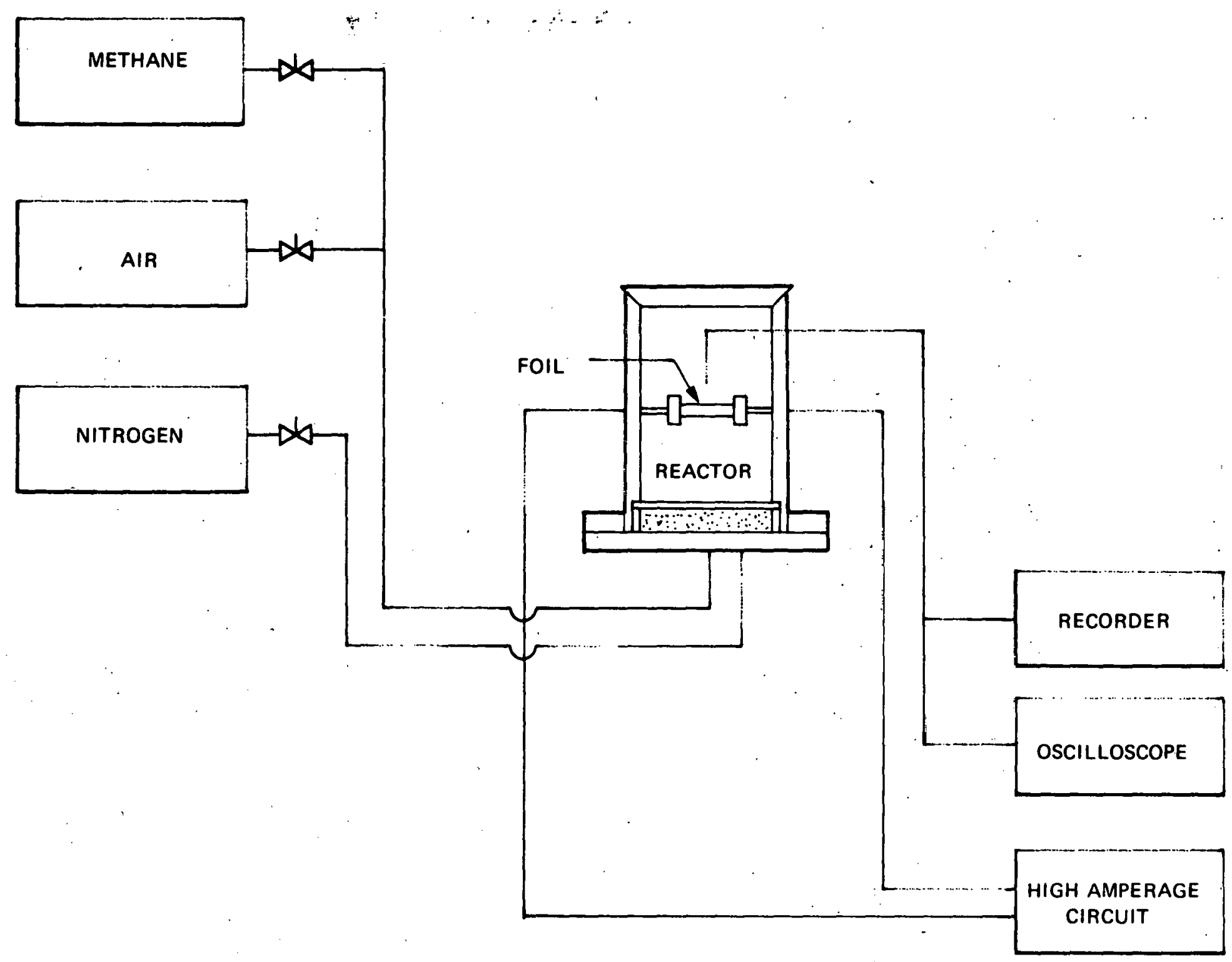

FIGURE 7.17 OVERVIEW OF METHANE-AIR IGNITION FACILITY 
The present system has two desirable features--it is simple and relatively inexpensive. Vendors for the major materials and instruments are listed in Table 7.5 .

\subsubsection{Reactor}

Figure 7.18 presents a detailed schematic of the reactor. It consists of a $8^{\prime \prime}(20.3 \mathrm{~cm})$ long by $5.25^{\prime \prime}(13.3 \mathrm{~cm})$ diameter lucite glass pipe blind flanged on one end with a piece of $1 / 2$ " lucte and fitted at the other end with. a "pop-off" cover. The bottom inch of the vessel is the mixing chamber for the methane-air. To promote good mixing, it is filled with $3 / 32^{\prime \prime}(0.24 \mathrm{~cm})$ diameter glass beads and separated from the reactor proper with a $100 \mu \mathrm{m} 1 / 4^{\prime \prime}(0.64 \mathrm{~cm})$ brass-sintered plate. The sintered plate provides the necessary pressure drop to smooth the flow of gas before it enters the reactor and serves as a flame ariestor which prevents flashback into the lines. The reactor top is beveled at $45^{\circ}$ and fits on a mating bevel on the walls of the reactor. The center of the reactor top is fitted with a $1 / 4 "$ brass pipe plug to provide the necessary weight for stability under gas flow conditions. When methane-air flows through the reactor, the top floats on a stream of gas exiting the vessel along the beveled edge. When ignition occurs inside the reactor, the top rises approximately 1-1/2 and'falls back on to the vessel.

The electrodes are located at the midpoint of the reactor proper. They consist of $1 / 4$ " brass rod threaded into a brass $3 / 8^{\prime \prime}$. $(0.95 \mathrm{~cm})$ by $1^{\prime \prime}(2.54 \mathrm{~cm})$ clamp which enables good electrical contact with the foil. The electrodes are fed through the side of the vessel with teflon ferruled compression fittings which allow the electrodes to be rotated to change foil orientation. A compression fitting also holds a $1 / 4$ " stainless steel tube $1^{\prime \prime}$ from the top of the vessel which supports the thermocouple assembly and houses the thermocouple wiring.

\subsubsection{Electrical Heating System}

A diagram of the electrical heating system is presented in Figure 7.19. The heating circuit consists of a 100 amp service which heats the foil via 100 and 50 amp variable transformers. The transformers are 
Table 7.5

LIST OF VENDORS

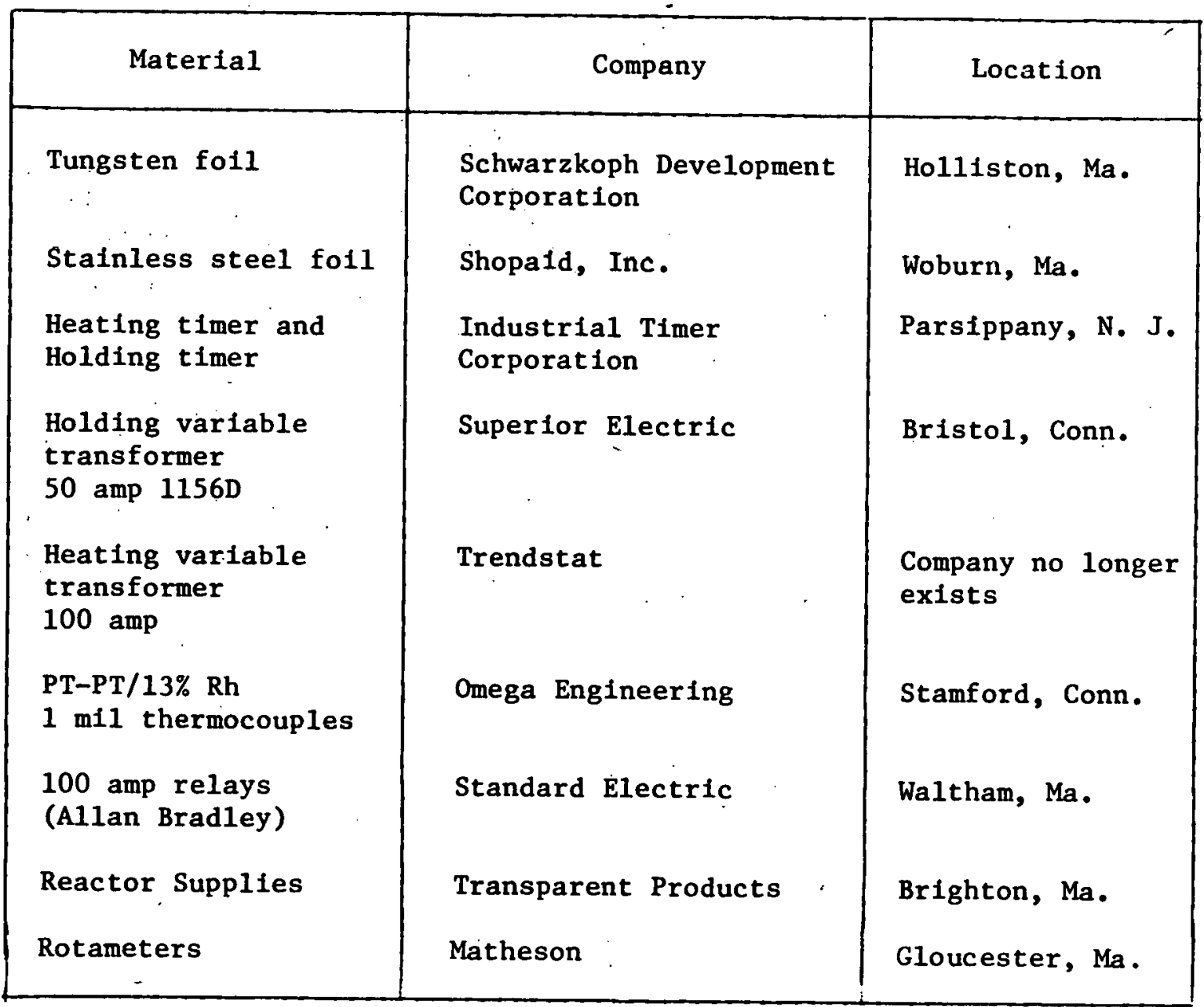




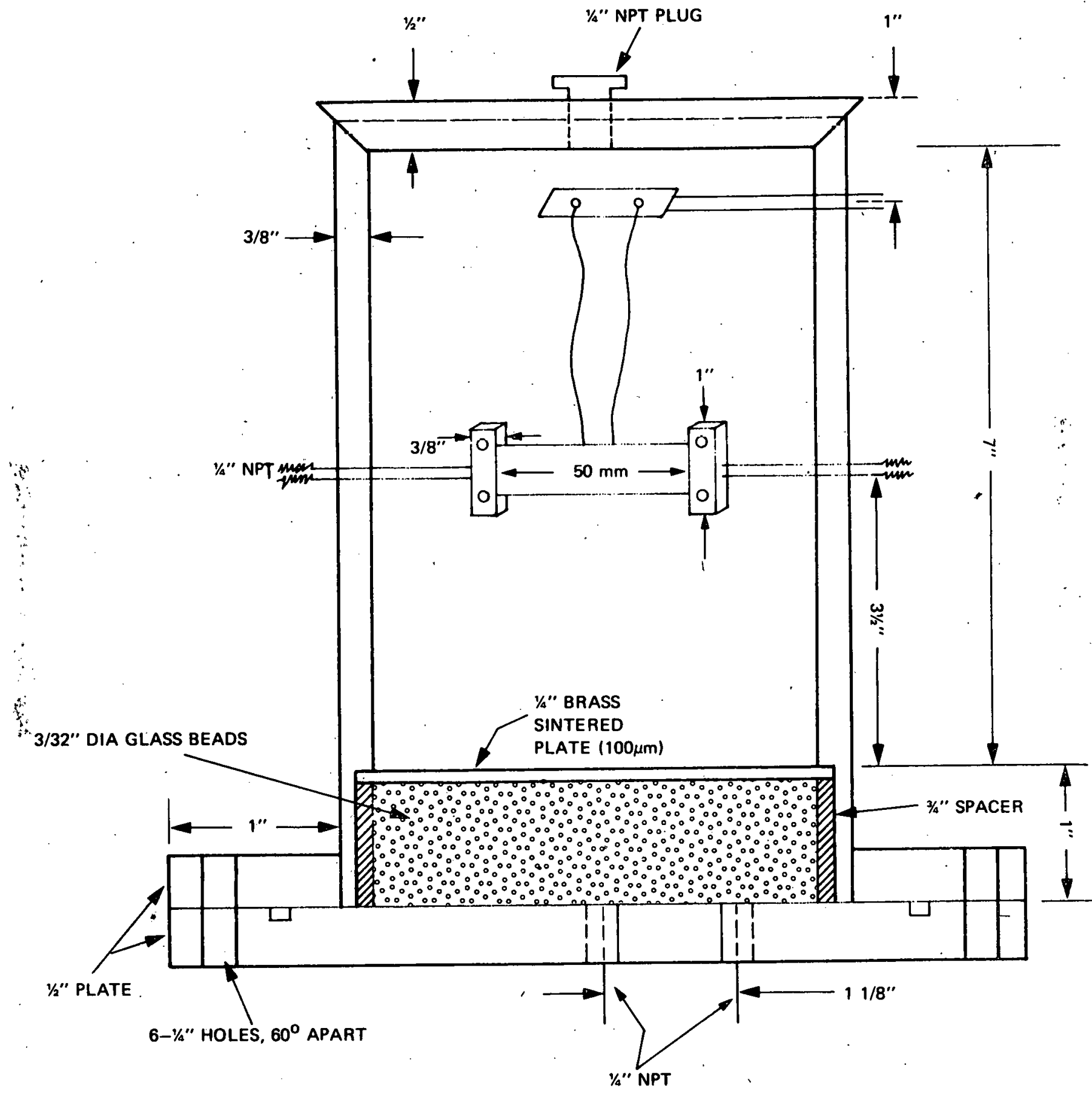

FIGURE 7.18 REACTOR SCHEMATIC 


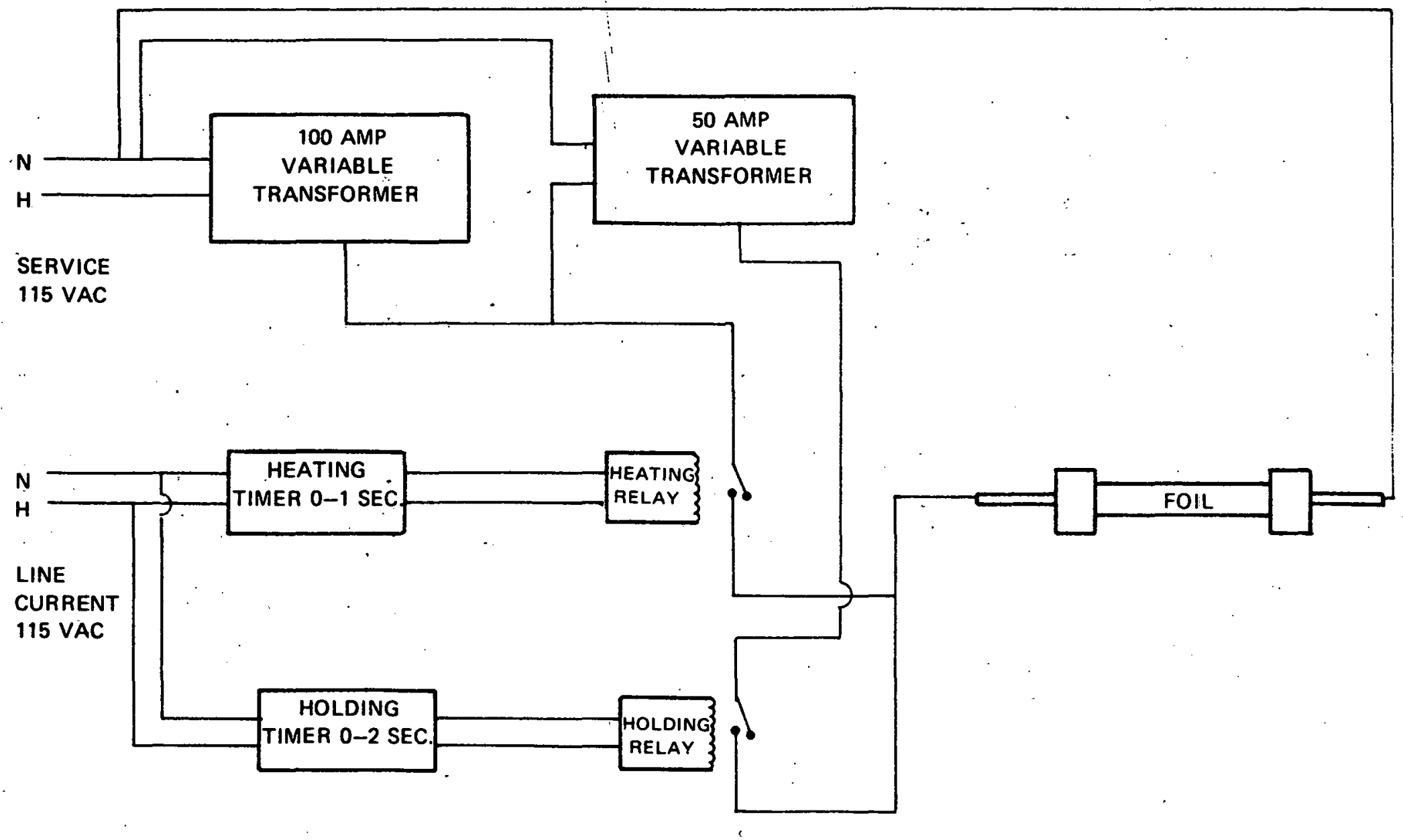

FIGURE 7.19 ELECTRICAL HEATING SYSTEM 
controlled by $100 \mathrm{amp}$ relays and 1 and $2 \mathrm{sec}$ industrial timers. The 100 amp service is the primary of the $100 \mathrm{amp}$ variac (the heating variac). Its secondary is branched to the heating relay and the primary side of the 50 amp variac (the holding variac). The secondary of the holding variac is connected directly to the holding relay. The two hot wires on the load side of each relay form a junction with a lead going to the hot side of the electrode.

The sequence of events which determines the time-temperature history of the foil are as follows:

Heating Period--The heating relay is closed for a 0-1 sec time duration (16 ms gradations) and the holding relay is open. Only the heating variac is providing power to heat the foil; when the peak temperature 1s attained, the heating relay opens and the holding period begins.

Holding Period--As soon as the heating relay opens, the holding relay closes for a $0-2 \mathrm{sec}$ time period (16 ms gradations). During this holding period the foil remains at the peak temperature reached during the heating period. The foil is heated by the two variacs in series, the holding variac dropping the output voltage of the heating variac. In this way a sharp transition is made between the heating and isothermal periods.

Cooling Period--At the end of the predetermined holding time $(0-2 \mathrm{sec})$, the holding relay opens and the foil is quenched by natural cooling. It should be noted that if the holding time duration is set at $0 \mathrm{sec}$, the holding relay never closes and the foil begins cooling immediately after peak temperature is attained during the heating period.

\subsubsection{Flow System}

A schematic of the methane-air flow system is presented in Figure 7.20. Basically, the system allows the methane-air flowing to the reactor to be switched from a high to low flow rate without changing 


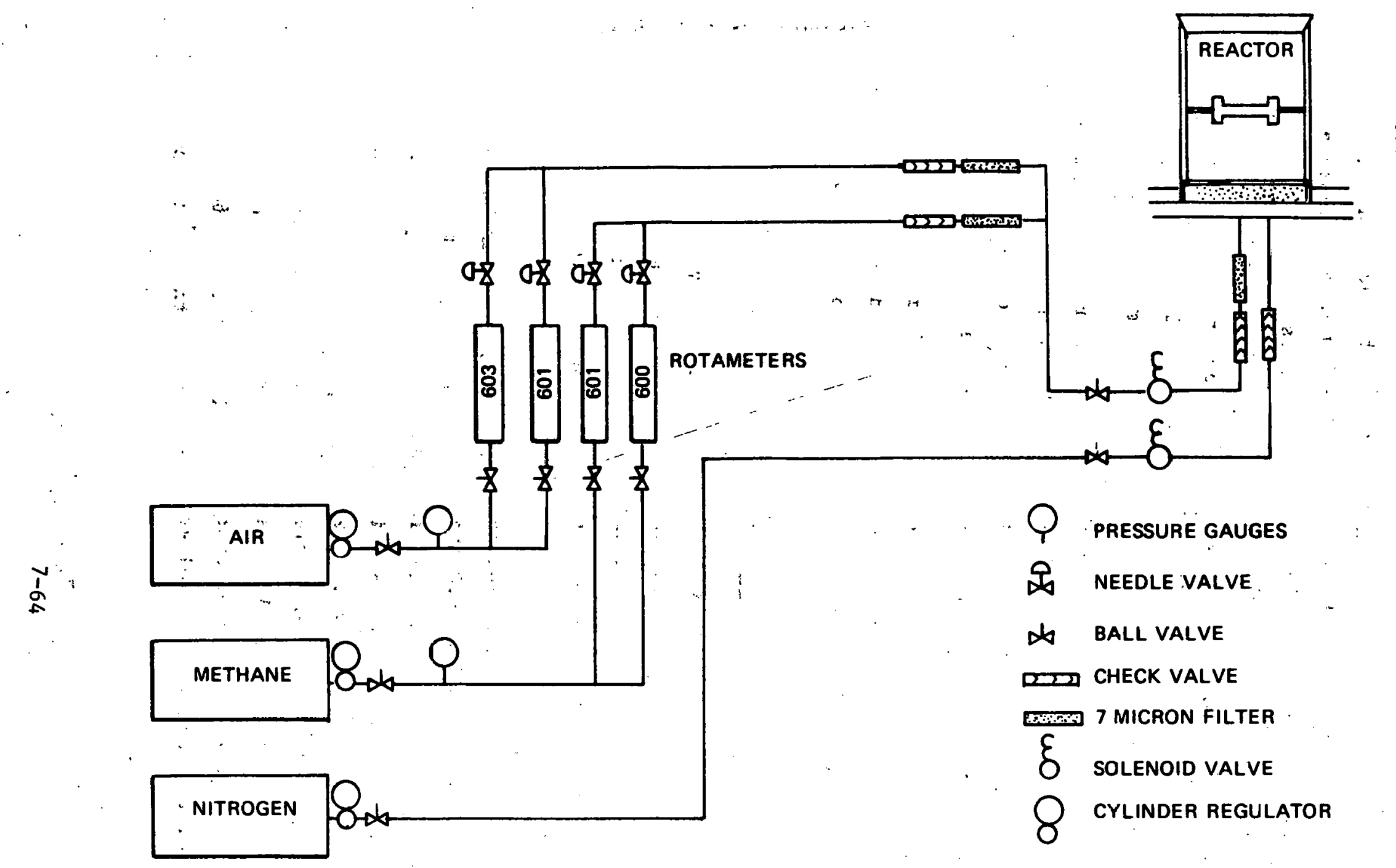

FIGURE 7.20 METHANE-AIR MIXING AND PURGE SYSTEM 
stoichiometry. The methane and air metering is done by four rotameters and needle valves. The Matheson 603 rotameter for air and 601 rotameter for methane measure the flow at the high rate, while the Matheson 601 for air and 600 for methane monitor the flow at the low rate. Pressure gauges upstream of the rotameters allow accurate conversion of the rotameter reading to a volumetric flow rate at standard conditions. The methane and air lines are checked and filtered before mixing to prevent back flow and possible flashback. The methane-alr line entering the reactor is also checked and filtered as a safety precaution.

Nitrogen is plumbed directly to the reactor to extinguish the flame and purge the system once 1gnition takes place. The solenoid valves in Figure 7.20 are wired so that the methane-air can be shut off as soon as ignition occurs and replaced with a high nitrogen purge.

All tubing which contains the pre-mixed methane-air is standard wall $1 / 4^{\prime \prime}$ stainless steel with stainless steel compression-type tube fittings. The remalnder of the lines consist of $1 / 4^{\prime \prime}$ copper tubing with brass compression fittings.

\subsubsection{Thermocouple Monitoring System}

The temperature-time history of the foil is recorded by a one mil platinum-platinum/13\% Rhodium ( $25 \mu \mathrm{m}$ wire diameter, 77 mm bead diameter) sandwiched between two pieces of foil and connected to a fast response strip chart recorder and a storage oscilloscope. The thermocouple time constant is $5 \mathrm{~ms}$.

Due to the fragility of the fine thermocouple wire, a mounting assembly had to be devised to handle the thermocouple. A schematic of the thermocouple assembly is presented in Figure 7.21A. The thermocouple wire is sandwiched between two pieces of cellophane tape excluding the first centimeter from the bead. A 22 gauge bare copper wire is placed between the two fine thermocouple wires to make the assembly structurally rigid. To electrically insulate the first centimeter of the thermocouple from the foll, the thermocouple bead is sandwiched between two sheets of one mil $(25 \mu \mathrm{m})$ asbestos. During the experiment, 


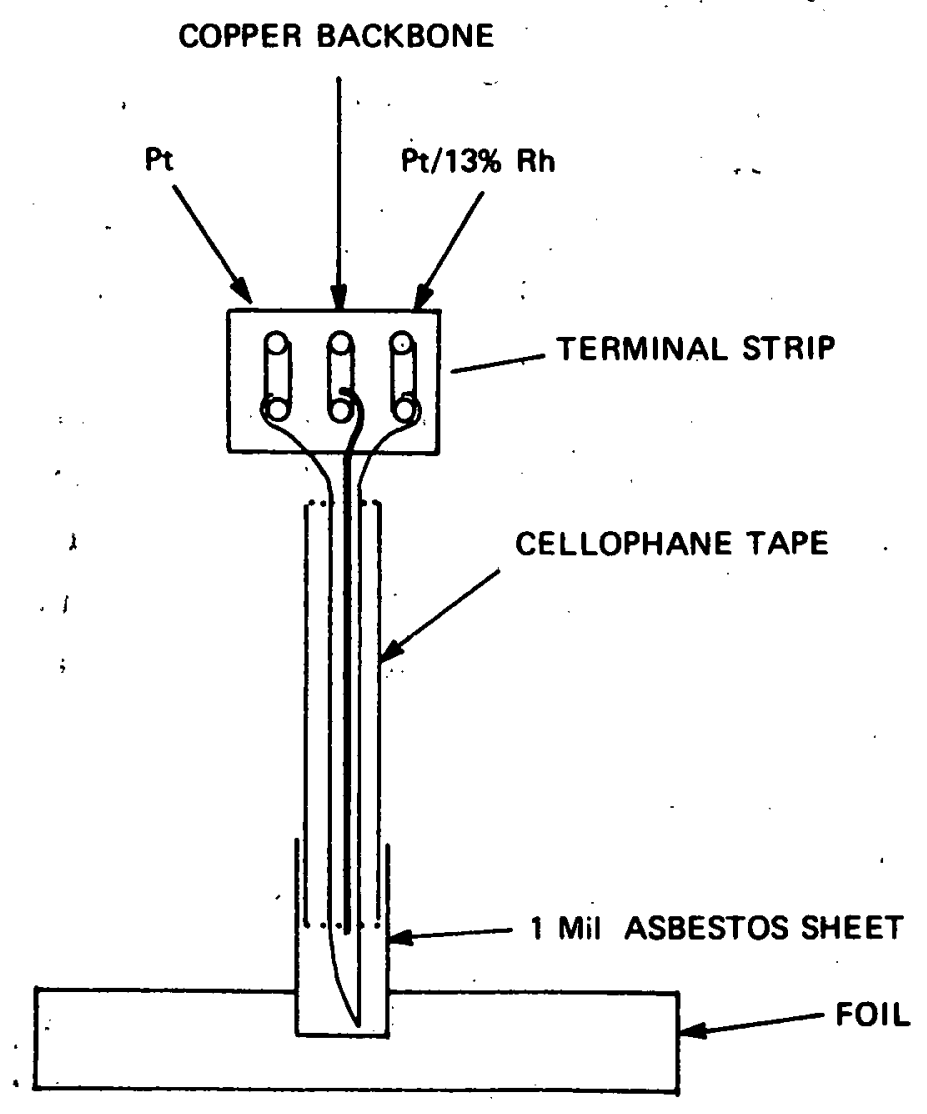

FIGURE 7.21A FRONT VIEW OF THERMOCOUPLE ASSEMBLY

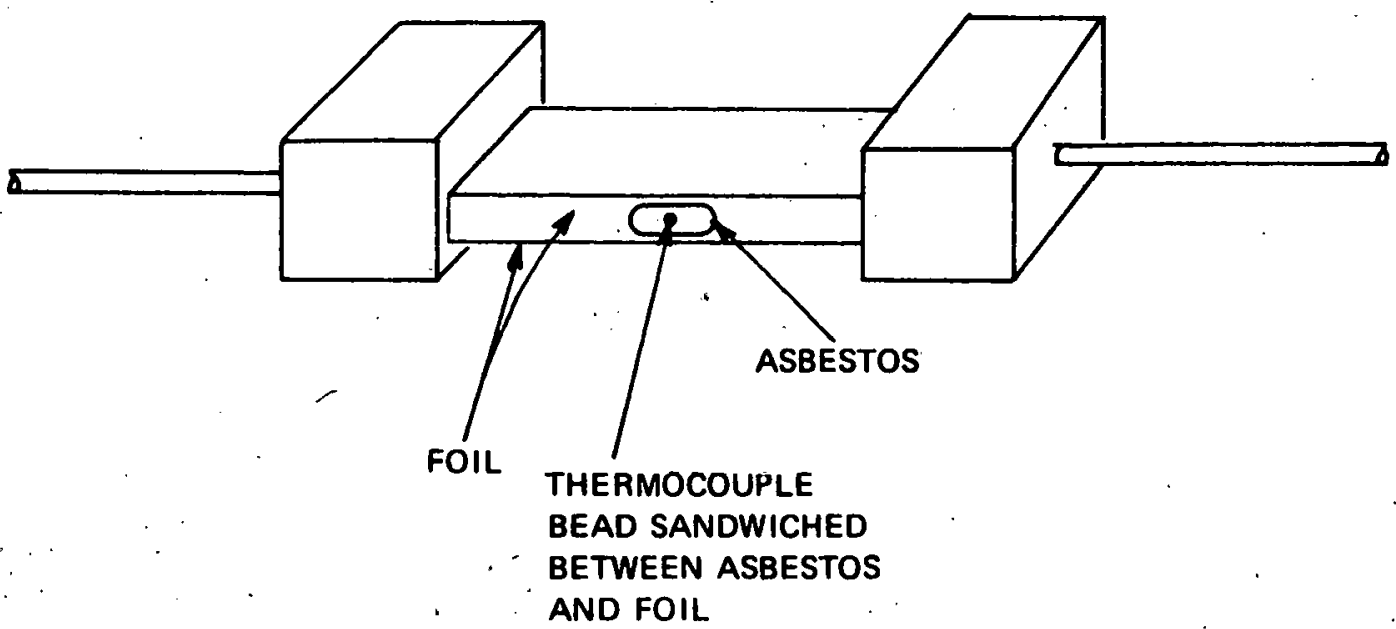

FIGURE 7.21B THERMOCOUPLE INSERTED IN FOIL 
the section of thermocouple wire covered with asbestos is sandwiched between the two pieces of foil as shown in Figure 7.21B. The foil temperature can be measured with high precision by this technique ( $\pm 0.4 \%$ since the radiation loss from the thermocouple is minimal due to the fact that it is tightly. enclosed by the two hot planes of foil. Al1 thermocouple leads between the reactor and monitoring instruments are shielded to minimize electrical noise. A $0^{\circ} \mathrm{C}$ reference function was not used in monitoring the thermocouple signal because of noise problems. The millivolt signal corresponding to room temperature was added to the millivolt output from the thermocouple to calculate the actual surface temperature.

\subsubsection{Experimental Procedure}

Upon completion of the experimental setup, some preliminary work was conducted to fine tune the facility and identify the run conditions which would lead to a successful completion of the program. The next two sections describe this work and summarlze the procedures and conditions of the experiment.

\subsubsection{Preliminary Experiments}

Rotameters were calibrated at 50 psia for methane and air using a $50 \mathrm{ml}$ bubble meter. Using these calibration curves, the needle valves were set to provide a mixture of $6.5 \%$ methane in air to the reactor. This composition was confirmed by gas chromatographic analysis of a 2 liter sample of the mixture entering the reactor. The results are summarized in Table 7.6.

Table 7.6

Gas Chromatographic Analysis of Methane-Air Mixture*

Trial $\%$ Methane In A1r

\begin{tabular}{lll}
1 & & $7.5 \%$ \\
2 & $6.5 \%$ \\
4 & & $6.9 \%$ \\
& & $7.4 \%$ \\
\hline & AVERAGE & $7.0 \%$
\end{tabular}

${ }^{*} 6 \mathrm{ft} \times 1 / 4$ inch Porapak column at $20^{\circ} \mathrm{C}$; thermal conductivity detector at $175^{\circ} \mathrm{C}$. 
Note that the composition of the mixture used in this study is in the range of the most probable stoichiometries for ignition.

Folls were heated to $1500^{\circ} \mathrm{C}$ with rise times ranging from $16-160 \mathrm{~ms}$. The peak temperatures obtained with the $16 \mathrm{~ms}$ rise time was not repeatable due to the irreproducible behavior of the mechanical timer and relays. The longer the rise time, the easier it is to control peak temperature. A rise time of $83 \mathrm{~ms}$ was chosen for all the runs because at this setting the time-temperature histories are well controlled and the heating rate is reasonably high ( $\left.15,000^{\circ} \mathrm{C} / \mathrm{sec}\right)$.

The Ignition experiments used tungsten foil for the small sizes and Type 325 stainless steel foil for the larger sizes. Because of tungsten's low electrical resistivity, the current draw for the larger sizes was excessively high ( 250 amps). Tungsten could easily withstand $1500^{\circ} \mathrm{C}$ for times less than one sec but stainless steel was limited to $1100^{\circ} \mathrm{C}$ before oxidation became a problem. Thus, tungsten was chosen for the 2 and $3 \mathrm{~mm}$ sizes while stainless steel was chosen for the 5 and $10 \mathrm{~mm}$ sizes.

\subsubsection{Experimental Procedure and Conditions}

Two pieces of precut foil ( $\pm .05 \mathrm{~mm}$ tolerance) are inserted between the brass electrodes. The thermocouple assembly is connected to the reactor leads, checked for polarity and inserted between the two pieces of foil. The reactor is covered and then purged with a high flow of nitrogen $(4 \mathrm{l} / \mathrm{min})$ for $300 \mathrm{sec}$. The flow of nitrogen is then reduced and the variacs are adjusted to provide a given time-temperature history. The foil is heated and the temperature monitored by the recorder and storage oscilloscope. This procedure is repeated until the desired time-temperature history is obtained. Once the variac. settings are determined for a given temperature trace in a nitrogen atmosphere, the reactor is purchased at $2000 \mathrm{cc} / \mathrm{min}$ with the methane-air mixture for 300 seconds. The purge rate is then reduced to $230 \mathrm{cc} / \mathrm{min}$ and the foil is heated. If Ignition does not occur, the variac settings are readjusted to obtain a higher temperature and the foil is heated 
again. If ignition occurs, the methane-air is immediately shut off to the reactor by the solenoid valve and a high nitrogen flow is initiated.

The experimental conditions for the ignition experiments are summarized in Table 7.7. The mixture composition and velocity were chosen lu enhance the probability of ignition. In this way, lack of. ignition would be definitive proof that LNG explosion cannot occur during ship collision.

\subsubsection{Results}

\subsubsection{Pulse Ignition Tests}

Nearly all our results were obtained under pulse heating conditions, i.e., rapid heating to peak temperature followed by immediate cooling via radiative, convective and conductive heat transfer. Typical temperature time profiles for the $2 \mathrm{~mm}$ and $10 \mathrm{~mm}$ strips are shown in Figures 7.22 and 7.23. The temperature rise curves are obtained from oscilloscope traces while the decay curves are from the strip-chart recorder. As expected, the temperature rise and decay of the $10 \mathrm{~mm}$ sample lags behind that of the $2 \mathrm{~mm}$ strip. Profiles for the $3 \mathrm{~mm}$ and $5 \mathrm{~mm}$ strips show only slight lagging compared to the $2 \mathrm{~mm}$ sample.

Figure 7.24 shows the temperature rise profile of a $3 \mathrm{~mm}$ tungsten strip at the same heating variac setting in nitrogen and methane-air. Comparison of the profiles during the first $0.2 \mathrm{sec}$ demonstrates the repeatability of the heating circuit. The higher temperature of the methane-air run at $0.2-0.4 \mathrm{sec}$ is a result of local reaction and ignition. Methane-air runs without ignition generally show a much smaller temperature gap. Assuming that the temperature gap is a good indication of chemical reaction, we may conclude that the onset of ignition occurs within $100 \mathrm{~ms}$ of the attainment of peak temperature.

Table 7.8 summarizes the pulse ignition tests in $7 \%$ methane-air mixtures. Tungsten strips allow peak surface temperatures above $1500^{\circ} \mathrm{C}$ as can be seen by the $3 \mathrm{~mm}$ runs; stainless steel strips must be used for larger sizes to avoid currents exceeding 250A. The result of each run is either ignition (I) or no ignition (NI) with the temperature 
Table 7.7

\section{EXPERIMENTAL CONDITIONS}

Composition of mixture

Velocity of mixture

Flow rate of mixture

Pressure

Ambient temperature

Hot surface length

Hot surface width

Hot surface orientation

Temperature rise time

Heating rate
$7 \%$ methane-air

$1.6 \mathrm{~cm} / \mathrm{min}$

$230 \mathrm{cc} / \mathrm{min}$

1 atm

$21^{\circ} \mathrm{C}$

$50 \mathrm{~mm}$

$2 \mathrm{~mm}, 3 \mathrm{~mm}$ (tungsten)

$5 \mathrm{~mm}, 10 \mathrm{~mm}$ (stainless steel)

Vertica1

$83 \mathrm{~ms}$

$12,000-18,000^{\circ} \mathrm{C} / \mathrm{sec}$ 


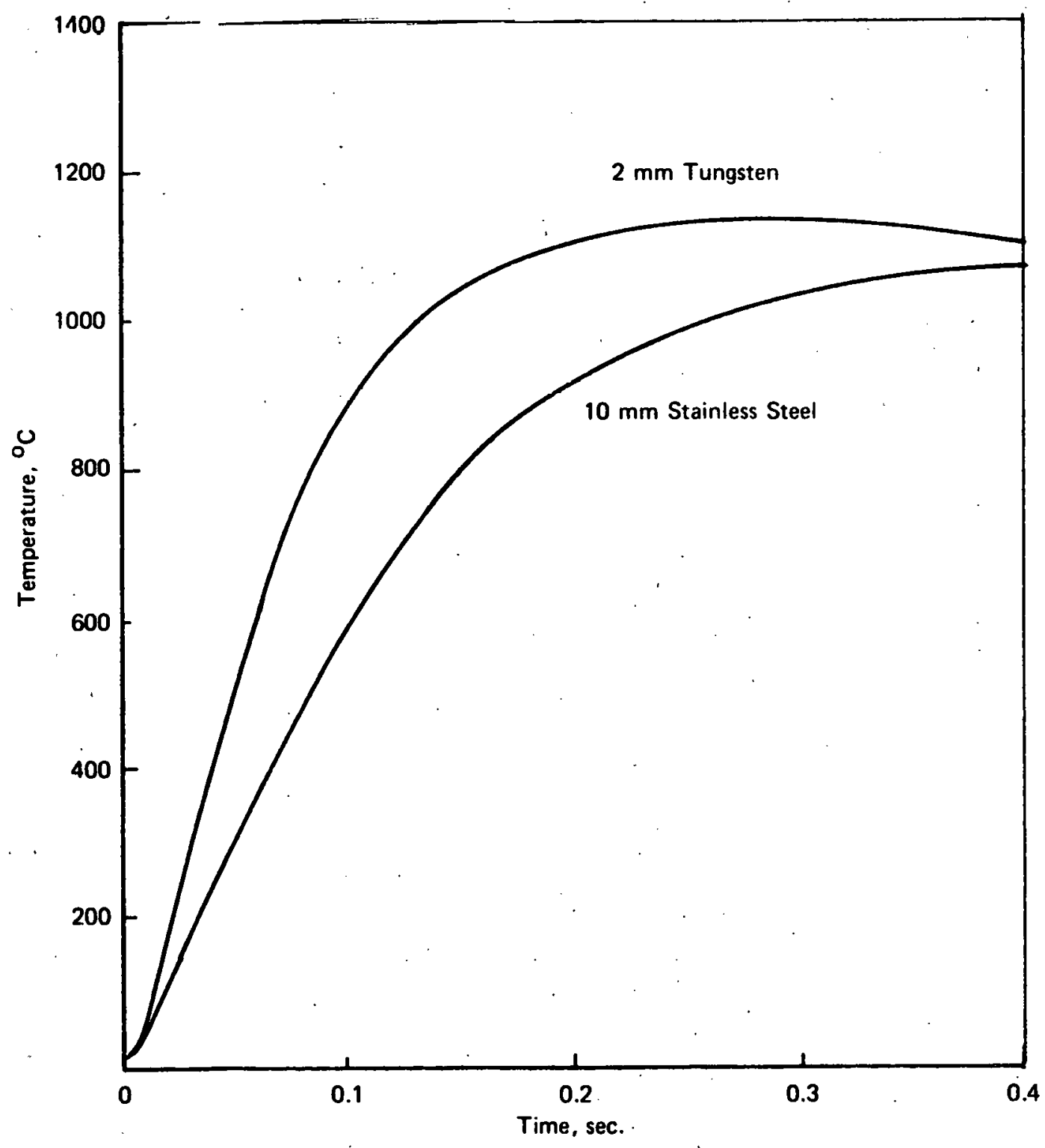

FIGURE 7.22 TEMPERATURE RISE PROFILES FOR $2 \mathrm{~mm}(2 \mathrm{~T}-7)$ AND $10 \mathrm{~mm}(10 S-3)$ METAL STRIPS 


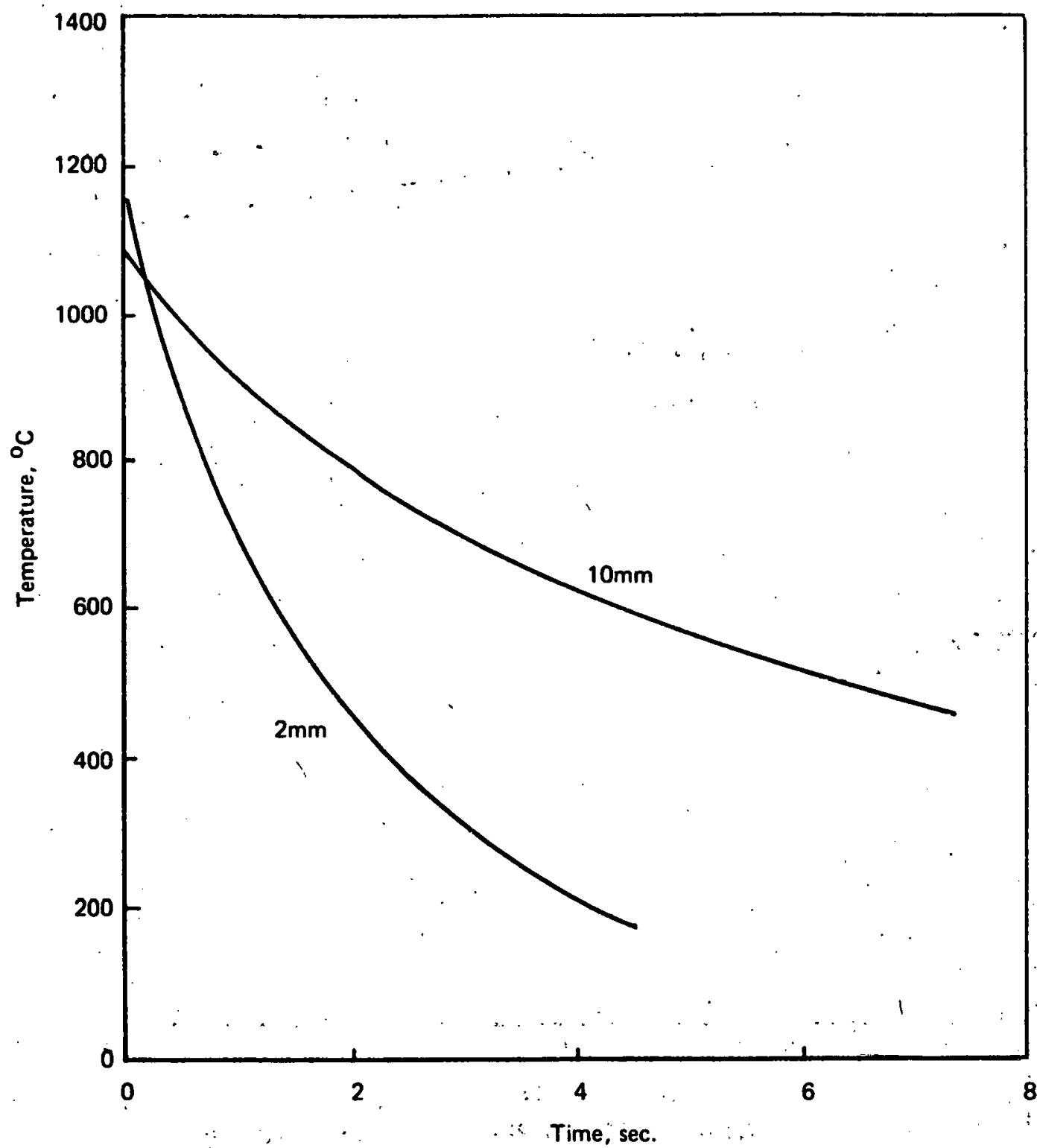

FIGURE $7: 23$ TEMPERATURE DECAY PROFILES FOR $2 \mathrm{~mm}(2 \mathrm{~T}-7)$ AND $10 \mathrm{~mm}(10 S-3)$ METAL STRIPS 


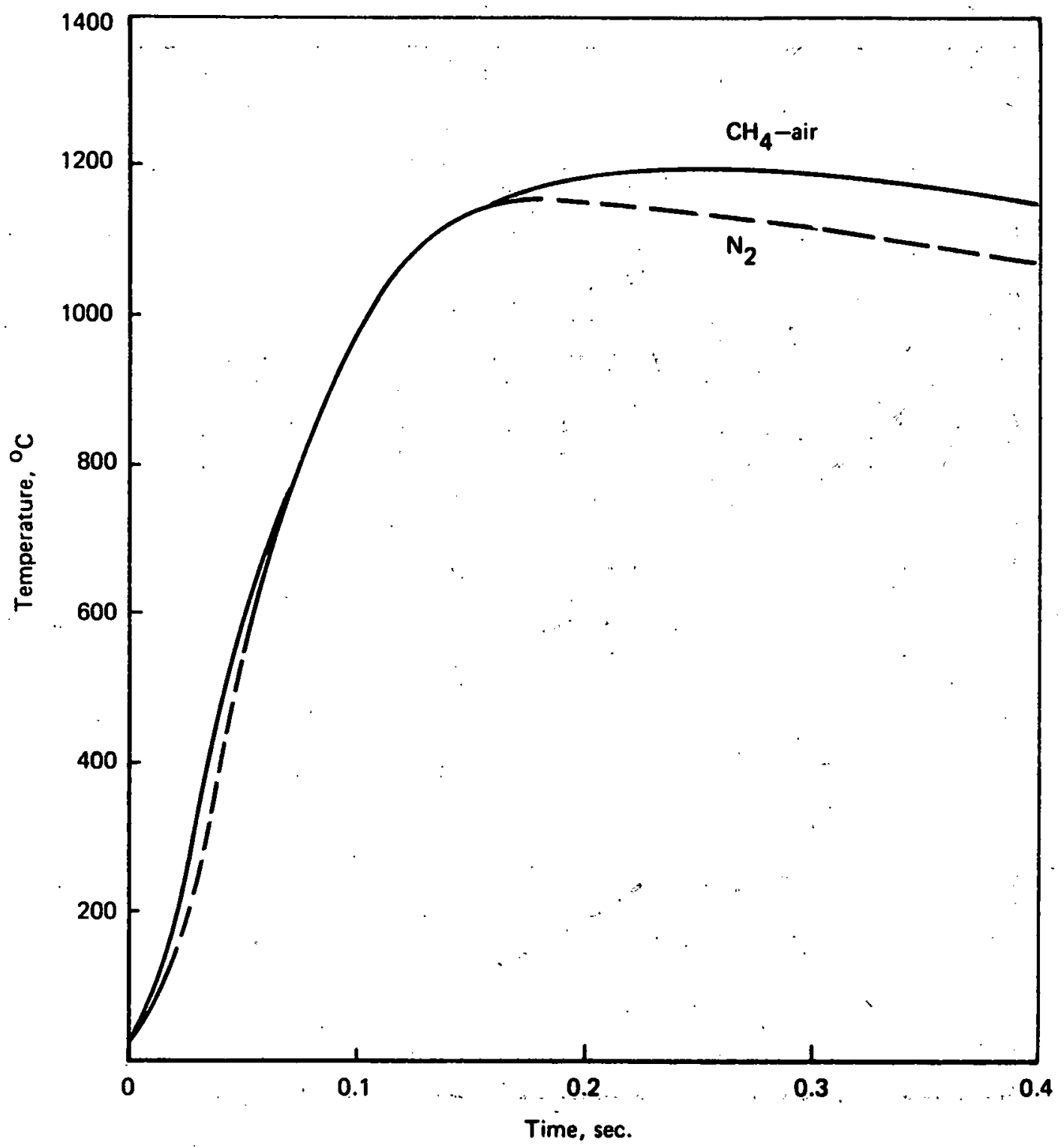

FIGURE 7.24. INITIAL TEMPERATURE-TIME PROFILE FOR $3 \mathrm{~mm}$ TUNGSTEN STRIP IN .NITROGEN AND METHANEAIR AT SAME VARIAC SETTING (3T-5) 
Table 7.8

PULSE IGNITION TESTS

IN SEVEN PERCENT METHANE-AIR MIXTURES

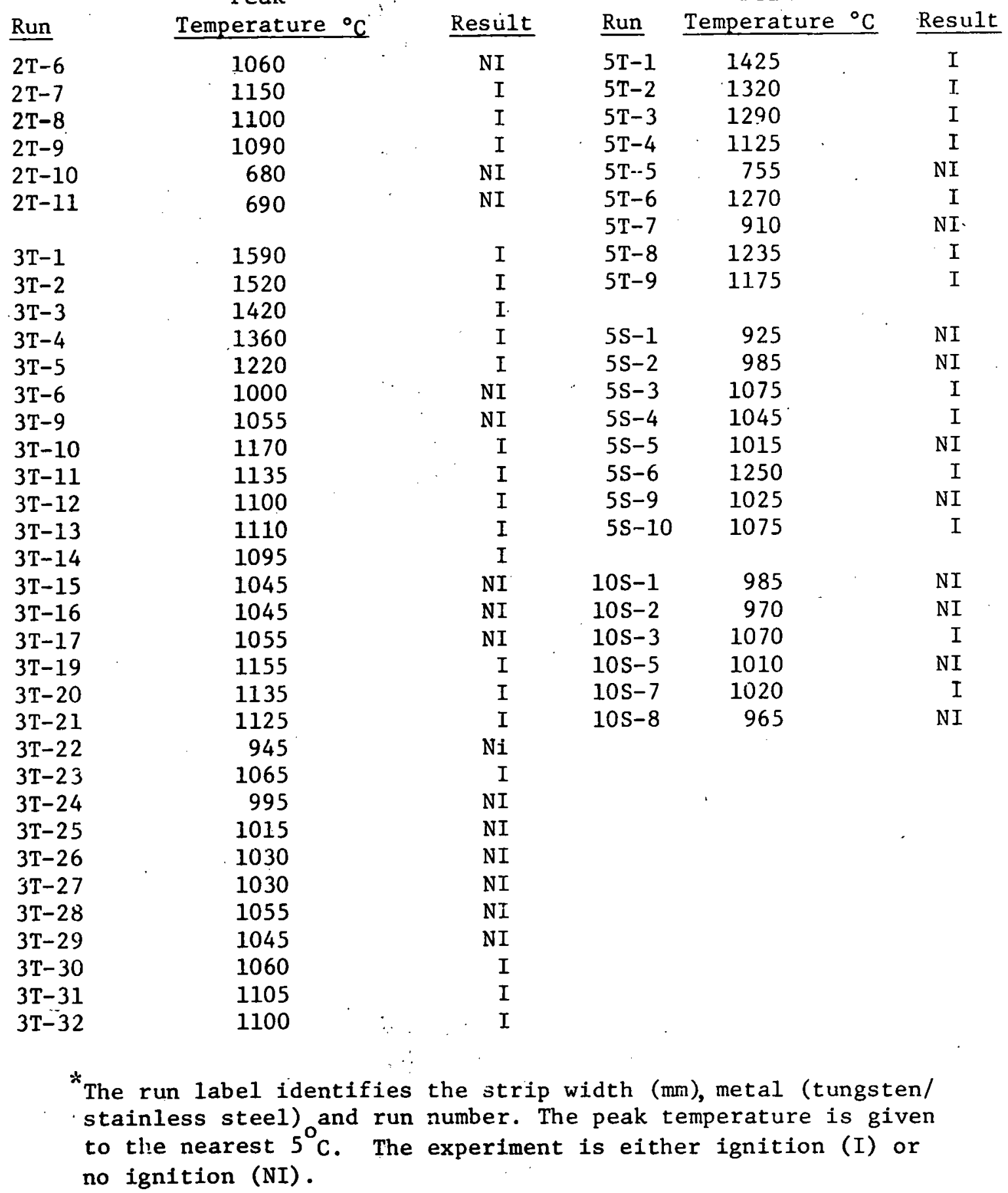


range between the highest NI and lowest I runs defining the "ignition temperature." The large number of $3 \mathrm{~mm}$ runs were obtained on three separate days thus ensuring data repeatability: The number of $2 \mathrm{~mm}$ runs is 1 imited due to difficulties in maintaining thermocouple position between the parallel metal strips during ignition. The significant $5 \mathrm{~mm}$ runs were obtained using stainless steel since the high currents generated by the tungsten samples precluded effective control of temperature-time history.

The results of Table 7.8 are summarized in Table 7.9 and Figure 7.25. Table 7.9 shows that reliable ignition temperatures can be obtained with sufficient effort. The effect of strip size on ignition temperature (Figure 7.25) is consistent with the results of Cutler (1974) and Rae et al. (1964). Direct comparisons cannot be made since Cutler (1974) employed a much higher heating rate and Rae et al. (1964) used a shutter to effect contact between the flammable mixture and the hot surface. Figure 7.25 compares well with Figure 7.8 (Rae et al., 1964); a similar gas heating rate probably accounts for the reasonable agreement in ignition temperature.

Table 7.9

IGNITION TEMPERATURES FOR METAL STRIPS IN SEVEN PERCENT METHANE-AIR MIXTURES

Strip
Width

2

3

5

10
Ignition Temperature

1060-1090

1055-1060

1025-1045

1010-1020

The calculations of Appendix F (Table F.4) show that it is not unreasonable to expect a hot surface, $2-10 \mathrm{~mm}$ in width at $1200-1500^{\circ} \mathrm{C}$, upon ship collision. Therefore, the $1000-1100^{\circ} \mathrm{C}$ ignition temperature range measured in the present investigation demonstrates that such surfaces are capable of igniting a locally flamable methane-air 


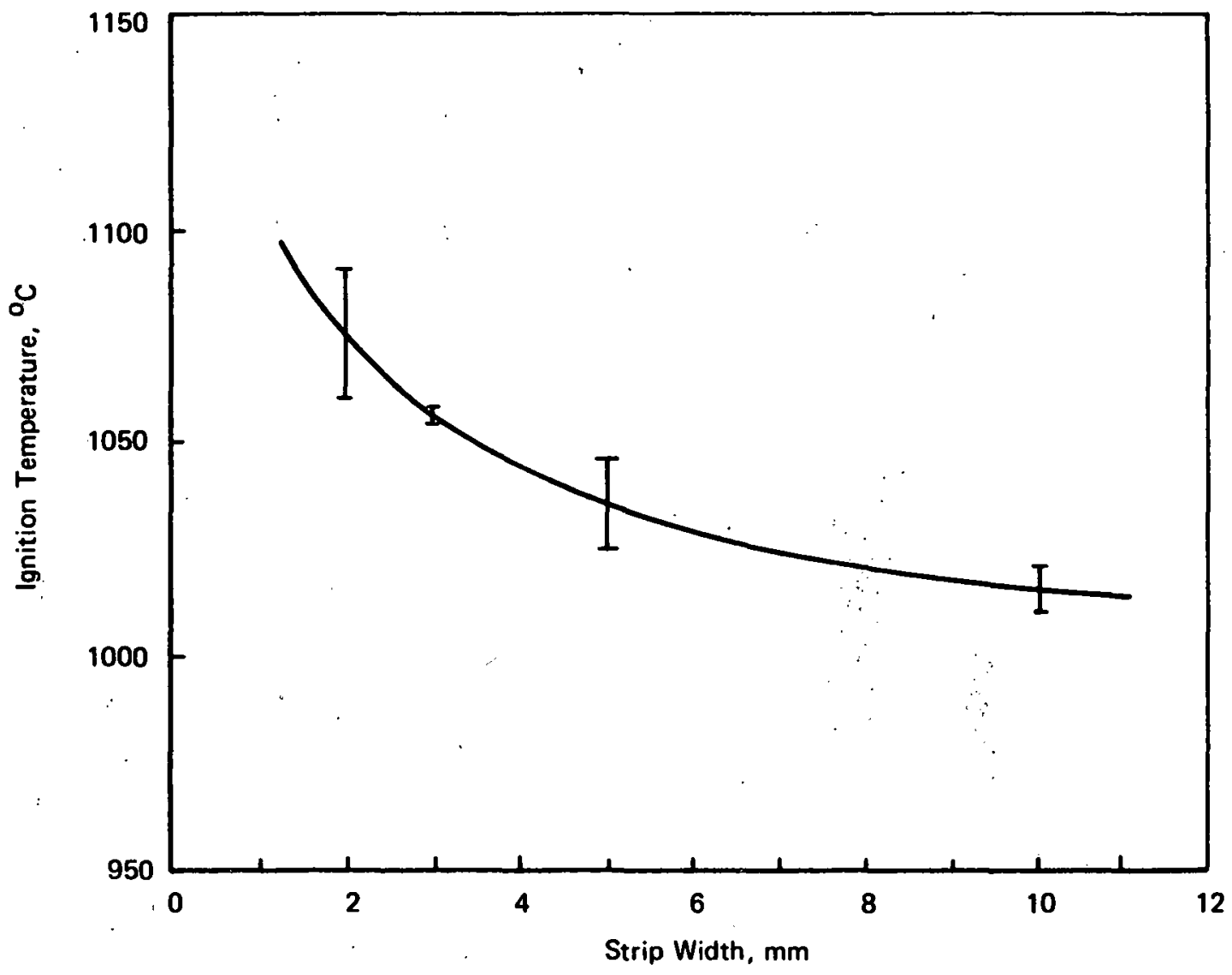

FIGURE 7.25 IGNITION TEMPERATURE VS. STRIP WIDTH IN 7\% METHANE-AIR MIXTURES 
mixture. The flammable mixture apparently ignites given contact with the hot surface for at least $100 \mathrm{~ms}$; even shorter contact times are probably sufficient above $1200^{\circ} \mathrm{C}$.

A limited number of "holding" experiments were conducted near the ignition temperature for the $3 \mathrm{~mm}, 5 \mathrm{~mm}$ and $10 \mathrm{~mm}$ samples. In these runs, the strip was rapidly heated as in the pulse ignition tests and then held at the peak temperature for a predetermined length of time or until ignition occurred. Holding at peak temperature for $30 \mathrm{sec}$ or more, $10-50^{\circ} \mathrm{C}$ below the maximum no ignition temperature for the pulse tests, still resulted in no ignition. Ignitions produced near the minimum ignition temperature for the pulse tests gave the highest ignition delay times, sometimes reaching $0.2-0.3 \mathrm{sec}$.

\subsubsection{Comparison with Theory}

Based on the theory of Section 7.3.5.5, we have seen that our ignition data should be correlated by

$$
\ln \mathrm{L}^{\prime}=\mathrm{E} / \mathrm{s} \mathrm{RT}_{\mathrm{w}}
$$

where $L$ is the characteristic size, $E$ the activation energy, $T_{w}$ the critical surface temperature for ignition, and $s$ a constant given by

$$
\begin{aligned}
& s=1 / 2 \\
& s=1 \\
& s=2
\end{aligned}
$$

free convection

forced convection

stagnant conditions

Equation (6.1) can be tested by replotting the data of Figure 7.25 as shown in Figure 7.26. The linearity of the results confirms the theory. The slope of the line gives $E / s R \simeq 48,000$; since $E / R$ for methane-air, as discussed in Section 7.3.5.5 is 25,000, we find that $s=1 / 2$. Thus, in our experiments, free convection conditions prevailed, a reasonable result considering the extremely low flow velocity of $\sim 1.6 \mathrm{~cm} / \mathrm{min}$.

\subsubsection{Tests with Painted Surfaces}

Rust prevention on ship steel requires suitable paint; such paint may influence the ignition temperature. To test this hypothesis, we conducted pulse ignition tests in $7 \%$ methane-air mixtures using tungsten 


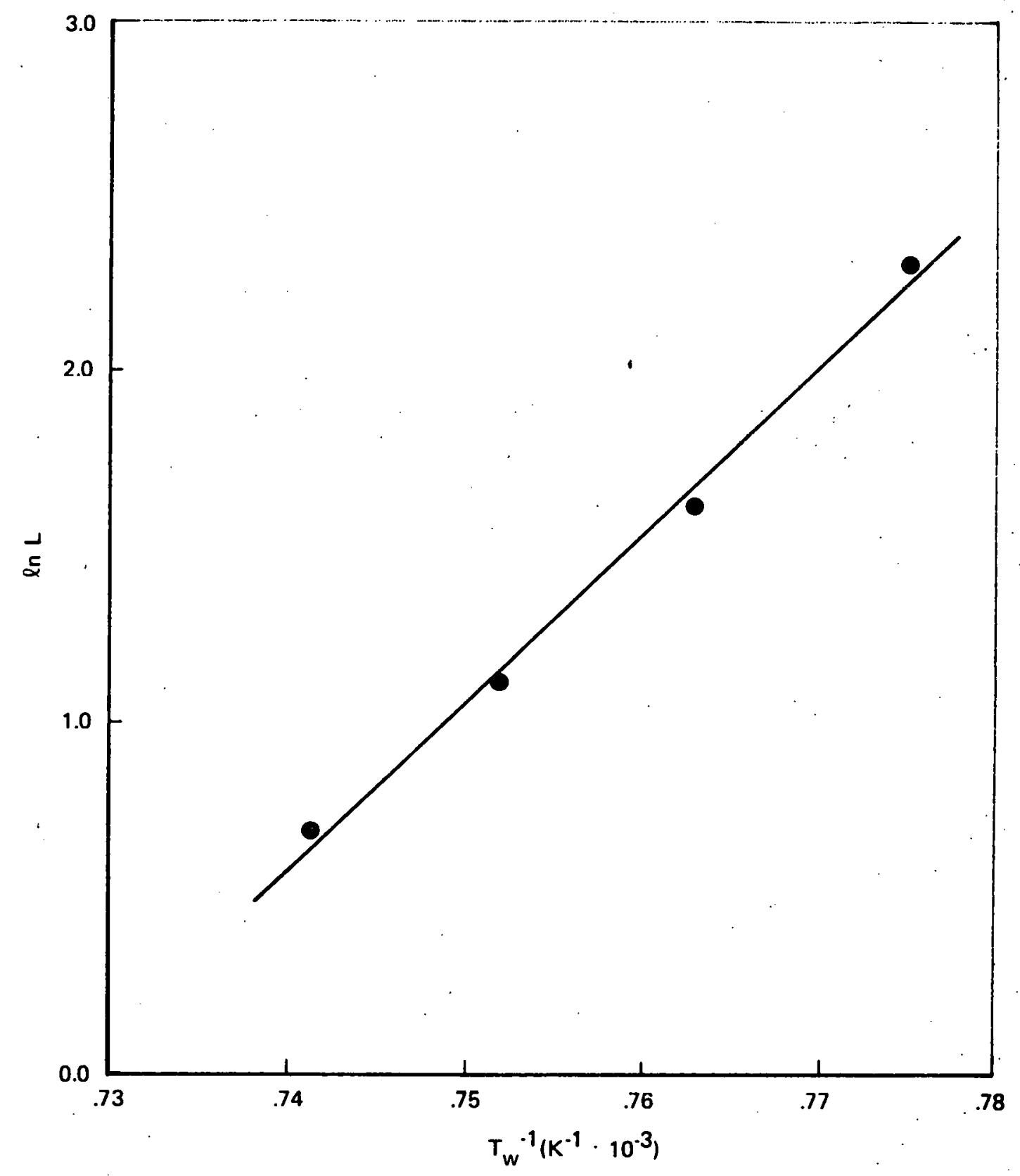

FIGURE 7.26 DEPENDENCE OF STRIP SIZE ON SURFACE IGNITION TEMPERATURE 
and stainless steel strips treated with the same painting process as on typical General Dynamics ships (Hickey, 1980).

The International Paint Co., Union, N. J. treated our metal samples with phosphoric acid etch to improve adhesion. Three $25 \mathrm{~mm}$ layers were then sprayed on the surface. The first coat is an inorganic zinc silicate; the second and third coats are a chlorinated rubber polymer modified with chlorinated paroffin wax (Hickey, 1980).

Table 7.10

PULSE IGNITION TESTS FOR PAINTED METAL STRIPS ${ }^{*}$

$\underline{\text { Run }}$

Peak Temperature, ${ }^{\circ} \mathrm{C}$

$\underline{\text { Result }}$

3CT-1

565

3CT-2

745

NI

$5 \mathrm{CS}-1$

595

5CS-2

720

5Cs- 3

805

I

NI

I

I

The run label identifies the strip width (mm), coated tungsten (CT) or stainless steel (CS) samples and the run number. The peak temperature is given to the nearest $5^{\circ} \mathrm{C}$. The result of the experiment is either ignition (I) or no ignition (NI).

Table 7.10presents the results of these tests. The important conclusion is that ignition occurs at $600-700^{\circ} \mathrm{C}$, some $400^{\circ} \mathrm{C}$ less than for the uncoated samples. Since paint will be scraped from the steel surface during ship collision, it is difficult to assess the exact impact of the paint on LNG ignition except to say that the paint will probably facilitate and certainly not hinder the ignition process. Upon heating, the paint produces a puff of black smoke and then separates from the surface. Methane-air ignition occurs through production of a paintinduced pilot flame near the metal surface. 
7.5 The Occurrence of Flammable Mixtures at Potential Ignition Sites

7.5.1 Background

From the preceding review of the mechanisms for the ignition of LNG vapor, it is concluded that adiabatic shear (frictional heating) resulting from the sliding contact of two steel surfaces is the most likely cause of ignition during a collision. The hull of the impacting ship sliding by that of the impacted vessel can result in hot surfaces of sufficient size, temperature, and duration to cause ignition of methane-air mixtures. Actual 1gnition, however, depends on whether the hot surfaces are exposed to flammable mixtures. The potential for hot surfaces and flammable mixtures to occur concurrently requires further analysis. A preliminary first order evaluation follows.

In this analysis it is assumed that the LNG tanker is fully loaded; filled with liquid and the remaining ullage space will contain LNG vapor at a pressure slightly greater than atmospheric. This pressure is maintained so as to prevent an inflow of air should a leak develop, to assist in the transfer of boll-off gas when it is being used for propulsion, and/or to avoid venting of boil-off gases while the ship is in or near port.

If a collision resulting in the breach of an LNG container occurs, it is most likely that penetration will be below the liquid-vapor interface. Downstream of the penetration some of the fluid will flash and upstream some of it will vaporize as it comes in contact with the hot surfaces of the penetrating body. During the early phase of the collision when surfaces are still hot, for ignition to occur, the vapor must mix with air and reach these surfaces in concentrations that are within the flammable limits.

In the following analysis, we consider the likelihood of flammable mixtures at hot surfaces. To do this we develop a model of the processes that take place and make several approximations or assumptions, such as the dimensions of the gap caused by penetration and flow velocities of fluids emftted from the cargo tank. This provides some insight 
as to the likelihood of ignition; however, a more rigorous and comprehensive analysis should be conducted.

\subsubsection{System Model}

A model of the system that we use as a basis for these evaluations is presented in Figure 7.27. We assume broadside 1mpact and the types of ignition mechanisms described in the preceding section. The bow of the striking vessel penetrates the LNG tanker and makes a hole, or a gap, in the LNG tank (region 1). Frictional heating in this region evaporates some of the LNG that comes in contact with 1t. This frictional energy is also sufficient to melt the contacting metal surfaces. Depending on the size and location of the original hole and the rate of frictional heating, the fluid escaping can be gas, a mixture of gas and liquid, or all liquid.

The escaping fluid from region 1 jets into region 2, the space between the inner and outer hulls of the tanker. As the fluid spills Into this space, it mixes with air and raises the pressure there and, hence, the mixture flows out through the gap between the hull of the striking ship and the outer hull of the tanker. Region 3 has surfaces sufficiently large and hot to ignite the mixture provided that this mixture is within flammability limits.

In accordance with the above scenario, the problem reduces to making rational estimates of the gaseous mixtures, that will flow over the hot surfaces in region 3. To make these estimates, the evaluation is carried out in two parts. First, estimates are made of the phase and amounts of natural gas which result from the penetration of the LNG tank, and second, estimates are made of the composition of the mixtures which arrive and pass over the ignition source. 


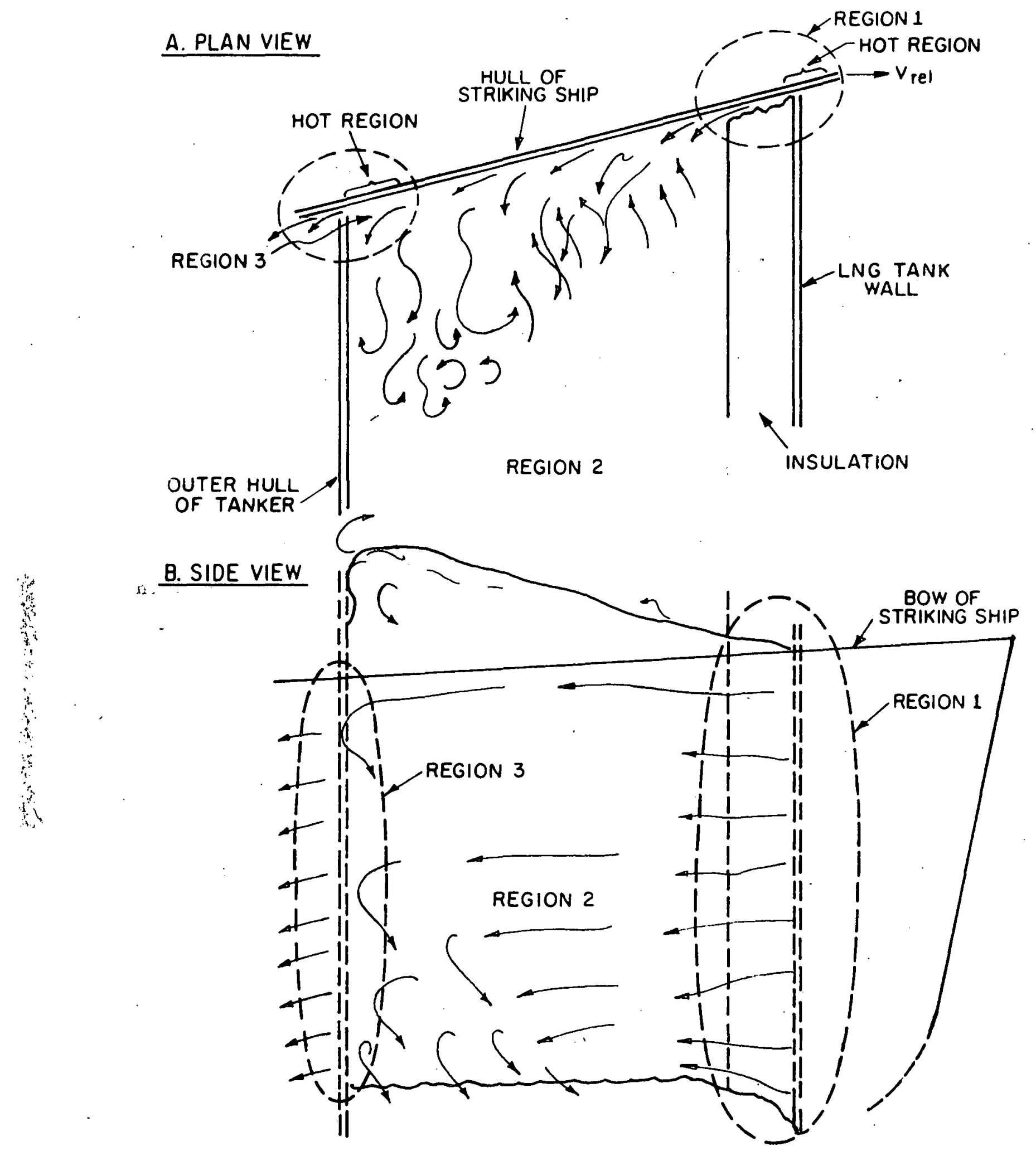

FIGURE 7.27 MODEL SYSTEM FOR CONSIDERING PRESENCE OF FLAMMABLE MIXTURES. 


\subsubsection{Fluid Spill at Region 1}

The flow rate of fluid spilled at region 1 depends primarily on the phase of the fluid jetting through the gap, the area of this gap and the driving pressure for flow. The quality of the mixture issuing from the LNG tank will be very low; that is, the fluid mixture will be mostly liquid except for evaporation induced by the frictional heating accompanying the penetration of the LNG tank by the bow of the striking ship.

Assuming that one-half of the energy absorbed in the collision impact is available as heat to vaporize the escaping liquid, we estimate that the rates at which the liquid in the tank can be transformed to saturated gas is $264 \mathrm{lb} / \mathrm{sec}$ and $92 \mathrm{lb} / \mathrm{sec}$ for Case I and Case II, "respectively. The transformation is caused by evaporation of LNG coming into contact with the hot surface of the striking ship as it penetrates the LNG tank. The figures above represent maximum rates of vaporization for they are based on the immediate transfer of the maximum frictional heating rates to the vaporization process. In fact, the transfer of the frictionally generated heat is not transferred immediately to the LNG, but over a period of time. If the rate of generation of gas in region 1 is larger than the rate at which it can exit through the gap, it is logical to assume that the tank's contents spill into region 2 in the gaseous form. A rough estimate of the maximum rate of gas spillage through a gap having a linear dimension of $24 \mathrm{ft}$ and a gap width of 1 inch (a cross sectional area of $2 \mathrm{ft}^{2}$ ) is $1801 \mathrm{~b} / \mathrm{sec}$. This estimate is based on the assumption of sonic flow through the gap with the driving pressure for sonic flow provided by pressure within the gas volume generated by evaporation and expansion against the surrounding LNG. The value of $180 \mathrm{lb} / \mathrm{sec}$ is less than the maximum rate of vapor generation for Case I and more than that for Case II. As the penetration of the LNG tank proceeds, the instantaneous heating rate for vaporization

* Case I - Collision with a cargo ship; Case II - Collision with a petroleum tanker. See Appendix F for further details. 
decreases IInearly with time, while the hole size for spillage increases. Accordingly, we may reasonably expect that for Case $I$, the form of the fluid spillage would first be gaseous, followed thereafter by an increasing proportion of liquid, and ending in entirely liquid spillage when frictional heating ceases. In Case II, the spillage would have a higher proportion of liquid at a given time after LNG tank penetration. The rate and quality of the fluid spillage depends on the assumptions regarding the size of the hole for spillage. If the hole is assumed to be smaller, the quantity of the fluid spilled vs. time becomes larger and vice versa. With a heat of $50 \mathrm{ft}$, the mass flow rate of all liquid would be about 20 times that of a sonic flow of gas in both cases assuming a hole of the same size. Accordingly, the mass flow of spillage from region 1 to region 2 will increase as the penetration of the LNG tank proceeds. For estimating purposes, $180 \mathrm{lb} / \mathrm{sec}$ of gas and $3600 \mathrm{lb} / \mathrm{sec}$ of 1 iquid are taken to bracket the likely circumstances of interest.

\subsubsection{Mixing in Region 2}

\subsubsection{Case of $1801 \mathrm{~b} / \mathrm{sec}$ Gas Jet Spillage}

For a $180 \mathrm{lb} / \mathrm{sec}$ of gas spillage, the minimum flow rate of entrained air required to give a flammable mixture at region 3 would amount to approximately $2175 \mathrm{lb} / \mathrm{sec}$ or $29,000 \mathrm{ft}^{3} / \mathrm{sec}$. The transverse area across which air for mixing must pass is estimated to be about $150 \mathrm{ft}^{2}$; therefore, on the average, the transverse alr velocities must be equal to $190 \mathrm{ft} / \mathrm{sec}$. First order momentum analysis of jet mixing shows that air in this amount will not be entrained and the average mixture reaching region 3 will most likely be fuel rich (>30\% by volume). Moreover, the composition of the gaseous mixture next to the hull of the striking ship and, hence, that passing over the ignition source would be greater than the average mixture because the flow next to the hull is farthest away from the source of entrained air.

The gas spillage rate of $180 \mathrm{lb} / \mathrm{sec}$ represents the maximum rate; the rate is associated with the conditions of Case I shortly after LNG 
tank penetration. The maximum rate of gas spillage for Case II is estimated to be about $92 \mathrm{lb} / \mathrm{sec}$. In either of these cases, the rate of gas evolution reduces linearly with the time after LNG tank penetration. However, the escaping fluld would have an increasing fraction of liquid as less gas is generated and the mass of escaping fluid actually increases with LNG tank penetration.

\subsubsection{Integral and Average Results of Gas Spillage}

From the perspective of integral and average quantities, we get the following circumstances for mixing. As before, the conditions of Case I and Case II, one half of the total frictional power generated at any instant of time after the penetration of the LNG tank is at region 1 are assumed. Moreover, it is assumed that this power fraction converts a mass of LNG to saturated gas in region 1 which escapes to region 2. The following table summarizes some pertinent results for the period when the bow of the striking ship is penetrating the LNG tank.

$\begin{array}{cccc}\begin{array}{c}\text { Frictional Heat } \\ \text { Generated (Btu) }\end{array} & \begin{array}{c}\text { Mass of Sat.Gas } \\ \text { Generated (lb) }\end{array} & \begin{array}{c}\text { Volume of Sat.Gas } \\ \text { Generated (ft })\end{array} & \begin{array}{c}\text { Period of LNG Tank } \\ \text { Penetration (sec) }\end{array} \\ 6.69 \times 10^{4} & 305 & 2655 & 2.31 \\ 4.70 \times 10^{4} & 215 & 1871^{4} & 4.65\end{array}$

The minimum amounts of air required to achieve a $15 \%$ methane by volume combustible mixture are $36851 \mathrm{~b}\left(48,813 \mathrm{ft}^{3}\right.$ at NTP) and $2537(34,409$ $\mathrm{ft}^{3}$ at NTP) for Case I and Case II, respectively. The transverse area of the jet across which the mixing air must pass is about $150 \mathrm{ft}^{2}$. Therefore, the linear dimension of the air to be entrained must be the order of 325 and $229 \mathrm{ft}$, and the average transverse air velocities for mixing would be 140 and $49 \mathrm{ft} / \mathrm{sec}$, respectively. Transverse entrainment velocities in the lower part of this range are probably reasonable, and the time averaged value of the mixture composition could be in the flammable range. Agaln, however, the mixture next to the ignition source would be richer in fuel than the average mixture and the actual fluid leaving region 1 would have a highêr proportion of liquid and a greater flow rate as LNG tank penetration proceeds. 


\subsubsection{Liquid Spillage}

When the penetration of the LNG tank and, therefore, frictional heating ceases, liquid flows through the gap torn in the LNG tank. A small proportion (approximately $3 \%$ ) of the liquid flashes as it flows into region 2 and its pressure drops about 10 psi, corresponding to an average-head of $50 \mathrm{ft}$ of LNG in the tank. Through a $2-\mathrm{ft}^{2}$ hole, approximately $3600 \mathrm{lb} / \mathrm{sec}$ of fluid issues from region 1 into region 2. The mostly liquid jet fans out across the space between the two hulls, splashes against the outer hull, and falls into the water ballast below. A fraction is evaporated directly in cooling the hull of the striking vesse1; the remainder is evaporated upon contact with the hull of the tanker and the water ballast.

The flow rate of $3600 \mathrm{lb} / \mathrm{sec}$ of liquid is 20 times the flow rate of $180 \mathrm{lb} / \mathrm{sec}$ of gas which has been previously estimated to produce a mixture at the ignition source (region 3 ), that is too rich in fuel for combustion.

\subsubsection{Potential for Ignition in Region 3}

For the simplified model, our assumptions are that the likelihood of hot surfaces contacting a flammable mixture for a sufficient time to cause ignition would be quite small, because the mixture reaching the ignition source is likely to be too fuel rich. This conclusion, however, is affected by such assumptions as the size of the gap, the amount of thermal energy available to convert liquid to gas, and time-averaged mixing takes place in the annular space between the two hulls.

If the gap were smaller (say of the order of $1 \mathrm{ft}^{2}$ ), less fluid would jet into region 2 and a fuel rich mixture at region 3 is less likely. Under these circumstances, a flammable mixture might, in fact, occur; certainly, at some hole size, sufficiently small, it would. On the other hand, in this analysis, it was assumed that one-half of the energy absorbed at impact would be transferred to the liquid, causing it to vaporize. Actually, onity a fraction of this energy would be 
directly transmitted to the liquid during the early stages of colliston. Structural members that are crushed and deformed will absorb much of the energy, and they may not be readily accessible to the liquid during the early stages of impact. With lower rates of vapor generation, more fluid jets into regton 2 and flammable mixtures in zone. 3 are even less likely.

Also, if the hot surfaces in Zone 3 are initially exposed to air and later after the container ruptures exposed to fuel rich mixtures, they must in the interval between be exposed, at least momentarily, to flammable mixtures. If the momentary interval, estimated to be of the order of 0.1 seconds, were of sufficient length, then again, ignition would occur.

Finally, it is not necessarily true that the hot surfaces will only occur inward of the outer full of the LNG tanker. Although the configuration of the two colliding ships at the area of impact favor: this condition, one can postulate occurrences where hot surfaces might extend outward from the outer hull. For example, if the impacting ship rotates slightly as it penetrates deck plate and other comporents of the LNG tanker, heated surfaces could be exposed to vapor external to the outer hull. As fuel rich mixtures pass these hot spots (at the periphery of the gap for vapor flow) conditions can be set up for the formation of a diffusion flame when ignition occurs. Under these circumstances a zone of recirculation will occur at the edge of the gap in which an ignitable flammable mixture will occur. This can very likely take place at the site of a hot spot, resulting in ignition.

\section{$\underline{7.5 .6}$ Summary}

In summary, it is diffucult to postulate a simple model that would indicate a high probability that a flammable mixture will contact a hot surface for a sufficient time to become ignited. The hot surfaces (created by frictional impact) that occur just inside the outer hull of the LNG tanker are likely to be exposed to mixtures that are too fuel rich for ignition to take place. Hot surfaces external to the outer hull where, due to recirculation, flammable mixtures are more 
likely to occur require that the motion of the two ships or bending of ship components during impact be more complex than depicted in the simple model we have described.

A more detailed analysis of the fluid mechanics and of the specifics of structural deformation is needed before the likelihood of ignition due to frictional impact can be fully answered. 


\subsection{Conclusions and Recommendations}

The review of ignition potential during a collision leads to the following results and conclusions:

1. The most probable source of methane-air ignition during ship collision comes from the production of hot surfaces via adiabatic shear. Discrete non-pyrophoric frictional sparks cannot cause ignition; however, ignition may be fostered by high spark númber densities. Electrical sparks are an effective ignition source, but most electrical lines are placed at the centerline of the ship, thus reducing the influence of so-called "break" sparks.

2. Flammable methane-air mixtures may be only available at the outer hull of the struck tanker, the oxidizer source being either air in the ballast space or the local environment. Large LNG leaks tend to produce highly fuel-rich mixtures which could inhibit ignition. Ignition is most probable at equivalence ratios near $\phi \simeq 0.7$.

3. Hot surfaces at $1200-1500^{\circ} \mathrm{C}$ are generated along the penetrating bow just inside the outer hull of the struck ship and on the outer hull itself close to the penetration point. These surfaces are approximately $1-10 \mathrm{~mm}$ in width and remaln hot for about $0.5-5.0 \mathrm{sec}$.

4. Based primarily on the work of Rae, et al." (1964), Cutler, et al. (1974), and Ono, et al. (1976), the temperature, time at temperature and size of the hot surface appears sufficient to ignite flammable methane-air mixtures.: However, extensive experimental work duplicating the hot surface size, heating rate and temperature expected upon tanker collision is required to substantiate this conclusion.

5. Using the Van't Hoff ignition criterion, we have developed simple correlations among surface ignition temperature, size, pressure and flow velocity consistent. with previous 
experimental work, particularly that of Ono, et a1. (1976). For a given pressure and velocity, the most important result is

$$
\ln \mathrm{L}=\mathrm{E} / \mathrm{sRT} \mathrm{w}_{\mathrm{w}}
$$

where $L$ is the width of the hot surface, $E$ the activation energy, $R$ the universal gas constant and $T_{W}$ the surface ignition temperature. The constant parameter $s$ is equal to two for stagnant conditions, one-half for free convection and unity for forced convection.

The experimental work conducted in this investigation gives the following results and conclusions:

1. An electrical heating circuit has been developed to provide a hot surface of well defined temperature, duration and heating rate consistent with expected values produced by tanker collision. A novel feature of the experimental facility is the use of miniature thermocouples sandwiched between two metal strips to obtain highly reproducible temperature-time profiles requiring no radiation corrections.

2. Pulse ignition tests were conducted for a methane-air mixture of equivalence ratio 0.7 flowing past vertical tungsten and stainless steel strips at $\sim 1 \mathrm{~cm} / \mathrm{min}$. At heating rates of $12,000-15,000^{\circ} \mathrm{C} / \mathrm{s}$, metal strips $2-10 \mathrm{~mm}$ wide gave surface ignition temperatures of $1000-1100^{\circ} \mathrm{C}$. Typically, ignition occurred within 0.1 - $0.2 \mathrm{~s}$ after attainment of the peak surace temperature. Surfaces coated with a primer/paint normally used on ship steel gave ignition temperatures of $600-700^{\circ} \mathrm{C}$. We conclude that the $1200-1500^{\circ} \mathrm{C}$ surfaces generated by ship collision are of sufficient size and duration to ignite flammable quiescent methane-air mixtures. However, ignition may not occur at higher gas velocities anticipated during and immediately following LNG tank penetration. 
3. The influence of strip width on ignition temperature was successfully correlated by Equation (6.1). For methaneair, $E / R \simeq 25,000$ giving $s=1 / 2$ or free convection conditions. This result is to be expected at the very low flow velocities of this investigation.

Based on the results to date, we recommend that the DOE consider the following additional work:

1. Development of a turbulent fuel-air mixing model to better answer the important question of whether or not a flammable mixture is available at a hot surface of a given geometry and position on the tanker hull.

2. Further experiments to assess the two important considerations for LNG accidents - the influence of initial fuel-air temperature and velocity on the surface temperature required for ignition.

3. Detailed experiments to obtain fundamental data on the relationships between ignition temperature and (a) surface orientation, (b) heating and cooling rates, (c) stoichiometry, (d) pressure, and (e) additives, particularly higher nydrocarbon fuels. The influence of temperature gradients across the heated metal strip should also be investigated, both experimentally and analytically. 
The maximum radius of spread for an instantaneous released LNG spill is given by Raj (1977).

$$
R=\left[\frac{v^{3} g \Delta}{\dot{y}^{2}}\right]^{1 / 8}
$$

The maximum spread radius for a continuous spill is:

$$
R=\left[\begin{array}{ll}
\frac{V}{t_{s}} & \frac{1}{\pi \dot{y}}
\end{array}\right] 1 / 2
$$

The above two equations can be written in dimensionless form by defining certain characteristic parameters. These are:

$$
\begin{aligned}
& \mathrm{L}=\text { characteristic length scale }=\mathrm{v}^{1 / 3} \\
& t_{\text {ch }}=\text { characteristic covaporation time }=\frac{\mathrm{J}}{\%} \\
& E=\text { dimensionless maximum spread }=\frac{\mathrm{R}}{\mathrm{L}} \\
& \tau=\text { dimensionless time }=\frac{t}{t_{c h}}
\end{aligned}
$$

Using the above parameters equations $\mathrm{A} 1$ and $\mathrm{A} 2$ are written as:

$$
\begin{aligned}
& \xi=\left[\frac{\operatorname{Lg} \Delta}{\dot{y}^{2}}\right]^{1 / 8} \text { INSTANTANEOUS } \\
& \xi=\frac{1}{\sqrt{\pi}} \cdot \frac{1}{\tau^{1 / 2}} \quad \text { ConTINUOUS }
\end{aligned}
$$

The above two equations are shown plotted in Figure $\Lambda .1$. l.t is seen that the dimensionless radius for instantaneous spili. is somewhat insensitive to the spill volume in the range of $1000 \mathrm{~m}^{3}$ to $25,000 \mathrm{~m}^{3}$. In the case of continuous spill, the radius of spread is inversely proportional to the square root of the spill time.

It is seen from the figure that for any spill time larger than about $2 \times 10^{-3}$ in dimensionless units, the spill can be considered to be essentially continuous. That is: 


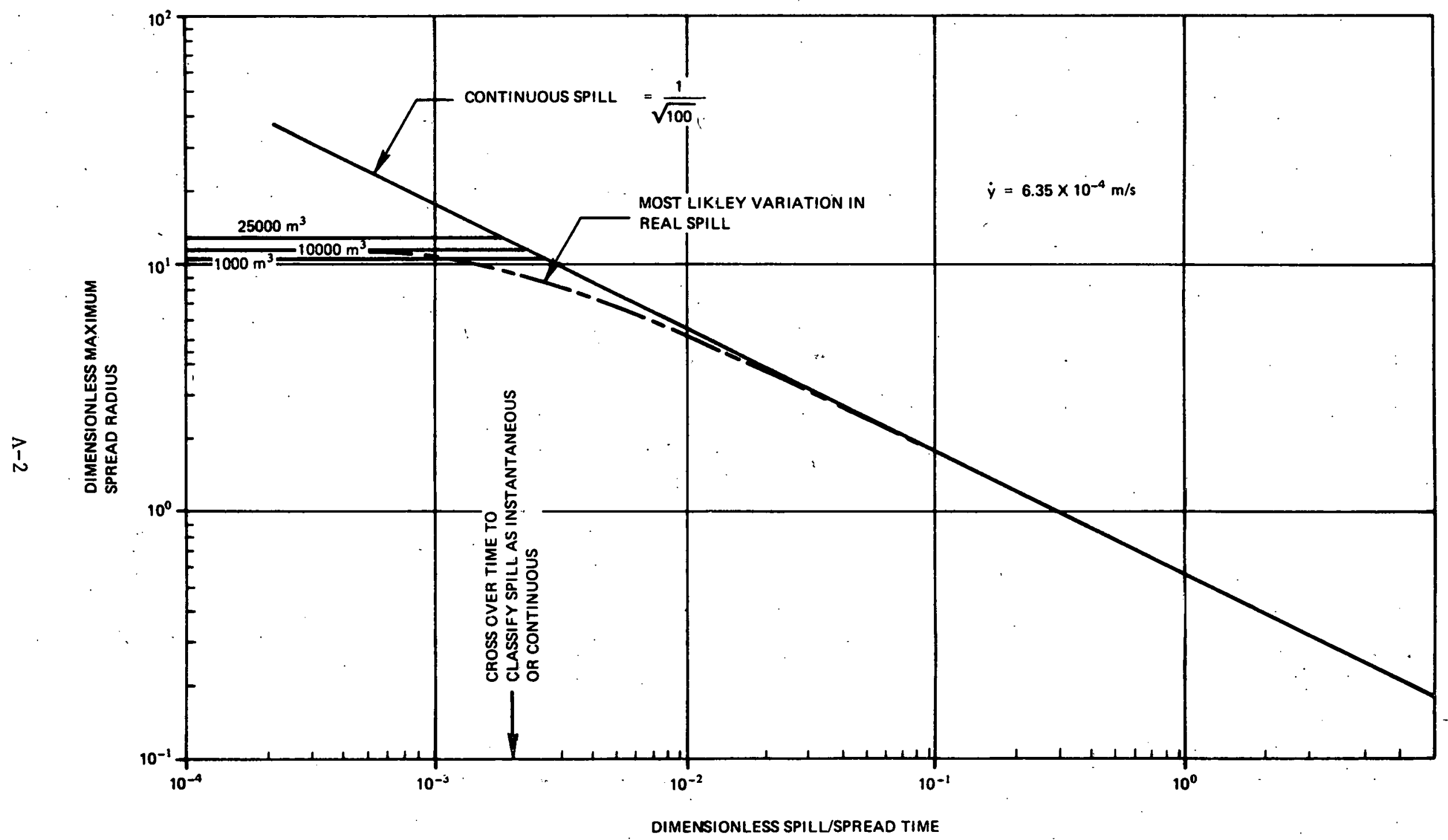

FIGURE A.1 MAXIMUM RADIUS OF SPREAD AS A FUNCTION OF SPILL TIME FOR LNG SPILL ON WATER 


$$
\tau_{\text {crossover }}=0.002
$$

The interpretation of the above criterion is illustrated with an example below.

\section{EXAMPLE:}

$25,000 \mathrm{~m}^{3}$ of LNG is spilled over a period of 3 minutes. Is this spill to be treated as a continuous spill or an instantaneous spil1? Assume the spill is on fire and that the liquid vaporization rate is $6.35 \times 10^{-4} \mathrm{~m} / \mathrm{s}$ (1.5 inch/min).

$$
\begin{aligned}
& \text { Characteristic length }=L=(25,000)^{1 / 3}=29.2 \mathrm{~m} \\
& \text { Characteristic evaporation time }=t_{\mathrm{ch}}=\frac{\mathrm{L}}{\dot{\dot{y}}}=\frac{29.2}{6.35 \times 10^{-4}}=46047 \mathrm{~s}
\end{aligned}
$$

Hence, crossover time $t_{\text {crossover }}=\tau_{\text {crossover }} t_{c h}=0.002 \times 46047=92 \mathrm{~s}$

Since the spill duration is $180 \mathrm{~s}$ and is longer than the crossover time of $92 \mathrm{~s}$, the spill can be treated as a continuous spill. Had the spill occurred in 1 minute, then it should be modeled as an instantaneous spill. 


\section{APPENDIX B}

\section{A MODEL FOR THE GRAVITY SPREAD OF A HEAVY VAPOR RELEASED CONTINUOUSLY FROM A SOURCE}

\section{$\underline{\text { SUMMARY }}$}

In this Appendix a model is derived to determine the rate of spread of a heavier than air vapor when it is released continuously. The key concept that is used is the dilution of vapor by air entrainment during the lateral spread. Expressions are derived for the width of cloud and the mean concentration of vapor in the cloud.

\section{PROBLEM}

A vapor of initial density $\rho$ is released at a volumetric rate of $2 \dot{V}$ from a source of semi-width $y_{o}$. The wind speed is $U_{w} \cdot$ Determine the spread law for the vapor.

\section{ASSURPT IONS}

In deriving the model we assume the following:

1. air in the ambient is dry;

2. the spread of vapor is only in the lateral (crosswind direction);

3. a parcel of vapor released moves downwind at wind speed;

4. entrainment of air is effected only by the. lateral spread speed of the vapor;

5.' the vapor cloud has uniform concentration and height at any given instant of time;

6. air and the vapor are perfect gases with the same molar specific heats;

7. the mixing of air and vapor is adiabatic.

Figure B-1 shows schematically the essentials of the model. The rectangular cross section of the vapor cloud expands due to air entrainment and moves down wind at wind speed.

MODEL EQUATIONS

We consider a slice of the cloud of unit distance in the windward direction at position $x$ (see Figure $B-1 b$ ). The equations of mass conservation, volume conservation, spread law, and the entrainment equation are written as follows and solved.*

* Symbols are described in the nomenclature. 


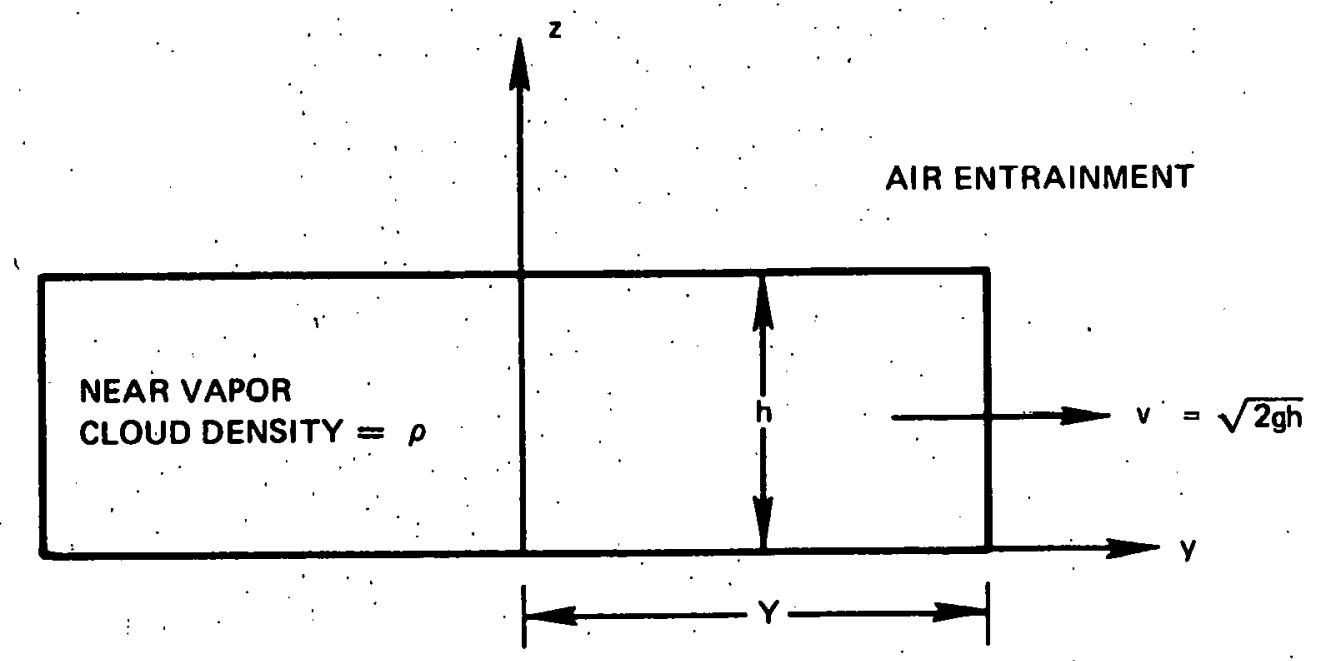

FIGURE B.1a SCHEMATIC REPRESENTATION OF THE TOP HAT CONCENTRATION PROFILE

$\because$
$\because$
$\because$
$\therefore$
$\because$
$\vdots$
$\vdots$

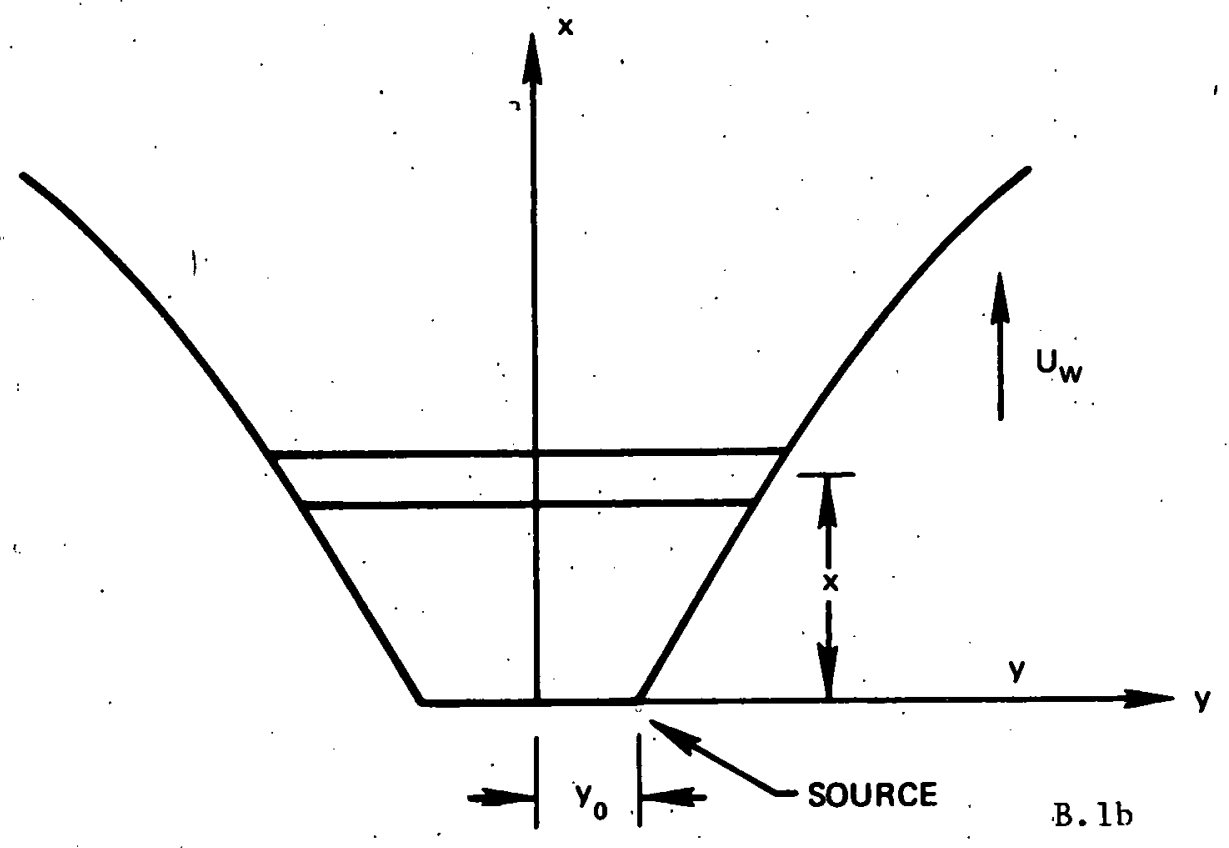

FIGURE B. 1 SCHEMATIC REPRESENTATION OF THE LATERAL SPREAD MODEL 
We consider only one half of the cloud.

(i) Entrainment law

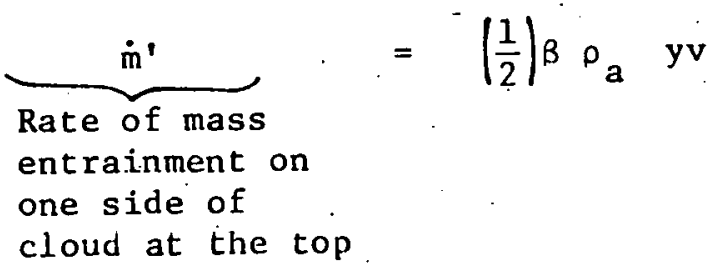

The $1 / 2$ on the right-hand side accounts for the fact that only the edge is moving laterally at velocity $v$.

\section{(ii) Spread Law}

$$
v=\frac{d y}{d t}=\sqrt{2 \operatorname{gh}\left(\frac{\rho}{\rho \cdot a}-: 1\right)}
$$

where $\rho$ is the mean density of the vapor cloud.

\section{(iii) Volume Conservation Law}

If $A$ is the cross sectional area (to one side of the centerline) of the vapor cloud, then we can write:

$$
A=A_{0}+A_{a}
$$

where $A_{a}$ is the total volume of air (per unit length in wind direction) entrained ${ }^{a}$ on one side of the vapor cloud. The above linear addition of volumes can be made because, in the adiabatic mixing of perfect gases having the same molar specific heat, the total volume of the mixture is equal to the sum of the individual vapor volumes.

$$
\begin{aligned}
& A_{a}=\frac{1}{\rho_{a}} \int_{0}^{t} \dot{m}^{\prime} d t=\frac{1}{\rho_{a}}\left[m^{\prime}-\dot{m}_{0}^{\prime}\right] \\
& \text { (iv) Mass Conservation }
\end{aligned}
$$

The total mass of gases in the slice of cloud is equal to the initial mass together with the entrained air mass. That is:

$$
m^{\prime}=m_{0}^{\prime}+\int_{0}^{t} \dot{m}^{\prime} d t
$$


We now substitute for $v$ in equation $B 1$ from equation $B 2$ and integrate to obtain:

$$
m^{\prime}-m_{0}^{\prime}=\frac{1}{2} \frac{\beta \rho_{a}}{2}\left(y^{2}-y_{o}^{2}\right)=\rho_{a} A_{a}
$$

Hence:

$$
A_{a}=\frac{B}{4}\left(y^{2}-y_{0}^{2}\right)
$$

Now:

$$
\rho=\frac{\text { mass }}{\text { volume }}=\frac{m^{\prime}}{A}=\frac{m_{o}^{\prime}+\rho_{a} A_{a}}{A_{0}+A_{a}}
$$

Hence:

$$
\left(\frac{\rho_{-}}{\rho_{a}}-1\right)=\frac{m_{0}-\rho_{a} A_{0}}{\rho_{a} A}
$$

Also:

$$
\mathrm{A}=\mathrm{yh}
$$

Substituting B8 and B9 in equation B2 we get:

$$
\frac{d y}{d t}=\sqrt{2 g h \frac{\left(m_{0}^{\prime}-\rho_{a} A_{0}\right)}{\rho_{a} y^{\prime h}}}
$$

Integrating we get:

$$
\frac{2}{3}\left(y^{3 / 2}-y_{0}^{3 / 2}\right)=\sqrt{2 g \frac{\left(m_{0}^{\prime}-\rho_{a} A_{0}\right)}{\rho_{a}}}
$$

i.e.

$$
\begin{aligned}
& \left(y^{3 / 2}-y_{o}^{3 / 2}\right)=\frac{3}{2} \sqrt{2 g A_{o}\left(\frac{\rho_{v}}{\rho_{a}}-1\right) t} \\
& \left\{\left(\frac{y}{y_{o}}\right)^{3 / 2}-1\right\}=\frac{3}{2} \sqrt{2 g h_{o}\left(\frac{\rho_{v}}{\rho_{a}}-1\right)} \frac{x}{U_{w} y_{o}}
\end{aligned}
$$

This gives the spread law with distance. We now define the following characteristic parameters: 


$$
\begin{aligned}
\xi & =\frac{y}{y_{0}}=\text { dimensionless spread } \\
t_{c h} & =\frac{y_{0}}{\sqrt{2 g h_{0}\left(\frac{p_{v}}{\omega_{a}}-1\right)}}=\frac{y_{0}}{v_{0}}=\text { characteristic spread time } \\
\tau & =\frac{t}{t_{c h}}=\frac{x}{U_{w} t} \text { dimensionless time }
\end{aligned}
$$

Hence equation B13a becomes:

$$
\xi^{3 / 2}=1+\frac{3}{2} \tau
$$

Cross sectional area of slice (from equations B6b and B14a) is given by:

$$
A=A_{0}+\frac{B}{4} y_{0}^{2}\left[\xi^{2}-1\right]
$$

Mass concentration of vapor:

$$
\begin{aligned}
& C_{\text {mass }}=\frac{\text { mass of vapor in the slice }}{\text { total mass of vapor/air mixture }}=\frac{\rho_{v} \Lambda_{0}}{m^{\prime}} \\
& C_{\text {mass }}=\frac{\rho_{v} A_{0}}{\rho_{v} A_{0}+\rho_{a} A_{a}}=\frac{1}{\left[1+\frac{\rho_{a}}{\rho_{v}} \frac{\beta y_{o}}{4 A_{o}}\left(\xi^{2}-1\right)\right]}
\end{aligned}
$$

Similarly the mole concentration is given by:

$$
C_{\text {mole }}=\frac{1}{\left[1+\frac{\rho_{a}}{\rho_{v}} \frac{\mu_{v}}{\mu_{a}} \frac{\beta}{4} \frac{y_{o}^{2}}{A_{o}}\left(\xi^{2}-1\right)\right]}
$$

Sideward velocity of spread (from equation B10)

$$
v=\sqrt{2 g \frac{A_{o}}{y}\left(\frac{\rho_{v}}{\rho_{a}}-1\right)}=v_{o} \sqrt{\frac{y_{0}}{y}}=\frac{v_{o}}{\sqrt{\xi}}
$$




\section{TERMINATION OF LATERAL GRAVITY SPREAD}

The lateral spread of vapor induced by gravity becomes smali when the vapor mixing on the edges is dominated by atmospheric turbulence. There is no simple criterion by which such a termination of gravity spread can be measured. Therefore, we have assumed a very simple gravity spread velocity criterion. The lateral gravity spread is assumed to terminate when the combined vector velocity due to wind and lateral gravity is less than 1.12 times the wind speed. This translates into a terminating gravity spread velocity of $50 \%$ of wind speed.

\section{SPECIFIC. EXAMPLE}

Consider the spill of $25,000 \mathrm{~m}^{3}$ of LNG onto water surface in a duration of 10 minutes. It is desired to describe the gravity spread of the vapors generated by the LNG boiling on water. Following specific parameter values are used:

Quantity of LNG spilled

Density of LNG

Density of LNG vapor

Regression rate on water

Density of air at ambient condition

Wind speed $U_{W}$

Entrainment coefficient $\beta$

$$
\begin{aligned}
& =25,000 \mathrm{~m}^{3} \\
& =425 \mathrm{~kg} / \mathrm{m}^{3} \\
& =1.84 \mathrm{~kg} / \mathrm{m}^{3} \\
& =4.23 \times 10^{-4} \mathrm{~m} / \mathrm{s} \\
& =1.2 \mathrm{~kg} / \mathrm{m}^{3} \\
& =3 \mathrm{~m} / \mathrm{s} \\
& =0.1
\end{aligned}
$$

Hence,

$$
\begin{aligned}
\text { Maximum radius of spread }=\mathrm{R} & =177 \mathrm{~m} \\
\text { Volumetric flow rate of vapor in one } & =4812 \mathrm{~m} / \mathrm{s} \\
\text { half of the center line }=\dot{\mathrm{V}} & =\frac{\dot{\mathrm{V}}}{\mathrm{R} U_{\mathrm{w}}}=9.06 \mathrm{~m} \\
\text { Initial thickness of vapor cloud }=\mathrm{h}_{\mathrm{o}} & =9.73 \mathrm{~m} / \mathrm{s} \\
\text { Initlal lateral spread velocity }=\mathrm{v}_{\mathrm{o}} & =9.19 \mathrm{~s} . \\
\text { Characteristic time }=\mathrm{t}_{\mathrm{ch}} & =18.19
\end{aligned}
$$

The half width of spread and the mean vapor concentration (mole \%) are shown plotted as functions of downwind distance in Figure B.2 for the above case.

\section{RESULTS}

It is seen that within a distance of about $1 \mathrm{~km}$ downwind the mean vapor concentration is reduced below flammable limit. The semi-width of the cloud at this stage is about 10 times the initial semi-width; that is the semi-width is about $1800 \mathrm{~m}$. 


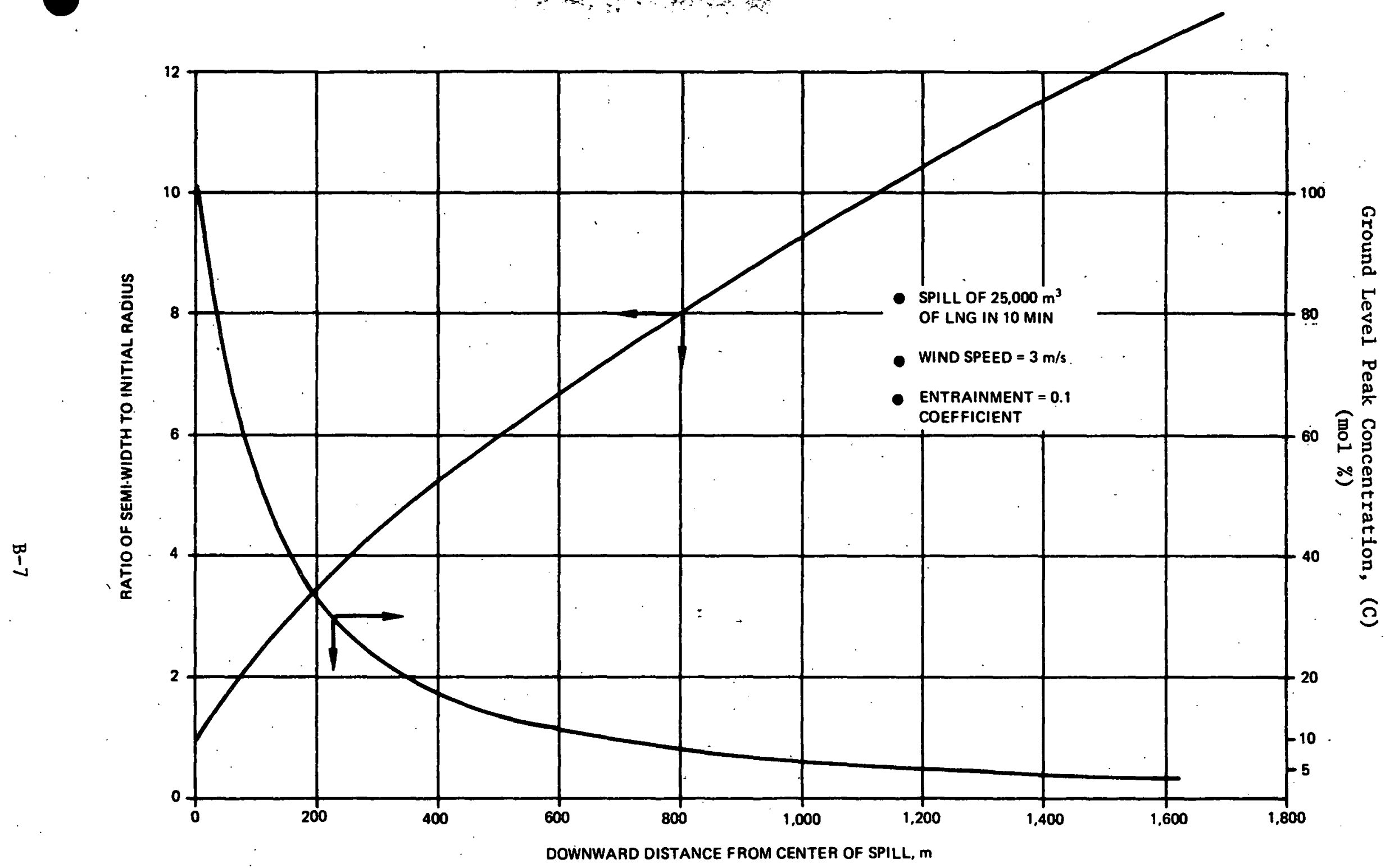

LATERAL GRAVITY SPREAD OF

LNG VAPOR FROM A CONTINUOUS

SPILL OF LNG ONTO WATER

FIGURE B. 2 LATERAL GRAVITY SPREAD OF LNG

VAPOR FROM A CONTINUOUS SPILL OF LNG ONTO WATER 


\section{NOMENCLATURE}
A $=$ cross sectional area of the vapor cloud
$\mathrm{m}^{2}$
$\mathrm{A}_{\mathrm{a}}=$ total volume of ambient air entrained per unit
$\mathrm{m}^{2}$ windward length of cloud
A = initial cross sectional area of cloud
$m^{2}$
C = concentration of vapor in the cloud
$\mathrm{g}=$ acceleration due to gravity
$\mathrm{m} / \mathrm{s}^{2}$
h height of cloud
m
$\mathrm{m}^{\prime} \quad=$ mass of vapor in a slice of cloud of unit length in the wind direction
t $=$ time
$\mathbf{S}$
$\mathrm{U}_{\mathrm{w}} \quad=$ wind speed
$\mathrm{m} / \mathrm{s}$
= lateral spread speed of cloud
$\mathrm{m} / \mathrm{s}$
$x=$ downwind distance
m
$y=$ crosswind extent of cloud
m

\section{GREEK}

$\beta=$ entrainment coefficient

$\mu=$ molecular weight of species (air, vapor, mixture) $\mathrm{kg} / \mathrm{kmole}$

$\xi \quad=$ dimensionless lateral spread

$\rho \quad=$ density

$\mathrm{kg} / \mathrm{m}^{3}$

$\tau=$ dimensionless time 


\section{APPENDIX C}

\section{CALCULATION OF HEAT TRANSFER TO THE HULL PLATE}

In this appendix we calculate the heat transfer from an LNG fire on water adjacent to the hull of an LNG tanker. The primary result of interest is the rate of rise of temperature of the hull plate and the possibility of softening of the steel due to heating.

In the case of steel its yield strength is reduced by a factor of 2 to 3 when its temperature reaches $700 \mathrm{~K}$ (Meyer-Athens, 1968). At this point, it loses much of its ability to provide the structural capability for which it was originally intended.

Here we estimate the time required for the steel to reach various elevated temperatures when subjected to the thermal effects of an LNG flame, using the following assumptions:

1. The heat flux from the flame to the steel is maximum; that is it has value of $100 \mathrm{~kW} / \mathrm{m}^{2}$ ( $\left.\mathrm{Raj}, 1977\right)$.

2. The steel is a slab with no curvature:

3. All of the heat transferred to the plate is absorbed. The convective and radiative cooling from the backside of the plate is assumed to be so small that it may be neglected.

4. The conductive heat transfer in the metai laterally away from the heated zone is small enough to be neglected.

5. The temperature gradient across the steel slab is small enough to be neglected. 
Based upon these assumptions, an energy balance on the steel slab, and equating the heat input to the rise in thermal enthalpy the time ( $t$ ) required to reach a given temperature ( $T$ ) is as follows:

$$
t=\frac{\rho_{S} \delta_{S} C_{S}\left(T-T{ }_{0}\right)}{\dot{q}}
$$

where

$$
\begin{aligned}
& \rho_{s}=\text { density }=7800 \mathrm{~kg} / \mathrm{m}^{3} \\
& \delta_{s}=\text { thickness of slab }=.0254 \mathrm{~m} \\
& c_{s}=\text { specific heat }=0.46 \mathrm{~kJ} / \mathrm{kg} \mathrm{K} \\
& T_{0}=\text { initial temperature }=300 \mathrm{~K} \\
& \dot{q}=\text { heat flux }=100 \mathrm{~kW} / \mathrm{m}^{2}
\end{aligned}
$$

Estimates of the time required for the steel to reach various temperatures have been estimated and are presented in Table C.1, along with additional estimates that consider convective cooling of the backface of the slab.

\section{TABLE C. 1}

Durations for the Hull Plate to Rise to Given Temperatures With and Without Backface Cooling When Exposed to LNG Fires on the Outside

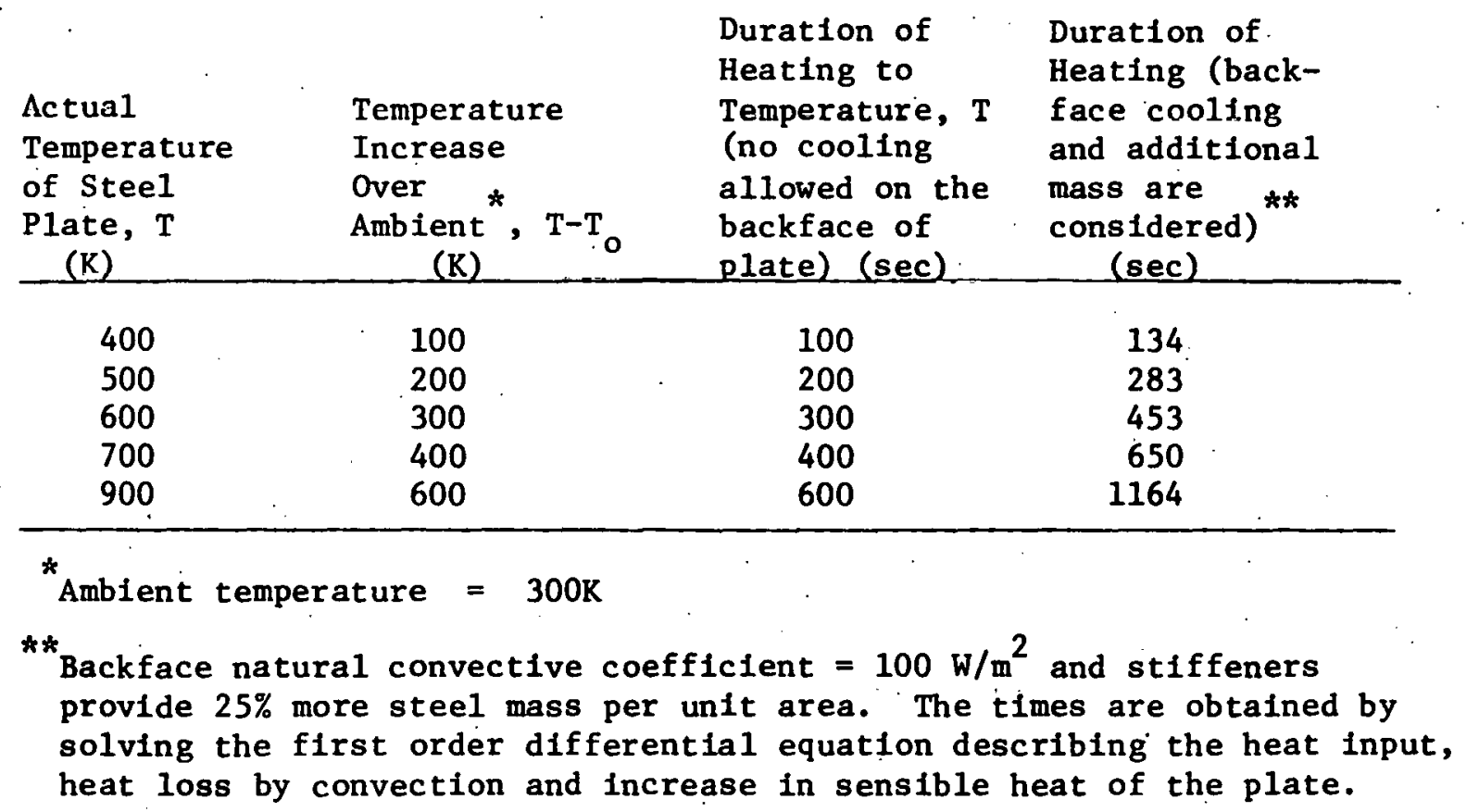


APPENDIX D

EFFECT OF AN EXTERNAL FLAME ON LNG

TANK COVERS AND INSULATION

In this appendix the heating of a steel cover for an LNG tank on board an LNG tanker as the result of a very large fire produced by a massive $\left(e .8 ., 25,000 \mathrm{~m}^{3}\right)$ spill of LNG is estimated. In addition, the thermal response of the tank insulation, if and when the cover fails, is also evaluated.

Thermal Response of the Protective Steel Cover

The time for the steel cover to reach a temperature of $700 \mathrm{~K}$ at about which it will lose most of 1 ts strength has been estimated using the same assumptions and relationships presented in Appendix $C$, except that the steel thickness is assumed to be one-half that of the value used for the hull plate. On this basis the exposure time required to reach a temperature of $700 \mathrm{~K}$ is 200 seconds (or about 3 minutes). This time is a minimum value because of the conservative assumptions used in its derivation. A fire lasting less than the 200 seconds may not result in the yielding of the steel cover.

It is noteworthy that the time to failure is inversely. related to the heat flux. Thus, when the heat flux is 10 er than $100 \mathrm{~kW} / \mathrm{m}^{2}$, a longer exposure can be tolerated. Furthermore, as the heat flux from the fire decreases, heat losses from the steel as in convective cooling or conductive losses laterally away from the heated zone will become comparatively important. In fact, for sufficiently low heat fluxes, the steel might reach a steady temperature at which any additional heat input is lost to the environment. If this temperature is below $700 \mathrm{~K}$ the steel may withstand very long heating exposures without failure. It is estimated that the critical heat flux below which the integrity of the steel structure might be maintained is in the range of 10 to $20 \mathrm{~kW} / \mathrm{m}^{2}$. 


\section{Thermal Responses of the Insulation}

While the steel is heating up, it will radiate heat towards the insulation. The maximum heat flux that can be radiated is about $14 \mathrm{~kW} / \mathrm{m}^{2}$ and will occur only when the steel reaches a temperature of $700 \mathrm{~K}$. This flux is small compared with that from the LNG flames $\left(100 \mathrm{~kW} / \mathrm{m}^{2}\right)$. Should the steel cover fail, the insulation may be subjected directly to $100 \mathrm{~kW} / \mathrm{m}^{2}$. The area of insulation exposed to such a heat flux will depend greatly on the way in which the cover fails and is difficult to compute. Should the cover unzip, large areas will be exposed and the insulation depending upon its composition, is expected to,char, Ignite, and burn. Should local cracking occur, the LNG flames will impinge on the insulation in only localized areas. The burning of combustible insulations may be slow because of their limited access to air.

To provide an indication as to the rate at which insulation may deteriorate or recede due to direct exposure of the LNG flame we have estimated the surface regression rate for a typical polyurethane insulation based on the heating causing it to vaporize. The relationship used in this estimate consists of a simplified energy balance between the rate of heat input and the rate at which the insulation vaporizes, neglecting heat losses and heat generated by the combustion of vapors. It is expressed as follows:

$$
v=\frac{1}{\delta_{i}} \quad\left[\frac{q^{\prime \prime}}{C_{i}\left(T_{v}-T_{0}\right)+L_{i}}\right]
$$

where:

$$
\begin{aligned}
& v^{\prime \prime}=\text { surface regression rate } \\
& q^{\prime}=\text { imposed heat flux } \\
& \delta_{1}=\text { insulation density }=32 \mathrm{~kg} / \mathrm{m}^{4} \\
& \mathrm{C}_{1}=\text { insulation spectfic heat }=1400 \mathrm{~J} / \mathrm{kg}^{\circ} \mathrm{K} \\
& \mathrm{T}_{\mathrm{v}}=\text { vaporization temperature }=620^{\circ} \mathrm{K}^{*}
\end{aligned}
$$

\section{$\star$} Obtained in a private communtcation with Factory Mutual Research Corporation. 
$T_{0}=$ initial ambient temperature

$\mathrm{L}_{1}^{0}=$ heat of vaporization $=1.5 \times 10^{6} \mathrm{~J} / \mathrm{kg}$

Assuming a maximum heat flux of $100 \mathrm{~kW} / \mathrm{m}^{2}$, the surface regression rate becomes $1.6 \times 10^{-3} \mathrm{~m} / \mathrm{s}$. Thus, an insulation thickness of $0.2 \mathrm{~m}$ will be destroyed in about 2 minutes in the regions where it is subjected to $100 \mathrm{~kW} / \mathrm{m}^{2}$. In regions where the heat flux is lower, a proportionately slower regression rate will be obtained.

It is noteworthy that the back temperature of the insulation remains cold even after its surface starts to vaporize. This is due to the low thermal conductivity of the insulation. 'Consequently, little heat is transferred to the LNG until the insulation is reduced to a critical thickness of about 1/2" which, occurs at about 110 second after the insulation is subjected to the $100 \mathrm{~kW} / \mathrm{m}^{2}$. The heat flux into the LNG vessel will then rapidly increase with time due to the decrease in the insulation. thickness below the critical value. When the insulation becomes completely destroyed, heat flux into the LNG vessel will reach that Imposed by the fire (namely, $100 \mathrm{~kW} / \mathrm{m}^{2}$ ).

To assess the impact of that heat transfer on LNG venting or pressure build up, we must know the total area of heat transfer, where the insulation has been destroyed. Such an area is difficult to estimate, however, because it depends on the failure model of the protective steel dome. Consequently, we estimate the minimum insulation area $\left(\mathrm{A}_{\mathrm{min}}\right.$ ) that must be affected so that the boil-off due to heat input exceeds the maximum safe venting rate $(\dot{m})$ of the vessel. From an energy balance on the LNG we get:

\footnotetext{
* An Assessment of Thermal Insulation Materials and Systems for. Building Applications," BNL-50862, p. 89.
} 


$$
A_{\min }=\frac{\dot{M} L_{L N G}}{\dot{g}^{\prime \prime}}
$$

where,

$$
L_{L N G}=\text { heat of vaporization of } L N G=511 \mathrm{~kJ} / \mathrm{kg}
$$

and

$$
\dot{g}^{\prime}=\text { heat flux input from the fire. }
$$

Assuming $\dot{\mathrm{M}}=25 \mathrm{~kg} / \mathrm{s}$ and $\dot{\mathrm{g}}^{\prime \prime}=100 \mathrm{~kW} / \mathrm{m}^{2}$,

the minimum area is $130 \mathrm{M}^{2}$.

Note that this area is inversely related to the heat flux for which we have chosen the maximum possible value.

n:

D-4 


\section{APPENDIX E}

\section{FIRE PROTECTION COATINGS}

Passive fire protection of structures can be achleved through the use of light-welght, fire-resisting mastic coatings which are normally sprayed or trowelled on exposed surfaces. Fire-resisting mastic coatings act as sacrificial materials which degrade upon exposure to a fire but, by design, prevent the fire from damaging the substance for a specific period of time. The period of protection needed to allow fire-fighting capabilities to reach and act upon the fire can be adjusted ordinarily by varying the thickness of the coatings. One hour or more of protection can be achieved by most coatings. After fire exposure, the coating is normally scraped off and fresh material applied.

Fire-resisting mastic coatings generally function through one of two mechanisms: Intumescence and transpirational cooling. Intumescent coatings grow to form a thick insulating semi-rigid charred foam barrier when exposed to fire. Typically, a 0.25 inch thick coating will form a blanket barrier of up to 1.9 inches thick. The foam is formed through the simultaneous melting of the surface and the liberation of gases. which, in turn, form small bubbles that subsequently harden into a char. The foaming process is endothermic and takes place around $450^{\circ} \mathrm{F}$. The substrate is kept cool through a combination of the foam-forming endothermic reaction, transpirational cooling by the liberated gases, thermal insulation of the formed foam, and reradiation of heat by the charred surface. Generally, intumescent materials generate toxic or irritating gaseous products upon exposure to a fire. This restricts their use to exterior surfaces.

Coatings which protect surfaces by transpirational cooling are generally composed of materials containing water of hydration. When exposed to a fire, the coating volatilizes at a fixed temperature (approx. $220-250^{\circ} \mathrm{F}$ ) and continues to liberate: cooling vapors that percolate from the interlor. The highly endothermic process continues until the water has been depleted. The residual porous char which is 
formed acts as a thermal insulator and reradiator to afford additional protection.

Mastic materials are ordinarily applied by specially trained technicians. Spraying can be performed either prior to the erection of the structure (which would include a subsequent "touch up" at joints or after the structure had been assembled).

Table E-1 lists pertinent data on various mastic coatings that can be considered for structural applications. In addition to fire protection effectiveness, important in the selection of coatings are, such properties as:

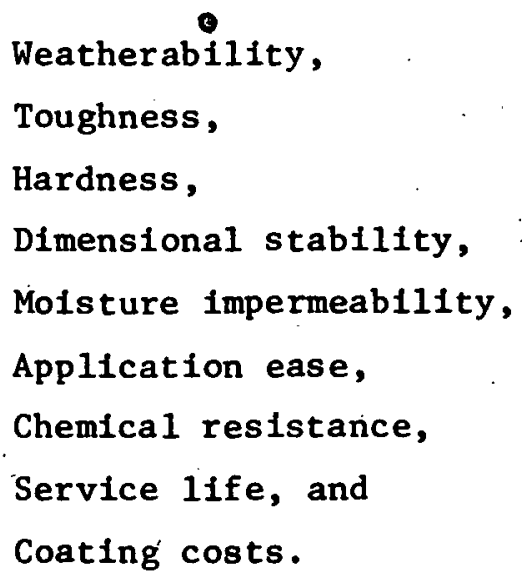

The materials shown in Table E-1 are weatherable to various degrees. Some need topcoats, however, or other protective measures such as impervious films.

One of the promising insulating materials that has low thermal conductivity, low density, good adhesion (to steel) and weathering properties is an epoxy-based intumescent coating developed by the AVCO Corporation. This material is sold under the trade name of CHARTEK 59.

Laboratory experiments conducted with a steel wall $(0.25$ inch thick) sandwiched with 1-meter mineral wool on both sides and topped with 0.26 inch of CHARTEK 59 and exposed to $1255 \mathrm{~K}\left(1800^{\circ} \mathrm{F}\right)$ indicate that the backface temperature does not rise above $310 \mathrm{~K}\left(100^{\circ} \mathrm{F}\right)$ in 
TABLE E-1

SUMMARY OF MASTIC COATINGS FOR PASSIVE FIRE PROTECTION

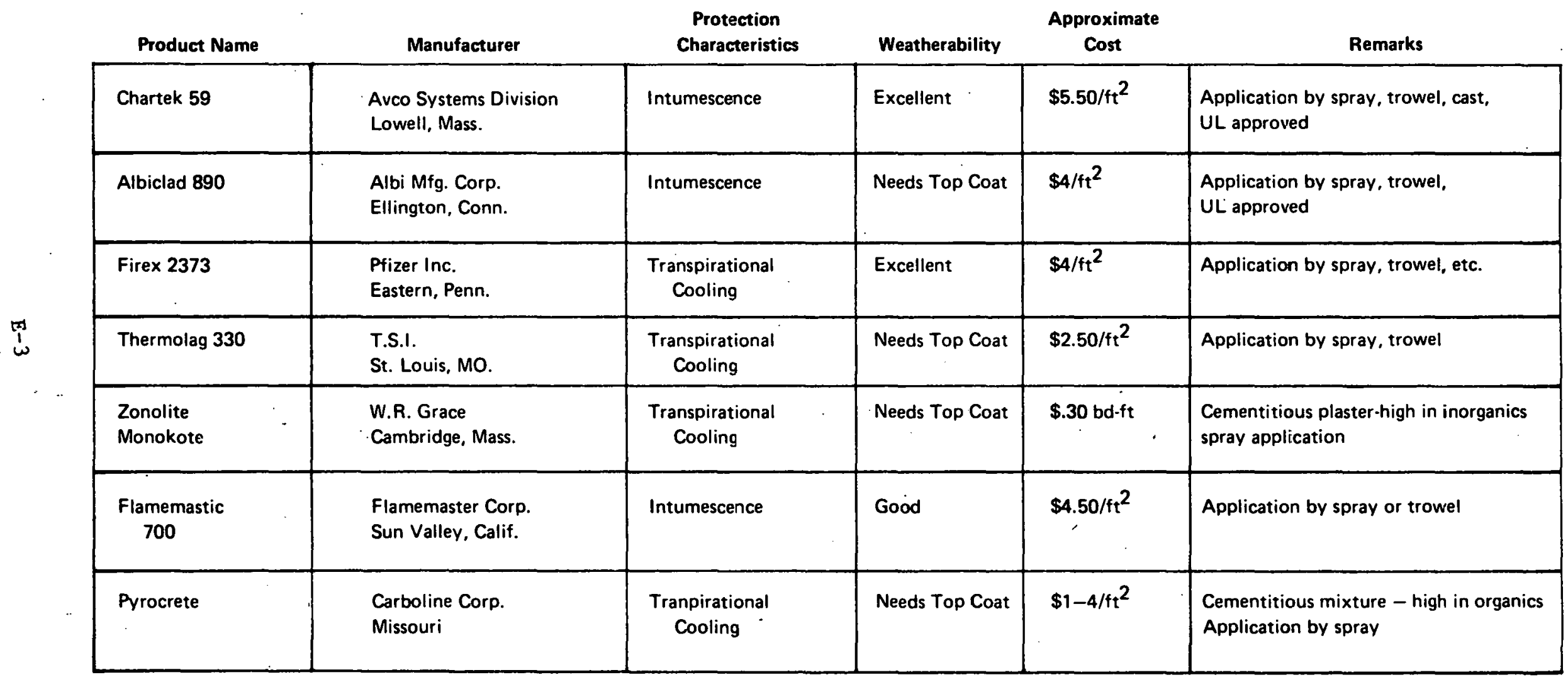


50-minutes. When the mineral wool thickness is increased to 2 inches, the backface temperature remains below $310 \mathrm{~K}$, even after 80 -minnute exposure. Figures $E-1$ and E-2, taken from reference [1], indicate the backface temperature variation with time for different thicknesses of steel, mineral wool, and CHARTEK 59.

CHARTEX intumesces at about $500 \mathrm{~K}\left(450^{\circ} \mathrm{F}\right)$ and in the process may give off toxic gases. In none of the tests above the emission of toxic gases if any, were measured. 


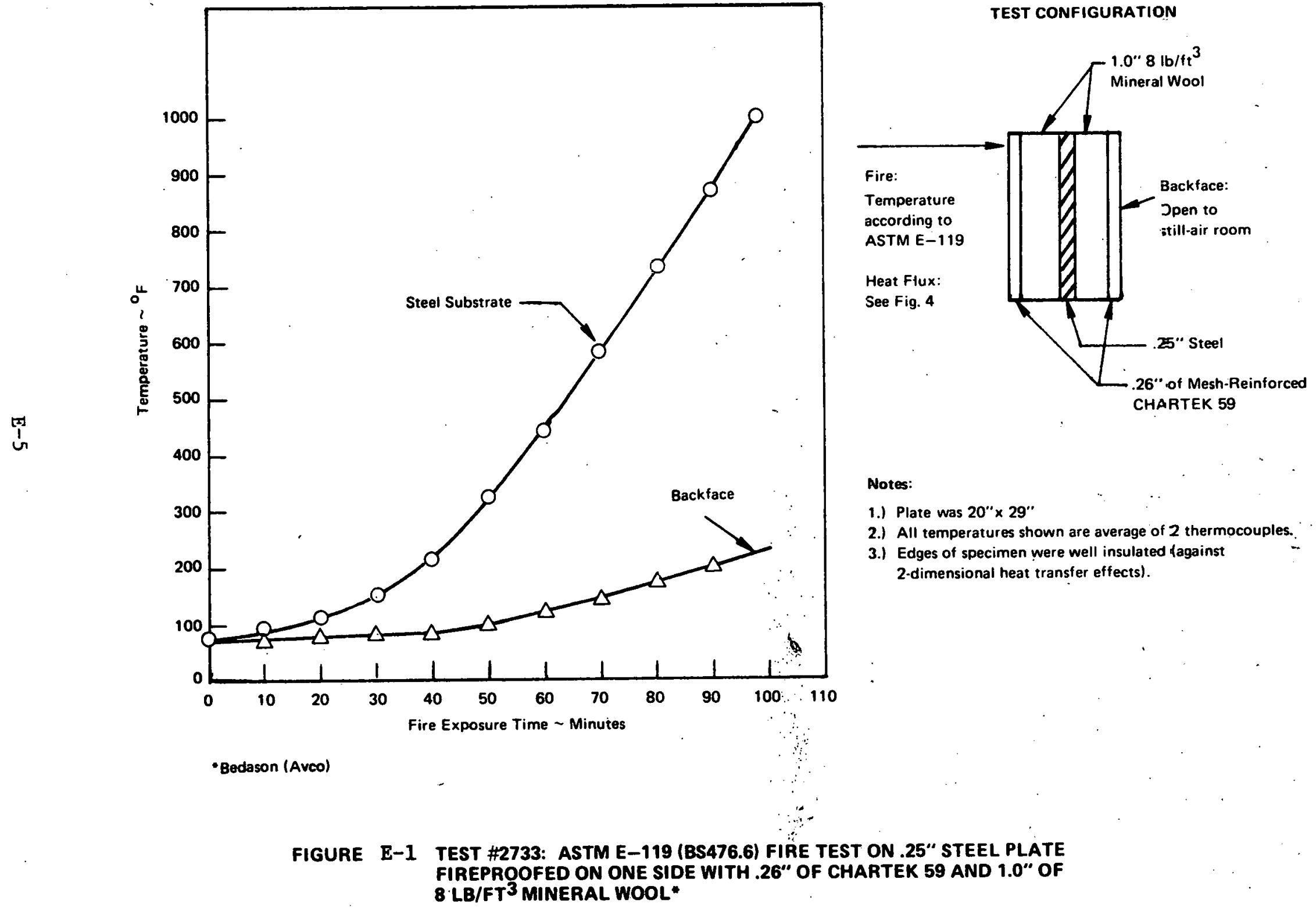




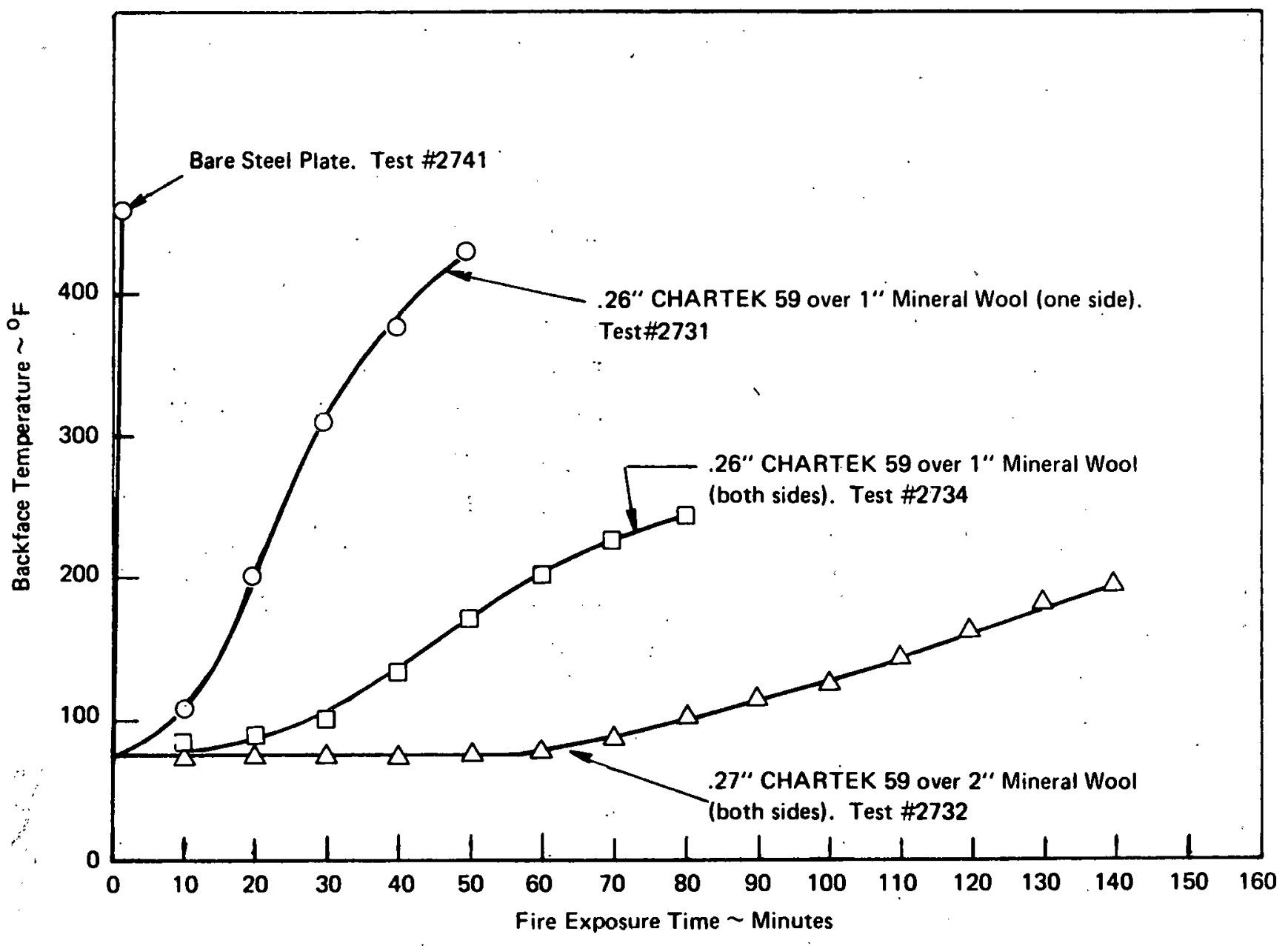

"Bedason (Avco)

Notes: 1.) Plate was $20^{\prime \prime} \times 29^{\prime \prime}$.

2.) All temperatures shown are average of $\mathbf{2}$ or $\mathbf{3}$ thermocouples.

3.) Edges of specimen were well insulated (against 2-dimensional heat transfer effects).

FIGURE E-2 COMPARISON OF BACKFACE TEMPERATURES OF VARIOUS $1800^{\circ} \mathrm{F}$ "HOT START" FIRE TESTS SHOWING DEGREES OF EFFECTIVENESS OF CHARTEK 59 AND MINERAL WOOL (.25" THICK STEEL PLATE FIRE-EXPOSED ON ONE SIDE ONLY)* 
APPENDIX F

TEMPERATURE, SIZE AND DURATION OF HOT SPOT

CREATED BY FRICTIONAL IMPACT OF LNG TANKER

We esrimate here the temperature, time at temperature, and size of the most likely hot surface seen by a premixed methane-air mixture upon frictional impact of two ships. We assume that the LNG tanker is struck broadside by the bow of either a cargo vessel or crude oil tanker. We also assume that vaporization and mixing of LNG and air are rapid enough to provide a flammable mixture at the hot surface during its lifetime. If vaporization is instantaneous, methane will escape from the LNG tank as a turbulent jet. Flammable mixtures will be produced along the boundary layer separating methane and air; however, the probability of contact between a flammable "eddy" and the hot surface is difficult to estimate. At this point, we simply presume contact and assess the resulting conditions for ignition.

\section{F.1 Collision Geometry}

The ship configuration for analysis of LNG tank penetration is shown in Figure F.1. Following ADL Report C-81967 (1978), we model the bow of the striking ship as a $20^{\circ}$ half-angle "wedge.' We assume a beam-on collision (i.e., the ships collide at $90^{\circ}$. to each other) with a moored LNG tanker on the basis that such collisions are most severe and occur frequently. We further assume a three meter separation between the inner and outer hulls of the tanker and a one meter separation between the inner hull and the ING tank (Athens, 1979). Above the water line, air in the ballast space is entrained by the outflowing methane; hence, a flammable mixture is only available for hot surfaces generated on the outer hull.

We consider two impact cases as described in Table F.1. The smaller vessel represents a cargo ship while the larger vessel represents another tanker. The bow depth is assumed to be the ship height above the water 1ine (Athens, 1979). The selected impact velocities 


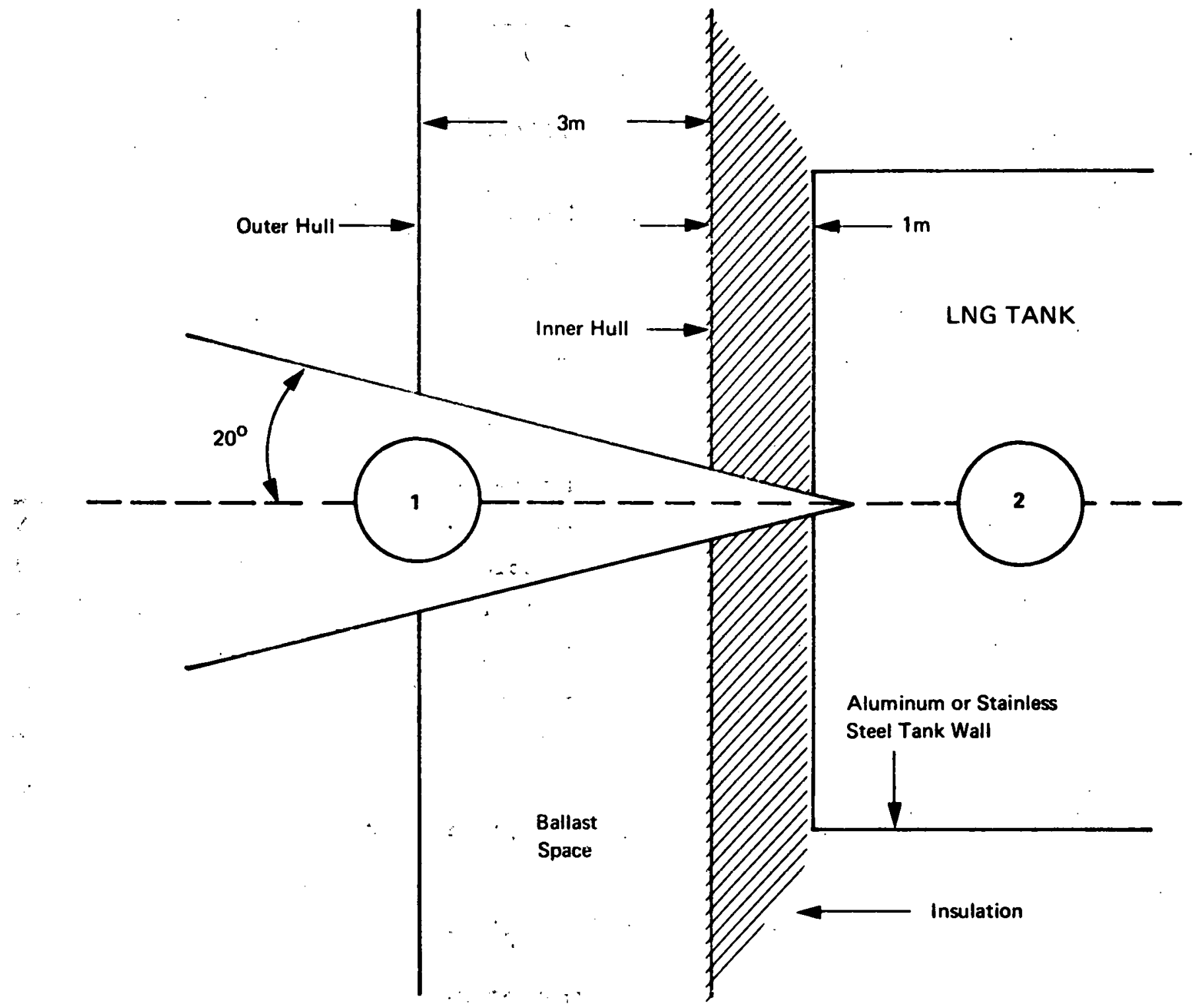

FIGURE F.1 SHIP CONFIGURATION UPON LNG TANK PENETRATION. BALLAST SPACE CONTAINS WATER, WITH AIR ABOVE WATER LINE. 
are roughly twice those calculated for tank penetration of a single hull ship (ADL, 1978).

Table F.1

Size and Velocity of Striking Ship

\begin{tabular}{|c|c|c|c|}
\hline Case & Displacement (kg) & Bow Depth (m) & Velocity (m/s) \\
\hline 1 & $2.5 \cdot 10^{7}$ & 8 & 5.0 \\
\hline 2 & $10 \cdot 10^{7}$ & 16 & 2.5 \\
\hline
\end{tabular}

\section{F.2 Co11ision Load and Velocity at Tank Rupture}

The load $\left(\mathrm{nt} / \mathrm{m}^{2}\right)$ and relative velocity $(\mathrm{m} / \mathrm{s})$ developed at bow-hull interfaces at the moment of LNG tank penetration determine the peak temperature of surfaces accessible to flammable mixtures. We can estimate this load and velocity by assuming that (1) the impact force and deceleration are constant during the collision and (2) reaction to the impact force is supplied solely by the interfaces between the striking bow and the outer and inner hulls of the LNG tanker, as shown in Figure F.1.

From conservation of momentum for a completely inelastic collision, we have

$$
M_{1} v_{0}=\left(M_{1}+M_{2}+m_{2}\right) v_{f}
$$

where $M_{1}$ and $M_{2}$ are the masses of the striking and struck vessels, respectively, $v_{0}$ is the initial velocity of the striking ship, $v_{f}$ the final velocity of the combined ships, and $m_{2}$ the virtual increase in the mass of the struck vessel due to viscous drag (Minorsky, 1959). Minorsky (1959) assumes that

$$
\mathrm{m}_{2}=0.4 \mathrm{M}_{2}
$$


based on data obtained on transient vibrations of hulls in deep water. The fraction of initial energy $f$ absorbed on collision is given by

$$
f=\left\{1-\frac{\left(M_{1}+M_{2}+m_{2}\right) v_{f}^{2}}{M_{1} v_{o}^{2}}\right\}
$$

From equations (F1) and (F2), we have

$$
f=\frac{1.4 \mathrm{M}_{2}}{\mathrm{M}_{1}+1.4 \mathrm{M}_{2}}
$$

and thus the kinetic energy absorbed on impact is

$$
\Delta \mathrm{KE}=\frac{\mathrm{i}}{2} \mathrm{fM}_{1} \mathrm{v}_{\mathrm{o}}^{2}=\frac{\mathrm{M}_{1}}{2}\left(\frac{1.4 \mathrm{M}_{2}}{\mathrm{M}_{1}+1.4 \mathrm{M}_{2}}\right) \mathrm{v}_{0}^{2}
$$

The average impact force $F$ and deceleration $d$ are given by

$$
\begin{gathered}
\mathrm{F}=\Delta \mathrm{KE} / \mathrm{L} \\
\mathrm{d}=\Delta \mathrm{KE} / \mathrm{M}_{1} \mathrm{~L}
\end{gathered}
$$

where $L$ is the total penetration distance. Assuming a coefficient of friction of unity, the load $W_{p}$ at penetration is given by

$$
W_{p}=\frac{F}{\sqrt{2} \cos 25^{\circ} A_{L}}
$$

where the load area $A_{L}$ from Figure $F .1$ is approximately

$$
A_{L}=4 \mathrm{ht} / \cos 20^{\circ}
$$

where we have considered all four hull-hull interactions and where $h$ is the bow depth and $t$ the hull thickness. For constant deceleration, the relative velocity $\mathrm{v}$ and penetration distance $\mathrm{x}$ can be estimated during the initial collision process by

$$
\begin{gathered}
v=v_{0}-d t \\
x=v_{0} t=\frac{1}{2} d t^{2}
\end{gathered}
$$


For a typical LNG tanker colliston, $M_{2}=10 \cdot 10^{7} \mathrm{~kg}, t=2.5$ - $10^{-2} \mathrm{~m}$ and $\mathrm{L}=8 \mathrm{~m}$ (Athens, 1979; Marine Casualty Report, 1975; Marine Casualty Report, 1977). Under these conditions, $\triangle K E, F, d$ and $W_{p}$ for Cases 1 and 2 are as shown in Table F.2. The penetration time $t_{p}$ and relative velocity $V_{p}$ at $x=4 m$ (Figure F.1) can be estimated via Equations (F11) and (F10), respectively, and are also listed in Table F.2. Calculations indicate that at least an additional 1-2 seconds are required to achieve zero relative velocity.

\section{F. 3. Characteristics of Hot Surface Created by Frictional Impact}

The calculation of surface temperature has been considered by Bowden and Tabor (1950), Holm (1947), Archard (1958) and Randolph et a1. (1976). The most important experimental results are as follows: (1) surface heating is confined to a thin layer in the region where rubbing actually occurs; (2) the maximum surface temperature corresponds to the lower of the melting points of the rubbing materials; and (3) below the melting point, the steady state surface temperature is proportional to $\mathrm{P}^{1 / 2} \mathrm{~V}$ where $\mathrm{P}$ is the normal surface force ( $n t$ ) and $\mathrm{V}$ the relative velocity of the two surfaces. At moderate loads and speeds, surface temperatures greater than $1000^{\circ} \mathrm{C}$ are easily reached. Since rubbing predominates at surface asperities, fluctuations in surface temperature are observed, with typical temperature rise times of 0.5-5.0 msec. In what follows, we will estimate the surface temperature at LNG tank rupture using the method of Holm (1948).

Consider heat generation at a single circular asperity of area $A=\pi a^{2}$ and velocity $V$ as shown in Figure F.2. From time $t=0$ on, heat is produced at the constant rate $Q(\mathrm{~J} / \mathrm{s})$ without loss to the surroundings and uniformly distributed over the contact area A. Holm (1948) assumes that a moving asperity is analogous to a stationary contact to which a source of heat is suddenly applied. For friction between two similar metals, a non-steady analysis then gives (Holm, 1948)

$$
T-T_{0}=B(z)\left(T_{s}-T_{0}\right)
$$


Table F. 2

Relevant Collision Parameters for Beam-on Impact

Parameter

$M_{1}(\mathrm{~kg})$
$v_{0}(\mathrm{~m} / \mathrm{s})$
$\mathrm{h}(\mathrm{m})$

$\triangle \mathrm{KE}(\mathrm{J})$

F (nt)

$\mathrm{d}\left(\mathrm{m} / \mathrm{s}^{2}\right)$

$\mathrm{w}_{\mathrm{p}}\left(\mathrm{nt} / \mathrm{m}^{2}\right)$

$\begin{array}{ll}t_{p} & (s) \\ v_{p}(m / s)\end{array}$
Case 1

$2.5 \cdot 10^{7}$

5.0 .

8

$2.7 \cdot 10^{8}$

$3.3 \cdot 10^{7}$

1.3

$3.0 \cdot 10^{7}$

0.9

3.8

\section{Case 2}

$$
\begin{gathered}
10 \cdot 10^{7} \\
2.5 \\
16
\end{gathered}
$$

$1.8 \cdot 10^{8}$

$2.3 \cdot 10^{7}$

0.23

$1.0 \cdot 10^{7}$

1.7

2.1 


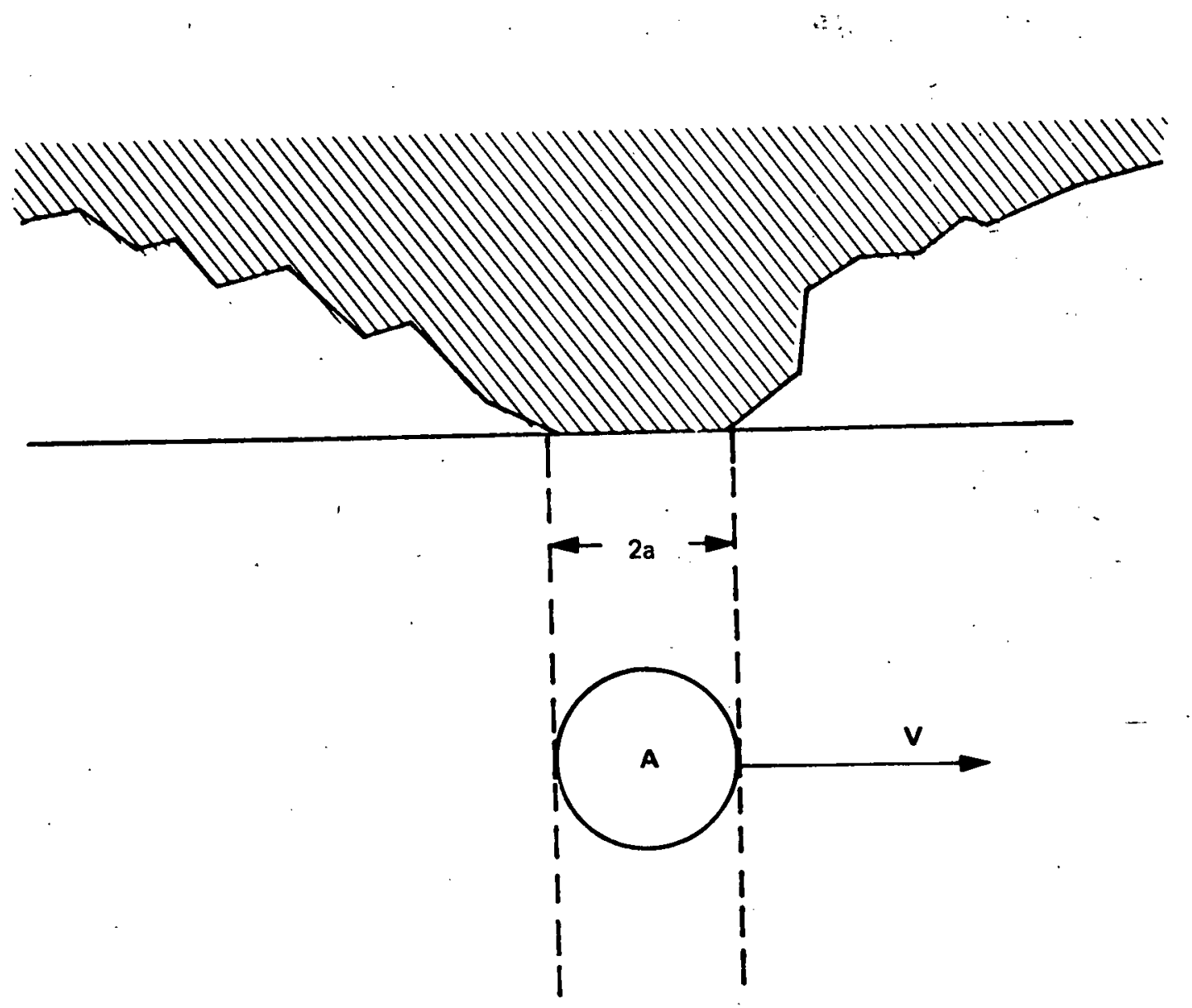

FIGURE F. 2 CIRCULAR ASPERITY OF AREA $\pi a^{2}$ AND VELOCITY $V$ (ARCHARD, 1958) 


$$
\left(T-T_{0}\right)_{c}=(1-B(z))\left(T-T_{0}\right)
$$

where

$$
\begin{aligned}
& T_{s}-T_{0}:=Q / 8 k a \\
& \therefore=\left(\pi^{2} \alpha / 4 a^{2}\right) \cdot t
\end{aligned}
$$

and $B(z)$ is given by Figure F.3. In equations (F.13-F.14), $T_{0}$ is the initial surface temperature, $T_{s}$ the steady state temperature, $\left(T-T_{0}\right)_{C}$ the temperature drop upon cooling, $k$ the thermal conductivity and $\alpha=k / \rho c_{p}$ the thermal diffusivity of the metal.' The time $t$ is the average contact time in the direction of motion (Figure F.2), which is

$$
t=\frac{\pi}{2}(a / v)
$$

The heat production rate $Q$ is given by.

$$
Q=\mu \frac{P V}{n}
$$

where $\mu$ is the coefficient of friction, $P$ the entire contact force (nt) and $n$ the number of circular surface asperities. Combining equations (F14) and (Fi7), we have

$$
T_{s}-T_{0}=\frac{\mu P V}{8 n k a}
$$

According to Bowden and Tabor (1950), the area of contact of a single asperity is determined by

$$
\pi \mathrm{a}^{2}=\mathrm{P} / \mathrm{np}_{\mathrm{m}}
$$

where

$$
\mathrm{P}_{\mathbf{m}}=3 \mathrm{Y}
$$

is the plastic deformation pressure and $\mathrm{Y}$ the elastic limit. Thus, equation (F18) becomes

$$
T_{s}-T_{0}=\frac{\mu}{8 k} \sqrt{3 \pi Y}\left(\frac{P}{n}\right)^{1 / 2} V
$$




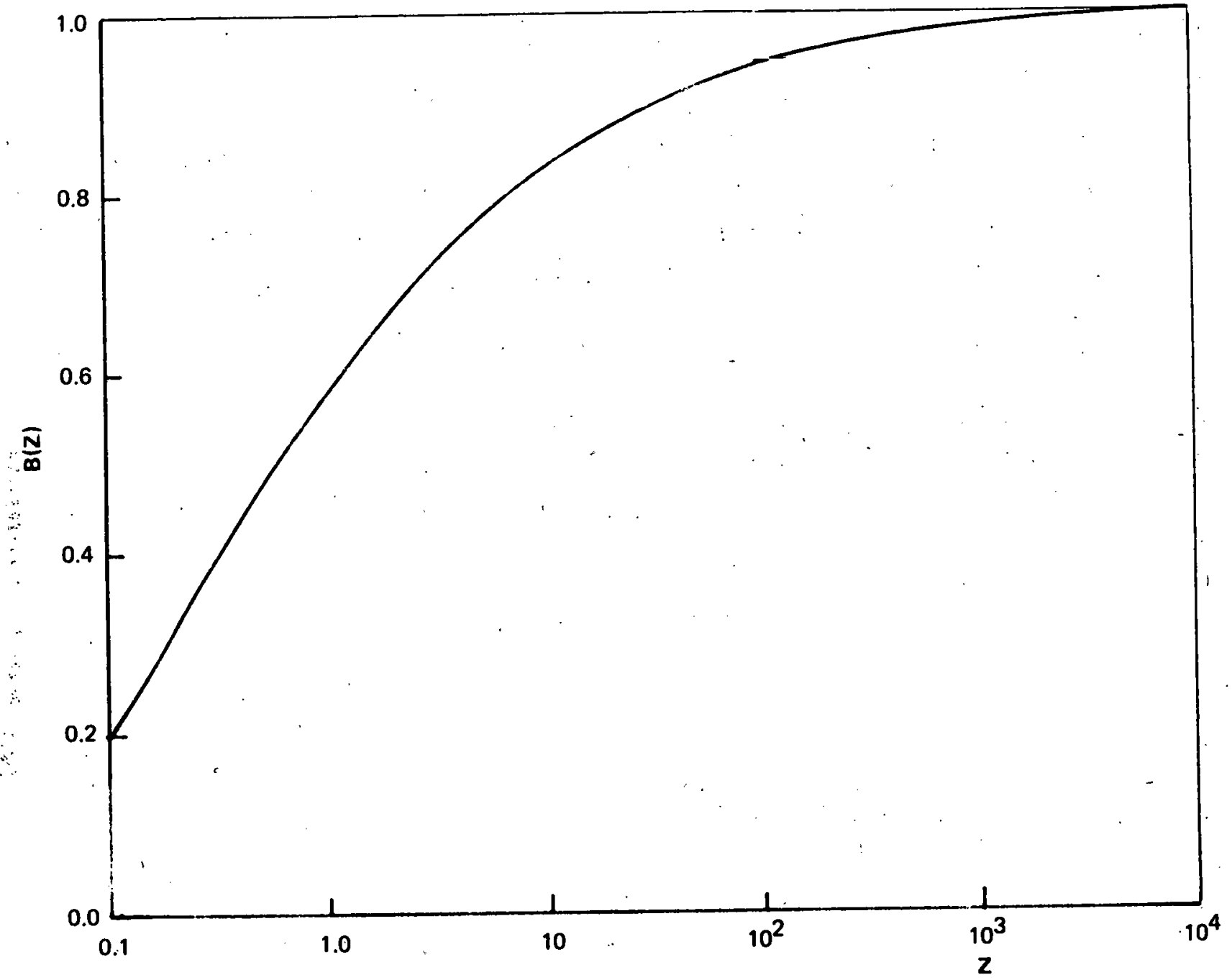

FIGURE F. 3 INFLUENCE OF FRICTIONAL CONTACT TIME ON RELATIONSHIP BETWEEN INSTANTANEOUS AND STEADY STATE SURFACE TEMPERATUBES (HOLM, 1948). $\left.B(Z)=\left(T-T_{0}\right) / T_{s}-T_{0}\right)=1-e^{Z}\left[1-\operatorname{enf}\left(Z^{1 / 2}\right)\right]$ AND $Z=\left(\pi^{2} \alpha / 4 a^{2}\right) t$. 
Note that $\left(\mathrm{T}_{s}-\mathrm{T}_{0}\right) \propto \mathrm{P}^{1 / 2} \mathrm{~V} / \mathrm{k}$ from equation $(\mathrm{F} 21)$ and that the heat-up time $t \propto a^{2} / k$ from equation (F15), both of which have received experimental confirmation (Bowden and Tabor, 1950). Note also that equation (F21) is limited to the melting point of steel or

$$
\left(\mathrm{T}_{\mathrm{S}}-\mathrm{T}_{\mathrm{O}}\right)_{\max }=1500^{\circ} \mathrm{C}
$$

The contact force $P$ at the moment of LNG tank rupture is given by

$$
P=W_{P} A_{a}
$$

where $A_{a}$ is the apparent contact area $\left(\mathrm{m}^{2}\right)$. Combining equations, (F21), (F22) and (F23), we have finally

$$
\left(T_{s}-T_{o}\right)_{p}=\frac{\mu}{8 k} \sqrt{3 \pi Y}\left(\frac{W_{p} A_{a}}{n}\right)^{1 / 2} v_{p} \leq 1500^{\circ} \mathrm{C}
$$

where $\left(\mathrm{T}_{\mathrm{s}}-\mathrm{T}_{\mathrm{o}}\right)_{\mathrm{p}}$ is the steady state metal temperature at LNG tank penetration. The actual surface temperature at penetration $\left(T-T_{0}\right)_{P}$ can be obtained from equation (F12) via

$$
z=\frac{\pi^{3}}{8} \sqrt{3 \pi Y}\left(\frac{n}{W_{p} A_{a}}\right)^{1 / 2} \frac{\alpha}{V_{p}}
$$

which can be derived by combining equations (F15), (F16), (F19), (F20) and (F23). Similarly, the time required for cooling to 80 or 90 percent of $\left(T-T_{o}\right)_{p}$ can be obtained from equation (F13) with $z$ given by

$$
z=\frac{3 \pi^{3}}{4}\left(\frac{n}{W_{p} A_{a}}\right) \alpha Y t
$$

The contact region and the associated hot surface accessible to flammable mixtures is shown in Figure F.4. At long contact time, a significant area also becomes hot on the hull of the struck ship near the point of penetration; this additional area is not considered in this analysis. The contact region is assumed to be a $2 \times 50 \mathrm{~mm}$ surface undergoing frictional heating. Other properties of the contact region are included in Table F.3. A stationary hot surface on the bow of the striking ship is generated downstream of the contact region. The 


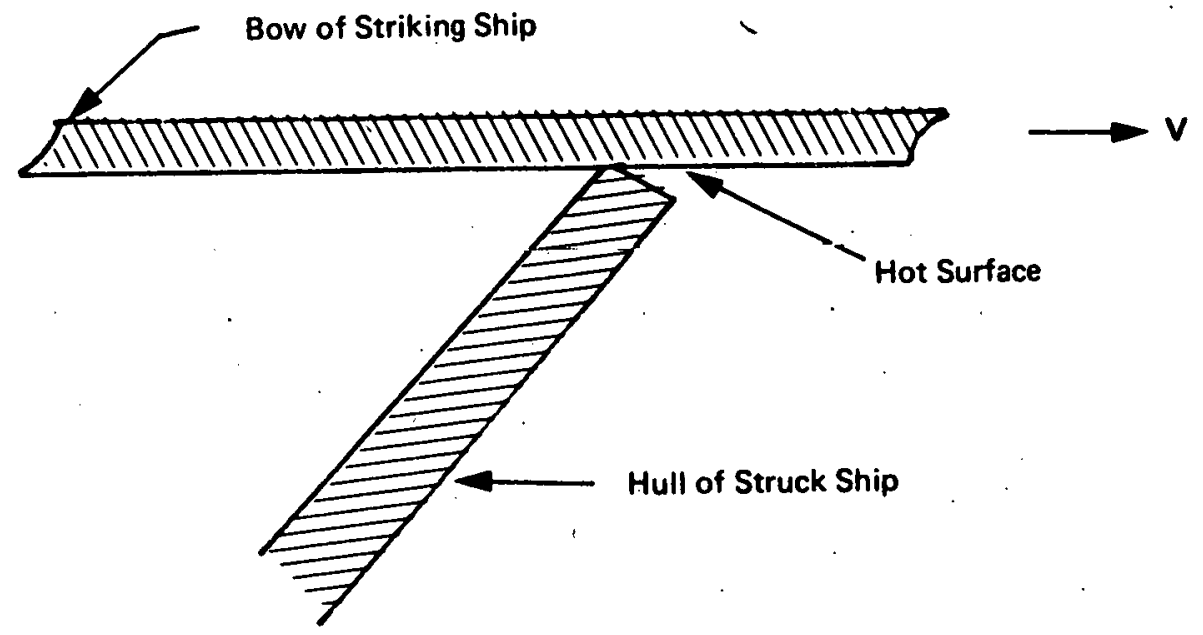

a) Top View

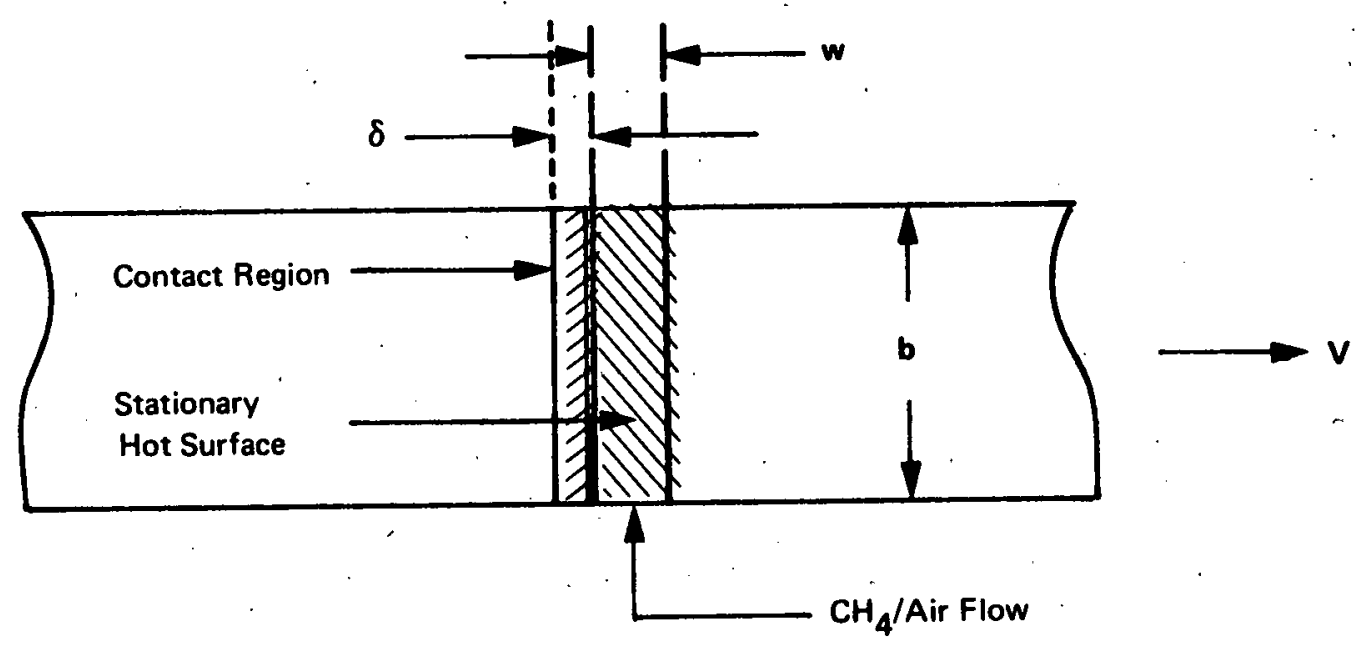

b) Side View

FIGURE F.4 GEOMETRY OF FRICTIONALLY-INDUCED HOT SURFACE. BOW OF STRIKING SHIP IS MOVING AT VELOCITY V. 
Table F. 3

Properties of Ship Steel

at the Contact Region

$\begin{array}{ll}\text { Density }\left(\mathrm{kg} / \mathrm{m}^{3}\right) & \rho=8 \cdot 10^{3} \\ \text { Specific Heat }\left(\mathrm{J} / \mathrm{kg}^{-}{ }^{\circ} \mathrm{C}\right) & \mathrm{C}_{\mathrm{p}}=5 \cdot 10^{2} \\ \text { Thermal Conductivity }\left(\mathrm{J} / \mathrm{m}-{ }^{\circ} \mathrm{C}-\mathrm{s}\right) & \mathrm{k}=40 \\ \text { Thermal Diffusivity }\left(\mathrm{m}^{2} / \mathrm{s}\right) & \alpha=10^{-5} \\ \text { Elastic Limit }\left(\mathrm{nt} / \mathrm{m}^{2}\right) & \mathrm{Y}=5 \cdot 10^{8} \\ \text { Coefficient of Friction } & \mu=1.0 \\ \text { Contact Width (m) } & \delta=2 \cdot 10^{-3} \mathrm{~m} \\ \text { Contact Length (m) } & \mathrm{b}=50 \cdot 10^{-3} \mathrm{~m}\end{array}$


length of this surface is also $50 \mathrm{~mm}$; if the lifetime of the hot surface is $t_{e}$, then its width and area immediately following penetration will be

$$
w=v_{p} t_{e}
$$

and

$$
A^{*}=b v_{p} t_{e}
$$

Based on the geometry of Figure F.4, the temperature and size characteristics of a frictionally-induced hot surface can be estimated as shown in Table F.4. $\left(T_{S}-T_{0}\right)$ and $\left(T-T_{0}\right)$ are estimated using equations (F24), (F12) and (F25) using the values of $\mathrm{W}_{\mathrm{p}}$ and $\mathrm{V}_{\mathrm{p}}$ for Cases 1 and 2 of Table F.2. The apparent surface area is $A_{a}=\delta b=10^{-4} \mathrm{~m}^{2}$. For closely packed asperities, the predicted temperatures are applicable to both the apparent and real contact areas (Archard, 1958). The coefficient of friction is assumed to be equal to unity from friction machine experiments which show that during welding, $\mu$ rises to between 0.5 and 1.5 (Archard, 1958).

Experimental work reported by Bowden and Tabor (1950) and Holm (1948) shows that to a good approximation, the appearance of frictionally-induced hot spots depends only on the load and relative velocity and not on the geometry of the contact region. This result suggests that at any moment in time, only a few asperities are responsible for frictional heating. Following previous work (Holm, 1948, Randolph et al., 1976), we consider two subcases, $n=1$ and $n=10$. As shown in Table F.4, for all subcases, both the steady state and actual surface temperatures can be approximated by the melting point of the metal (The computed temperatures are given in parentheses.) Since temperatures approaching $1500^{\circ} \mathrm{C}$ can be generated during tanker collision, Ignition is likely given a hot surface of adequate size and duration.

The size of the hot surface can be estimated via equations (F13), (F26), (F27) and (F28). The 1ifetime $t_{e}$ of the surface is 1imited due to thermal conduction into the metal bulk. Table F.4 presents $t$ calculations for cooling to $90 \%$ and $80 \%$ of the initial surface temperature. 
Table F. 4

Characteristics of Hot Surface Generated

upon LNG Tank Penetration

Parameter Case 1 $(n=1)$ Case 1 $(n=10)$ Case 2 $(n=1)$ Case $2(n=10)$

$\mathrm{T}_{\mathrm{S}}-\mathrm{T}_{\mathrm{o}}\left({ }^{\circ} \mathrm{C}\right) \quad 1500(50,900) \quad 1500(16,100) \quad 1500(16,300) \quad 1500(5160)$

$\mathrm{T}-\mathrm{T}_{0}\left({ }^{\circ} \mathrm{C}\right) \cdot 1500(5600) \quad 1500(2900) \quad 1500(2900) \quad 1480$

$\begin{array}{lllll}t_{e, 90} \text { (ms) } & 0.3 & 0.03 & 0.1 & 0.01\end{array}$

$t_{e, 80^{(m s)} \quad 3.0} \quad 0.3 \quad 1.0 \quad 0.1$

$\begin{array}{lllll}\mathrm{w}_{90}(\mathrm{~mm}) & 1.3 & 0.13 & 0.2 & 0.02\end{array}$

$\mathrm{w}_{80}$ (mim) $\quad 13 \quad 1.3 \quad 2.0 \quad 0.2$

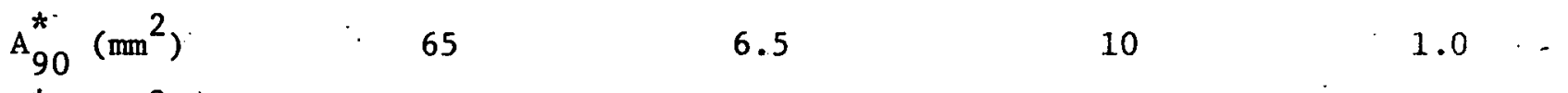

$\mathrm{A}_{80}^{*}\left(\mathrm{~mm}^{2}\right) \quad 650 \quad 65 \quad 100 \quad 10$

* Assume $\delta=2 \mathrm{~mm}, \mathrm{~b}=50 \mathrm{~mm}$ and thus $\mathrm{A}_{\mathrm{a}}=10^{-4} \mathrm{~m}^{2}, \mu=1.0$ for Case 1 and 2 of Table F.2. $t_{e, 90}$ and $t_{e, 80}$ are the hot surface lifetimes for $\left(T-T_{0}\right)_{c} /$ $\left(\mathrm{T}-\mathrm{T}_{\mathrm{o}}\right.$ ) equal to 0.9 and 0.8 , respectively. Similar definitions apply for the hot surface width $w$ and area $A$. 
For an initial $\left(T-T_{0}\right)$ of $1500^{\circ} \mathrm{C}$, the final $\left(T-T_{0}\right)_{c}$ will be 1350 and $1200^{\circ} \mathrm{C}$, respectively. Hence, the computed hot surface widths and areas (assuming a length of $50 \mathrm{~mm}$ ) represent the size of a hot surface whose minimum temperature is either 1350 or $1200^{\circ} \mathrm{C}$. That portion of the surface nearest the contact region is at $1500^{\circ} \mathrm{C}$, while for example that ${ }^{\mathrm{w}} 80 \mathrm{~mm}$ away is at $1200^{\circ} \mathrm{C}$. $\dot{A}_{80}$ is a good estimate for the available area since $1200^{\circ} \mathrm{C}$ is close to the minimum ignition temperature for methane/air mixtures. For Case 1, the size of the hot surface will decrease by approximately $40 \%$ in the first second after penetration due to the large reduction in relative velocity; little reduction in hot surface size is predicted for Case 2. From Table F.4, it appears that hot surfaces of $10-650 \mathrm{~mm}^{2}$ can be anticipated during the collision process. Such sizes are sufficient for ignition.

If the flammable mixture is stationary, the hot surface will be avallable until the relative velocity approaches zero. From equation (F10), this time is estimated to be 0.5-5.0 s. However, gas velocities could approach $100 \mathrm{~m} / \mathrm{s}$ (near sonic conditions), giving gas-solid contact times of $0.5-1.0 \mathrm{~ms}$ and thus preventing ignition. For a surface of "maximum" temperature $\left(1500^{\circ} \mathrm{C}\right)$ and area $\left(650 \mathrm{~mm}^{2}\right)$, a critical gas velocity exists above which ignition is not possible for the typical tanker collision. Until this approach velocity has been experimentally determined, we judge that velocities of $0-100 \mathrm{~m} / \mathrm{s}$ with a maximum hot surface temperature duration of $5 \mathrm{~s}$ (for the near-zero velocity case) must be considered for any complete experimental analysis of ignition probability.

In summary, hot surfaces accessible to flammable methane-air mixtures during LNG tanker collisions can be characterized by the following parameters:
(1) Temperature
$1200-1500^{\circ} \mathrm{C}$
(2) Area
$10-650 \mathrm{~mm}^{2}$
(3) Temperature Duration
$0.5-5.0 \mathrm{~s}$
(4) Gas Velocity
$0-100 \mathrm{~m} / \mathrm{s}$
(5) Gas-Solid Contact Time
$0.5-5000 \mathrm{~ms}$ 
The temperature, temperature duration and hot surface area are felt to be reasonable estimates. The gas velocity and gas-solid contact time require further analysis. 
A

A

A

A

A

a

$B(z) \quad 1-e^{z}\left[1-\operatorname{erf}\left(z^{1 / 2}\right)\right]$

b

${ }_{\text {P }}$

$\mathrm{D}_{1}$

$\mathrm{D}_{2}$

D

d

$\mathrm{d}_{\mathrm{q}}$

E

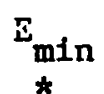

$\mathrm{E}^{*}$

F

h

k

$\mathrm{L}$

$L_{i}$

$\mathbf{M}_{1}$

$\mathrm{M}_{2}$

area of asperity $\left(\mathrm{m}^{2}\right)$

load area $\left(\mathrm{m}^{2}\right)$

hot surface area $\left(\mathrm{m}^{2}\right)$

radius of asperity (m)

deceleration $\left(\mathrm{m} / \mathrm{s}^{2}\right)$

quenching distance (mm)

impact force (nt)

bow depth (m)

frequency factor $\left(\left[\operatorname{moles} / \mathrm{m}^{3}\right]^{1-n} \cdot \mathrm{s}^{-1}\right)$

apparent contact area $\left(\mathrm{m}^{2}\right)$

length of contact region and hot' surface (m)

specific heat $\left(\mathrm{J} / \mathrm{kg}^{\circ} \mathrm{C} ; \mathrm{J} / \mathrm{mole} \cdot{ }^{\circ} \mathrm{C}\right)$

Damkohler number of first kind

Damkohler number of second kind

transient Damkohler number

activation energy ( $\mathrm{J} / \mathrm{mole})$

minimum ignition energy (mJ)

dimensionless activation energy

thermal conductivity $\left(\mathrm{J} / \mathrm{m} \cdot{ }^{\circ} \mathrm{C} \cdot\right)$

hot surface width; penetration distance (m)

flammability limit of $i^{\text {th }}$ fuel

mass of striking vessel ( $\mathrm{kg})$

mass of struck vessel (kg) 


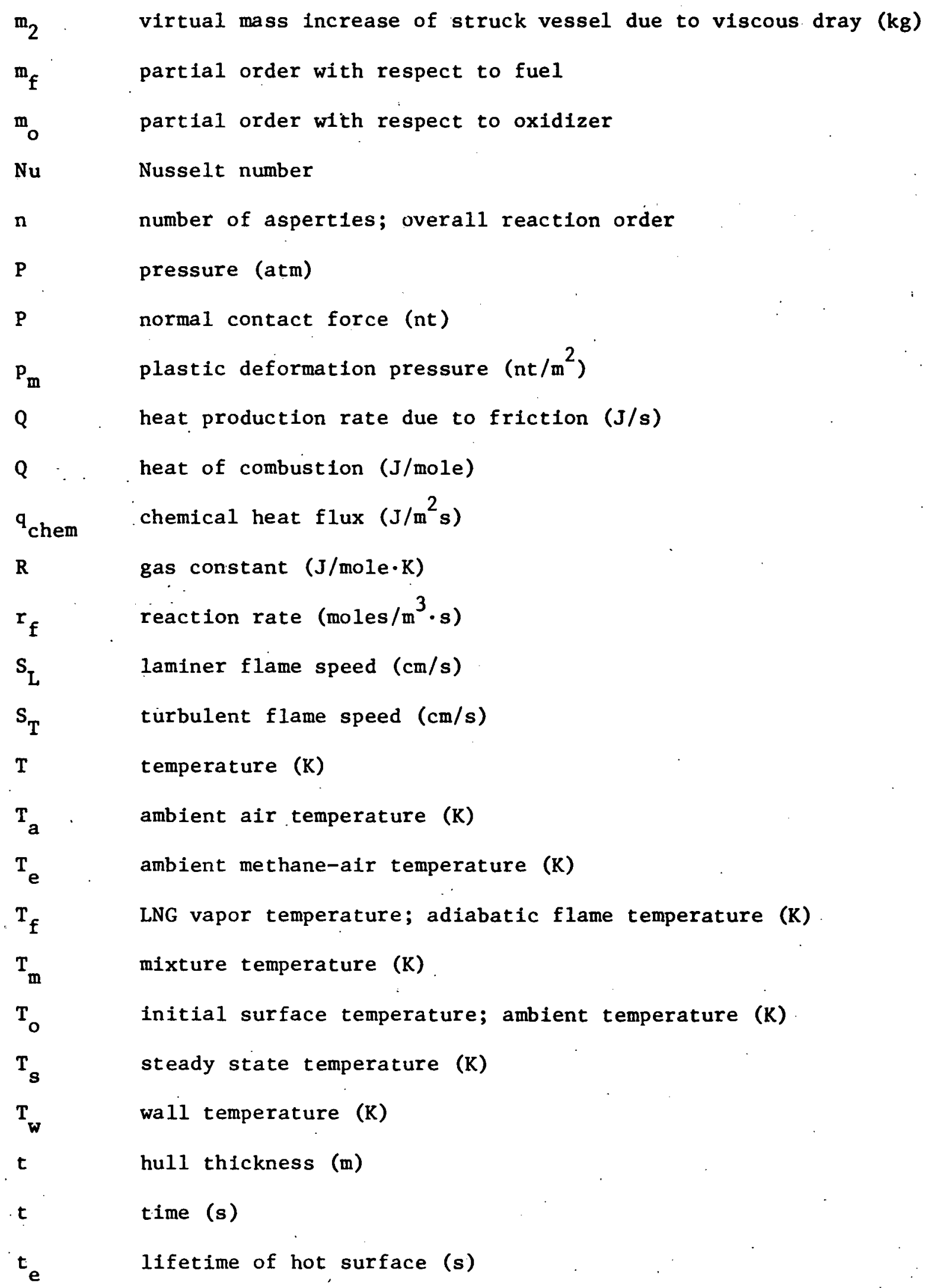




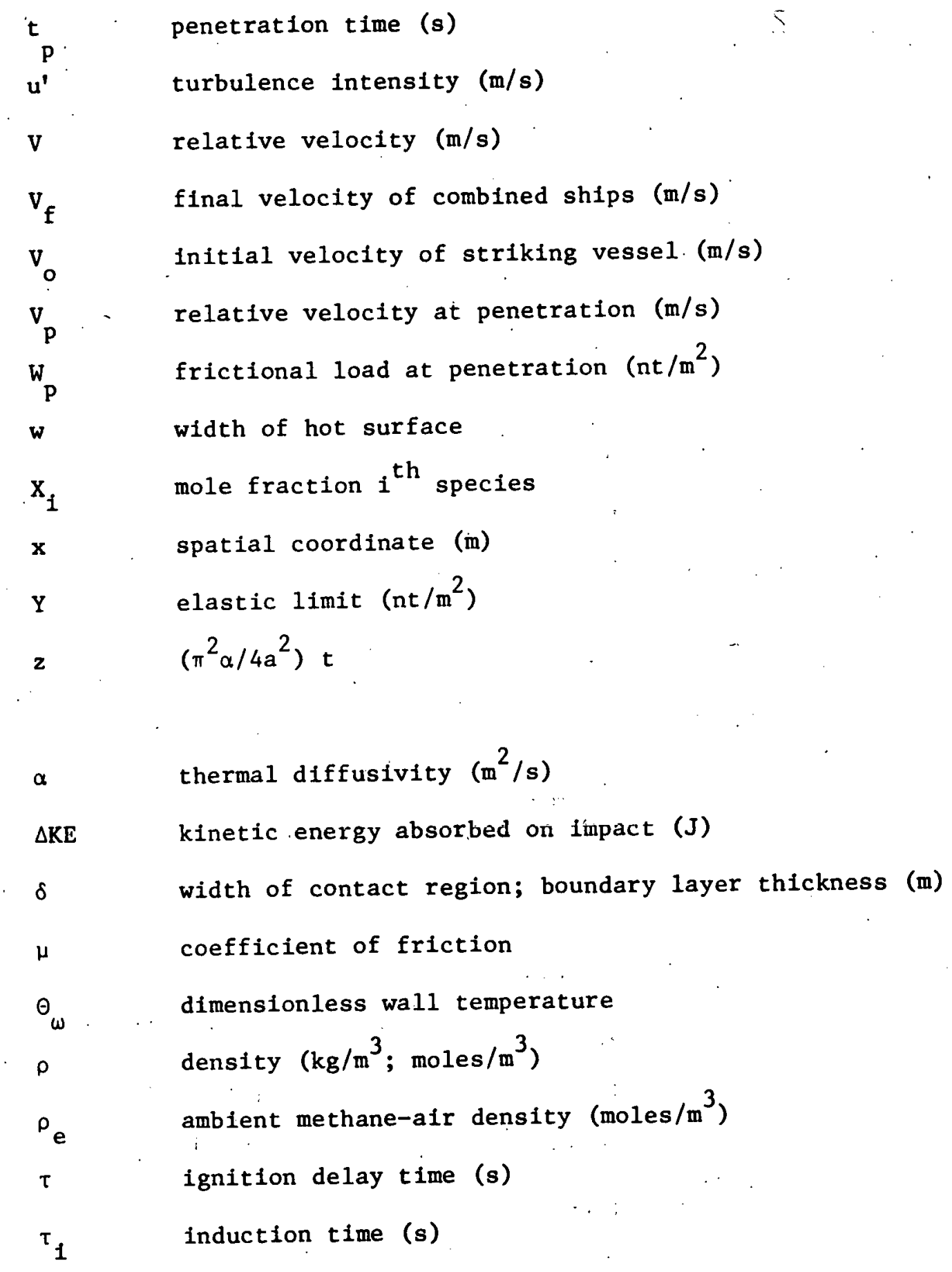




\section{REFERENCES}

Adomeit, G. (1965), Tenth Symp. (Int.) on Combustion, The Combustion Institute, Pittsburgh, 237.

Arthur D. Little, Inc. Report C-81967 (1978).

Af fens, W. A. and Lange, E. A. (1979), Naval Engineers Journal (2), 76 .

Alkidas, A. and Durbetaki, P. (1971), Comb. Sci. Tech. 3, 187.

Alkidas, A. and Durbetaki; P. (1973a), Comb. Sci. Tech. 7, 135.

Alkidas, A. and Durbetaki, P. (1973b), Trans. ASME 95, 564.

Anonymous (1978), "Energy Requirements for an LNG Gelation Process," Massachusetts Institute of Technology.

Anthony, D. B. Howard, J. B. Meissner, H. P., and Hottel, H. C. (1974), Rev. Sci. Instrum. 45. 992.

Archard, J. F. (1958), Wear 2 , 438 .

Athens, P. (1979), Personal Communication:

Athens, P. "The Collision Resistance of the Ben Franklin," Exhibit No. PA-1, Federa1 Power Commission Hearings, Docket No. CP73-38 et a1. (March 25, 1974).

Ballal, D. R. and Lefebvre, A. H. (1975), Comb. and Flame 24, 99.

Ballal, D. R. and Lefebvre, A. H. (1977), Proc. Roy. Soc. 357A, 163.

Barreto, E. Reynolds, S. I. and Jurenka, H.: (1974), J. Appi. Phys. $\underline{45}(8), 3317$.

Baumeister, T. (1967), Marks' Standard Handbook for Mechanical Engineers, 7 th Edition, McGraw-Hill, p.:610:

Bird, R. B., Stewart, W. E. and Lightfoot, E. N. (1960), Transport Phenomena, Wiley, New York, 353.

Blickensderfer, R. (1975), Comb: and Flame 25, 143.

Bowden, F. P and Lewis, R. D. (1958), Engineering 186 (Aug. 22), 241.

Bowden, F. P. and Tabor, D. (1950), The Friction and Lubrication of Solids, Oxford, Lond. 
REFERENCES (continued)

Brown and Marco (1958), Introduction to Heat Transfer, Third Edition, McGraw-Hill, p. 16 .

Burgess, M. J. and Wheeler, R. V. (1928), Safety Mines Res. Rept. No. 46 .

Burgess, M. J. and Wheeler, R. V. (1929), Safety Mines Res. Rept. No. 54 .

Chatterfee, N. and Geist, J. M. (1972), AGA Conference, Atlanta, Ga.

Coward, H. F. and Guest, P. G. (1927), J. Am. Chem. Loc. 49, 2479.

Creitz, E. C. (May 1972), "Extinction of Fires by Halogenated Compounds--A Suggested Mechanism," Fire Technology, Vol. 8, No: 2, pp. 131-141.

Crossley, R. W., Dorko, E. A., Scheller, K. and Burcat, A. (1972), Comb. and Flame, 19, 373.

Cutler, D. P. (1974), Comb. and Flame, 22, 105.

Desy, D. H., Neumeier, L. A. and Rispeck, J. S. (1975), USBM RI 8005.

Dutkiewics, B., "Methanol Competitive with LNG on Long Hau1," 011 and Gas Journal, April 30, 1973, Vol. 71, No. 18, pp. 167-178.

E1 Paso, et a1., FPC Docket Nos. CP3-258, et a1.,. Vo1. II. April 1, 1977.

Eshback, 0. W. (1957), Handbook of Engineering Fundamentals, 2nd Edition, John Wiley and Sons, pp. 1-145.

Germeles, A. E., and Drake, E.M. (October 1975), "Gravity Spreading and Atmospheric Dispersion of LNG Vapor. Clouds," paper presented at the Fourth International Symposium on Transport of Hazardous Cargoes by Sea and Inland Waterways, Jacksonville, Florida.

Hanson, 0. A. (April 1960), "Materials Below - $100^{\circ} \mathrm{F}$," Mechanical Engineering, p. 60.

Hickey, J. (1980), Personal Communication.

Hi11, R. D. (1978), J. Appl. Phys. 50(1), 127.

Hillstrom, W. W. (1978), Ballistic Research Laboratory Report, ARBRL-MR-02820.

Holm, R. (1948), J. Appl. Phys. 19, 361 . 


\section{REFERENCES (continued)}

Johnson, P. (June 1978), "Overview of OTA's Assessment, entitled "Transportation of Liquefied Natural Gas: Safety Siting and Policy Concerns;" Committee Reprint, Committee on Commerce, Sclence and Transportation, United States Senate.

Khitrin, L. N. and Goldenberg, S. A. (1975), Sixth Symposium on Combustion, Reinhold, New York, 545.

Kono, M., Kumayo1, S. and Saka1,. T. (1976), Sixteenth Symp. (Int.) on Combustion, The Combustion Institute, Pittsburgh, 757.

Krarchenko, V. S., Erygin, A. T. and Yakovlev, V. A. (1973), Fizika Goreniya Vzryva $\underline{9}(4), 603$.

Kubaschewski, 0. and Hopkins, B. E. (1962), Oxidation of Metals and Alloys, Butterworth, London.

Law, C. K. (1978a), Int. J. Heat Mass Transfer 21, 1363.

Law, C. K. (1978b), AIAA J. 16, 630 .

Law, C. K. (1979), Comb. Sci. Tech. 19, 237.

Lewis, B. and von Elbe, G. (1961); Combustion, Flames and Explosion of Gases, Academic Press, New York.

Lifshitz, A., Scheller, K., Burcat, A., Skinner, G. B. (1971), Comb. and Flame, 16, 311 .

Litchfield, E. L. (1960), USBM RI 5671.

Marine Casualty Report, USCG/NTSB-MAR-75-1 (1975).

Marine Casualty Report, USCG/NTSB-MAR-77-1 (1977).

Meyer-Athens, C. (1968), "Fire Tests on Protected Steel Girders," proc. Symp. No. 2 on Behavior of Structural Steel in Fire, held at Fire Research Station in Boreham Wood, U. K., January 1967, H.M.S.O., London.

Minorsky, V. U. (October 1959), "An Analysis of Ship Collisions with Reference to Protection of Nuclear Power Plants," Journal of Ship Research.

Minorsky; V. U. (1959), J. Ship Research, October 1. 
REFERENCES (continued)

Mullen, J. W., Fenn, J. B. and Irby, M. R. (1949), Third Symposium on Combustion, Flame and Explosion Phenomena, Willlams and Wilkins, Baltimore; 317 .

Mullins, B. P. and Penner, S. S. (1959), Explosions, Detonations, Flammability and Ignition, Pergamon, New York.

Murty Kanury, A. (1975), Introduction to Combustion Phenomena, Gordon and Breach, New York.

Ono, S., Kawano, H., Niko, H. and Fukuyama, G. (1976), Bulletin JSME 19,676

Paterson, S. (1940), Phil. Mag 28, 1; 30, 437.

Porrice11i, J. D. (1977), FPC Docket No. CP73-258.

Powell, F. (1969), Ind. Eng. Chem. 61(12), 29.

Rae, D. (1961), Çomb. and Flame 5, 341 :

Rae', D. (1966), Safety Mines Res. Rept. No. 236.

Rae, D., Singh, B. and Danson, R. (1964), Safety Mines Res. Rept. No. 224 .

Raj, P. K. (May 1977), "Calculations of Thermal Radiation Hazards from LNG Fires--A Review of the State of the Art," Paper No. 2, Session 18, Presented at the AGA Transmission Conference, St. Louis, MO.

Raj, P. K. and A. S. Kalelkar (January 1974), "Assessment Models in Support of the Hazard Assessment Handbook (CG-446-3)," Chapter 9, Technical Report Prepared for the U.S. Coast Guard, NTIS publication No. AD776617.

Rainaldi, N. (February 1970), "Advance Report on Halon 2402," Fire Technology, Vol. 6, No. 1, pp. 59-67.

Randolph, A., Halter, L. and Popolato, A. (1976), Ind. Eng. Chem. Fundam. $15(1), 1$.

Rose, H. E. and Priede, T. (1959), Seventh Symp. (Int.) on Combustion, Butterworths, London, 436, 454.

Royal, M. J. and Nimmo, N. M. (February 1973), "Big Methanol P1ants offer Cheaper LNG Alternatives," Oil and Gas Journal, Vol. 71, No. 6, pp. 52-55. 


\section{REFERENCES (continued)}

Rudnicki, M. I., et al (January 1980), "Study of Gelled LNG," Aerojet Energy Conversion Company Final Report, DOE Contracts E-EP-78-C03-2057 and DE-AC03-78EV02057.

Shanes, L. M. (August 1977), "The Structure and Rheological Properties of Liquefied Natural Gas Gelled with Water and Methanol Clathrates," Doctora1 Thesis Digest, Department of Chemical Engineering, Massachusetts Institute of Technology. .

Sharma, 0. P. and Sirignano, W. A. (1969), Comb. Sc1. Tech. 1, 95.

Sharma, 0. P. and Sirignano, w. A. (1970), Comb. Sc1. Tech. 1, 481.

Sharp, George G., Inc., Contract MA-RD-76048, November 20, 1975.

Silver, R. S. (1937), Ph1l. Mag. 23, 633.

Silver, R. S. (1937),. Phil. Mag. 23, 633.

Stout, H. P. and Jones, E. (1949), Third Symposium on Combustion, Flame and Explosion Phenomena, Williams and Wilkins, Baltimore, 329.

Strumbus, W. P., U. S. Patent 3,834,174, September 10, 1974.

Tervarson, A. and Pion, R. F., (1976), "Flammability of Plastics-I. Burning Intensity," Combustion and Flame, 26, pp. 85-103.

Titman, H. (1955), Trans. Inst. Mining Engr. 115, 536:

Tolson, P. (1972), Comb. and Flame, 18, 19.

Toong, T. Y. (1957), Sixth Symposium on Combustion, Reinho1d, New York, 532 .

Tsuboi, T. and Wagner, H. Gg. (1974), Fifteenth Symp. (Int.) on Combustion, The Combustion Institute, Pittsburgh, 883 .

Vander Wall, E. M. (March 1971), "Investigation of the Stability of Gelled Methane for Use in a Jet Engine," Aerojet General Co., Contract NAS 3-10305, NASA CR-72876.

Woisin, G. (1971), "On the Collision of Nuclear Sh1ps," Jahrubuch der Schiffbautechinik, G.S. 65 Band.

Zabatakis, M. G. (1965), "Flammability Characteristics of Combustible Gases and Vapors," Bullein 627, Bureau of Mines, U.S. Department of Interior. 